\title{
Mariette Mecamploell
}

- Moreathan What
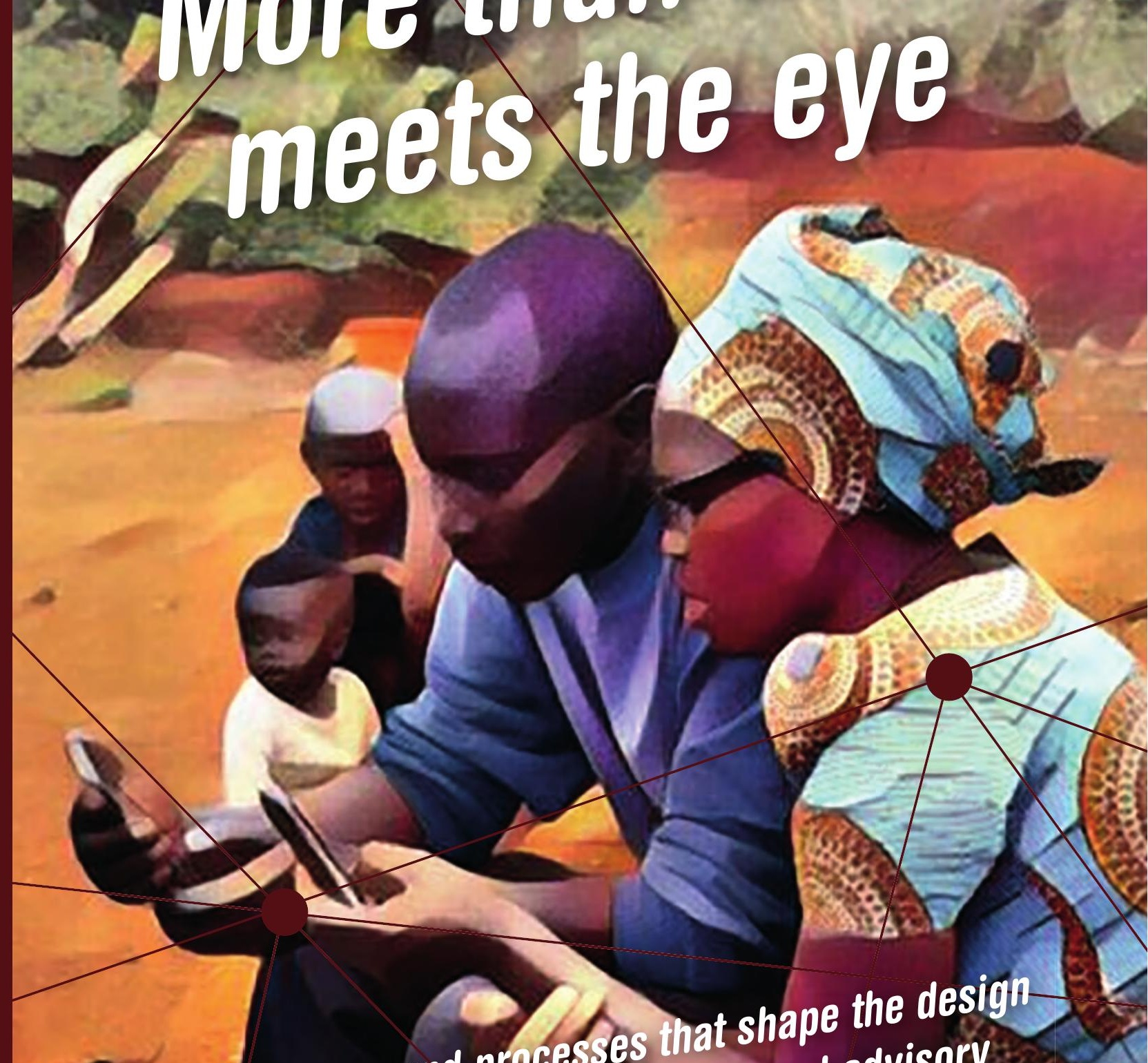

Factors and processos cureultural advisory and use of digital agricul in Africa and decision support in All ch 


\section{Propositions}

1. Digitalization currently induces unfavourable binary and individualist thinking about complex agricultural problems.

(this thesis)

2. Participatory design processes should focus on the back-end of digital services to provoke responsible designs.

(this thesis)

3. Replacing critical thinking and skepticism with opportunism in research for development is a gamble with the livelihood systems of vulnerable people.

4. The mores of the academic community constrain the identity and autonomy of women in science.

5. Agricultural development in the Global South is a fast-fashion industry of technological innovations.

6. Improving opportunities for PhDs outside academia starts by abandoning the term 'student' and recognizing them as professionals.

7. Humans must first experience the side-effects of 'too little' and 'too much' in order to learn the value of 'enough'.

8. The Covid-19 pandemic showed society that vector diseases demand collective containment rather than individual eradication.

Propositions belonging to the doctoral thesis titled:

More than what meets the eye: Factors and processes that shape the design and use of digital agricultural advisory and decision support in Africa

Mariette McCampbell

Wageningen, 01 October 2021 



\section{More than what meets the eye}

Factors and processes that shape the design and use of digital agricultural advisory and decision support in Africa

Mariette McCampbell 


\section{Thesis committee}

\section{Promotors}

Prof. dr. ir. C. Leeuwis

Professor of Knowledge, Technology and Innovation

Wageningen University \& Research

Prof. dr. ir. L.W.A. Klerkx

Personal Professor of Agrifood Innovation and Transition

Wageningen University \& Research

\section{Other members}

Prof. dr. Art Dewulf, Wageningen University and Research

Dr. Benjamin Addom, The Commonwealth Secretariat

Dr. Henny Romijn, Eindhoven University of Technology

Dr. Graham Thiele, International Potato Center

This research was conducted under the auspices of the Graduate School of Social Sciences (WASS) 


\section{More than what meets the eye}

\section{Factors and processes that shape the design and use of digital agricultural advisory and decision support in Africa}

\section{Mariette McCampbell}

\section{Thesis}

Submitted in fulfilment of the requirements for the degree of doctor at Wageningen University by the authority of the Rector Magnificus,

Prof. Dr A.P.J. Mol, in the presence of the

Thesis Committee appointed by the Academic Board to be defended in public on Friday 1 October 2021 At 1.30 p.m. in the Aula 


\section{Mariette McCampbell}

More than what meets the eye:

Factors and processes that shape the design and use of digital agricultural advisory and decision support in Africa

300 pages

PhD thesis, Wageningen University, Wageningen, the Netherlands (2021)

With references, with summaries in English and Dutch

ISBN: 978-94-6395-961-2

DOI: https://doi.org/10.18174/553063 


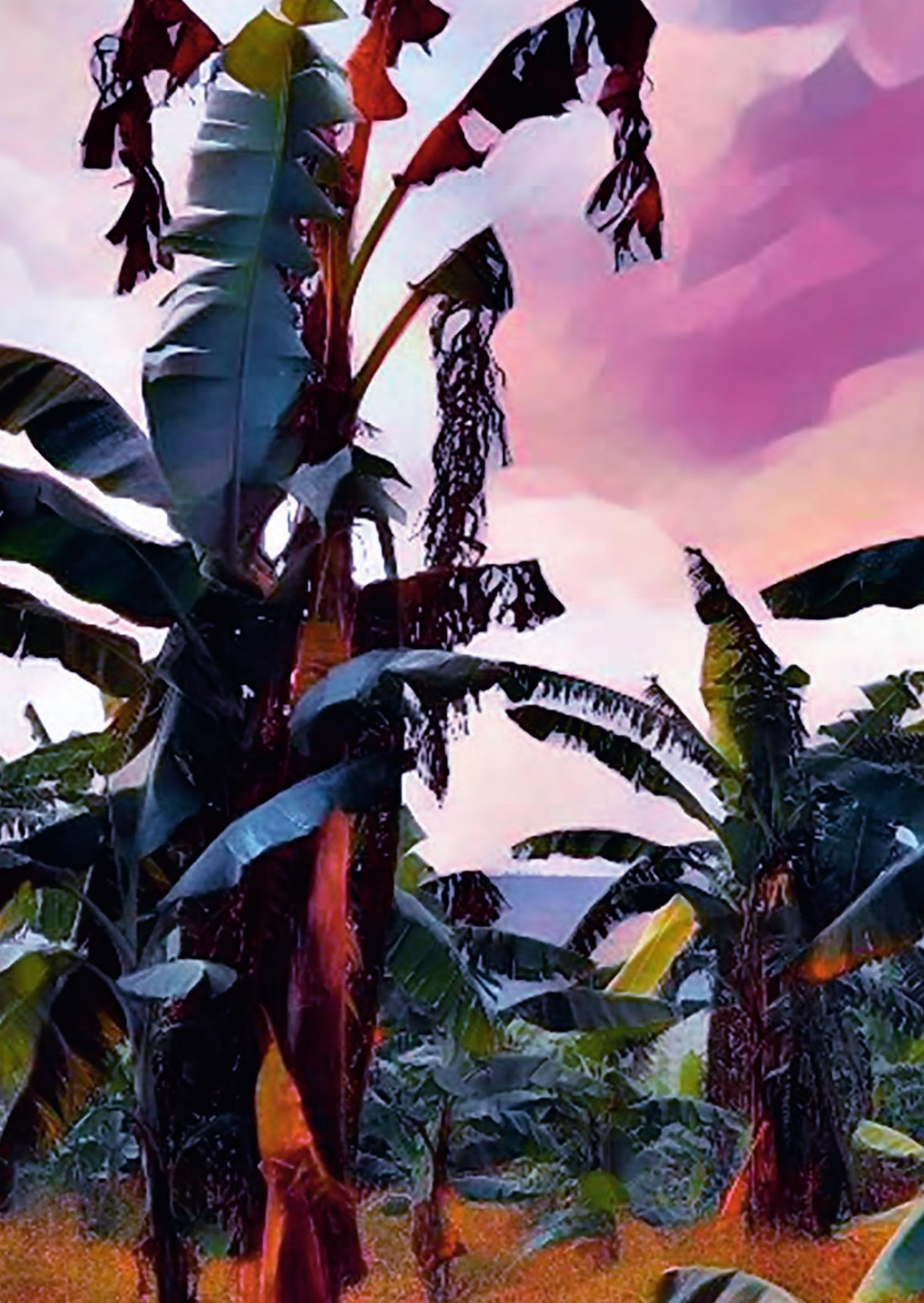




\section{Summary (English)}

Over the past few decades, digitalization has undeniably been transformative and disruptive and digital innovations became an integral part of people's day-to-day life. The years 2020 and 2021, in which the world came to a temporary standstill due to the SARS-CoV-2 or COVID19 pandemic, undoubtedly showed the power of digital technologies: Globally, and almost overnight did work, education, and private lives shift from being place-based and face-to-face to being cloud-based and remote. In a predigitalized era, this would have been unthinkable.

The global availability of (low-cost) digital technologies and services, and subsequently emerging processes of digitization and digitalization, have made digital innovation a key goal and investment theme in many sectors, including in agriculture, both in the Global North and Global South. For the Global South context specifically, there is keen hope that longstanding, complex problems can be addressed with the aid of digital technologies. In the context of African agriculture, digital technologies and services are deployed with the goal to improve food and nutrition security, healthier diets, rural income and livelihoods, mitigating climate change, building resilience, and access to information for everyone.

Although digital agriculture can currently be considered a hype and the number of (scientific) publications appearing on a daily basis is skyrocketing, we still know very little about the processes through which digital agriculture services are designed and the complex and uncertain circumstances wherein design decisions are made. We also have limited understanding about the role that design plays in determining the societal consequences of digitalization and who is, ultimately, affected and in what way (positive or negative).

This dissertation aims to contribute to these research gaps by developing understanding about factors and processes that determine the design and use of digital innovation that are created to address complex agricultural problems. Through this research the question 'What factors and processes shape the design and use of digital advisory and decision support services that are developed for addressing complex agricultural problems in Africa?' was answered. The specific focus was thereby on digital agriculture advisory and decision support. The geographic focus is on Africa, with two case studies from Rwanda (the case of Banana Xanthomonas Wilt as a complex 
agricultural problem for which a solution is sought, and the case of ICT4BXW as a case of a digital agriculture project that developed an agricultural advisory and decision support service).

The dissertation includes eight chapters of which six are based on empirical research:

Chapter 1 is a general introduction that presents the topic of research, the scientific state-of-the-art, and the research design.

Chapter 2 is a problem diagnostics chapter that uses a systems analysis approach to assess the complex problem of Banana Xanthomonas Wilt (BXW) disease. Findings show that when addressing BXW, the academic and practice focus has been mostly on the biophysical and technological dimensions of the system, while the social, cultural, economic, institutional, and political dimensions are often overlooked. Another finding is that knowledge of and information exchange between different actors in the system is generally insufficient. Based on this, I argue that digital technologies and services could support with making real-time data, contextualized information, and knowledge available across the system.

Chapter 3 studies the current capacity of farmers to use digital technologies and services. For this purpose, the user readiness framework was developed and employed. This framework was then used for an ex-ante assessment of current information and communication practices and farmer readiness to use digital (phone-based) agricultural extension services. The ex-ante assessment showed that a mismatch exists between the anticipated user and use (the fictional farmer that digital interventions and services are designed for) and the real-life user and use (surveyed Rwandan farmers in the study).

Chapter 4 looks at the real-world making of digital interventions and services by studying how in the case of ICT4BXW the smartphone-based service was developed and piloted in Rwanda using a participatory design process. The case study findings show that participatory approaches are in practice no panacea. Although users were included in the design process, their influence on the design was mostly limited to the visible design, e.g. interface, content. The participatory process itself does not remove issues such as power imbalances, digital literacy and capacity limitations dimensions e.g. by giving equal power to every stakeholder. Furthermore, anticipation of and reflexivity on potential long-term and more systemic impacts or digital rights such as 
privacy, security, or informed consent, do not receive much attention, and there is limited incentive for stakeholders to adhere to digital rights or guidelines for responsible innovation since these are fragmented and lack formal enforcement.

Chapter 5 is an in-depth conceptual analysis of a specific issue: inclusion and exclusion. The chapter aims to conceptually advance understanding about inclusion (and exclusion) for the context of digital agriculture in a Global South context through a literature review. I found that, within this context, inclusion and exclusion are primarily debated in relation to people's access to technologies or services. However, the positive and negative impact of digitalization on people plays out at various levels and is not necessarily time or place based. Processes causing inclusion and exclusion can become less tangible and there may be a delay before people are confronted with their inclusion or exclusion. I conclude that the common rationale about inclusion needs rethinking.

Chapters 6 and 7 are sister chapters for which findings from chapter 2 provided input. In chapter 6 we present the design of Musa-game, an experimental boardgame to study individual and collective action towards governing a public bad, specifically BXW. Chapter 7 continues were chapter 6 ends, presenting results from a real-life field-test with Musa-game in Rwanda. It looks at emergence and spatiality in relation to farmers' decisions while playing the game and examines how this affects the individual and collective performance in the game. This chapter additionally explores how a shift to digital communication (e.g. using mobile phones, apps) may influence (collective) (collective) decision making. Results show that collective action is more effective than individual action. However, most players used a non-cooperative strategy, thereby increasing both individual and collective risk, and reducing collective performance in the game. Findings suggest that digital services could help with collective learning and sense-making, providing the right knowledge at the right time. However, many of the services built specifically for agricultural advisory or decision support target farmers individually and provide no or limited opportunities for two- or multi-way interaction, which I observe to be a potential risk for effective management of complex agricultural problems.

Chapter 8 summarizes the study's empirical findings and debates what these findings mean for the field of digital agriculture and the study of complex agricultural problems and collective action problems. 


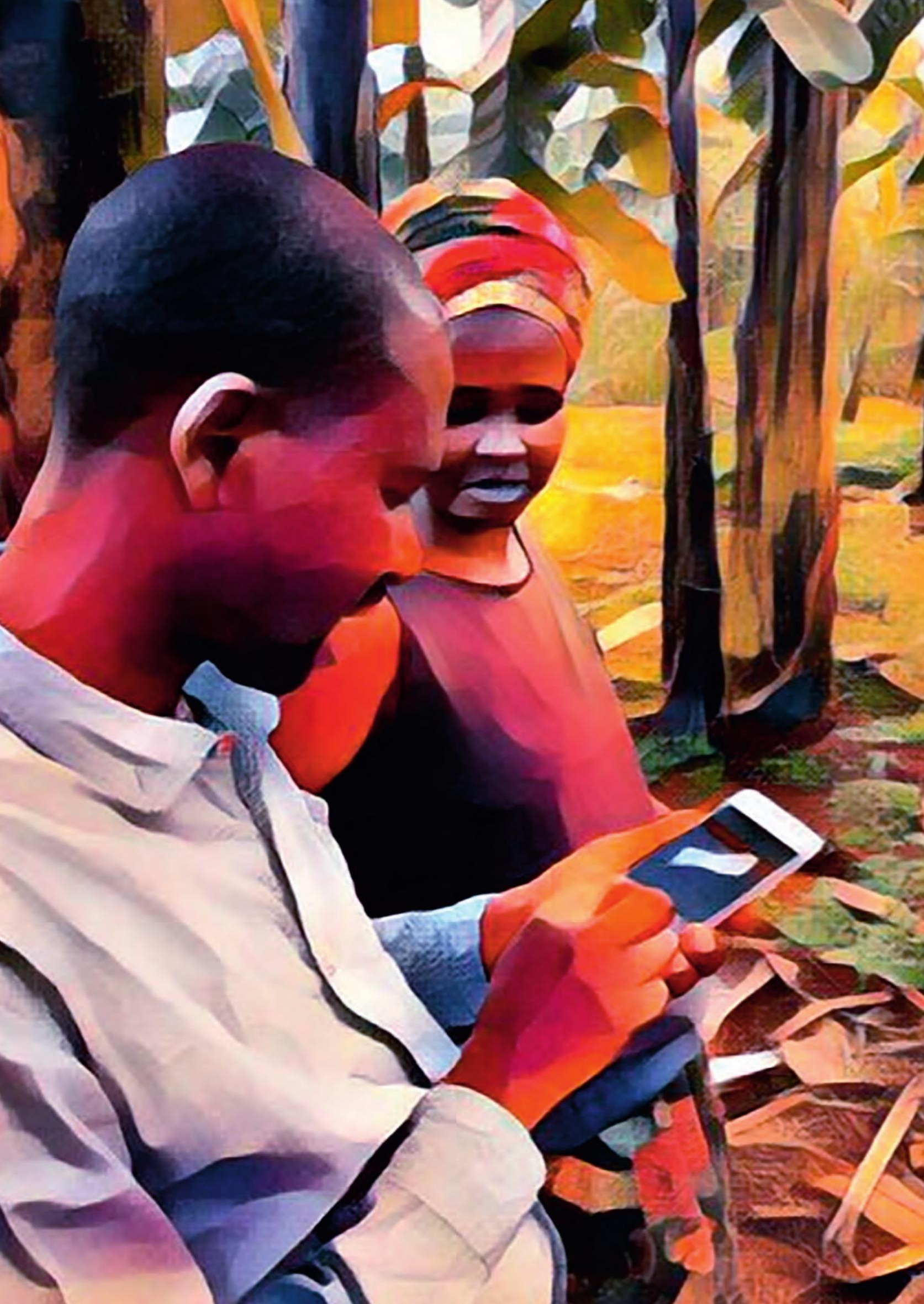




\section{Samenvatting (Nederlands)}

Zonder twijfel zijn digitalisatie processen transformatief en ontwrichtend geweest in de afgelopen decennia, en digitale innovaties zijn een integraal onderdeel geworden van ons dagelijks leven. De jaren 2020 en 2021, waarin de wereld tijdelijk stil kwam te staan door de SARS-CoV-2, ook wel COVID-19, pandemie, heeft zonder twijfel de kracht van digitale technologieën zichtbaar gemaakt: Wereldwijd, en vrijwel van de ene op de andere dag, verplaatsten werk, educatie, en persoonlijke levens zich van zijnde plaatsgebonden en mens-tot-mens naar cloud-gebaseerd en op afstand. Dit zou ondenkbaar geweest zijn in een pre-gedigitaliseerd tijdperk.

De wereldwijde beschikbaarheid van (betaalbare) digitale technologieën en diensten, en de daaropvolgende digitaliserings-processen, hebben ertoe geleidt dat digitale innovatie een belangrijk doel en investerings-thema is geworden in vele sectoren, waaronder in de landbouwsector, zowel in het rijke westen als in armere landen in het zuiden. Binnen de specifieke context van ontwikkelingslanden zien we de levendige hoop dat al lang bestaande, complexe problemen aangepakt kunnen worden met de hulp van digitale technologieën. In de context van landbouw op het Afrikaanse continent worden digitale technologieën en diensten bijvoorbeeld toegepast met het doel verbeteringen te bewerkstelligen rondom voedselzekerheid, voedselkwaliteit, rurale inkomens, levensonderhoud, klimaatverandering, menselijke veerkracht, en universele toegang tot informatie.

Digitale landbouw kan momenteel beschouwd worden als een trend, bijvoorbeeld zichtbaar in het sterk toenemende aantal (wetenschappelijke) artikelen rondom het onderwerp dat recentelijk is verschenen. Desondanks weten we relatief heel weinig over het proces waarbij digitale landbouw diensten worden ontworpen, en de complexe en onzekere omstandigheden waarin beslissingen over een ontwerp genomen moeten worden. Daarnaast hebben we slechts beperkte kennis over de rol van ontwerp bij het bepalen van de sociaal maatschappelijke consequenties van digitalisatie, en wie daar uiteindelijk (al dan niet positief) door beïnvloed wordt en op welke wijze.

Dit proefschrift heeft als doel om een bijdrage te leveren aan de hiervoor benoemde onderzoekhiaten. Het onderzoek tracht kennis en begrip te ontwikkelen rondom de factoren en processen die bepalend zijn voor het ontwerp en het gebruik van digitale innovaties die specifiek gecreëerd worden om complexe problematiek binnen de 
landbouwsector te adresseren. Door middel van dit onderzoek werd de volgende vraag beantwoord: 'Welke factoren en processen geven vorm aan het ontwerp en gebruik van digitaal ondersteunde advies en besluitvorming diensten die ontwikkeld worden om complexe problematiek binnen de Afrikaanse landbouw aan te pakken?' The specifieke focus ligt bij dit onderzoek op digitaal ondersteunde landbouw adviezen en besluitvorming. Geografisch gezien is de blik gericht op Afrika, met twee Rwandese casussen (Banana Xanthomonas Wilt (BXW) als de casus voor een complex landbouwprobleem waarvoor een oplossing gezocht wordt, en het ICT4BXW project als casus voor een landbouw digitalisatie project dat een advies en besluitvorming dienst ontwikkelde).

Het proefschrift omvat acht (8) hoofdstukken waarvan er zes (6) gebaseerd zijn op empirisch onderzoek.

Hoofdstuk 1, is een algemene introductie waarin het onderwerp van de studie, de wetenschappelijke state-of-the-art, en de onderzoeksopzet gepresenteerd worden.

Hoofdstuk 2, is een probleem diagnostisch hoofdstuk. De complexe problematiek rondom Banana Xanthomonas Wilt ziekte wordt in dit hoofdstuk geanalyseerd waarbij gebruik wordt gemaakt van een system analyse benadering. De onderzoeksresultaten laten zien dat zowel de wetenschappelijke als de praktische focus bij de aanpak van BXW voornamelijk heeft gelegen op de biofysische en technologische dimensies van het systeem. Sociale, culturele, economische, institutionele, en politieke dimensies zijn daarentegen vaak veronachtzaamd. Een andere bevinding is dat de kennis van en informatie-uitwisseling tussen verschillende betrokkenen binnen het systeem veelal ontoereikend is. Op basis van deze resultaten beargumenteer ik dat digitale technologieën en diensten een ondersteunende rol kunnen spelen bij het beschikbaar maken van actuele data, gecontextualiseerde informatie, en relevante kennis binnen het systeem.

Hoofdstuk 3, bestudeerd de bestaande bekwaamheid van boeren in het gebruik van digitale technologieën en diensten. Voor dit gedeelte van het onderzoek werd een theoretisch kader ontwikkeld en toegepast, het zogenaamde 'User Readiness Framework'. Dit kader is vervolgens gebruikt om een ex-ante onderzoek uit te voeren naar de huidige informatie en communicatie praktijken en de mate van gereedheid van boeren om gebruik te maken van digital landbouw adviesdiensten (veelal via mobiele telefoons). Dit ex-ante onderzoek liet een wanverhouding zien tussen de 
veronderstelde gebruiker en gebruik van de dienst (m.a.w. de fictionele boer waarvoor digitale interventies en diensten ontworpen worden) en de daadwerkelijke gebruiker en gebruik (m.a.w. de Rwandese boeren die deelnamen aan de onderzoeks-enquête).

Hoofdstuk 4, bekijkt hoe digital interventies en diensten in de praktijk ontwikkeld worden. Hiertoe werd het participatieve ontwerpproces bestudeerd dat, in het geval van het ICT4BXW project, werd gebruikt om in Rwanda een smartphone-applicatie te ontwikkelen en testen. De casus bevindingen laten zien dat participatieve methodes in de praktijk geen wondermiddel zijn. Gebruikers maakten deel uit van het ontwerpproces maar desondanks werd hun invloed op het ontwerp beperkt tot voornamelijk het zichtbare ontwerp, bijvoorbeeld de interface, en informatie content. Het participatieve proces lost op zichzelf problematiek rondom machtsverschillen of digitale geletterdheid en bekwaamheid niet op. Het proces zorgt er, bijvoorbeeld, niet voor gelijke machtsverdeling tussen belanghebbenden. Daarnaast werd zichtbaar dat de anticipatie van en reflectie op zaken zoals de potentiële lange termijn en systemische gevolgen van digitalisatie, of digitale rechten zoals privacy, veiligheid, en geïnformeerde toestemming slechts weinig onder de aandacht zijn. Er is dan ook maar beperkte aansporing om richtlijnen voor digitale rechten en verantwoorde innovatie na te leven aangezien deze richtlijnen gefragmenteerd zijn en het ontbreekt aan formele handhaving.

Hoofdstuk 5 presenteert een diepgaande conceptuele analyse van een specifiek probleem: de inclusie en exclusie van mensen. Door middel van een literatuuronderzoek tracht dit hoofdstuk een bijdrage te leveren aan het conceptuele begrip van inclusie en exclusie voor de context van landbouw digitalisatie vanuit het perspectief van Afrika en ontwikkelingslanden. Mijn bevindingen laten zien dat, in de context, inclusie en exclusie voornamelijk bediscussieerd worden in relatie tot mensen hun directe toegang tot specifieke digitale technologieën en diensten. Echter, de gevolgen van digitalisatie voor mensen speelt zich af op verschillende niveaus en is niet per se gebonden aan een tijd of plaats. Dit betekent dat de processen die inclusie en exclusie veroorzaken minder zichtbaar en tastbaar worden en ook dat een persoon met vertraging, m.a.w. pas na enige tijd, geconfronteerd wordt met hun inclusie of buitensluiting. Ik concludeer in dit hoofdstuk dat de algemene redenering over inclusie heroverwogen dient te worden. 
De hoofdstukken 6 en 7 zijn verwant aan elkaar en werden ontwikkeld gebaseerd op resultaten van hoofdstuk 2. In hoofdstuk 6 presenteren we het ontwerp van Musagame, een experimenteel bordspel waarmee individuele en collectieve acties rondom het beheersen van een 'publiek probleem' (public bad), specifiek BXW. Hoofdstuk 7 gaat verder waar hoofdstuk 6 eindigt en presenteert de resultaten van een veld-test met Musa-game in Rwanda. Er wordt gekeken naar het ontstaan van publieke problemen en de rol van locatie in relatie tot de keuzes die boeren maken wanneer zij een spel spelen. Ook wordt beoordeeld hoe de gemaakte keuzes de individuele en collectieve spel resultaten beïnvloedt. Het hoofdstuk exploreert daarnaast naar de mogelijke invloed van een transitie naar digitale communicatie (bijv. door het gebruik van mobiele telefoons en apps) op de (collectieve) besluitvorming. De resultaten duiden erop dat collectieve acties meer effectief zijn dan individuele acties. Echter, de meeste spelers kozen voor een zogenaamde niet-coöperatieve strategie, wat leidde tot verhoogde risico's voor zowel individuele spelers als het collectief en een verminderd collectief resultaat in het spel. De resultaten suggereren dat digitale diensten kunnen helpen bij collectief leren en begripsvorming door het aanleveren van de juiste kennis op het juiste moment. Echter, de meeste diensten die specifiek ontwikkeld worden voor landbouw advies en besluitvorming richten zich op de individuele boer en bieden slechts beperkte of geen mogelijkheden tot interactie in twee of meerdere richtingen. Ik zie dit als een potentieel risico voor het effectieve management van complexe landbouwproblematiek.

Hoofdstuk 8 vat de empirische onderzoeksresultaten samen en bediscussieerd wat deze resultaten betekenen met betrekking tot landbouw digitalisatie en het bestuderen van complexe landbouwproblemen en collectieve actie problemen. 


\section{Table of contents}

1.1 INTRODUCTION 2

1.2 A PROLIFERATING INTEREST IN DIGITALIZATION FOR DEVELOPMENT PROGRESS 4

1.3 THE SCIENTIFIC BODIES OF LITERATURE THAT THIS THESIS CONTRIBUTES TO 10

1.4 Research OBjective 22

1.5 RESEARCH DESIGN

1.6 What Follows: ConNections between research themes AND EMPIRICAL CHAPTERS 29

2 XANTHOMONAS WILT OF BANANA (BXW) IN CENTRAL AFRICA: OPPORTUNITIES, CHALLENGES, AND PATHWAYS FOR CITIZEN SCIENCE AND ICT-BASED CONTROL AND PREVENTION STRATEGIES

ABSTRACT $\quad 34$

$2.1 \quad$ INTRODUCTION

2.2 Historical OVERVIEW AND GAPS IN OUR UNDERSTANDING OF BXW AND ITS MANAGEMENT IN THE GREAT LAKES Region

2.3 CONCEPTUAL AND METHODOLOGICAL FRAMEWORK

2.4 RESULTS: UNRAVELING DIMENSIONS OF THE BXW PROBLEM

$\begin{array}{llr}2.5 & 54\end{array}$

$\begin{array}{lll}2.6 & \text { CONCLUSIONS } & 60\end{array}$

3 ARE FARMERS READY TO USE PHONE BASED DIGITAL TOOLS FOR AGRONOMIC ADVICE? EXANTE USER READINESS ASSESSMENT USING THE CASE OF RWANDAN BANANA FARMERS $\quad 63$ ABSTRACT

$\begin{array}{lll}3.1 & \mathbf{1 N T R O D U C T I O N} & \mathbf{6 5}\end{array}$

3.2 Conceptual framework: An Approach to Study Technology User Readiness for Using Digital Agriculture $\begin{array}{lr}\text { TECHNOLOGIES } & 67\end{array}$

3.3 Materials and Methods $\quad 70$

$\begin{array}{llr}3.4 & \text { RESULTS } & 75\end{array}$

$\begin{array}{lll}3.5 & \text { DISCUSSION } & 80\end{array}$

$\begin{array}{lll}3.6 & \text { CONCLUSIONS AND RECOMMENDATIONS } & 86\end{array}$

4 GOOD INTENTIONS IN COMPLEX REALITIES: CHALLENGES FOR DESIGNING RESPONSIBLY IN DIGITAL AGRICULTURE IN LOW-INCOME COUNTRIES ABSTRACT
90

$\begin{array}{llr}4.1 & 91\end{array}$

$\begin{array}{lll}4.2 & \text { CONCEPTUAL FRAMEWORK } & 92\end{array}$ 
4.3 DIGITAL RIGHTS IN AGRICULTURE IN LICS

4.4 METHODS 96

4.5 FINDINGS

4.6 ANTICIPATION: CONSIDERING CONSEQUENCES AND IMPACT ON DIGITAL RIGHTS 103

4.7 REFLEXIVITY: STEERING CAPACITY IN DIGITAL DESIGN 104

4.8 RESPONSIVENESS: PROJECT LIMITATIONS \& POSITIVIST MINDSET

4.9 DISCUSSION 106

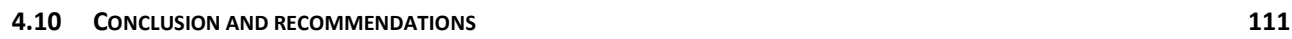

5 A PROBLEMATIZATION OF INCLUSION AND EXCLUSION: TRADE-OFFS AND NUANCES IN THE DIGITALIZATION OF AFRICAN AGRICULTURE

$\begin{array}{ll}\text { ABSTRACT } & 116\end{array}$

$\begin{array}{llr}5.1 & \text { INTRODUCTION } & 117\end{array}$

$\begin{array}{llr}5.2 & \text { METHOD AND CONCEPTUAL FRAMING } & 118\end{array}$

\begin{tabular}{l}
5.3 OBSERVED MECHANISMS OF INCLUSION AND EXCLUSION IN DIGITAL AGRICULTURE \\
\hline
\end{tabular}

5.4 RETHINKING INCLUSION AND EXCLUSION FOR THE CONTEXT OF DIGITAL AGRICULTURE

6 ADDING EMERGENCE AND SPATIALITY TO A PUBLIC BAD GAME TO STUDY DYNAMICS IN SOCIO-ECOLOGICAL SYSTEMS (PART I): THE DESIGN OF MUSA-GAME FOR INTEGRATIVE ANALYSIS OF COLLECTIVE ACTION IN BANANA DISEASE MANAGEMENT $\begin{array}{lr}\text { ABSTRACT } & 134\end{array}$

$\begin{array}{llr}6.1 & 135\end{array}$

$\begin{array}{llr}6.2 & \text { THEORETICAL FRAMEWORK } & 137\end{array}$

6.3 METHODOLOGICAL BACKGROUND AND PROPOSAL 142

6.4 THE PHYSICAL ENVIRONMENT, AND MECHANICS, OF THE MUSA-GAME

$\begin{array}{llr}6.5 & 159\end{array}$

7 A PUBLIC BAD GAME METHOD TO STUDY DYNAMICS IN SOCIO-ECOLOGICAL SYSTEMS (PART II): RESULTS OF TESTING MUSA-GAME IN RWANDA AND ADDING EMERGENCE AND SPATIALITY

\begin{tabular}{lr} 
TO THE ANALYSIS & 163 \\
\hline
\end{tabular}

$\begin{array}{lr}\text { ABSTRACT } & 164\end{array}$

$\begin{array}{llr}7.1 & 165\end{array}$

$\begin{array}{llr}7.2 & \text { THEORETICAL FRAMEWORK } & 166\end{array}$

$\begin{array}{llr}7.3 & \text { METHODS } & 170\end{array}$

$\begin{array}{llr}7.4 & \text { RESULTS AND ANALYSIS } & 175\end{array}$

$\begin{array}{llr}7.5 & \text { DISCUSSION AND CONCLUSIONS } & 191\end{array}$

8 DISCUSSION AND SYNTHESIS 201

$\begin{array}{llr}8.1 & \text { PRELUDE } & 202\end{array}$

8.2 A RESEARCH JOURNEY INTO DIGITAL AGRICULTURE ADVISORY AND DECISION SUPPORT IN AN AFRICAN CONTEXT 203

8.3 THE RESEARCH FINDINGS IN A BROADER PERSPECTIVE: CONTRIBUTIONS OF THE THESIS TO THE SCIENTIFIC DEBATE ON DIGITAL $\begin{array}{lr}\text { AGRICULTURE } & 213\end{array}$

$\begin{array}{lrr}8.4 & \text { REFLCTION ON THE RESEARCH } & 233\end{array}$

\begin{tabular}{lr}
8.5 & FINAL REFLECTION \\
\hline
\end{tabular} 
SUPPLEMENTAL MATERIAL

APPENDIX 1: DETAILS ABOUT SURVEY DATA USED AS INPUT FOR ANALYSIS

APPENDIX 2: INTERNATIONAL SECTOR POLICIES AND GUIDELINES AVAILABLE FOR REGULATING THE DESIGN OF DIGITAL AGRICULTURE TOOLS AND SYSTEMS

APPENDIX 3: TAM USE SURVEY

APPENDIX 4: FGD QUESTIONS FOR FARMERS

APPENDIX 5: CONSENT FORM FGD AND SURVEYS

APPENDIX 6: OVERVIEW OF VARIABLES PER CATEGORY AND SUB-CATEGORY

APPENDIX 7: INPUT FOR SES FRAMEWORK ADAPTED TO BXW DISEASE IN RWANDA

APPENDIX 8: MANUAL MUSA ANALYSIS TOOL

APPENDIX 9: CONSENT FORMS FOR GAME EXPERIMENT (THE MUSA-GAME) 
$\mathrm{A}_{\mathrm{C}}$ $452 x^{2}$

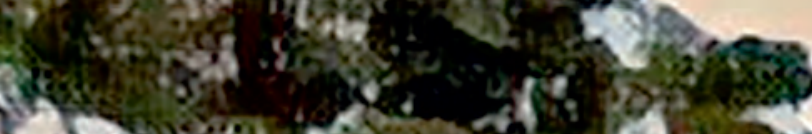
$4.11 x^{-4}=3$ Q. $x^{-3}+10$

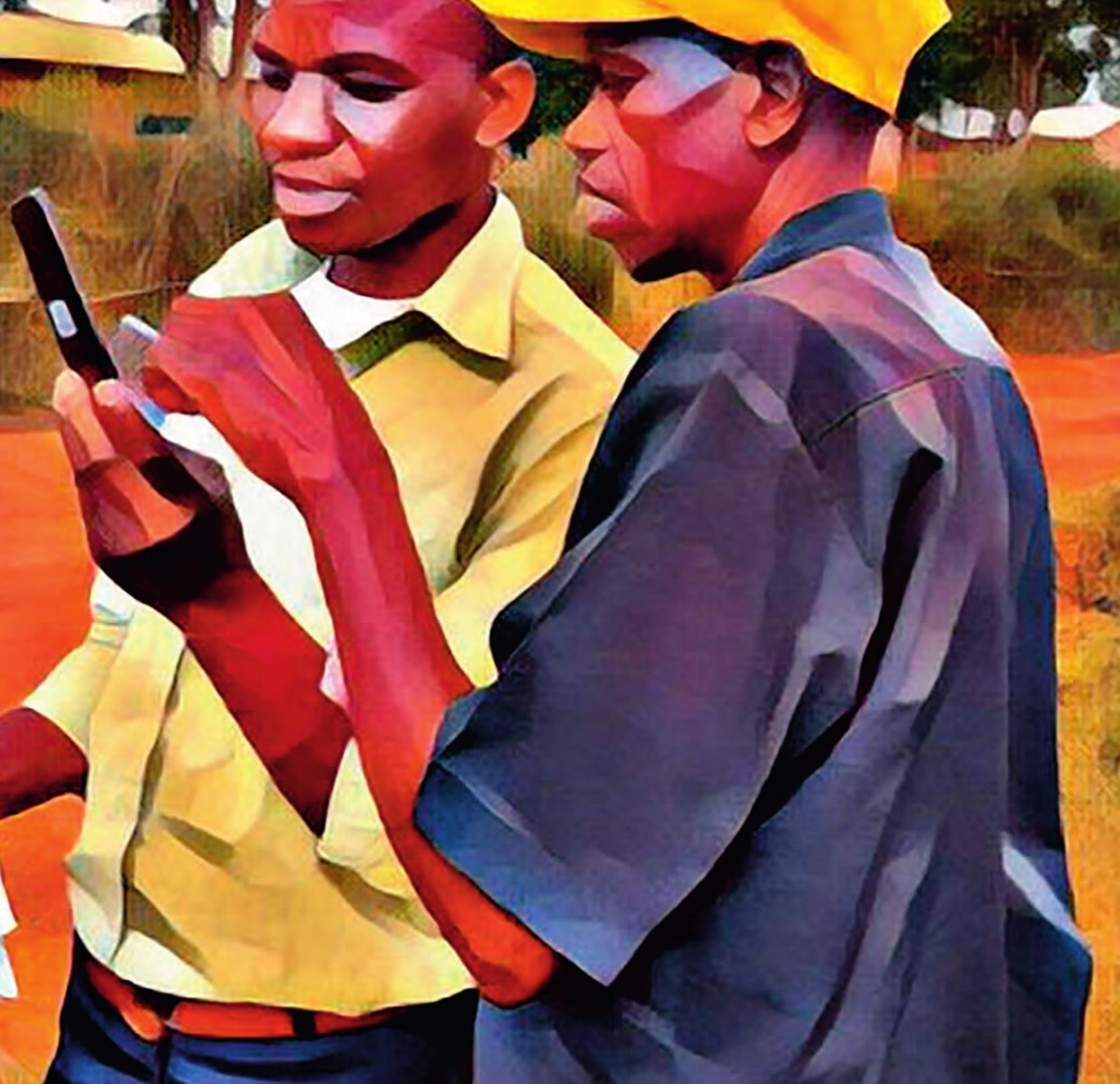




$$
36
$$


General introduction 


\subsection{Introduction}

Over the past few decades, digitalization (Table 1) has undeniably been transformative and disruptive and digital innovations became an integral part of people's day-to-day life (Scholz et al., 2018; Vial, 2019). These technologies have altered, and continue to alter, how we communicate, do business, take decisions, spend our time, etc. and the norms and values that we attach to this (Hinings, Gegenhuber, \& Greenwood, 2018; Skog, Wimelius, \& Sandberg, 2018). Gone are the days that we could not be reached after we left our homes; information about any topic or place is never more than a query in a search engine away; more and more people spend their workdays in front of a computer screen, and we likely add more hours to our screentime when off work; shops, banks, insurance companies, etc. are open $24 / 7$ since they moved from physical buildings to an online environment; we can connect with friends and family all over the world in real-time and at almost no cost; and so on and so forth. The years 2020 and 2021, in which the world came to a temporary standstill due to the SARS-CoV-2 or COVID19 pandemic, undoubtedly showed the power of digital technologies: Globally, and almost overnight did work, education, and private lives shift from being place-based and face-to-face to being cloud-based and remote (Dwivedi et al., 2020; Wang, Schlagwein, Cecez-Kecmanovic, \& Cahalane, 2020). In a predigitalized era, this would have been unthinkable.

For the purpose of this thesis I use definitions for digital innovations from other scholars to classify digital innovations into two categories: digital technologies, and digital services and solutions (mostly shortened to services in this thesis) (Baumüller \& Addom, 2020; Trendov, Varas, \& Zeng, 2019, see also table 1). The former refers to infrastructure (e.g. cables, masts) and hardware (e.g. mobile phones, sensors, drones) needed to operate, offer, and access to digital services and solutions (Trendov et al., 2019). The latter refers to the services and products offered to users that use the support of digital technologies (Baumüller \& Addom, 2020). Heeks (2018, p.12-14) nicely captures what defines digital technologies and services: Their core functionality is to capture, input, process, store, and output data; Their application functionality is to undertake processes, such as storing or sharing data, making calculations, determining geographic location, and doing this cheaper, at a larger scale, faster, better, and in ways previously impossible when compared to other technologies; The primary affordances they offer are provision of information that can feed into decision-action-result chains, 
and one-way/two-way/multi-way communication from one recipient to another. Other affordances include; computation, creation of content, commercial or non-commercial transactions, content distribution, collaboration, and coordination of (human and/or non-human parts of) a system.

\section{Table 1: Definitions of terms related to digitalization in agriculture}

Term

Digitization

Digitalization

Datafication

Digital (societal) transformation

Digital technologies

Digital services and solutions

Digital agriculture; e-agriculture

Precision agriculture; smart farming

\section{Definition}

Process in which analogue information about real world is transformed to a digital form (binary series consisting of the numbers 0 and 1) that can be processed by computers and other electronic equipment (Bloomberg, 2018)

The introduction and use of digital technologies, services, and solutions (e.g. computers, mobile phones, the Internet) into existing (organisations, industrial, social) systems which results in a restructuring of these systems (Fielke, Taylor, \& Jakku, 2020) Process in which subjects, objects, and practices, i.e. aspects of life, are transformed into digital, quantifiable, and machine-readable data that allow for tracking, monitoring, (predictive) analysis, and optimization (Williamson, 2018)

Use of digital technologies and services as transformative forces to reach the goals of agriculture 4.0/fourth agricultural revolution e.g. improving productivity, resource use optimization, food security and safety, (environmental) sustainability (Parra-López, ReinaUsuga, Carmona-Torres, Sayadi, \& Klerkx, 2021) entailing a variety of digitization, digitalization, and datafication activities (Rijswijk et al., 2021)

Infrastructure (e.g. cables, masts) and hardware (e.g. mobile phones, sensors, drones) needed to operate, offer, and access digital services and solutions (Trendov et al., 2019)

Services and products offered to users that use the support of digital technologies (Baumüller \& Addom, 2020)

Suite of on-farm and off-farm digital tools, technologies, and services (e.g. mobile phones, precision technology, drones and robotics) used in the management of and decision-making about agricultural systems and value chains (C. Eastwood, Klerkx, \& Nettle, 2017; Wolfert, Ge, Verdouw, \& Bogaardt, 2017). Also referred to as ICT4Ag and D4Ag in the context of the Global South/Africa/LMICs/developing countries.

Utilization of advanced, software-managed and sensor-monitored, technologies (e.g. robotics, satellite and drone imagery, loT, data analytics) for tracking, monitoring, automating, and analyzing operations in agricultural systems with the aim to optimize accuracy, effectiveness, and efficiency of crop production and resource use while considering temporal and spatial variability (Onyango, Nyaga, Wetterlind, Söderström, \& Piikki, 2021). 
Chapter 1

Overtime, digital hardware has become more advanced, integrating a suite of technologies that previously required separate hardware (Mutchler, Shim, \& Ormond, 2011). For example, today's smartphones are pocket-sized computers with built-in phones, cameras, voice recorders, GPS, and so on. Advances such as the Internet of things (IOT) make that digital devices are ever more connected to the Internet, enabling global connectivity of people and their devices that collect, share, and receive (realtime) data and information (Nižetić, Šolić, López-de-lpiña González-de-Artaza, \& Patrono, 2020). Increasingly the power of data and data generating technologies have been approached almost religiously, referred to as dataism, as a means to save the world while generating (new) economic power and profits (Harari, 2017). Similar reification has also entered international development as is further substantiated in the next section.

\subsection{A proliferating interest in digitalization for development progress}

Digitalization and datafication in the context of development in general and agriculture specifically are surrounded by hype (Gatti \& Visser, 2020; Heeks \& Shekhar, 2019; lazzolino, 2021a). The global availability of (low-cost) digital technologies and services, and subsequently emerging processes of digitization and digitalization, have made digital innovation a key goal and investment theme in many sectors (e.g. education, health, agriculture, finance) both in the Global North and Global South (lazzolino, 2021b; Reis, Amorim, Melão, Cohen, \& Rodrigues, 2020; World Bank Group \& China Development Bank, 2017). For the Global South context specifically, there is keen hope that longstanding, complex problems can be addressed with the aid of digital technologies (Lajoie-O'Malley, Bronson, van der Burg, \& Klerkx, 2020; Leeuwis et al., 2018; Roberts \& Hernandez, 2019). This optimism arises from the affordances mentioned in the previous section and broader changes that these affordances may bring about, such as: Automation (potentially increasing efficiency and effectiveness and decreasing costs); connection and network building (connecting human and nonhuman entities, and making them inclusive); equalisation (reducing information asymmetries by creating equal access); illumination of human activity (e.g. through surveillance and digital control); innovation (and malleability); and universalisation (breaking down with old time/space barriers) (Heeks, 2018). 
In a video about their digital strategy, USAID, a forefront funding and implementing organization in the field of ICT4D, pronounces that digital tools "hold immense potential to help people live freer, healthier, and more prosperous lives" ${ }^{1}$. These so called ICT4D (Information and Communication Technologies for Development) (Heeks, 2018) or D4D (Digital/Data for Development) (Cinnamon, 2020; Qureshi, 2020)² interventions are said to facilitate, among other things, access to credit and financial services for the rural poor (Agyekumhene et al., 2018), provision of accurate, timely, and relevant information (Qiang, Kuek, Dymond, \& Esselaar, 2011), early warning about threats and disasters (Duncombe, 2014), and connecting people in rural areas with each other and with people in urban areas (Trendov et al., 2019). Until now, the development sector has mostly been opportunistic about digitalization, visible in the promises about and expectations of the transformative capacity of digital technologies and services (Hanson, Shaw, Puplampu, \& Arthur, 2020; Heeks, 2020b). Research on the topic of digital for development confirms that digital technologies present a wide variety of opportunities and may be drivers of development and change (Heeks, 2018). For example, an RCT study to the impact of an application providing personalized information on rice production in Nigeria showed $7 \%$ yield increase and $10 \%$ profit increase (Arouna, Michler, Yergo, \& Saito, 2020). However, there are challenges too and several of those are being discussed later in this chapter and throughout the thesis. Many challenges relate to what differentiates the Global North from the Global South, which is that (people in) the Global South generally faces more uncertainty, resource constraints, inequality, and localism (i.e. closer connections and face-to-face interactions) (Heeks, 2018). Additionally, institutionally there may be more reliance on informal, personal processes and systems or top-down hierarchies (idem) as I will further elaborate in the next section.

\subsubsection{Digital development in the context of smallholder farming systems}

The sub-field of ICT4D that is focused on agriculture is known as ICT4Ag (Information and Communication Technologies for Agriculture) or D4Ag (Digital/Data for Agriculture). Both abbreviations refer to the use of a wide range of digital

\footnotetext{
${ }^{1}$ USAID Digital Strategy. April 2021: https://www.youtube.com/watch?v=YJSsvEG7Gi4

2 Scholars refer to D4D as 'Data for Development', however, for example, the European Union (https://ec.europa.eu/commission/presscorner/detail/en/ip_20_2321) and Belgium's development cooperation Enabel (https://www.enabel.be/publication/digital-development-d4d-strategic-note-belgiandevelopment-cooperation) use the abbreviation with the meaning 'Digital for Development'.
} 


\section{Chapter 1}

technologies, services, and data for transforming business models and practices, and addressing bottlenecks across agricultural value chains, especially in smallholder farming systems (Tsan, Totapally, Hailu, \& Addom, 2019). In this thesis, I refer to the concepts of ICT4Ag and D4Ag as digital agriculture in a Global South, African, Lowand Middle-Income Countries (LMIC), or developing countries context.

As noted earlier, digitalization and datafication in the context of development in general and agriculture specifically are surrounded by hype, in the following paragraphs I elaborate this further. Investments in digital development are increasing and diversifying (GIE, 2019) and the number of digital agriculture services and solutions in Low and Middle Income Countries (LMICS) has grown from 53 in 2009 to $700+$ in 2020 (GSMA, 2020). International organizations like: USAID, BMGF, GIZ, FAO, WorldBank, Dalberg, GSMA, and CGIAR all pay considerable attention to digital agriculture in recent years, for example by funding and implementing projects (e.g. GIZ's SAIS project ${ }^{3}$, IFAD's collaboration with Precision Agriculture for Development ${ }^{4}$ ) setting up infrastructure (e.g. CGIAR Big Data platforms' GARDIAN agricultural data network ${ }^{5}$, and Evidence Clearing House ${ }^{6}$ ), publishing reports (e.g. GSMA, 2020; Trendov et al., 2019; Tsan et al., 2019; World Bank Group, 2019), and developing toolkits, strategies, and guidelines (e.g. GMSA \& Frogdesign, n.d.). More recently, Big Tech (e.g. Facebook, Google), large Agribusiness companies (e.g. Bayer Global, John Deere), and corporate philanthropic organizations (Syngenta foundation) have entered the field through partnerships or their own products (Gatti \& Visser, 2020). Kenya's capital city Nairobi received the nickname "Silicon Savannah" for hosting many tech start-ups (lazzolino, 2021a). IFAD's Associate Vice-President of the Strategy and Knowledge Department Meike van Ginneken recently said during one of their Innovation Talks that: "There is no need to convince ourselves of the power of digital agriculture" 7 . Witnessing the proliferation of online events, webinars, and courses; reports and guidelines published; and calls for funding since the start of the Covid-19 pandemic, the field's exponential growth continues in 2021. Hence, the 'hype-phase' of digital agriculture in the Global South has not (yet) passed. It seems that there is no escape

\footnotetext{
${ }^{3}$ GIZ SAIS project: https://www.giz.de/en/worldwide/83909.html

${ }^{4}$ IFAD/PAD collaboration: https://www.ifad.org/en/web/latest/-/blog/digital-agriculture-key-to-helpingsmall-scale-producers-overcome-covid-19-challenges

${ }^{5}$ CGIAR GARDIAN: https://gardian.bigdata.cgiar.org/\#!/

${ }^{6}$ CGIAR Evidence Clearing House: https://bigdata.cgiar.org/evidence-clearing-house/

${ }^{7}$ IFAD innovation talk, May 2021: https://precisionag.org/showcasing-our-collaboration-with-ifad/
} 
from digitalization, everyone must become a member of the digital ecosystem. It is in this setting that this PhD dissertation needs to be seen, to critically scrutinize this hype.

\subsubsection{Rationale for the research in this dissertation}

I developed the idea for this research project in 2017, in a hotel conference room in Kigali, Rwanda while I attended the launch of a new agricultural development project. Implementation of phone-based solutions was one of the project's objectives. Around that same time, I observed an upsurge of a wide array of projects piloting digital services and solutions to support (rural) development (see Table 2 for an overview). Those projects were being introduced by public (e.g. governments, NGOs, research institutes) and private organizations and promised to contribute to solving a wide array of complex (agricultural) problems in the Global South. Many of these digital services and solutions were targeting farmers, extension agents, and market actors in Africa. Examples of problems typically that projects aimed to address then, and still today, include access to reliable and profitable markets (Nakasone, Torero, \& Minten, 2014), timely and trustworthy agricultural information (Aker, Ghosh, \& Burrell, 2016), and control and prevention of crop pests and diseases (Powell, 2017). The greater goal of digital agriculture in the Global South was, and is, to improve food and nutrition security, healthier diets, rural income and livelihoods, mitigating climate change, building resilience, and access to information for all groups including women, youth, and minorities, and state growth (Barrett et al., 2020; Birner, Daum, \& Pray, 2021; lazzolino, 2021a; Lajoie-O'Malley et al., 2020).

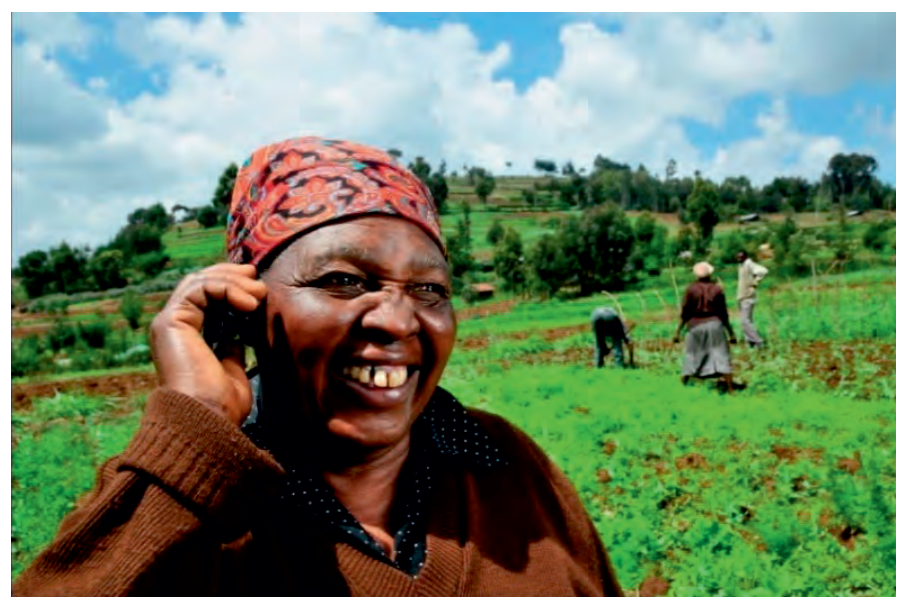

Picture 1: Picture of a Kenyan female farmer with a mobile phone (CIAT/Neil Palmer, 2010). 


\section{Chapter 1}

Standing in that hotel conference room I watched people proudly presenting the anticipated outcomes and impact of their project, illustrated by beautiful pictures. One of those pictures looked oddly familiar to me. It was a photograph of a smiling Kenyan woman holding a mobile phone to her ear (Picture 1) and I had seen it before, more than once in fact. In the following months I kept seeing that same picture again and again. The smiling Kenyan lady had become the face of digital development in African agriculture and was used by different organizations for different projects.

I wondered: If one picture was the face of so many projects by different organizations and represented their success, then what was really behind the scenes? Why were these services and interventions developed? How were they designed and implemented, and by and for whom? What were their consequences for farmers and the agricultural sector more broadly?

This thesis describes my journey to discover about what is behind the hardware and interface of the digital technologies, services, and solutions that are being developed for smallholder farmers in the Global South, particularly Africa: To observe and understand what is beyond what meets the eye. It responds to my observation that the processes through which digital agriculture services are designed, the complex and uncertain circumstances wherein design decisions are made, and the norms and values informing decision making about designs mostly stay under the radar. Likewise, our scientific understanding about the role that design plays in determining the societal consequences of digitalization and who is, ultimately, affected and in what way (positive or negative) is limited. With the thesis I aim to respond to this research gap. The focus will thereby be primarily on two of the service typologies presented in Table 2: Agricultural advice and decision support, and problem diagnostics. For simplicity, I generally refer to them both as advisory and decision support in this and the synthesis chapter.

In the next section, I further describe the main debates in the literature that informed my research and to which I contribute with the research findings. This supports the reader to understand how my research fits in the very broad field of digital agriculture and what it expects to contribute. This is followed by more details about the research objectives and questions (section 1.4). The chapter finishes with first an overview of the research design (section 1.5), and finally an outline for the six empirical chapters (section 1.6). 

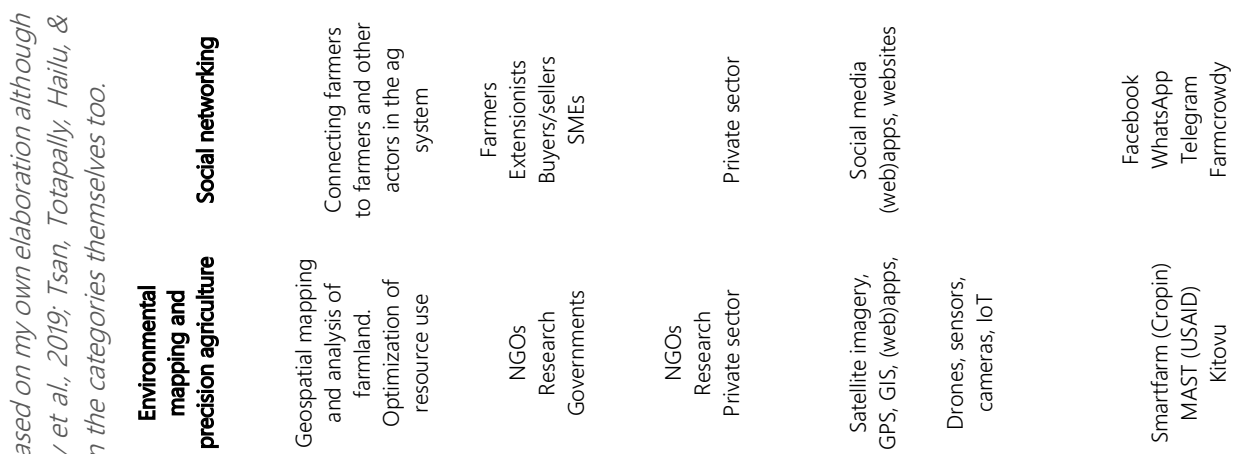

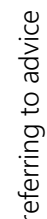

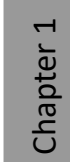

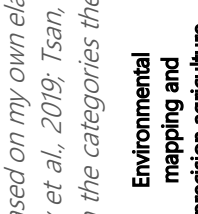

ठे गे

造造

\& के के

ปั

( )

का $\sum^{2}$

胥 $\infty$

के बे क्ष

क के

वे 0 व

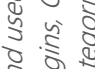

ह

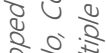

(1) $\frac{1}{2}$

$\begin{array}{lll}2 & 1 \\ 0 & 0 & 0\end{array}$

㐫令

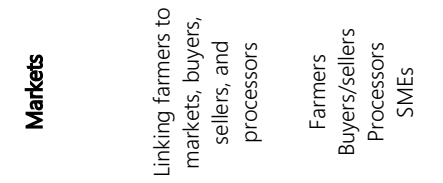

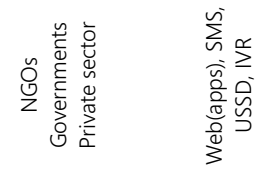

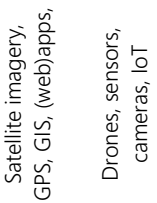

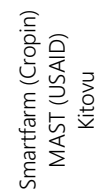

$\frac{\frac{1}{2}}{3}$

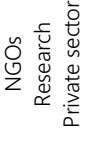

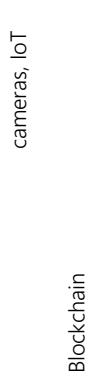

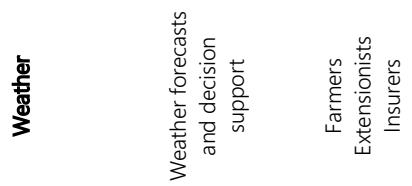

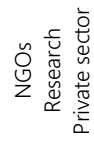

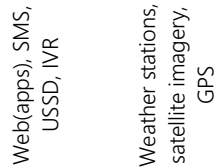

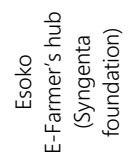

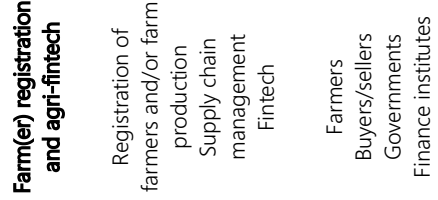

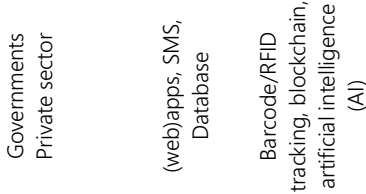

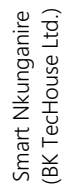

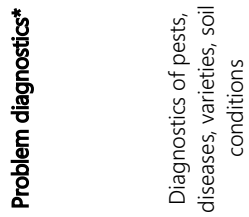

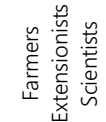

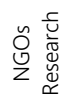

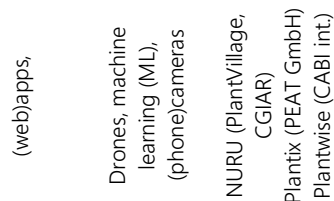
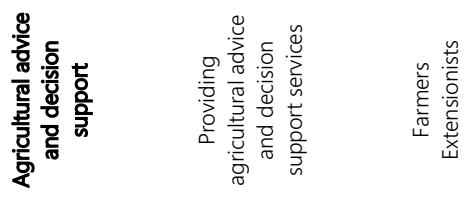

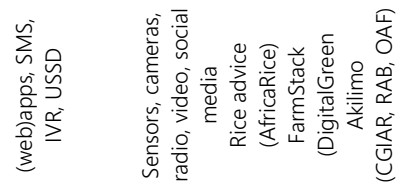

को ह ह

बत पर

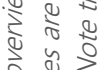

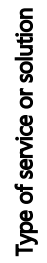

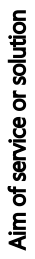
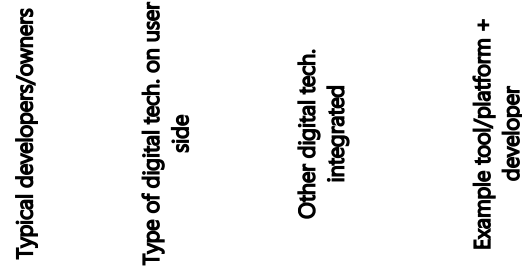

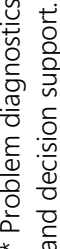




\subsection{The scientific bodies of literature that this thesis contributes to}

The above introduction showed how much digitalization has been embraced by practitioners in the development and agricultural sectors. Academically, digital agriculture is on the agenda too: More than $50 \%$ of the publications included in a literature review to the use of digital services by farmers in LMICS were from 2018-2020 (in a dataset covering material from the period 2000-2020) (Porciello, Coggins, OtunbaPayne, \& Mabaya, 2021b). It would be impossible to give an all-encompassing report of all topics addressed in the literature today. I hence limit myself to only those themes that are relevant for my research, meaning that I concentrate on literature in regard to factors affecting adoption of designed technologies and services (e.g. access, inclusion, capacity, readiness), designing digital agriculture technologies and services, and ethical and responsible design and innovation. I mostly discuss studies with a Global South/Africa focus.

With its thematic focus on how digital agriculture technologies, services, and interventions for agricultural advisory and decision support are designed, by whom, and with what objectives and outcomes, the thesis contributes to three of five thematic research clusters in the global social science literature on digital agriculture, smart farming, and agriculture 4.0 as identified in a review of the extant social science literature by Klerkx et al. (2019): (1) adoption, uses and adaptation of digital technologies on farm; (2) how digitalization may affect agricultural knowledge and innovation systems, and (3) power, ownership, privacy and ethics in digitalizing agricultural production systems and value chains ${ }^{8}$.

\footnotetext{
${ }^{8}$ The two other themes are mostly outside the scope of my research, although I will tangentially touch upon them in the synthesis chapter. The theme of economics and management of digitalized agricultural production systems and value chains is in my view more forward-looking, focusing on 'what may be there or happen in the future' when it comes to the Global South (Barrett, 2021; Birner et al., 2021; Reardon et al., 2019). These studies are opportunistic e.g. focusing on smart farming and more advanced (data-driven) technologies sketching the 'future of farming' (Fabregas et al., 2019; A. King, 2017; Wolfert et al., 2017; Xin \& Zazueta, 2016), urging services and data to be bundled (Barrett et al., 2020), and seeking suitable business models (Birner et al., 2021) or suspicious about changing political economies (Mann, 2018; Rotz et al., 2019) impact of platformization (lazzolino \& Mann, 2019), nudging towards desired behaviour (Brooks, 2021). Lastly, The fifth theme covers effects of digitalization on farmer identity, skills, and farm work (both in high-income countries and LMICS) leading to, for example, changing definitions of farming and farmer identity, and shifting labour and expertise needs (Bronson, 2019; Duncombe, 2014; Eastwood et al., 2019, 2017).
} 
This section and the thesis are organized according to four layers (Figure 1, see also Figure 4), these represent the various angles from which I approach my research topic in the thesis. The layers are: (1) Digital technology or service; (2) users, (3) (collective action) problem context, and (4) digital ecosystem (see : Visualization of the different levels on which the thesis zooms in. I define the levels as follows: Digital technology or service refers to the digital hardware (e.g. mobile (smart)phone, GPS, drone) and software (e.g. smartphone application, database), this may include conventional hardware such as radio too. Users refers to the direct and indirect users of digital technologies and services, and the (data) outputs of those services (e.g. farmers, extension agents, public and private developers, and implementers. for more detail). In the next section, I start with the tool layer, discussing how digital technologies and services evolved, observed issues with access and readiness, and how these relate to the adoption, uses and adaptation cluster.

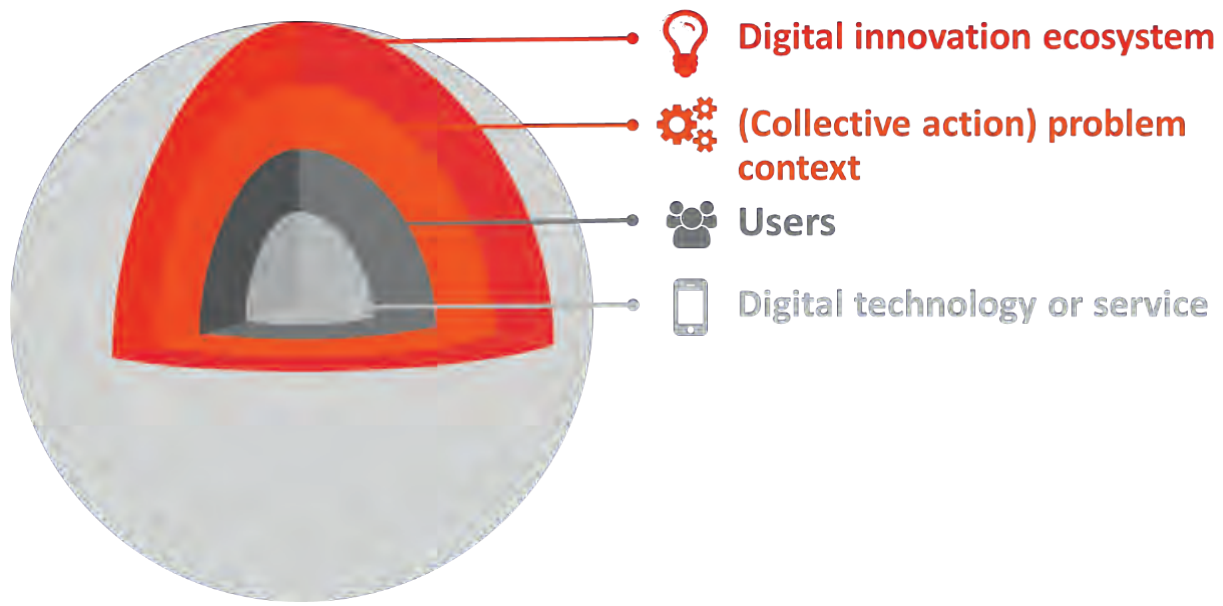

Figure 1: Visualization of the different levels on which the thesis zooms in. I define the levels as follows: Digital technology or service refers to the digital hardware (e.g. mobile (smart)phone, GPS, drone) and software (e.g. smartphone application, database), this may include conventional hardware such as radio too. Users refers to the direct and indirect users of digital technologies and services, and the (data) outputs of those services (e.g. farmers, extension agents, public and private developers, and implementers. (collective action) problem context focuses on the complex problems for which digital technologies and services are developed, and the (local) context in which that problem is embedded (e.g. Banana Xanthomonas Wilt disease in the context of this study). Digital innovation ecosystem refers to the broader assemblage of digital technologies and services, users, developers, institutions, political and socio-cultural arrangements etc. that form a system in which they act, interact, impact and are impactea by each other. 


\subsubsection{Digital tools: Challenges that come with the use of new digital technologies}

Digital technologies may currently be in the spotlight, however various Information and Communication Technologies (ICT) have been used in the agricultural sector since decades (Bronson, 2019; Leeuwis, 1993), complementing paper-based learning materials and face-to-face interaction between farmers, extension agents, and other actors, and their effectiveness in transforming agricultural advisory services has been a topic of interest for some time (e.g. Sulaiman, Hall, Kalaivani, Dorai, \& Reddy, 2012). Most current scientific studies to digital agriculture with a Global South focus fit into the adoption, uses, and adaptation theme (Klerkx, 2019). These studies are descriptions of 'what is out there', with researchers analysing the existing technologies, and services and solutions (e.g. Aker, Ghosh, \& Burrell, 2016; Fawole \& Olajide, 2012; Nakasone, Torero, \& Minten, 2014; Wright et al., 2016). Initially the technological focus was on conventional ICTs such as radio and telecentres (Breitenbach, 2013; Mulozi, 2008; Zanello, 2012). With the proliferation of mobile phones and the Internet, the type of ICTs accessible to individuals in the Global South changed and became more advanced. Mobile phones quickly gained attention to host advisory and decision support services (Aker \& Ksoll, 2016; Baumüller, 2016; Duncombe, 2014; Eichler Inwood \& Dale, 2019). To date, more high-tech digital technologies such as drones, block-chain, satellite imagery, machine learning and artificial intelligence remain out of reach for most farmers and other local level actors. However, these can count on rising interest from funders and public and private actors mainly because of options to gain access to previously inaccessible data about farm(ers) (lazzolino, 2021b), those large quantities of data being utilized for e.g. precision agriculture, data analytics, and development of farmer profiles ${ }^{9}$ (Nyaga, Onyango, Wetterlind, \& Söderström, 2021; Onyango et al., 2021).

This thesis, too, primarily focuses on mobile phone-based technologies and the services designed for those technologies. While the literature has explored the adoption and use of digital advisory and decision support services in an ex-post way, e.g. highlighting reasons for adoption and sustainability challenges, the relation between the approach used to design and implement a service and the adoptability of the resulting service has remained under researched. This thesis responds to this gap by contributing

\footnotetext{
${ }^{9}$ See for example this initiative by USAID and the Grameen foundation https://www.usaid.gov/sites/default/files/documents/15396/Data_Driven_Agriculture_Farmer_Profile.pdf
} 
scientific understanding about how design choices affect access to technologies and services.

\section{Digital divides and capacity}

The skills, knowledge, and literacy levels needed to adopt and use digital technologies and services are a widely recognized challenge (Trendov, Varas, and Zeng, 2019). Many scholars highlighting challenges regarding technology adoption, scaling, and (financial) sustainability, also express concerns about so-called digital divides, and how some user groups are excluded to access them, primarily due to factors such as age, income, gender, farm size (Aker, 2011; Alabi, 2016; Aleke, Ojiako, \& Wainwright, 2011; Mwombe, Mugivane, Adolwa, \& Nderitu, 2014; Xie, Luo, \& Zhong, 2021). Hence, especially already disadvantaged groups are vulnerable to exclusion from access to digital advisory services (Duncombe, 2014; GSMA, 2020), while they are the ones most in need of them (Haworth et al., 2018). Beyond access to hardware, access to resources such as software and localized content is a challenge too (Zewge \& Dittrich, 2017).

Another cause for digital divides, beyond access to digital technologies and services, is digital literacy (Baumüller \& Addom, 2020; Misaki, Apiola, Gaiani, \& Tedre, 2018; Okeke, Nwalieji, \& Uzuegbunam, 2015). This issue affects capacity to use digital technologies (Nakasone \& Torero, 2016). Currently, digital technologies tend to favour those with higher level (technical) skills, alienating others (Torero, 2021). Based on this, some scholars call on governments and international institutes to actively collaborate and ensure that, in the near future, all farmers are included in the digital economy (Mehrabi et al., 2020).

Most of the literature explores divides from the perspective of access and a specific digital technology or service, and capacity from the perspective of the user (oftentimes farmers or extensionists). However, other, less local and tangible, factors that shape inclusion and exclusion are meagerly addressed in the literature. The same counts for the capacity of other stakeholders (e.g. developers, project implementers) in the system. In this thesis I look at both inclusion and capacity in a more holistic way. In chapter 3, I develop a framework for ex-ante assessment of user capacity to use digital technologies and services, primarily phone-based ones. Beyond digital literacy, this chapter contributes understanding about other dimensions that influence userreadiness. In chapter 4 I look not only at the capacity of users but also that of other stakeholders in the cases study. Regarding inclusion, I take a critical attitude toward the 


\section{Chapter 1}

push to include everyone. I do this by first assessing how inclusivity is approached while designing a digital service (chapter 4). After that, I problematize the currently dominant perceptions about inclusion and exclusion in chapter 5 (which as mentioned are primarily focused on access and inclusion of everyone) thereby overlooking that in the context of digitalization processes of in- and exclusion continue beyond the level of technology access and that inclusion may not always be beneficial.

\subsubsection{Users: Participatory design as the answer to adoption, use, and sustainability challenges?}

The above section showed that it is important to consider diversity within agricultural systems, to build digital literacy (Baumüller \& Addom, 2020; El Bilali \& Allahyari, 2018; Misaki et al., 2018) and to choose or design a digital technology or service that fits the capacity of users, i.e. a more low-tech, user friendly choice may be demanded (Aker et al., 2016; Haworth et al., 2018). The dissertation contributes novel understanding about how, in real-life, developers of digital advisory and decision support services cater for these needs. I do this by looking at the approach taken to design a service, which I see as a sub-theme to the broader adoption theme which zooms in on the user rather than the technology or service.

\section{From technocracy to user centred thinking and participatory approaches}

Technology is often perceived as something modern and transformative that will create new possibilities and provide access to a better future. This thinking from the perspective of the technology has a long tradition and has been setting the agenda in digital agriculture too (Gigler, 2011; Krauss, 2021). In these classical innovation models, technologies that are developed for and by countries in the Global North are often directly transferred to countries and people in the Global South, which neglects that technological innovations have more than just technological implications (e.g. sociocultural, political) (Stilgoe, Owen, \& Macnaghten, 2013), that they do not exist in isolation of their users and user context (Mramba, Rumanyika, Apiola, \& Suhonen, 2017), and that technology and society shape each other (Williams \& Edge, 1996). In the context of ICT4D in Africa this has resulted in a critique that the technologies and services developed are often based on deterministic assumptions, a-contextualized, and built with Western-values in mind (Krauss, 2021). 
Thus, this traditional way of thinking about designing products for the Global South is being criticized for being too technocratic, top-down, linear, and failing to consider that a technology is always used in a specific context and by a specific user. Beyond what digital technologies are capable to do, it then matters what we, as humans, want them to do and for whom (Bronson, 2019). Without considering the user and user context there is a considerable chance that the technology fails to be adopted, become (economically) sustainable, or have a (positive) impact (Krauss, 2021). As a response to the critiques on technocratic thinking a new, more user centred way of thinking about design emerged which seeks to design products that find a balance between technological feasibility, economic viability, and user desirability (IDEO.org, 2015). In line with this, specific participatory design approaches arose ${ }^{10}$ that present an alternative that is more social, bottom-up, iterative, and considerate of the users and use context (Holeman \& Kane, 2020) (see also Figure 2). These approaches attempt to cooperate with and learn from potential technology or service users with the goal to develop products that match user practices, needs, and preferences (Steen, 2011) and have become increasingly popular and praised in the field of digital agriculture (Kenny \& Regan, 2021; Ortiz-Crespo et al., 2020; Steinke et al., 2020) and a variety of manuals and toolkits for implementing Human Centred Design approaches in a development or agriculture context are available (e.g. Frogdesign, 2012; GSMA \& Frogdesign, n.d.; IDEO.org, 2015; University, 2018). The popularization of these approaches fits with the call to develop products that are grounded in the needs and knowledge of end-users in their communities and use context (Rumanyika, Apiola, Mramba, Oyelere, \& Tedre, 2021), and design thinking is increasingly promoted as 'good practice' in the international community through aforementioned toolkits, as well as principles like the Principles for Digital Development (Digital Impact Alliance, n.d.) and scientists and practitioners reporting on their experiences with participatory design approaches ${ }^{11}$.

\footnotetext{
${ }^{10}$ Alternately referred to as e.g. user or human centred design, participatory design, co-design, or cocreation: (Berthet et al., 2018; Kenny \& Regan, 2021; Ortiz-Crespo et al., 2020; Rose et al., 2018; Steinke et al., 2020)

${ }^{11}$ For example by the CGIAR: https://bigdata.cgiar.org/blog-post/designing-mobile-phone-solutions-foragricultural-extension-perspectives-matter/
} 


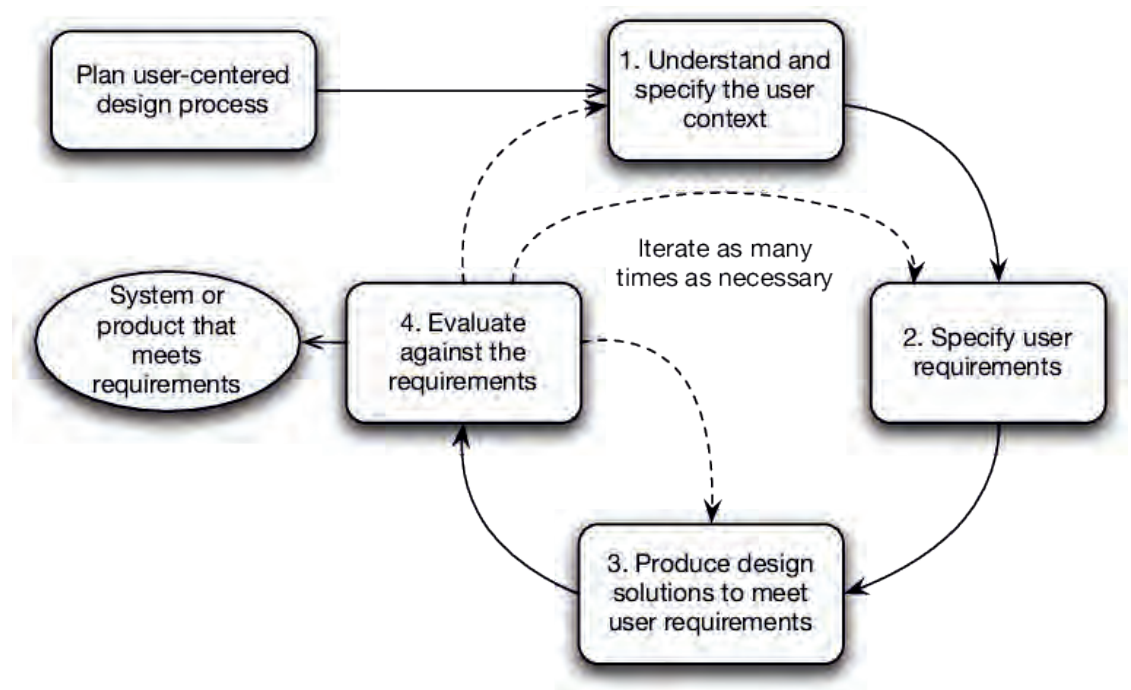

Figure 2: Human-centred design process based on 1SO 9241-210:2010 human-centred design for interactive systems (ISO, 2010), giving a schematic impression of a typical participatory design process that goes through different phases in which a product (i.e. digital technology or service or complete intervention) is being designed, implemented, and evaluated.

Nevertheless, research on the HCD design process and the complex and uncertain considerations wherein design decisions are made or the design values that are followed is limited (Hyysalo, 2012) especially in agriculture. Most scientific work on the topic related to digital agriculture to date is prescriptive in nature, proposing and describing participatory design methods to overcome barriers with adoption, digital divides and inclusivity, or sustainability (Berthet, Hickey, \& Klerkx, 2018; Cerf, Jeuffroy, Prost, \& Meynard, 2012; Macken-Walsh, 2019; Ortiz-Crespo et al., 2020; Steinke et al., 2020; Van De Gevel, Van Etten, \& Deterding, 2020). However, no one-size-fits-all approach to participatory design exists, and engaging users in the design process is not neutral, existing power configurations may be shaken by requiring that control be relinquished and given to potential customers, consumers and end-users (Sanders \& Stappers, 2008). Hence, how designers e.g. foster interaction with the user and cope with challenges of diverging interests is crucial (Heiskanen, Hyysalo, Kotro, \& Repo, 2010). With my research I contribute scientific understanding that is more evaluative in nature, by assessing the factors and processes within a participatory design approach that shape the design-choices made by various actors, the actual design of digital agriculture advisory and decision support services that results from this design process. I do this primarily in chapter 4, using the case study that I describe later in section 1.5.3. 
in chapter 5 goes more in-depth on how design and design-choices affect inclusion and exclusion of users. The same chapter also contributes a more holistic way of looking at design-choices (considering them as belonging to a package of innovations and an innovation ecosystem), based on the notion that a technology cannot be seen in isolation of its users and use context.

\subsubsection{Problem context: The origin of the idea that digital advisory and decision support services can solve complex problems}

As elaborated in section 1.1, digital technologies generate optimism about being able to solve complex agricultural problems, particularly through the information provision affordance and communication affordance that could make the decisionaction-result chain more efficient and effective. In other words, opportunities to collect and exchange data, information, and knowledge emerge from the enhanced availability of digital technologies and services (Cieslik et al., 2018). Efficient and effective agricultural advisory and decision support are longstanding topics of interest (Leeuwis \& van den Ban, 2004) and continue to be. This is confirmed by the third research cluster to which this thesis contributes; how digitalization may affect agricultural knowledge and innovation systems (Klerkx et al., 2019). Researchers explore the (potential) role of digitalization in knowledge and innovation systems in smallholder farming systems (Aker, 2011; Ingram \& Maye, 2020; Islam \& Grönlund, 2011), and additionally look at how smartphone applications can improve accountability in extension systems (Namyenya, Daum, Rwamigisa, \& Birner, 2021). Scholars focusing on digital agriculture in general are attempting to 'digi-grasp' how digitalization affords new dynamics in agricultural knowledge and innovation systems (Dufva \& Dufva, 2019; Fielke et al., 2021) while options for longitudinal and cross-border influence are emerging (Klerkx et al., 2019). Yet, there is a gap in the literature regarding how the approach used to design a digital service and the outputs of that approach may affect knowledge exchange and decisionmaking about complex agricultural problems. With the first and the last two chapters of this thesis I aim to respond to this gap by contributing understanding about how digitalization may or may not make knowledge exchange and decision-making processes more effective. I deliberately write 'may or may not' here, because in chapter $7 \mathrm{I}$ also assess what negative side-effects could arise if digital services play a mediating role in the agricultural knowledge system. 
Chapter 1

\section{What makes an complex agricultural problems 'complex'}

Complex agricultural problems are typically unstructured, embedded in the agricultural system and therefore persistent, relentless, and crosscutting (Weber and Khademian, 2014). Often, these problems cannot be resolved and must be managed continuously to contain them within acceptable limits. Complex problems in Africa are furthermore characterized by a high level of stability or inflexibility in the system, linked to dominant political cultures, bio-physical infrastructures, poverty, and path dependencies (Leeuwis et al., 2018). Examples of complex problems are pests and crop diseases such as fall army worm, BXW, or potato wilt and late blight, or climate variability like droughts or extreme rainfall (Cieslik et al., 2018). These are all challenges in smallholder agriculture that, despite years of investments, research, and extension interventions, persist and continue to impact the livelihoods of farmers in the Global South (Weber \& Khademian, 2014) and for which the help of digital technologies and services is called today ${ }^{12}$. Instead, a more integrated and knowledge-based approach that looks beyond the technological and biophysical dimensions is needed (Markham, 2009) to consider how the problem is embedded in other dimensions of the agricultural system (e.g. socio-cultural, economic, political, institutional) (Schut, Klerkx, et al., 2014). This also demands collaboration between various actors (e.g. farmers, extensionists, researchers) and at different levels (Schut, van Paassen, Leeuwis, \& Klerkx, 2014). Given the two affordances mentioned at the top of this section, the optimism that digitalization may be (part of) the answer is not surprising, all the more when also considering that availability of information and inter-user communication were found to be critical for effective production and management of public goods (Poteete, Janssen, \& Ostrom, 2010). Below I explain more about this.

\section{What may happen if a complex problem is left unmanaged}

Many complex agricultural problems create a social dilemma for people, forcing them to take decisions in regard to governing common resources (e.g. water resources for irrigation systems), or provision of common goods (e.g. agricultural credit), or prevention of common threats (e.g. control of crop diseases) (Cieslik et al., 2018). In this thesis, I focus on the latter, by looking at how digitally-mediated

\footnotetext{
${ }^{12}$ Examples of services built for this purpose are: BXW-App (https://ict4bxw.com/); Plantvillage NURU (https://plantvillage.psu.edu/projects); weatherimpact (https://www.weatherimpact.com/); rain4Africa (https://www.rain4africa.org/); and FAMEWS (http://www.fao.org/fall-armyworm/monitoring-tools/famewsmobile-app/en/)
} 
communication may affect decision-making about managing a complex problem to prevent it from becoming a public bad. The prevention of a public bad (e.g. a crop disease) is related to the production or maintenance of a public good, or the use of a common good (Sonnemans, Schram, \& Offerman, 1998). The difference between the two goods is that for the first use by one individual does not affect the availability for another individual, while for the latter it does. A public bad, then, is a problem that is non-rivalrous, non-excludable, and causes loss in the social-welfare of individuals and communities. The management of public and common goods or prevention of public bads requires people to collaborate (Nagendra \& Ostrom, 2012). This so-called collective action (Ostrom, 2000) is something to which digital technologies and services may contribute (Loh, 2015; Thapa, Sein, \& Sæbø, 2012). This thesis contributes understanding about how communication affects decision-making about the governance of Banana Xanthomonas Wilt disease and collective action in chapters 6 and 7. These chapters also give a more comprehensive conceptual framework about public bad risk-governance and collective action.

\subsubsection{The digital innovation ecosystem in the Global South and Africa: Towards organizing responsible innovation}

Just like a complex agricultural problem is embedded in all dimensions of the agricultural system (see section 1.3.3) so are digital technologies and services also included in a broader digital innovation ecosystem, which is the assemblage of diverse technologies (e.g. various digital devices and infrastructure); services; developers, users, funders, and other stakeholders; and institutional and political arrangements (e.g. digital rights, codes of conduct, design guidelines) (Birch \& Cochrane, 2021) and also conceptualized as a system of systems each with embedded systems (Pigford, Hickey, \& Klerkx, 2018). In turn, these new ecosystems need to find their place in existing agricultural innovation systems (whereby the agricultural innovation system may include multiple ecosystems) and will likely affect and change those (Ayre et al., 2019; Fielke et al., 2020). The notion that the individual technologies and services are embedded in a larger system links with section 1.3.2 where I write that, while making choices about the design of new digital technology or service, the user and use context should always be considered. In this final conceptual section, I look at the growing body of literature that Klerkx et al., 2019 refer to as the power, ownership, privacy, and ethics in digitalizing agricultural production systems and value chains research cluster. Topics related to this cluster more recently gained attention and form a critical stream in the 


\section{Chapter 1}

literature that studies (socio-cultural) losses that digitalization may cause, negative impacts, and responsibility within digital agriculture and in relation to data ethics (Bronson, 2018; Carbonell, 2016; van der Burg, Bogaardt, \& Wolfert, 2019). These topics emerged in response to growing concerns that digital technologies can have far reaching impacts. Below I explain in more detail about the origin of these concerns.

In section 1.2, I elaborated that digital innovations and data generating innovations come with properties that differentiate them from other technological innovations and that digitalization processes in the Global North and Global South are not the same. For example, they are not time and place restricted and reduce or remove existing boundaries and hierarchies in agricultural and communication systems (or create new ones) (Heeks, 2018). These affordances can be positive for users (see section 1.2 for details about those affordances and broader changes they may trigger), however the side-effects may be negative too.

Thus, digitalization will likely have far-reaching, disruptive, implications for existing agricultural innovation systems (Ezeomah \& Duncombe, 2019; Fielke et al., 2019; Hinings et al., 2018) resulting in questions about what should be considered ethical and responsible digital innovation (Royakkers, Timmer, Kool, \& van Est, 2018; Wakunuma, 2019), e.g. asking who is responsible and accountable for the impact of digitalization (Rijswijk et al., 2021). It is no surprise that such questions arise, since innovation almost always comes with contestation, especially about an innovation's (unintended, unwanted, unanticipated) consequences (Valkenburg, 2020). Innovation critics would argue that innovation contributes to exacerbation of things that are already wrong in (developmental) societies, such as social inequality and injustice (Jasanoff, 2002). Such a stance fits with the realization that the introduction of and reliance on digital technologies may be like pandora's box, and that these technologies have results in a proliferation of ethical, socio-economic, and socio-technical questions about these technologies that scholars try to answer. Especially the Big Tech Five (Google, Apple, Facebook, Amazon, Microsoft) and Silicon Valley in general are thereby under scrutiny in what has been called the 'Techlash' period (Hemphill, 2019): "A strong and negative reaction to the growing power and influence of large technology companies, particularly those based in Silicon Valley" (Oxford English Dictionary). It seems to be a counterreaction to the technological solutionism thinking that often surrounds digital technologies, where technology is seen as provider of a quick-fix for complex (societal) problems (Milan, 2020; Morozov, 2013). 
However, as mentioned in section 1.2, many actors in the field of digital agriculture remain opportunistic about the future of digitalization in agriculture and the positive transformations it will bring. For example, in regard to digital agriculture advisory in the Global South the latter is the case, even though, for some time now, scholars acknowledge that there is limited hard evidence of positive impact on specific complex agricultural problems or rural livelihoods in general (e.g. Ajani, 2014; Hussain, 2016; Sulaiman, Hall, Kalaivani, Dorai, \& Reddy, 2012) and that most reported impact is limited to basic statistics (e.g. number of registered users) or anecdotal, providing insufficient quality empirical data to be conclusive about the use and outcomes of digital services (Porciello et al., 2021b; Tsan et al., 2019). A global review to the outcomes of digitalization in LMICs for four types of digital services (advisory and extension; finance; farm tools; and market linkages) and four outcome categories (agricultural-led economic growth; resilience and risk; healthy people and planet; inclusivity, empowerment, and agency) also reveals that only positive or nil impacts are reported on, or impacts are mentioned without defining them (Porciello et al., 2021a). Thus, the current literature appears to focus primarily on effectiveness, i.e. what works, but ignores or condones what does not work or has unintended consequences for the broader agricultural or digital innovation system. A new research agenda is emerging however as I explain further below.

\section{An emerging research agenda for research and action in digital innovation (eco)systems}

In-depth and critical research to important issues such as the influence of digitalization on e.g. in- and exclusion of different actors, socio-cultural change, complex agricultural problems, hierarchies and power in agricultural systems, ethics and responsibility with a Global North focus developed in the past few years e.g. looking at responsible innovation, engagement in and re-scripting of agricultural systems (Bronson, 2019; Eastwood, Klerkx, Ayre, \& Dela Rue, 2019; Rose \& Chilvers, 2018); impact of precision agriculture on sustainable agriculture (Clapp \& Ruder, 2020); technological lock-in and power relations (Clapp \& Ruder, 2020; Schimpf \& Diamond, 2020); perceptions about risks of digitalization (Regan, 2019); trust and rights in the context of smart-farming (Bronson, 2018; Jakku et al., 2019). Much of this work builds on conceptual framing around Responsible Research and Innovation (Blok \& Lemmens, 2015; Stilgoe et al., 2013; L. von Schomberg \& Blok, 2019; R. von Schomberg, 2011). 


\section{Chapter 1}

Similar topics only recently emerged on the agenda for ICT4D, e.g. how digitalization could change political economies (Mann, 2018), that data-driven technologies may lead to new inequalities (Cinnamon, 2020), or even new forms of colonialism (Schopp, Schelenz, Heesen, \& Pawelec, 2019) and also on a political level the African continent is lacking behind: For example, by 2020 only half of the African countries had followed the European example and adopted data protection laws and regulations (Privacy International, 2020). However, there is growing recognition that also in the context of agriculture in the Global South there is a 'dark side' to digitalization (Coad, Nightingale, Stilgoe, \& Vezzani, 2020; Gomez, 2020) Abebe et al., 2021; Brooks, 2021; Gras \& Cáceres, 2020; Klerkx \& Rose, 2020). The focus of this thesis on the factors and processes that shape the design and use of digital advisory and decision support services contributes to this emerging critical field as it specifically focuses on the unintended consequences too. This way, the research takes the debate about responsibility and ethics away from the development and assessment of guidelines, codes of conduct, and regulatory frameworks (Dearden \& Kleine, 2020; van der Burg et al., 2019; Wiseman, Pesce, et al., 2019) ${ }^{13,14}$, moving it in the direction of technology and service design and how design processes and decision-making about design influence responsibility and ethics (chapters 4 and 5), as well as how design decisions may have broader implications for knowledge exchange and decision-making about complex agricultural problems (chapter 7).

\subsection{Research objective}

With this dissertation I aim to contribute to the research gaps identified in section 1.1 by developing understanding about factors determining the design and use of digital innovations created to address complex agricultural problems such as the management of crop diseases. The research provides a reality check: Does the field of

\footnotetext{
${ }^{13}$ See also pioneering practitioner work by organizations such as GODAN Action: https://www.godan.info/; and the Engine Room: https://www.theengineroom.org/

${ }^{14}$ Beyond the field of agriculture there is a growing number of tools and frameworks aiming to build awareness about potential risks and harms of collecting and sharing data, and guide practitioners with developing more responsible data practices. Perhaps the most well-known and widely adopted initiative to guide investments in and decision-making about digital development projects and interventions are the Principles for Digital Development (Waugaman, 2016) which are endorsed by dozens of organizations active across the development sector today. Another recent initiative are the CARE principles (care standing for Collective benefit, Authority of control, Responsibility, Ethics (Carroll et al., 2020) which aim to compliment the widely adopted FAIR principles (Findable, Accessible, Interoperable, Reusable) by protecting the data rights and interests of indigenous people with the slogan 'Be FAIR and CARE'.
} 
digital agriculture deliver on its promises from the perspective of design? Emphasis is on what is being developed today, and what may be 'lost' while designing and using digital innovations. As a researcher I have been in a position which allowed me to perform this type of critical research since I was given an opportunity to study 'the making' of a smartphone-based service for banana disease management, and the implementation of that service, from up-close. Section 1.5, later in this chapter, gives more detail about this case-study, the ICT4BXW project, which plays a central role in my research.

The study aims to answer the following main research question:

What factors and processes shape the design and use of digital advisory and decision support services that are developed for addressing complex agricultural problems in Africa?

The study foci are Africa (where I was based during the first years of the study, working for a CGIAR centre), digital agricultural advisory and decision support services (also referred to as digital extension in the dissertation), and (participatory) design processes. In terms of technological focus, there is more emphasis on phone-based technologies and services, since these are the most common contemporary digital technology used in Africa to date and the technology of choice for many digital agriculture services.

I identified four sub-research questions that support with answering my main research question:

1. What factors and processes within a participatory design approach shape the design-choices and actual design of digital agriculture advisory and decision support services?

2. How does the capacity of users and other actors influence readiness for developing and using digital agriculture advisory and decision support services?

3. What factors shape inclusion and exclusion in digitalization processes in African smallholder agriculture?

4. How may (digital) communication strategies affect farmers' individual and collective performance in disease management practices and preventing a public bad?

In the next section I explain the research design that I used for my study and how the questions link to the different empirical chapters and layers introduced in section 1.1, Figure 1. 


\subsection{Research design}

Each empirical chapter of the dissertation has a focus on one or more of the layers introduced in section 1.1, and gives a (partial) answer to one or more sub-research questions (Table 3). Figure 4, in section 1.6 later in this chapter, shows how the six individual empirical chapters link with the research questions, the study levels, and each other.

Table 3: Overview of links between sub-research questions, system levels studied, and empirical chapters.

\section{Sub-research question}

\section{Chapters \\ with (partial) \\ answer to \\ question}

How may (digital) communication strategies affect farmers' individual and collective performance in disease management practices and preventing a public bad?

How does the capacity of users and other actors influence readiness for developing and using digital agriculture services and solutions?

What factors and processes in a participatory design approach shape the design-choices and actual design of digital agriculture services?

What are the reasons for and impacts of inclusion and exclusion in digitalization processes in African smallholder agriculture?

\section{2}

6

7

3

4
4

\section{Level(s) studied}

- (Problem) context

- (Problem) context

- (Problem) context

- Digital technology/

service

- Digital technology/

service

- Users

- Innovation ecosystem

- Digital technology/

service

- Users

- Innovation ecosystem

- Digital technology/

service

- Users

- Innovation ecosystem

- Digital technology/

service

- Users

- Innovation ecosystem

- Digital technology/

service

- Users

- Innovation ecosystem

- Digital technology/

service

- Users

- Innovation ecosystem

- Digital technology/

service

- Users

- Innovation ecosystem 


\subsubsection{Research approach}

For my study I used a multi-faceted case study design that includes action research, field-experimental research, and various cross-sectional designs. This research design allowed me to generate in-depth, multi-faceted understanding about the development and use of digital agriculture technologies and services in a real-life context (Crowe et al., 2011). The multi-faceted design also fits with the desire to zoom in on the different levels described in the previous section. A mixed-methods approach was used, combining a variety of qualitative and quantitative data collection and analysis methods (Table 4). The study has three (chronological) phases: Diagnostic phase (examining the socio-technical context of an agricultural collective action problem), intervention phase (investigating the design and implementation of a digital agriculture intervention), and deep-dive phase (exploring the influence of digital agriculture interventions on inclusivity and collective action).

\subsubsection{Data collection and analysis methods}

As outlined in the previous section, the study used a mixed-methods approach with both qualitative and quantitative methods. Table 4 provides a broad overview of the diverse methods used per empirical chapter, and the sample size and sampling frame per method. More specific details about the chapter research designs, and individual methods are given in the methods section of each of the chapters.

Table 4: Overview of used research methods per chapter.

\begin{tabular}{|c|c|c|c|c|}
\hline Method & $\begin{array}{l}\text { Chapter } \\
\text { in which } \\
\text { method } \\
\text { was used }\end{array}$ & $\begin{array}{l}\text { Sampling } \\
\text { details }\end{array}$ & $\begin{array}{l}\text { Sample size } \\
\text { (when applicable) }\end{array}$ & $\begin{array}{l}\text { Data analysis } \\
\text { method }\end{array}$ \\
\hline $\begin{array}{l}\text { Literature and secondary } \\
\text { data review }\end{array}$ & 2 & Snowball & & Non-structured \\
\hline $\begin{array}{l}\text { Observational data of } \\
\text { banana production * }\end{array}$ & 2 & Purposive & $\begin{array}{l}5 \text { locations, } 3 \\
\text { districts }\end{array}$ & Thematic content \\
\hline $\begin{array}{l}\text { Group interviews with } \\
\text { banana farmers }\end{array}$ & 2 & Purposive & $\begin{array}{l}4 \text { interviews, +/- } \\
50 \text { farmers }\end{array}$ & Thematic content \\
\hline Baseline survey with farmers & 3 & $\begin{array}{l}\text { Stratified } \\
\text { random }\end{array}$ & $\begin{array}{l}690 \text { banana } \\
\text { farmers }\end{array}$ & $\begin{array}{l}\text { Descriptive } \\
\text { statistics; robust } \\
\text { inference }\end{array}$ \\
\hline $\begin{array}{l}\text { Surveys with farmers and } \\
\text { farmer promoters }\end{array}$ & & Exhaustive & $\begin{array}{l}40 \text { farmers; } 5 \\
\text { farmer promoters }\end{array}$ & Descriptive statistics \\
\hline $\begin{array}{l}\text { Interviews with actors in } \\
\text { extension system }\end{array}$ & 3 & Purposive & 9 interviews & Thematic content \\
\hline
\end{tabular}


Chapter 1

\begin{tabular}{|c|c|c|c|c|}
\hline $\begin{array}{l}\text { Key informant interviews } \\
\text { with staff and partners }\end{array}$ & 4 & Purposive & $\begin{array}{l}17 \text { semi- } \\
\text { structured } \\
\text { interviews }\end{array}$ & Thematic content \\
\hline $\begin{array}{l}\text { Group interviews with } \\
\text { banana farmers }\end{array}$ & 4 & purposive & $\begin{array}{l}9 \text { interviews in } \\
\text { two districts, total } \\
45 \text { farmers }\end{array}$ & Thematic content \\
\hline USE-survey with FPs & 4 & Exhaustive & $\begin{array}{l}18 \text { surveys with } \\
\text { farmer promoters }\end{array}$ & $\begin{array}{l}\text { Descriptive } \\
\text { statistics, content }\end{array}$ \\
\hline $\begin{array}{l}\text { Field observations (FPs using } \\
\text { app) }\end{array}$ & 4 & Exhaustive & $\begin{array}{l}1 \text { case (BXW-App), } \\
2 \text { districts }\end{array}$ & Thematic content \\
\hline $\begin{array}{l}\text { Process tracing of design } \\
\text { process }\end{array}$ & 4 & Purposive & 1 case (BXW-App) & Thematic content \\
\hline $\begin{array}{l}\text { Non-systematic literature } \\
\text { review }\end{array}$ & 5 & Purposive & 28 articles & Structured \\
\hline $\begin{array}{l}\text { Experimental field board } \\
\text { game (Musa-game) with } \\
\text { farmers }\end{array}$ & $6+7$ & $\begin{array}{l}\text { Randomized } \\
\text { complete block } \\
\text { sampling }\end{array}$ & $\begin{array}{l}12 \text { games in four } \\
\text { villages, total } 48 \\
\text { banana farmers }\end{array}$ & $\begin{array}{l}\text { Computational } \\
\text { software (Musa } \\
\text { analysis tool) }\end{array}$ \\
\hline $\begin{array}{l}\text { Post-game focus group } \\
\text { discussion }\end{array}$ & $6+7$ & $\begin{array}{l}\text { Exhaustive } \\
\text { sampling }\end{array}$ & $\begin{array}{l}48 \text { banana } \\
\text { farmers }\end{array}$ & Thematic content \\
\hline
\end{tabular}

\subsubsection{Selected case studies}

For my research I used two related cases. First, the case of Banana Xanthomonas Wilt (BXW) disease. Chapters 2, 6 and 7 take BXW and banana farming systems as their study object, especially focusing on Rwanda. BXW is an infectious banana disease causing up to $100 \%$ yield loss for farmers throughout East and Central Africa (Nkuba et al., 2015) causing an estimated economic loss of US\$2-8 billion over a decade (Tripathi, Ntui, Shah, \& Tripathi, 2021). No known cure for BXW exists and all banana varieties are to a more or lesser extent susceptible to the disease (Tinzaara et al., 2016) although results from experiments with CRISPR/Cas9-editing suggest that in the future disease-resistant varieties may become available (Tripathi et al., 2021). BXW is mostly spread by vectors such as insects, bats, birds, contaminated (cutting) tools (Biruma et al., 2007). BXW threatens farmer livelihoods and food security in the African Great Lakes region and is a longstanding, endemic agricultural problem for which eradication attempts have been unsuccessful (Shimwela et al., 2016). Farmers rely on cultural practices for disease control, yet proper implementation of management practices by farmers remains limited (Blomme et al., 2019) which is attributable to inaccessibility of the right and reliable information (Uwamahoro, Berlin, Bylund, Bucagu, \& Yuen, 2019). The disease can be perceived as a complex agricultural problem and a public bad, because of its persistence, the absence of a cure, and its complex 
embeddedness in the smallholder agricultural system. BXW also forms a collective action problem, as collective management of the disease gives better results than individual management (Blomme et al., 2019).

My second case is the one of the ICT4BXW project. This case gave me the opportunity to conduct participatory action research and allowed me to link theory with practice. In the discussion section of chapter 8 , I provide a methodological reflection which includes a reflection on my position as an action researcher. I used this case study primarily to study the development and implementation of a digital intervention in chapters 3 and 4 , and to explore the potential impact of digital communication on collective action in chapter 7. Parts of chapter 5 use the case to illustrate some of the literature review findings. ICT4BXW ${ }^{15}$ is a project that is led by the International Institute of Tropical Agriculture (IITA) and operates in Rwanda with the aim to use digital tools and citizen science to make the prevention and control of BXW disease more effective and (cost) efficient, first in Rwanda and later throughout East and Central Africa. The project corresponds to the call to advance BXW management in Rwanda through extension services with updated practices and improved monitoring efforts (Uwamahoro et al., 2019). Phase 1 of the project lasted from 2018-2020, thereafter it was renewed for another three years. For my research I focus only on phase 1 of the project.

A central hypothesis of the ICT4BXW project is that increased real-time diagnosis of disease presence, combined with improvements in farmers' and extensionists' knowledge about and use of control and prevention practices, will help to reduce disease impact. Mobile (smart)phones are the digital technology of choice in ICT4BXW, and the project developed a digital service (BXW-App, Figure 3) to aid with the diagnosis and monitoring of BXW, and provide information about BXW management and best practices for banana production. The project used a participatory design process to develop a digital service that is inclusive and responding to the needs of diverse users (i.e. banana farmers, village extensionists, government agents, researchers). ICT4BXW is thus one example of many projects that leverage digital technologies and develop a service and intervention for a specific agricultural problem with the aim to enhance the effectiveness and efficiency of managing that problem. This makes ICT4BXW a good case to study the design and use of a digital agriculture

\footnotetext{
${ }^{15}$ More information about the ICT4BXW project: https://www.researchgate.net/project/ICT4BXW-CitizenScience-and-ICT-for-advancing-the-prevention-and-control-of-Banana-Xanthomonas-Wilt-BXW-in-East-andCentral-Africa; and http://www.ICT4BXW.com
} 


\section{Chapter 1}

service. The geographic location of the case is interesting too. Rwanda was one of the first African countries to adopt a policy for digitalization in the agricultural sector. This ICT4Rag 2016-2020 strategy (Information and Communication Technology for Rwandan Agriculture) (MINAGRI, 2016) served to guide appropriate implementation of digital technologies and services in the country. The strategy fit with the country's grand future ambitions (MINECOFIN, 2013, 2020) e.g. the desire to become an ICT hub (MINICT, 2019) and initiatives such as the MaraPhone (the first 'made in Africa' smartphone which is assembled in Rwanda and South Africa ${ }^{16}$ and the \#ConnectRwanda campaign (a crowdsourcing campaign organized by operator MTN and the Rwandan Ministry of ICT and Innovation that gives smartphones to vulnerable households $)^{17}$. For a while the ICT4Rag strategy was one of the most progressive policies on the continent (Baumüller \& Addom, 2020; Tsan et al., 2019). Although Rwanda may be mentioned as a model country for its vision and mission, how digitalization works out in practice is rarely studied (an exception being a study to impact of E-soko on welfare by Kamande \& Nafula, 2016) as researchers usually concentrate on the bigger neighbours: Kenya, Tanzania, Uganda, which are all three in the top 7 of countries most published about (Porciello et al., 2021b).

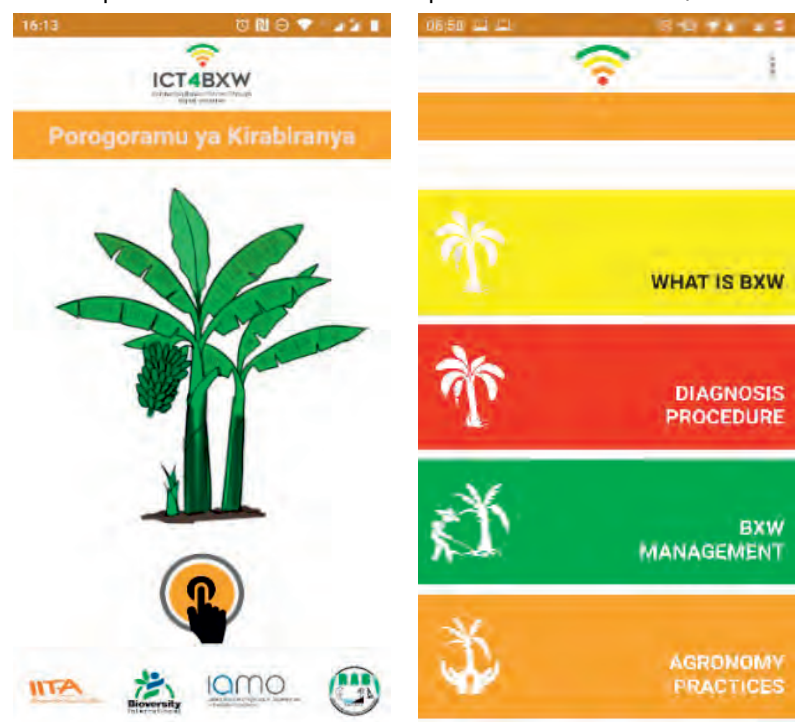

Figure 3: Screenshots of the frontpage and menu op BXW-App

\footnotetext{
${ }^{16}$ https://maraphones.com/

17 https://www.minict.gov.rw/news-detail/what-you-should-know-about-connect-rwanda-campaign
} 


\subsection{What follows: Connections between research themes and empirical chapters}

The study includes six empirical chapters and follows a chronological order. Figure 4 illustrates the chapter outline and how the different empirical chapters connect with each other and the four focus levels. Chapters 2 and 3 cover the diagnostic phase of the study and were conducted before the digital agriculture intervention.

Chapter 2 is a problem diagnostics chapter that uses a systems analysis approach to assess the complex problem of Banana Xanthomonas Wilt (BXW) disease. Approaching BXW disease as a vector disease that forms a complex problem, the research looks at the socio-technical context of the disease. The chapter builds on existing scientific and secondary data knowledge about the disease, substituting it with observational and interview data from Rwanda and Burundi. The chapter also explores how data, information, knowledge, and connectivity related interventions could contribute to (partially) resolving the complex problem and supporting collective and/or connective action. This way the chapter prepares for the later chapters that focus on digital technologies, services, and solutions.

It needs to be noted that chapter 2 pays considerable attention to the potential for citizen science as a specific approach to engaging with people on the ground, while later chapters do not. Although ideas from citizen science still appear in subsequent chapters (e.g. farmers and extension agents submitting field observations of crop diseases using mobile phone technology) the approach does not feature as a central theme in later chapters.

Chapter 3 studies the current capacity of farmers to use digital technologies and services. For this the user readiness framework (building on the COM-B model (Michie, Atkins, \& West, 2014; Michie, van Stralen, \& West, 2011) was developed and employed. The user readiness framework was then used for an ex-ante assessment of current information and communication practices and farmer readiness to use digital (phonebased) agricultural extension services. The chapter furthermore discusses possible implications of interventions and services that mismatch with user readiness for the inand exclusion of users.

Chapter 4 represents the intervention phase and looks at the real-world making of digital interventions and services by studying how in the case of ICT4BXW the smartphone-based service was developed and piloted in Rwanda using a participatory design process. For this chapter we used a case study approach and mixed methods, 


\section{Chapter 1}

including process tracing, group interviews with farmers, key informant interviews with ICT4BXW project staff and partners, and data from a survey with BXW-App users. Conceptually we built on design thinking theory, and conceptual thinking about Responsible Innovation (using the four dimensions (anticipation, inclusiveness, reflexivity, responsiveness) of the Responsible Research and Innovation framework) and digital rights. In the discussion we debate if the promises that come with the chosen design approach (e.g. inclusivity, designs that meet needs and demands of users, designing digital technologies that 'do good') are being fulfilled.

Chapters 5, 6 and 7 are immersions (deep-dive phase) that build on findings from the diagnostic and intervention phases. These last three empirical chapters go deeper into topics addressed earlier in chapters 2-4.

Chapter 5 is an in-depth conceptual analysis of a specific issue: inclusion and exclusion. The chapter aims to conceptually advance understanding about inclusion (and exclusion) for the context of digital agriculture in a Global South context through a literature review. This chapter not only looks at what (tangible) in- and exclusion mean today, in relation to e.g. access to specific digital technologies, services or solutions, but also at higher-level, less tangible, or future processes of in- and exclusion.

Chapters 6 and 7 are sister chapters for which findings from chapter 2 provided input. In chapter 6 we present the design of Musa-game, an experimental boardgame to study individual and collective action towards governing a public bad, specifically BXW. This socio-ecological-systems field experimental design is based on Ostrom's conceptual thinking about public goods and public bads, and risk governance theory. Chapter 7 continues were chapter 6 ends, presenting results from a real-life field-test with Musa-game in Rwanda. It looks at emergence and spatiality in relation to farmers' decisions while playing the game and examines how this affects the individual and collective performance in the game. This chapter additionally explores how a shift to digital communication (e.g. using mobile phones, apps) may influence (collective) decision making. The findings from chapter 7 significantly influenced the discussion and recommendations regarding designing digital interventions that foster rather than obstruct collective action and successful prevention of a public bad in the final synthesis chapter.

The synthesis chapter, chapter 8, summarizes the study's empirical findings and debates what these findings mean for the field of digital agriculture and the study of complex agricultural problems and collective action problems. This chapter also reflects on the study design and gives recommendations for further research and policymaking. 
General introduction

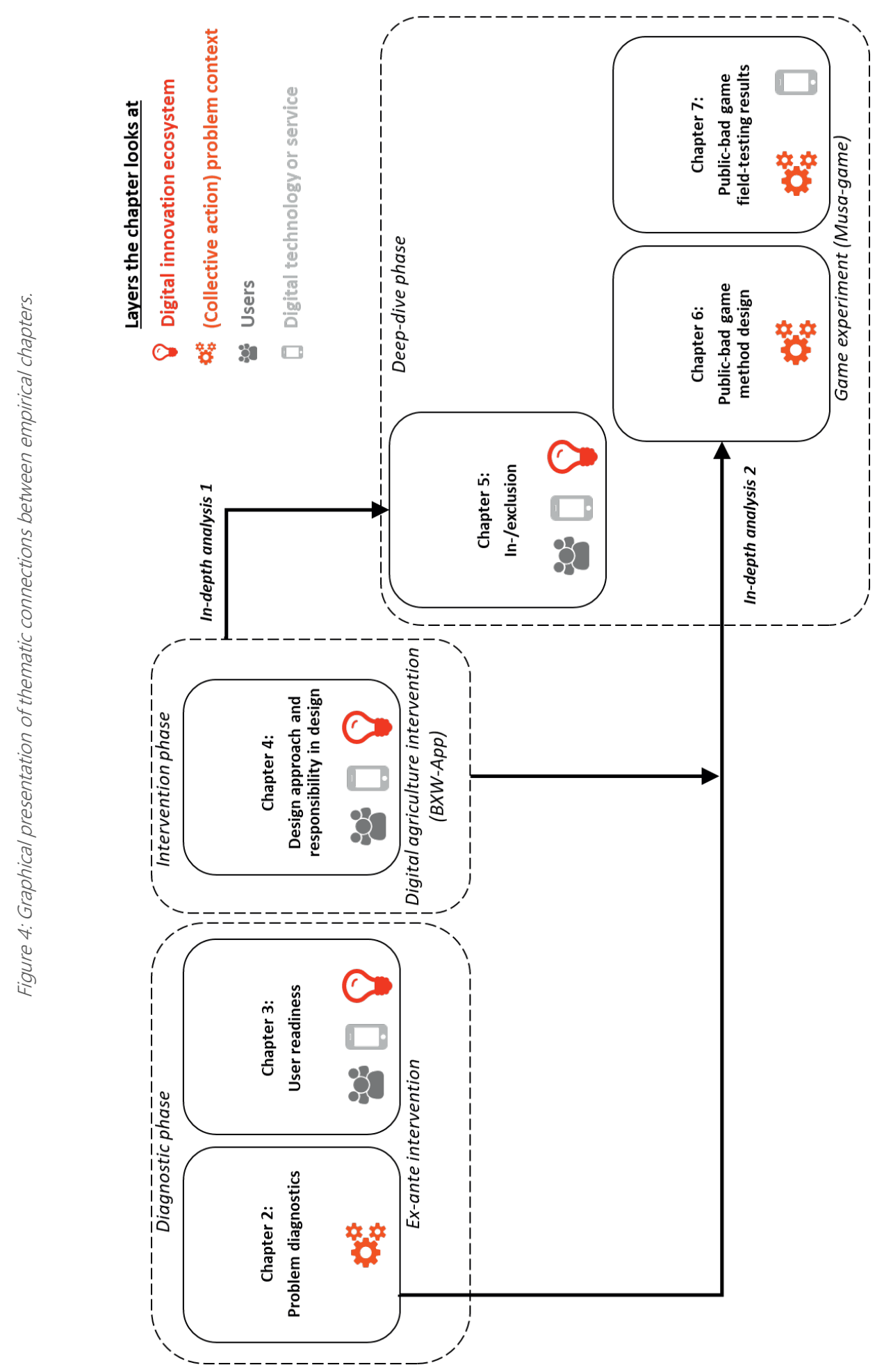




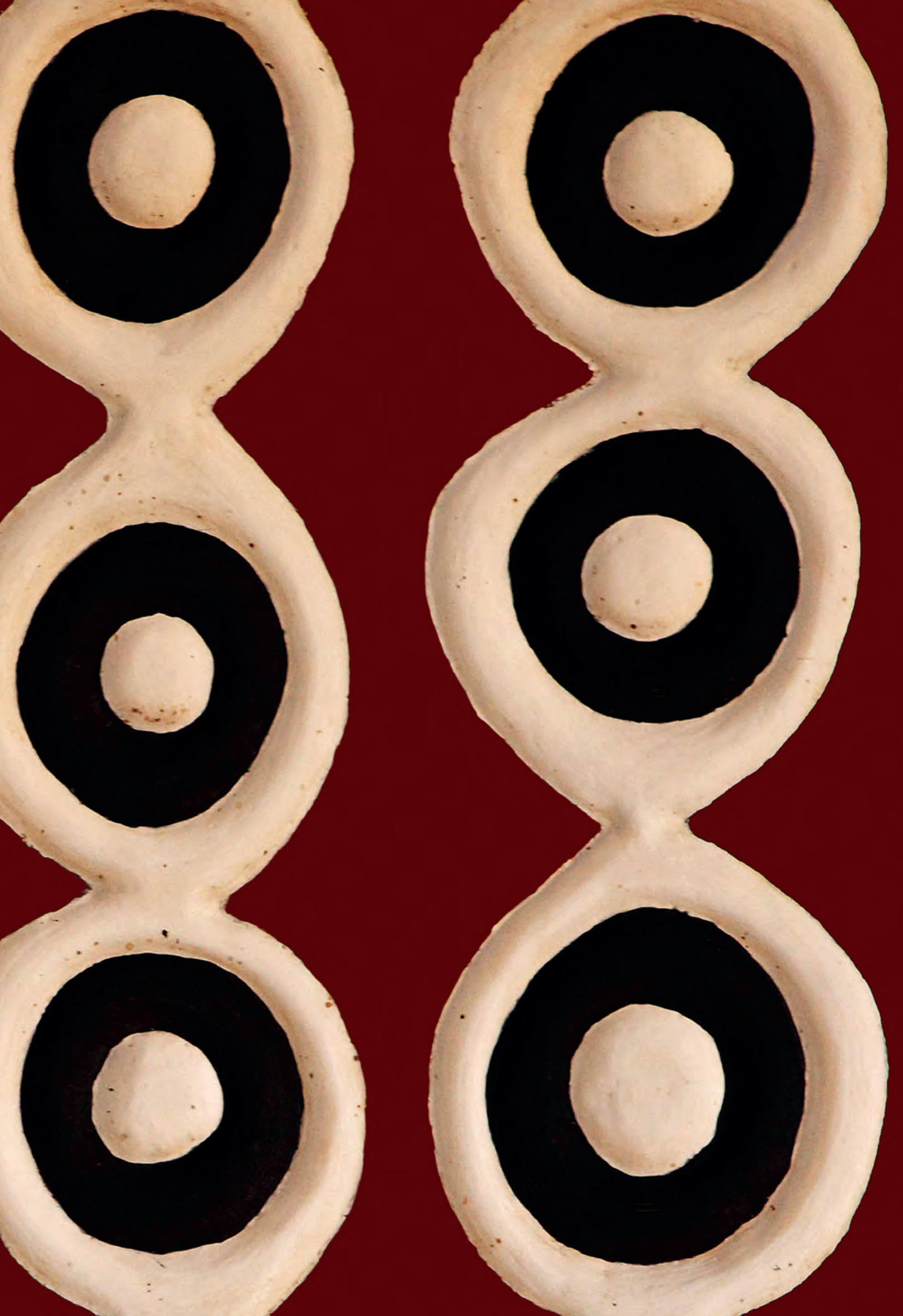




\section{Xanthomonas Wilt of Banana (BXW) in Central Africa}

Opportunities, challenges, and pathways for citizen science and ICT-based control and prevention strategies 


\section{Abstract}

Xanthomonas Wilt of Banana (BXW) is a complex problem in the African Great Lakes Region that is affecting the livelihoods of millions of smallholder farmers. Since the first disease reports from Uganda and the Democratic Republic of Congo in 2001, BXW has been studied widely. The majority of these studies focus on the technological or biophysical dimensions, while aspects and influence of socio-cultural, economic and institutional dimensions only recently started to gain attention. This paper provides an in-depth analysis of the broader BXW problem using a systems perspective, with the aim to add to the understanding about reasons for poor uptake of appropriate disease management practices, and limited ability to prevent rather than control BXW in the region. We comprehensively describe and analyse the various problem dimensions, and determine relations with data, information, knowledge, and connectivity. Building on this, the paper explores and discusses entry-points for the use of Information and Communication Technologies (ICT) and citizen science tools to better address BXW in banana production systems.

Chapter published as: McCampbell M, Schut M, Van den Bergh I, van Schagen B, Vanlauwe B, Blomme G, et al. (2018). Xanthomonas Wilt of Banana (BXW) in Central Africa: Opportunities, challenges, and pathways for citizen science and ICT-based control and prevention strategies. NJAS - Wageningen J Life Sci. 2018 Nov;86-87:89100. 
Xanthomonas Wilt of Banana (BXW) in Africa: Opportunities, challenges, and pathways

\subsection{Introduction}

Infectious crop diseases continue to cause large yield losses with underestimated social and economic impacts in developing countries (Vurro, Bonciani, \& Vannacci, 2010). Xanthomonas Wilt of Banana (BXW), caused by the bacterium Xanthomonas vasicola pv. Musacearum (formerly Xanthomonas campestris pv. Musacearum) (Studholme et al., 2020), affects production of all types of bananas, in all major production regions in East and Central Africa (Tripathi et al., 2009). The disease is detrimental to banana-based farming systems, due to easy spread, rapid in-plant development, absence of resistant cultivars, and inevitable death of infected plants (but not the whole physically interconnected mat due to incomplete systemicity) in absence of disease resistant varieties (idem). Banana is an important source of livelihood for millions of farmers, providing food and income, as well as playing an important role in the social life of populations in the African Great Lakes Region (i.e. Burundi, the Democratic Republic of the Congo, Kenya, Rwanda, Tanzania, and Uganda) (Van Damme, Ansoms, \& Baret, 2014). For example, 30\% of the cultivated land in the region is occupied by banana (Van Asten et al., 2004), and in a country like Rwanda banana contributes to approximately $50 \%$ of the diet of $32 \%$ of the households (Nkuba et al., 2015). Hence production declines not only impact household income but also food and nutrition security, and social and cultural wellbeing.

BXW is a complex problem that is rooted in a multitude of challenges, embedded and cross-cutting in six different system dimensions, and has shown to be persistent and recurrent. Since the first disease reports from central Uganda and east DR Congo in 2001, BXW has been studied widely. Most studies focus on the technological or biophysical dimensions (Biruma et al., 2007; Shimwela et al., 2016; Tinzaara et al., 2016) and cultural practices. Key practices are the originally recommended Complete Mat Uprooting technology (CMU), and the increasingly suggested Single Disease Stem Removal technology (SDSR) (box 1). CMU and SDSR should be combined/applied with other endorsed practices, e.g. early removal of the male bud using a forked stick, disinfection of tools, selection of clean planting material, in order to be most effective. Aspects and impacts of the non-technological dimensions (i.e. socio-cultural, economic, institutional, and political) only recently started to gain attention. Yet, addressing a complex problem like BXW requires an integrated approach with attention for both technological and non-technological dimensions (Schut, Klerkx, et al., 2014). In other words, a focus on solving individual (technological) challenges will likely be ineffective 


\section{Chapter 2}

when failing to simultaneously understand and address interrelationships with (nontechnological/socio-cultural, economic, institutional, and political) challenges, and the roles of different actors, and different system levels.

As amplified by Cieslik et al. (2018) in this issue, opportunities to collect and exchange data, information, and knowledge emerge from the enhanced availability of mobile/smart phones, smart Information and Communication Technologies (ICT), and internet in low- and middle-income countries. Moreover, these innovations give prospect to resolve communication and connectivity related challenges in rural areas. The emergent robust, affordable and low maintenance sensing, data processing, visualization and other ICT-enabled features have also led to growth in the number of so-called citizen science initiatives (Buytaert et al., 2014). Citizen science (also referred to as environmental or participatory monitoring) was introduced by Irwin (1995) more than two decades ago as a concept that enables active involvement of non-scientists in research design, data collection and data interpretation (Buytaert et al., 2014). Until now, most citizen science initiatives occurred in high-income countries where volunteers engaged in monitoring and reporting of environmental aspects (e.g. counting birds or insects, monitoring spread of communicable diseases). However, similar initiatives start to take off in developing countries too. Wageningen University and Research's Environmental Virtual Observatories for Connective Action (EVOCA) programme explores the potential of such ICT-based citizen science platforms for tackling complex socioecological problems in six case studies in Africa. The complex problem of BXW that we focus on in this paper represents one of those case studies. In this paper, we contribute to two strategic gaps in the scientific literature: (i) comprehensive understanding of both the technological and non-technological BXW problem dimensions (ii) how problem dimensions are related to (the lack of) data, information, knowledge, and connectivity. In doing so, the paper has three main objectives: (i) to comprehensively describe and analyse BXW in the Great Lakes Region, thereby contributing to a deeper understanding of the complex problem, (ii) to determine the potential role of data, information, knowledge, and connectivity in addressing the problem, and (iii) to explore whether and how citizen science and ICTbased platforms can contribute to overcoming specific BXW problems in Central Africa. 
Xanthomonas Wilt of Banana (BXW) in Africa: Opportunities, challenges, and pathways

BoX 1: Description of managing BXW, the traditional and the alternative way.

\section{The initial way: Complete Mat Uprooting (CMU)}

Uprooting of an entire banana mat after diagnosis of BXW, even if only one plant in the mat shows symptoms, has long been the recommended control BXW practice. Although very effective in removing most of the inoculum causing BXW, Complete Mat Uprooting (CMU) is tedious, labour intensive, time consuming. A side-effect is that asymptomatic plants are removed too. It requires from farmers to replace the removed mats with new planting material. This need makes CMU costly, further aggregated by high labour demand and long-term impact on production. Moreover, for optimal impact, i.e. reduce risk of reinfection, CMU should be practiced by all infected farmers in an area. Farmers are often reluctant to remove an entire banana mat when disease symptoms are minor and symptomless shoots could potentially still bear an edible bunch. Nevertheless, Blomme et al. (2017) suggest that in regions with intensive, market-oriented banana systems, where the goal is to eradicate BXW from the field, CMU could be a preferred management option. In addition, CMU would be applied where the disease appears for the first time in a location and is still limited to a few mats. Unfortunately, CMU cannot guarantee long term eradication of BXW, as there is always a risk of reinfection under small-scale farming conditions (Tinzaara et al., 2013).

\section{The alternative way Single Diseased Stem Removal (SDSR)}

Single Diseased Stem Removal (SDSR) technology is based on understanding that adjacent/physically attached shoots of an infected mother stem/plant are often disease free. SDSR is a less intensive alternative to CMU. Continuous removal of symptomatic plants, cutting them at soil level when observing first symptoms, can drastically reduce inoculum levels and disease incidence over time (from up to $80 \%$ to below $2 \%$ within 3 months, and below 1\% within 5-10 months) (Blomme et al., 2017). Advantages of SDSR over CMU are low cost, and simple and easy applicability. Additionally, farmers can individually control BXW in highland settings with highland type bananas [AAAEAH genome group] (van Schagen et al., 2016). This lessens need for collective action in AAA-EAH dominated systems in high elevation settings, allowing for effective out-scaling of the technology by targeting individual households. Nevertheless, a collective approach is preferable to prevent the incursion of inoculum from neighbouring infected farms. In lowland areas and in ABB dominated systems where insect vector mediated transmission is rampant, early male bud removal should be rigorously applied too. With SDSR there is no need for replanting and productivity of a BXW infected field can be restored in a relatively short time with nonremoved shoots that reach their harvest stage. This makes SDSR a suitable management strategy for subsistence banana systems that target management of BXW at acceptable levels (< 1\%) (Blomme et al., 2017). However, SDSR does not remove all inoculum and requires rigorous application for as long as disease is present on or near a farm. Practice alongside other cultural management practices is critical (e.g. male bud removal, and tool sterilization), making BXW management still knowledge and labour intensive and necessitating continuous training and extension efforts. 


\section{Chapter 2}

The next section provides a short historical background on banana farming and BXW in the Great Lakes Region (section 2.2). A conceptual and methodological framework is presented in section 2.3. Thereafter, the main characteristics of the BXW problem in the region are identified and discussed per system dimension (section 2.4). In section 2.4, we explore how these characteristics are interlinked with data, information, knowledge, and connectivity challenges. In the same section, we analyse how citizen science and ICT could offer appropriate intervention mechanisms for the identified problem characteristics. Lastly, section 2.6 provides a reflection on our findings and some practical recommendations.

\subsection{Historical overview and gaps in our understanding of BXW and its management in the Great Lakes Region}

\subsubsection{History, symptoms and spread of BXW}

Bananas form an important staple crop in East and Central Africa. Among the worlds' top ten producers of cooking bananas, Uganda ranks first, and DR Congo holds the 8th position (FAO and FAOSTAT, 2014). For production of dessert bananas Tanzania is the world's 8th largest producer, and Rwanda the 10th (FAO and FAOSTAT, 2014). More than $50 \%$ of Sub-Saharan Africa's production takes place in the African Great Lakes Region (Blomme et al., 2014; Frison \& Sharrock, 1998). Bananas are of major economic importance in this region, forming an important part of peoples' daily diet and providing income and food security to millions of smallholder households.

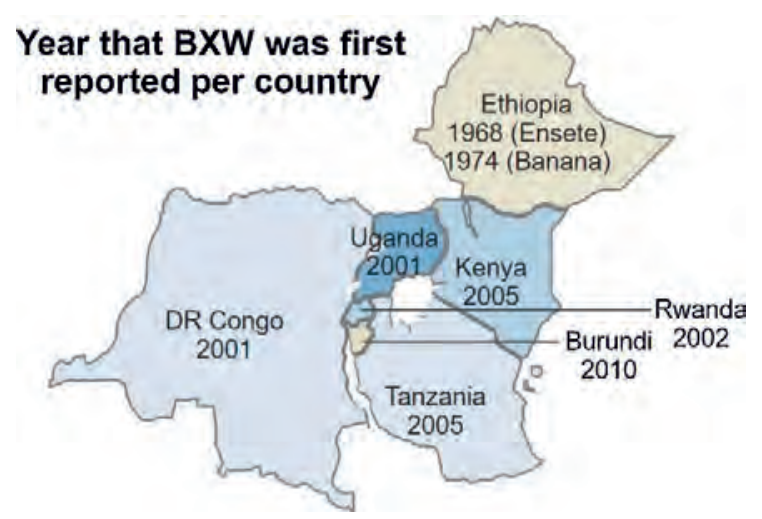

Figure 5: Schematic overview of historical spread of Xanthomonas Wilt of Banana (BXW) in the Great Lakes Region, with the year in which BXW was first reported (map developed based on data from Yirgou and Bradbury, 1974; Karamura et al., 2005; Niko et al., 2011; Tushemereirwe et al., 2003; Yirgou and Bradbury, 1968; Castellani, 1939). 
Xanthomonas Wilt of Banana (BXW) in Africa: Opportunities, challenges, and pathways BXW was first reported in Ethiopia on enset (Ensete ventricosum), a relative of banana, in 1968 (Yirgou \& Bradbury, 1968) and hereafter on banana in 1974 (Yirgou \& Bradbury, 1974) (Figure 5). BXW was recognized as a threat for banana production in the entire region but remained confined to Ethiopia until first outbreaks were observed in Central Uganda in 2001 (W. Tushemereirwe et al., 2003). Since then BXW has spread through to DR Congo (2001), Rwanda (2002), Tanzania, Kenya (2005) and Burundi (2010) respectively (Karamura, Osiru, Blomme, Lusty, \& Picq, 2005; Niko, Ndayihanzamaso, \& Lepoint, 2011; Tushemereirwe et al., 2003). Trans-boundary transmission of the disease has been reported. For example, in Rwanda, BXW was first identified in the NorthWestern region around Rubavu district, where local farmers mentioned seeing first symptoms around 2002-2003. BXW most likely spread into Rwanda from DR Congo's Kivu region due to continuous exchange of people and goods across the Rubavu-Goma border and the fact that first outbreaks of BXW in DR Congo were confirmed near this border in the Masisi region north of Goma (Reeder et al., 2007).

Several governments took rigorous actions in an attempt to eradicate BXW. For example, Uganda installed task forces assigned with the mission to cut down and destroy infected plantations/fields, remove male buds to prevent insect vector transmission, and control cutting of bunches with non-sterilized tools (Tushemereirwe, Okaasai, \& Kubiriba, 2006). These types of interventions are rigorous and have had effect in reducing disease incidence (Bouwmeester, Heuvelink, \& Stoorvogel, 2016). However, the invasive nature of uprooting entire plantations received little support from farmers (Blomme et al., 2017). Although disease eradication has been achieved in some sites, BXW has reached endemic status in other sites where resurgence is observed after a period of control, often due to a less rigorous application of control measures (Tinzaara, Karamura, \& Kubiriba, 2014). Additionally, endemicity of BXW is sometimes attributed to lack of awareness and knowledge about disease transmission, diagnosis, and disease management by stakeholders across the value chain. Alternatively, reluctance of farmers to actively apply awareness and knowledge due to the invasive/time-consuming nature of recommended practices can be a cause. As complete eradication of the disease has proven difficult to achieve, the focus has shifted towards development of strategies that use SDSR and complementary approaches to reach a situation in which $\mathrm{BXW}$ is manageable and disease incidence minimized to economically acceptable levels. 


\subsubsection{Gaps in understanding the disease and its management}

Since the first reports of BXW in the Great Lakes Region in 2001, there have been numerous publications analysing the disease. Initial focus of academic literature was on improving understanding about the disease's epidemiology and control (mainly building on existing knowledge from banana bacterial wilts in Asia and Latin America), and later on strategies to develop BXW resistant banana cultivars, mostly through genetic engineering (Tripathi et al., 2009; Biruma et al., 2007). This contributed to considerable progress in terms of knowledge about the technological and biophysical dimensions of BXW, including disease epidemiology, bio-engineering of resistant varieties and, updating/finetuning cultural control practices. Based on increased understanding of e.g. within plant and mat systemicity and disease spread/dissemination, cultural control practices were developed and updated. The concentration on understanding the biophysical and technological dimensions of the crop protection problem corresponds with findings by (Schut, Rodenburg, Klerkx, van Ast, \& Bastiaans, 2014), who concluded that there is generally much less attention for other problem dimensions (e.g. socio-cultural (e.g. stakeholder beliefs, or locally preferred practices), economic (e.g. costs of disease management), and institutional (e.g. trade policies, or disease control strategies)). Capturing the impact of these system dimensions, e.g. on BXW transmission at farm and regional scales, as well as the role of surveillance and control mechanisms, and their impact on combating BXW (Tinzaara et al., 2016; Markham, 2009), becomes gradually more important now that focus shifts from developing knowledge to developing suitable interventions. This includes investigating (i) diversity among farmers, their production objectives and barriers for adopting (BXW) technologies, (ii) effective strategies of information provision and capacity development for farmers, (iii) information needs and communication preferences to better understand and address constraints and challenges, and (iv) how multi-stakeholder processes can support joint problem identification, analysis and collective action (Schut, Klerkx, et al., 2014). This diagnostics paper does not offer such an investigation, yet it conveys the importance of each problem dimension by providing a comprehensive assessment of their contribution to the persistence of BXW. 


\subsection{Conceptual and methodological framework}

\subsubsection{Conceptual framework}

The conceptual framework for this study is rooted in three coherent theoretical concepts that fit the study's purpose: (i) systems perspective on complex agricultural problems, (ii) ICT for agriculture and citizen science, and (iii) theoretical understanding of data, knowledge, information, and connectivity. Each of these concepts responds to one of the study objectives. We use systems perspective to frame our analysis of BXW in Section 4. Theory on ICT for agriculture and citizen science informs our assessment and discussion of potential contributions of ICT in addressing BXW. Furthermore, the four intervention categories presented in the discussion section build on the notion that ICT for agriculture and citizen science are approaches for generating and exchanging various classes of content, as well as connecting people. The concepts of data, knowledge, information, and connectivity additionally help to perceive differences between the categories.

\subsubsection{Complex problems and systems perspectives}

Complex agricultural problems are problems in the agricultural domain that cannot be resolved but rather must be managed. Complex agricultural problems are typically unstructured, embedded in the agricultural system and therefore persistent, relentless, and crosscutting (Weber and Khademian, 2014). BXW can be considered a complex problem as it, too, is persistent, unresolvable, and embedded and crosscutting in the banana system. BXW is rooted in a multitude of challenges in various system dimensions (i.e. biophysical, technological, social, cultural, economic, institutional, and political) (Markham, 2009), and as past experiences have shown that technology-based solutions do not necessarily provide the full answer, an alternative approach, which is more integrated and knowledge-based, is required (Markham, 2009). Addressing such problems rather requires collaboration between different actors (e.g. farmers, extensionists, researchers), at different levels (e.g. local, regional, national) to address challenges in different dimensions (e.g. social, economic, institutional) (Schut, van Paassen, et al., 2014). Improving understanding of the interplay of various system dimensions is important, given that current efforts to out-scale interventions and technologies, which gave promising results at local or farm level, mostly yield unsatisfying success rates (Tinzaara et al., 2016). This associates with the notion that interventions aiming to solve crop disease issues must be tailored to a specific crop 
Chapter 2

production system (Jogo, Karamura, Tinzaara, Kubiriba, \& Rietveld, 2013), and that farmers should be offered management options fitting with their local and individual context (Blomme et al., 2017).

\subsubsection{ICT for agriculture and citizen science}

With their strength to allow for co-creation of knowledge and joint reflection, contemporary ICTs offer immense potential for addressing a variety of today's complex agricultural problems. For example, interventions in which contemporary ICTs such as mobile phones complement or replace face-to-face agricultural service delivery are increasingly observed (FAO, 2017). As much as ICTs can be useful, they should not be seen as a panacea for solving all complex agricultural problems, or for providing all pieces of the puzzle that are required to manage complex problems (Deichmann, Goyal, \& Mishra, 2016; Nelson, 2010).

Contemporary ICTs (e.g. mobile phones, tablets) are a key driver for the recent boom in citizen science initiatives. Citizen science initiatives focus on crowd-sourcing data from citizens, often in conjunction with an online, ICT-based platform (Fradera et al., 2015). The term citizen science represents (i) a science that assists the needs and concerns of citizens and, (ii) a form of science developed and enacted by citizens themselves. Most citizen science platforms aim to monitor the environment and foster collaborative research, learning, and action (Cieslik et al., 2018). Citizen science emerged from the observed need for an approach to enhance dialogue between scientific and citizen groups, as well as to recognize the added value of building on expertise and understandings possessed by citizens in decision making processes (Irwin, 1995). Benefits include increased awareness and knowledge, and a more participatory and democratic research process for citizens, while scientists profit from faster access to larger data sets for studying complex problems at lower costs (Fradera et al., 2015). Identified challenges with citizen science include the potential difference between who participates, and the population targeted, reliability of data collected, and communication of models developed based on citizen science data (Buytaert et al., 2012).

\subsubsection{Framing data, knowledge, information, and connectivity}

Deployment of ICT tools and citizen science-based interventions in agriculture are only useful when they mediate in generating and sharing content or connecting people in the agricultural system. It has been argued that ICT-based platforms can 
Xanthomonas Wilt of Banana (BXW) in Africa: Opportunities, challenges, and pathways enhance connectivity between disassociated populations, enabling participatory monitoring (collection and exchange of data), broad accessibility of information, and dialogue about scientific-based models (knowledge creation) (Jalbert \& Kinchy, 2016). To further conceptualize this, we first look at the understanding of, and differences between, data, information, and knowledge. These have been described widely (Ackoff, 1999; Alavi \& Leidner, 2001; Cees Leeuwis \& van den Ban, 2004b) and the difference between the three concepts can be subtle (Alavi and Leidner, 2001; Leeuwis and van den Ban, 2004b). Given the scope of this paper we use broader definitions of the three terms. In this study, we understand data as raw facts and numbers from observations or measurements (for example outputs from measurements of the number of banana mats infected with BXW); information as processed or interpreted data made tangible in useful descriptions (for example a message informing extensionists that $20 \%$ of all banana mats in a region are infected with BXW and need to be managed with appropriate cultural control practices) that turn it into something that is accessible and actionable; and knowledge as interpreted and personalized data and information (for example the knowledge that with a 20\% plant incidence rate SDSR is the most effective management strategy for farmers operating in that region) (Alavi and Leidner, 2001; Leeuwis and van den Ban, 2004b; Ackoff, 1999).

Knowledge is influenced by and influences for example mindset, behaviour, and learning processes (Leeuwis and van den Ban, 2004). It also informs people's capacity to understand patterns to which they can take action (Alavi and Leidner, 2001; Ackoff, 1999). Data, information, and knowledge are connected through a forward flow: data is processed into information, which is then assimilated into knowledge. A reverse flow is possible too, when knowledge explains information and filters and processes data (Heeks, 2018).

The difference between information and knowledge is that the first entails processed data useful to its recipient, while the second aggregates information to a higher level by assimilating it into a coherent framework of understanding (idem). This brings us to the additional description of knowledge as the sum of what has been perceived, discovered and learned (6).

Alavi and Leidner (2001) make two important points to take into account for exchanging information and knowledge that is actionable to a receiver: (i) most information has little value to a user unless it goes through a process of reflection, enlightenment, or learning, and (ii) knowledge is individual and to be useful for someone else it needs to 


\section{Chapter 2}

be expressed and communicated in such way to a receiver that it is interpretable. This links with the notion that uncontextualized knowledge, that is analysed and interpreted by experts and then projected back to a locality, is likely inappropriate for utilization (Cieslik et al., 2018; Leeuwis and van den Ban, 2004).

Lastly, we understand connectivity as the ability of and opportunity for stakeholders to interact and collaborate, as well as to coordinate and organize themselves (Bennett \& Segerberg, 2012). Connectivity relates to how people interact, and who interacts with whom, and can therefore influence collection and exchange of data, information, and knowledge. The absence of effective stakeholder collaboration and connectivity can form a bottleneck for agricultural system development (Schut, Klerkx, et al., 2014), is often related to heterogeneity in communities and weak leadership and control arrangements, power imbalances and information asymmetries (Olson, 1965; Poteete et al., 2010), and a limiting factor to solving complex agricultural problems (Schut, Rodenburg, et al., 2014). For example, banana farmers excluded from interactions with extension officers and operating individually are more likely to lack access to information about BXW management. According to Bennett and Segerberg (2012) digital innovations foster opportunities for communicative ways of organizing that do not rely on formal organizational coordination but rather on self-organizing networks, thereby creating new spaces of interaction that can be accessed by many. Cieslik et al. (2018) argue that this may be of relevance in the context of environmental management in developing countries, hence for an agricultural challenge like BXW.

\subsubsection{Methodological framework}

\subsubsection{Study location}

Although much of the data presented in this paper apply broadly across the Great Lakes Region, we sometimes focus on specific BXW related issues in Rwanda. This is for three reasons. First, BXW has been a recurring problem in Rwanda since the initial identification in 2002, despite attempts to control it. Officials in the Ministry of Agriculture and Animal Resources articulated existence of keen interest for innovations providing a lasting solution (Ministry of Agriculture, personal communication, July 2017). Second, Rwanda has the most ambitious objectives for use of ICT in rural and agricultural transformation in the African Great Lakes Region. The country profiles itself as the ICT hub in Africa and adopted several policies and strategies to enhance the use of ICT among which the 'National ICT for Rwandan Agriculture Strategy' (MINAGRI, 
Xanthomonas Wilt of Banana (BXW) in Africa: Opportunities, challenges, and pathways 2016). Third, Rwanda is the main focus country of the EVOCA case study that was the entry-point for our diagnostics study.

\subsubsection{Data collection and analysis}

Data for this qualitative paper were gathered through various methods: literature and secondary data review, scoping field visits, semi-structured interviews, and semi-structured group interviews. The methods' focus on BXW was stronger than on ICT and citizen science in response to our research objectives. This mixed approach was appropriate since it (i) allowed for a broad assessment of scientific and field level knowledge and understanding about BXW, (ii) provided the necessary input to unravel the research problem across all system dimensions both technologically and socially in section 2.4 and (iii) supported development of suitable pathways for interventions in section 2.5. More specifically, Table 5 in section 2.4 was developed based on review of literature and secondary data, while Table 6 in section 2.5.1 emerged from synthesizing information from section 4 and linking this with the data, information, knowledge and connectivity concepts as laid out in the conceptual framework.

First, literature and secondary data were reviewed. For the BXW, banana systems, and citizen science related literature snowball sampling was used, tracing references in articles to identify additional relevant peer-reviewed articles and grey-literature. Advancements in understanding of technological and biophysical aspects, that led to changing/fine-tuned ideas about appropriate BXW control strategies, and recently developed interest for social aspects were considered. Therefore, recent publications (from 2015 to 2017) were consulted first and supported identification of older relevant publications. ICT for agriculture related literature was purposively selected from a set of articles retrieved through search queries in Web of Science, Scopus and CABabstract. Selection took place based on relevance in relation to the study objectives. Catering for developments in the research field, focus was on recent publications (after 2007). Second, scoping visits to banana production areas in Rwanda's Eastern Province (Kayonza District, 2 areas visited) and Southern Province (Kamonyi District, 1 area visited) took place between January and June 2017, and Burundi's Muyinga District (August 2017, 2 areas visited). Sampling was purposive, based on presence of existing projects from IITA (CIALCA, in Rwanda) and Bioversity International (DFAP-AMASHIGA, in Burundi). Third, aforementioned visits facilitated semi-structured interviews in Rwanda. We purposively selected 2 lead farmers who represented members of a banana innovation platform in Kayonza, covering experiences with BXW, disease 
Chapter 2

incidence in the area, and management strategies. Fourth, four semi-structured group interviews were organized with in total approximately 50 smallholder farmers (mixed male, female, age) in Muyinga, Burundi, focusing on experiences with different control strategies and use of mobile technologies. These interviews asked a regular set of questions used by project staff during routine visits with the addition of questions about mobile technology by the researcher.

\subsection{Results: unravelling dimensions of the BXW problem}

This section unravels the different dimensions of BXW as a complex problem and identifies different challenges under each of the six system dimensions. Table 5 summarizes for each dimension a problem description and characteristics that are discussed in detail in adjacent paragraphs. We build on findings and interpretations from scientific literature and secondary data, and supplement by input retrieved from field visits and focus group discussions.

\subsubsection{Biophysical dimension}

Biophysical characteristics refer to issues of biological nature that may or may not be controlled. Roughly, edible bananas are divided into four categories, each with their own varieties and purposes: (i) dessert (sweet yellow banana, eaten ripe), (ii) cooking (unripe green bananas for cooking, also known as matoke), (ii) plantain (for cooking and frying), and (iv) juicing (also called beer banana, used for production of local brews) (Vurro et al., 2010). Another means of categorization is in different subgroups: East African highland cooking and brewing cultivars (AAA-EA), exotic brewing, dessert and roasting types $(A B, A A A, A A B, A B B)$ and hybrids (Nkuba et al., 2015). No resistant cultivars have been identified (Tripathi et al., 2009), and the locally popular and widely spread ABB cultivars ('Pisang Awak' or 'Kayinja') are particularly prone to insect vectored transmission of Xcm (BXW) (Nkuba et al., 2015). This cultivar is particularly common in non-commercial, low management areas further which adds to risk for disease transmission. Susceptibility of banana to BXW and infection risk are intensified by the large and, especially in Rwanda, densely populated banana growing areas in the Great Lakes Region. Different vectors for BXW transmission are airborne (insects, bats, or nectar sucking and fruit pulp eating birds), contaminated garden tools, infected planting material and browsing animals. Especially airborne vectors are a typical biophysical challenge. The Great Lakes region is specifically suitable for this type 
Xanthomonas Wilt of Banana (BXW) in Africa: Opportunities, challenges, and pathways of transmission (Mwangi \& Nakato, 2009), due to - for example - insect favourable climatological conditions and, the aforementioned human population density and pressure on land. The resulting lowered ability to predict and control disease spread clarifies why BXW can suddenly pop-up in previously unaffected areas. BXW symptoms appear as early as 3-4 weeks (Tripathi et al., 2009) and up to 16 months (Ocimati et al., 2013) after infection, depending on conditions. Recent studies confirmed that BXW does not necessarily infect or cause symptoms in all shoots physically attached to an infected (mother) plant in a mat, a condition that is referred to as incomplete systemicity (Ocimati, Nakato, Fiaboe, Beed, \& Blomme, 2015). Symptoms of BXW are progressive yellowing, withering and necrosis of leaves; fruits that rapidly and prematurely ripen and show internal browning; shrivelling/rotting male flowers and bracts, stem and bunches; withering and rotting of the entire plant (Biruma et al., 2007).

The lack of BXW resistant cultivars necessitates use of cultural management practices. Survival of the inoculum on tools used in such practices and presence of e.g. free roaming animals (Tinzaara et al., 2013; Blomme et al., 2014) increases the complexity to prevent transmission within fields and over (long) distances. Biophysical characteristics impact chances of BXW resurgence after a disease-free period. Tendency is to reduce rigour after incidence levels reduced significantly, while in fact continuous field monitoring and application of appropriate management practices are needed (Tinzaara et al., 2013). This makes fighting BXW labour intensive both nationally and locally, however. Our discussions with farmers showed that farmers indeed tend to reduce monitoring practices when disease pressure is low, especially for fields further away from the homestead. Additionally, farmers critiqued impact of neighbours who fail to appropriately maintain their bananas and thereby increase disease infection risks. 


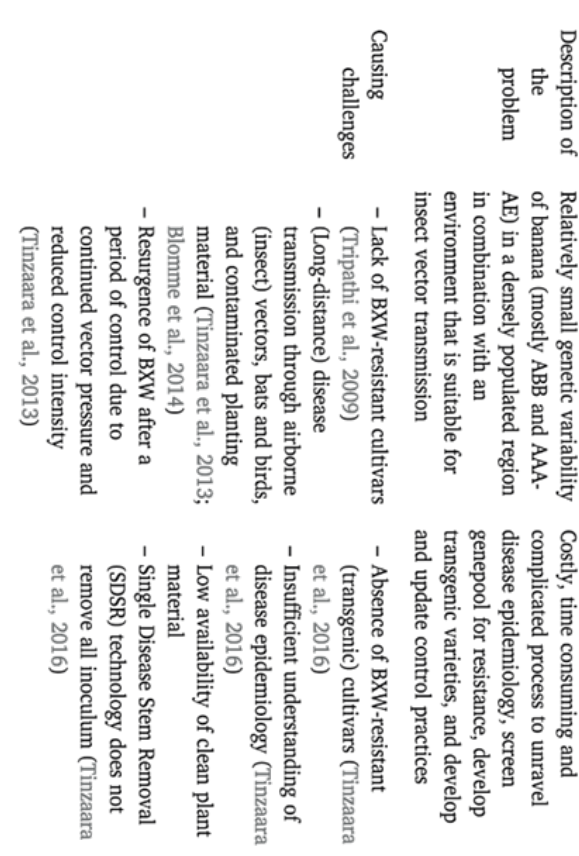

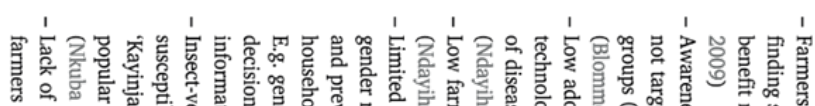

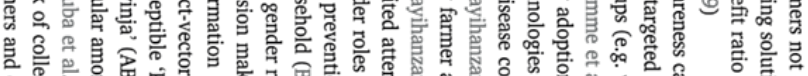

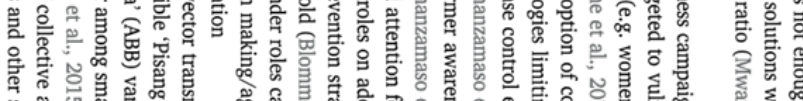

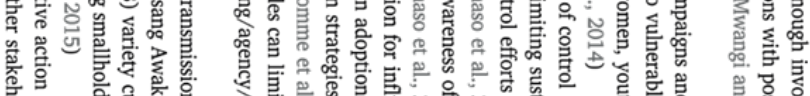

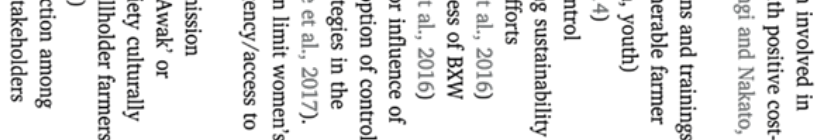

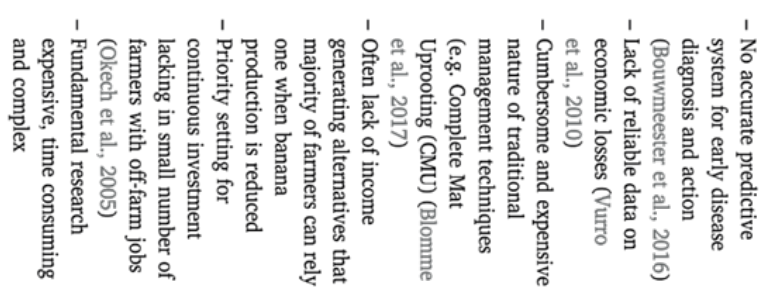

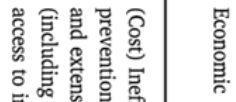

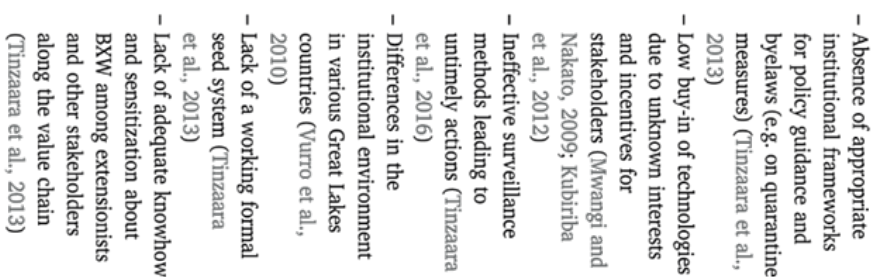

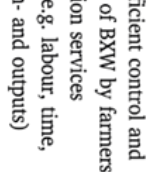

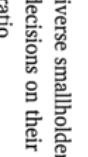

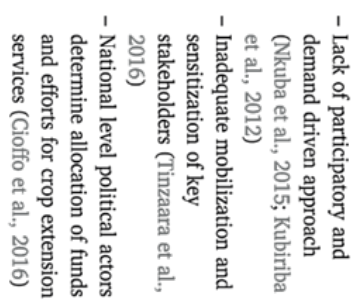


Xanthomonas Wilt of Banana (BXW) in Africa: Opportunities, challenges, and pathways

\subsubsection{Technological dimension}

Technological characteristics relate to the role technological advances play in solving agricultural issues. For example, technological advances like improved diagnostics, disease management strategies, and generally improved agronomic practices can all reduce risk of major disease outbreaks. Research on BXW led to improved diagnostics and increased knowledge about epidemiology, as well as the development of different technological options for e.g. diagnostics, management, and control. These options however face limitations, e.g. SDSR does not completely remove inoculum and CMU is labour intensive and requires replanting of uprooted mats.

Absence of BXW resistant cultivars forms a, partially, technical issue too. Efforts to develop transgenic cultivars with resistance are in an advanced stage, however not yet to the point of marketability. Additionally, transgenic cultivars are (1) only available for some popular cultivars, and (2) not or limitedly acceptable within existing regional biocontrol policies. Also, clean planting material is perceived as expensive while its availability is low. Correspondingly, we observed that farmers mostly sourced unscreened material (i.e. suckers/lateral shoots) from own or neighbouring farms, a practice posing the risk of disease spread/(re)introduction (Tinzaara et al., 2013).

\subsubsection{Socio-cultural dimension}

Socio-cultural challenges are mostly the result of common one-size-fits-all approaches that insufficiently respect needs and interests of diverse groups of farmers. Despite advances made, the epidemiological knowledgeability of extensionists and farmers is still insufficient to address the problem effectively (Tinzaara et al., 2016). For example, our interviews with trained farmers in Burundi revealed that some still struggled with recognizing the disease. Also, not all respondents applied regular or proper tool disinfection mostly due to limited awareness of the most appropriate practice. Incomplete knowhow/understanding and subsequent suboptimal implementation of appropriate control and prevention strategies leads to new and resurging $\mathrm{BXW}$ epidemics.

Farmers of different gender, age and socio-economic groups pursue different livelihood strategies to ensure food, income and nutrition security, and face different land, labour and other resource constraints (Klapwijk et al., 2014). Information about and access to markets forms an output constraint (Okello, Kirui, Njiraini, \& Gitonga, 2012). Smallholder, including banana-based, farming systems are thus diverse and 
complex. For example, van Damme et al. (2013) found three distinct categories of banana producers in the Great Lakes Region based on characteristics such as land-size and productivity. Analysis of the largest group of farmers, those with medium-sized farms, showed additional heterogeneity (e.g. in number of crops and crop management practices) which the authors attributed to varying risk coping strategies. This contributes to system resilience but impedes rapid transitions towards increased productivity (van Damme et al., 2013). Next to typologies based on farming system and livelihood characteristics, it is useful to differentiate according to the willingness of a farmer to invest and change practices. Hence, 'Silver bullet' solutions to production constraints are an illusion given the system's complexity (Giller et al., 2011), and thus technologies and service provisions like awareness campaigns and trainings, need to target the specific challenges and opportunities of vulnerable farmer groups (Blomme et al., 2017; Blomme et al., 2014).

Current farmer involvement in the search for innovations with positive cost-benefit ratio is limited (Mwangi and Nakato, 2009). This may impact local awareness about BXW and understanding of disease severity and spread (Tinzaara et al., 2016; Tinzaara et al., 2013) despite the many campaigns aiming to inform farmers. The result is disease transmission through, for example, non-disinfected farm tools or browsing domestic animals (Tripathi et al., 2009). Moreover, information provision about disease transmission, spread and control is ambiguous, inducing beliefs that BXW cannot be controlled effectively (Ndayihanzamaso et al., 2016). The resultant is low adoption of control and prevention technologies, limited collective action, late disease diagnosis, and ultimately poor sustainability of disease control efforts (Ndayihanzamaso et al., 2016).

Literature makes note of other persisting mindset issues and, indeed, during our scoping field visits and group interviews many of following challenges came to the surface. Farmers largely base decisions about disease control mechanisms on the economic risk involved, i.e. the estimated cost of controlling BXW needs to outweigh the estimated cost of losing the crop (Gent, Mahaffee, McRoberts, \& Pfender, 2013). In addition, perceptions of control technique effectiveness determine adoption decisions (Blomme et al., 2017). For BXW this mindset proves problematic as initial symptoms are mild with limited impact on plant mat productivity. Farmers are hence hesitant to quickly act as benefits of traditional control mechanisms, such as CMU, have no shortterm visibility (idem), while the effort required to apply them, and the negative tradeoffs are immediately visible. Additionally, the perception exists that individual efforts 
Xanthomonas Wilt of Banana (BXW) in Africa: Opportunities, challenges, and pathways are ineffective due to the high chance of reinfection if neighbours do not manage their fields (idem). Hence, most interventions have a curative control character and are implemented when disease manifestation and crop losses are visible in a large portion of a field.

The lack of considering gender issues when designing and disseminating interventions to control BXW is problematic as technology uptake affects and is affected by gender relations (Blomme et al., 2017). For example, gender roles influence success of management practices such as SDSR. Blomme et al. (idem) discuss potential conflicts between male (usually managing the perennial banana) and female (usually managing annual (inter) crops) household members during the application of SDSR. This is the case when SDSR is practiced during the growth period of the intercropped annual crop, which can then be disrupted/damaged by people walking in the field for monitoring or cutting and falling of (especially large) diseased stems. Consequently, annual cropping seasons should be considered when planning SDSR activities, for example by the removal of all visibly diseased plants before onset of the annual cropping season as to match labour demand by men and women, and limit movement in the field during the growth period of annual crops.

\subsubsection{Economic dimension}

Economic characteristics relate to the devastating impacts of BXW on household food, nutrition and income security, and the inefficient attempts to prevent and control it. From a scientific point of view, fundamental research is expensive, time consuming and complex. Economic impact and thus return on investment are not fully understood (Biruma et al., 2007), though its impact on food security is likely substantial. Accurate data on the short- and long-term economic impact of BXW are limited and mostly assumption based (Vurro et al., 2010; Nkuba et al., 2015). However, without effective control BXW certainly causes yield losses up to 100\% (Nkuba et al., 2015) especially in ABB-dominated production systems. The initial control measure to drastically reduce field inoculum levels (CMU) is cumbersome as it is time and labour intensive, and therefore expensive. Also, replanting is inadvisable before 6 months of fallowing (Blomme et al., 2014) and, adding time until first bunch production (approx. 18 months), production losses entail about 24 months. All along households' food, income and nutrition security are disrupted. Understandably, farmer willingness to control BXW with such cost-ineffective techniques is low (Blomme et al., 2017). Additionally, lack of sufficient strategies/timely intervention approaches to prevent 


\section{Chapter 2}

large-scale, and severe outbreaks induce unnecessary high control costs both locally, nationally, and regionally. Although SDSR technology is more farmer friendly, it still requires significant time and labour investments, especially in the initial application phase with high incidence levels. Consequently, farmers may perceive reason to opt for more economic coping strategies, e.g. switching other crops. Lastly, a dichotomy exists between farmers with and without off-farm income generating activities. The first has low motivation for continuous investment in banana management as it is not the main source of income. In group interviews this was mentioned as a concern and nuisance. The latter lacks room for financial manoeuvre both for managing the crop and when BXW affects the production while bananas provide an important income source.

\subsubsection{Institutional dimension}

Institutional challenges relate to the diverse appearances and performance of the institutional environment in the Great Lakes Region that affect ability to implement BXW control and prevention strategies at scale. Appropriate frameworks, guiding policies and byelaws (e.g. quarantine measures) are largely absent (Tinzaara et al., 2013). The institutional situation moreover differs per country (Vurro et al., 2010) complicating potential for and willingness to engage in regional action.

Trans-boundary pathogen transmission is difficult to prevent since both banana produce and planting material travel across borders without restraint. Additionally, surveillance methods are ineffective (Tinzaara et al., 2016), due to a common lack of organization, regularity or accuracy. Although Rwanda currently conducts a countrywide BXW mapping exercise, the absence of national and regional strategies and collaborations for continuous surveillance and intervention decreases ability to forecast disease spread. This affects potential for timely disease diagnosis and action, thereby impacting infection rates and crop yields. Interventions hence largely have a curative character due to limited research and developments for BXW prevention, and absence of predictive early-warning systems for BXW spread/ resurgence hotspots (Bouwmeester et al., 2016) to inform governments about targeted investments.

Extension services, including those for control and prevention of pests and diseases, in the Great Lakes Region are generally the responsibility of national agricultural research institutes. Research and (extension) service providers have a role in finding solutions that can increase development of and access to agricultural services by all farmers (Poulton, Dorward, \& Kydd, 2010). Continuous interaction between farmers and service 
Xanthomonas Wilt of Banana (BXW) in Africa: Opportunities, challenges, and pathways providers to make extension services more demand-driven, inclusive, and widely available can contribute to increasing benefits from rural development for all farmer categories. However, Government extension systems are often incapable to provide farmers with adequate support. Traditional extension services are usually expensive, ineffective or both, and more efficient extension models are required to improve this situation (Kabunga, Dubois, \& Qaim, 2011).

Indeed, we observed that Rwanda's Twigire Muhinzi extension programme aims to follow an approach that is demand-driven and participatory. Yet, (Cioffo, Ansoms, \& Murison (2016) noted that local actors, like sector and district agronomists, who assumedly are the most important providers of such demand-driven extension services often lack budgetary and decisional autonomy, and instead rely on top-down decisions and actions that may or may not match local realities. Although our primary data did not capture it, the nature of Rwanda's agricultural system tells that this issue may apply here too.

An important challenge in the fight against BXW is the lack of healthy planting material. This is both a technological, socio-cultural, and an institutional constraint. The lack of a working formal seed system forms an obstacle for reestablishment of uprooted fields. In absence of sufficient high-quality planting material from micro- (tissue culture) or macro-propagation (suckers or suckers-derived plantlets), farmers rely on unregulated sources. The socio-cultural practice to obtain planting material free of cost rather than purchasing it aggregates the issue. Most farmers source suckers from their own fields (60\%) or neighbouring fields (30\%) (Tripathi et al., 2009) thereby risking obtainment of BXW contaminated planting material (Tinzaara et al., 2013), a habit that was confirmed by farmers during group interviews.

\subsubsection{Political dimension}

Political characteristics result from top-down structures in some of the Great Lakes countries (e.g. Rwanda), and lack of collaboration and coordinated efforts between key stakeholders within and across different levels. Additionally, mobilization and sensitization of stakeholders along the value chain is inadequate (Tinzaara et al., 2016). The result is that current capacities and efforts to out-scale interventions and technologies often have unsatisfying results.

Most extension services still have a strong top-down, linear, and technological orientation, and focus on the development, transfer, adoption and diffusion of crop (protection) technologies to farmers (Schut et al., 2014b). This despite the alleged shift 
Chapter 2

of extension services towards a more systemic and participatory approach. A bottleneck is that decisions about fund allocation and priority crops are made by political actors at national level, thereby limiting agenda-setting and bargaining power of local actors. The lack of participatory and demand-driven approaches (Kubiriba, Karamura, Jogo, Tushemereirwe, \& Tinzaara, 2012; Nkuba et al., 2015; Vanlauwe et al., 2014) results in poor understanding of local agro-ecological and socio-economic context and related challenges, and has caused low adoption of technologies by farmers and relatively low buy-in of governments in scaling BXW prevention and control measures. The result is low stakeholder awareness about the BXW problem and its impact, with negative impact on interest for participation and investment in collective control and prevention initiatives. This translates in lack of regional mechanisms for surveillance and monitoring, and limited collaboration between stakeholders in the different affected countries (Tinzaara et al., 2013). This on the one hand complicates introduction of suitable regional institutional frameworks, and on the other hand prevents scaling of effective control strategies.

\subsection{Analysis and discussion}

\subsubsection{The role of data, information, knowledge, and connectivity in overcoming BXW}

The previous section presented an extensive series of findings based on our review of the literature, and interactions with farmers and banana experts. These provide a starting point to analyse how BXW challenges are related to data, information, knowledge, and connectivity constraints, and how ICT and citizen science can play a role in overcoming such BXW challenges (Table 6 , at the end of this section).

Relationships with knowledge and connectivity dominate, while data and information score lower. This confirms not necessarily the absence of data or information, but rather their relevance and reliability, as well as inclusive access form an issue (Bruce, 2016; Walsham, 2017). Regardless of some successful intervention approaches (e.g. through the use of Farmer Field Schools in Uganda (Kubiriba et al., 2012; Tinzaara et al., 2016), communication related problems are present for BXW. Concerning data, we see limitations in the amount of reliable and up-to-date data about disease diffusion patterns, severity of outbreaks, and effect of control measures, as well as socioeconomic and socio-cultural data that could feed into farmer decision-making tools and an early warning system. Development of informed policies and prevention 

strategies is also hindered by the absence of large-scale accurate data. Another data problem is the missing link between data collection and action-oriented research. The diversity of stakeholders causes two problems that we link to information. Firstly, the use of one-size-fits-all approaches results in a lack of actionable information, customized to the perceptions, practices, and resources of diverse target groups. Secondly, available information is not up-to-date (e.g. about current disease incidence) nor adapted to the local context (e.g. on use of preferred cultural management practices), fails to link technological and socio-economic data, and therefore either inaccessible or non-useful for various target groups. Knowledge problems include gaps in understanding of long- and short-term disease impact, and poor awareness of both the problem and suitable solutions for BXW by farmers and extension agents, causing negligence to take timely action. Additionally, both horizontal (between farmers, and between extension agents) and vertical (across value chain, and across innovation system) exchange of information that is translatable into actionable knowledge is limited. Absence of connections and collaborations between stakeholders at all levels is a cross-cutting problem that prevents effective exchange of data, information, and knowledge. 
Chapter 2

Table 6: Linkages between challenges in each dimension and data, information, knowledge, and connectivity.

\begin{tabular}{|c|c|c|c|c|c|}
\hline \multirow[b]{2}{*}{$\begin{array}{l}\text { Problem } \\
\text { dimension }\end{array}$} & \multirow[b]{2}{*}{$\begin{array}{l}\text { Specific BXW related } \\
\text { challenges }\end{array}$} & \multicolumn{4}{|c|}{$\begin{array}{l}\text { Type of problem where ICT and citizen science } \\
\text { can support }\end{array}$} \\
\hline & & $\begin{array}{l}\text { Data } \\
\text { related } \\
\text { problems }\end{array}$ & $\begin{array}{l}\text { Informatio } \\
\text { n related } \\
\text { problems }\end{array}$ & $\begin{array}{l}\text { Knowledge } \\
\text { related } \\
\text { problems }\end{array}$ & $\begin{array}{l}\text { Connectivity } \\
\text { related } \\
\text { problems }\end{array}$ \\
\hline
\end{tabular}

\begin{tabular}{|c|c|c|c|c|c|}
\hline \multirow[t]{2}{*}{ Biophysical } & $\begin{array}{l}\text { Long distance transmission } \\
\text { through variety of vectors }\end{array}$ & $\sqrt{ }$ & $\sqrt{ }$ & $\checkmark$ & $\sqrt{ }$ \\
\hline & Resurgence after period of control & $\sqrt{ }$ & $\sqrt{ }$ & $\sqrt{ }$ & $\sqrt{ }$ \\
\hline \multirow[t]{4}{*}{ Technological } & $\begin{array}{l}\text { Absence of resistant (transgenic) } \\
\text { cultivars }\end{array}$ & & & $\checkmark$ & $\checkmark$ \\
\hline & $\begin{array}{l}\text { Insufficient epidemiologic } \\
\text { understanding }\end{array}$ & $\checkmark$ & & $\checkmark$ & $\sqrt{ }$ \\
\hline & $\begin{array}{l}\text { Low availability of clean plant } \\
\text { material }\end{array}$ & & $\sqrt{ }$ & $\sqrt{ }$ & $\checkmark$ \\
\hline & $\begin{array}{l}\text { SDSR technology leaves some } \\
\text { inoculum }\end{array}$ & & & $\sqrt{ }$ & \\
\hline \multirow[t]{5}{*}{ Socio-cultural } & $\begin{array}{l}\text { Farmers not involved in finding } \\
\text { solutions }\end{array}$ & & & $\checkmark$ & $\checkmark$ \\
\hline & $\begin{array}{l}\text { Campaigns and trainings not } \\
\text { inclusive }\end{array}$ & & $\checkmark$ & $\checkmark$ & $\sqrt{ }$ \\
\hline & $\begin{array}{l}\text { Low adoption of control } \\
\text { technologies }\end{array}$ & & $\checkmark$ & $\checkmark$ & $\checkmark$ \\
\hline & $\begin{array}{l}\text { Low farmer awareness of the } \\
\text { disease }\end{array}$ & & $\checkmark$ & $\checkmark$ & $\checkmark$ \\
\hline & No attention for gender & & & $\sqrt{ }$ & $\sqrt{ }$ \\
\hline \multirow[t]{3}{*}{ Economic } & No accurate predictive system & $\sqrt{ }$ & $\checkmark$ & $\checkmark$ & $\sqrt{ }$ \\
\hline & $\begin{array}{l}\text { Lack of reliable data on economic } \\
\text { losses }\end{array}$ & $\sqrt{ }$ & $\checkmark$ & $\checkmark$ & $\checkmark$ \\
\hline & $\begin{array}{l}\text { Cumbersome and expensive } \\
\text { nature of traditional management } \\
\text { techniques }\end{array}$ & & & & $\checkmark$ \\
\hline \multirow[t]{6}{*}{ Institutional } & $\begin{array}{l}\text { Absence of appropriate } \\
\text { institutional frameworks }\end{array}$ & $\sqrt{ }$ & $\sqrt{ }$ & & $\sqrt{ }$ \\
\hline & Ineffective surveillance methods & $\sqrt{ }$ & $\checkmark$ & $\checkmark$ & $\sqrt{ }$ \\
\hline & $\begin{array}{l}\text { Different institutional } \\
\text { environments }\end{array}$ & & & & $\sqrt{ }$ \\
\hline & No formal seed system & & & & $\sqrt{ }$ \\
\hline & $\begin{array}{l}\text { Lack of disease knowhow at } \\
\text { institutional level }\end{array}$ & & $\checkmark$ & $\checkmark$ & $V$ \\
\hline & $\begin{array}{l}\text { Stakeholder incentives and } \\
\text { interests unknown }\end{array}$ & $\sqrt{ }$ & $\checkmark$ & & $\checkmark$ \\
\hline \multirow[t]{2}{*}{ Political } & $\begin{array}{l}\text { Inadequate mobilization of key } \\
\text { actors at all levels }\end{array}$ & & & & $\checkmark$ \\
\hline & $\begin{array}{l}\text { National level policy actors } \\
\text { determine allocation of funds and } \\
\text { activities }\end{array}$ & & & & $\checkmark$ \\
\hline
\end{tabular}




\subsubsection{The potential of citizen science and ICT-based tools for overcoming data-, information, knowledge- and connectivity- related BXW challenges}

Based on our findings we have developed four different intervention pathways: (1) data for prevention of new outbreaks, (2) information for BXW control, (3) knowledge for enhanced capacity to act timely and influence decision making and, (4) connectivity for connective action. These pathways build on the impression that citizen science and ICT enabled collection of data, exchange of information and knowledge, and stakeholder connectivity could positively contribute to addressing BXW. In summary, large scale data from citizen science would support timely diagnosis of new and recurrent/re-emerging (i.e. resurgence) disease outbreaks. Information exchanged through a digital platform could help farmers and extensionists to make decisions about actionable control strategies. Knowledge developed by engaged stakeholders can enhance capacity to act timely and increase dialogue. Lastly, connectivity between stakeholders would allow building of self-organized networks.

\subsubsection{Data-related interventions: citizen science and ICT for prevention of new BXW outbreaks}

Current efforts to manage BXW are mostly targeting control of the disease after it has been diagnosed in a farm or area. Adoption of preventive measures such as male bud removal, and tool sterilisation has been limited. More successful results have been obtained by taskforces that surveyed an area for disease outbreaks and enforced rigorous action when disease was diagnosed. However, such measures meet farmer reluctance for impracticability (Blomme et al., 2014) and are reported as too costly to be sustainable for smallholders (Tushemereirwe et al., 2006). Yet, the need for monitoring does not end with the control of BXW in a region given the high risk of resurgence and continuation of surveillance activities is critical. Thus, there is need for cost-efficient and effective interventions that enhance the ability to identify disease outbreaks early on thereby reducing necessity to control severe outbreaks in a late(r) stage. A system in which citizen science and ICT tools are used to crowd-source environmental data (e.g. about disease spread, incidence and severity), and that links existing (scientific) data with field level observations from farmers and extension service providers could be helpful here, possibly combined with historical and real-time data 
from satellite images or collected by drones. In such a system, farmers would play a leading role, sharing data (e.g. on location, BXW incidence and severity) that can support real-time monitoring and prediction of disease spread and incidence that would then provide decision support to farmers about accurate management strategies, to extensionists about hotspots for monitoring and training, and governments about where to focus investments.

\subsubsection{Information-related interventions: reliable and real-time data to improve BXW control}

Citizen science and ICT tools can support better access to information and in a far timelier manner, as well as increase meaningfulness and interpretability of information. This can positively affect farmer decision-making, and in turn be a first step towards improved technology adoption rates, more sustainable disease control, and increased prevention. Farmers base decisions on local conditions, and this needs to be considered when providing farmers with decision support (Wood et al., 2014). For example, enforcing the practice of $\mathrm{CMU}$ to control BXW spread in a region where bananas are mostly grown as a subsistence crop resulted in farmers rejecting/poorly adopting the practice due to its expensive and cumbersome nature (Blomme et al., 2014; Tushemereirwe et al., 2006). Albeit from a scientific perspective CMU may be the preferred technology for most effective disease eradication (or reduction in overall field inoculum level), technologies like SDSR could be more appropriate in a specific farming context and therefore better meet farmer needs and demands resulting in better uptake and impact. Digital innovations may support gathering and assessing appropriate information and control strategies for a specific farmer in a specific locality. For example, app or SMS based services could be combined with more conventional forms of communication used in the banana system to gather, process, and exchange information relevant to individual farmers or farmer communities. Experiments with the use of mobile phones for multiway interaction between science and practice for the control of BXW in Uganda showed opportunities for more cost-effective disease control and surveillance in the region (Nakato et al., 2016). This is promising given the lack of strong national and regional surveillance and monitoring mechanisms necessary for management of BXW (Tinzaara et al., 2014). Other examples of existing initiatives that provide farmers and extensionists with a tool for rapid diagnostics and control advice on crop pests and disease diagnosis are PEAT's Plantix and Penn State University's PlantVillage. Examples of crop specific tools are Africa Rice's Rice Advice, and ICAR- 
Xanthomonas Wilt of Banana (BXW) in Africa: Opportunities, challenges, and pathways National Rice Research Institutes' RiceXpert. Thus, we observe opportunities to - for example - provide decision-support on suitable BXW control strategies to different groups of farmers, including those who normally have difficulties to access information, such as women. This could include sensitizing farmers about risks of locally sourced plant material or, providing information about locally available clean seed resources. Bringing together all information needed for informed decision-making enhances the reliability and consistency of that information for farmers or other end-users.

\subsubsection{Knowledge-related interventions: enhanced knowledge, knowhow and capacity to act and influence}

Knowledge is critical for addressing complex problems as they are intertwined with peoples' actions and processes of change (Leeuwis and van den Ban, 2004). Not knowledge about BXW as such is key, but rather knowledge that can enhance the capacity of stakeholders in terms of understanding, defining and strategizing the broad range of existing and new challenges for addressing BXW. This also builds on stakeholder perceptions and beliefs about effective BXW management (Blomme et al., 2014, 2017).

However, for knowledge to become actionable it needs to be interpretable, something difficult to achieve with one-size-fits-all knowledge. ICT and citizen science could support here, integrating local and scientific knowledge and experiences. A suitable intervention would be the introduction of a digital platform (based on existing digital technologies and platforms such as WhatsApp, SMS, and Unstructured Simplified Service Data (USSD)) to exchange data, information, knowledge and expertise. Integration with a wide variety of digital technologies and platforms makes the platform inclusive for a larger variety of stakeholders. This way ICT and citizen science can enhance availability, accessibility, accuracy, and actionability of the knowledge and knowhow needed to make informed decisions at individual, household and institutional levels by assembling existing knowledge and translating it into new knowledge that is adjusted to the needs and context of its user. Additionally, it allows for collection of scientific and practical evidence of BXW's spread and impact (e.g. data on crop and economic losses) that can convince policy makers to engage in national and regional action. 


\subsubsection{Connectivity-related interventions: connective action among stakeholders}

Although newer management practices such as SDSR make individual level control of BXW very effective under certain conditions (e.g. at highland sites with AAAEA type bananas), stakeholder collaboration and connectivity remain an important bottleneck when aiming for BXW prevention rather than control. General absence of well-functioning networks that assist in monitoring, surveying and controlling crop diseases in developing countries results in incomplete data and provides a hurdle to effective disease control and prevention (Vurro et al., 2010). Hence, there is a need for scientists and farmers to collaborate and turn available information into relevant, actionable farming knowledge (Bruce, 2016). This especially for knowledge-intensive agricultural problems, like BXW, that require intensive training and extension efforts and close collaboration between trainers and learners (Kabunga et al., 2011).

Experimentation with new forms of social mechanisms and exchange of contextualized information through ICT and citizen science provides an entry-point for engaging farmers in research and development activities, creating opportunities for targeted, multi-way, multilevel interaction. Citizen science and ICT can enhance such multi-way information exchange by collecting the feedback from farmers to the research community that can shape new research questions and improve service delivery to farmers (Kindred, 2015; Phillipson, Lowe, Proctor, \& Ruto, 2012). Additionally, ICT provides opportunities for more inclusive services that benefit a larger number and broader variety of stakeholders (Bruce, 2016), and can support improved understanding and communication about best-bet practices according to science, and best-fit practices following farmers' context. Already some banana technologies stem from such a participatory, collective approach (e.g. SDSR and cost-effective macropropagation). Although face-to-face interactions with experts will still be needed, citizen science and ICT can enable, complement, or accelerate these approaches.

\subsection{Conclusions}

This paper contributes to a deeper understanding about BXW in the Great Lakes Region by unravelling this complex agricultural problem. We found that the BXW epidemic/constraint is a resultant of numerous challenges across various system dimensions and is not only caused by biophysical and technological challenges. Identified challenges sequentially link with data, information, knowledge, and 
Xanthomonas Wilt of Banana (BXW) in Africa: Opportunities, challenges, and pathways stakeholder connectivity challenges. This finding has largely been neglected in studies and interventions this far, potentially contributing to meagre results of efforts to control existing and prevent new or recurrent disease outbreaks. Literature on ICT and citizen science innovations suggests that these could potentially be put to effective deployment for addressing such information and communication related challenges. Related to this we identified four action pathways: (1) Data-related interventions: Citizen science for BXW prevention (e.g. involving farmers to collect large scale data on disease transmission patterns); (2) Information-related interventions: Reliable and real-time data to improve disease control (e.g. sharing personal(ized) and contextualized information to facilitate translation into applicable knowledge); (3) Knowledge-related interventions: Enhanced knowledge, knowhow and capacity to act and influence (e.g. establishing a digital platform for sharing of expertise on knowledge-based interventions) and (4) Connectivity-related interventions: Collective action among stakeholders (e.g. creation of a virtual platform for connective action).

Citizen science and ICT innovations based on these pathways are likely more costefficient and have an ability to reach larger groups of farmers than current extension services and interventions for disease management. However, ICTs nor citizen science alone will offer the panacea to a longstanding agricultural problem like BXW. Alternatively, they should be considered useful new modalities that support tackling such problems. We recommend that research and development efforts to address BXW in the Great Lakes Region should not primarily focus on the development of new tools and applications. Instead the focus should be on the identification of best-fit options for combining face-to-face interactions with ICT and citizen science-based innovations for problem solving. 



\section{Are farmers ready to use phone based digital tools for agronomic advice?}

Ex-ante User Readiness assessment using the case of Rwandan banana farmers 


\section{Abstract}

Digital extension is widely embraced in African agricultural development and promises unprecedented outcomes and impact. Especially mobile phones and phonebased services attract attention as tools supporting effectiveness and efficiency of agricultural extension. To date assessments of digital extension services are generally ex-post in nature, and consideration of users and broader systems relevant to the digital service occurs once the intervention design is broadly identified. However, an early understanding of the needs and readiness of users and their relevant context is a prerequisite for successful adoption and sustainable use of digital extension services. We explored the usefulness of ex-ante assessment of user readiness for phone-based services. We developed an ex-ante framework to assess user readiness which considers capabilities, opportunities, and motivations of targeted users. The case study of Rwandan banana farmers served to verify the User Readiness framework, using survey data from 690 smallholder banana farmers. Findings demonstrate limited farmer capacity to access and use phone-based agricultural extension services, especially the more advanced ones requiring a smartphone, and a mismatch between expected user readiness and actual user readiness, especially regarding the current capabilities and opportunities. Findings may serve as entry-points for designing suitable digital extension projects and interventions, pointing out a need for capacity building. The framework provided useful understanding about and limitations in current farmer readiness for using digital extension services. An ex-ante approach to explore user readiness before designing digital interventions for African smallholder farmers is recommended. The User Readiness framework supports informed strategizing and decision making about digital extension interventions. The framework is a relevant conceptual addition to existing readiness frameworks, participatory design methods, and ex-post methods for intervention performance assessment, as it provides a structured approach to developing pre-intervention insights about users and use context. This is the first ex-ante assessment of user readiness for digital extension services applied within an African context, and also the first attempt to analyse readiness of Rwandan farmers to use digital extension services.

Chapter under review as: McCampbell, M., Adewopo, J., Klerkx, L., and Leeuwis, C., Are farmers ready to use phone based digital tools for agronomic advice? Ex-ante User Readiness assessment using the case of Rwandan banana farmers. 


\subsection{Introduction}

Rapid technological advancements and increasing availability of all kinds of digital tools and technologies have led to widespread experimentation and implementation in Africa with digital agriculture (Daum et al., 2020), defined as the use of digital tools and technologies in the management of and decision-making about agricultural systems and value chains (Eastwood, Klerkx, Ayre, \& Dela Rue, 2017; Klerkx, Jakku, \& Labarthe, 2019; Wolfert, Ge, Verdouw, \& Bogaardt, 2017). Examples of digital agriculture include market and financial access tools, registration of farming activities, and agricultural advisory services. Many African governments have accordingly developed policies supporting digital agriculture (Malabo Montpellier Panel, 2019) e.g. Rwanda's ICT for Rwandan Agriculture Policy (2017) - and the African Union recognized digitalization as a top priority for achieving the ambitious goals under its Agenda 2063 (African Union, 2019). Digital agriculture additionally has an increasingly important share in donor portfolios visible also in rising investments (Tsan et al., 2019). The digital agriculture sector has expanded at an impressive rate over the past few years, with a reported $44 \%$ per annum increase in the number of registered farmers as users of digital tools (Tsan et al., 2019). The growing interest in the sector comes with high stakes and expectations for the outcomes and impact of interventions.

In this article we focus on one dimension of digital agriculture, namely digital agricultural extension. In this context we explore the current capacity of African farmer end users to adopt and use digital extension technologies and tools, especially phonebased services. Digital agricultural extension tools deliver or are a component of agricultural extension services, and include pest and disease diagnostic tools, soil management decision support systems, and tools that support the exchange of agricultural knowledge. Digital extension can be standalone, replacing traditional analogue extension, but mixed models where digital tools are combined with analogue, e.g. face-to-face extension, are possible too (Fabregas, Kremer, \& Schilbach, 2019; Klerkx et al., 2019; Steinke et al., 2020). Digital extension services promise to contribute to e.g. increased crop production, reduced pest and disease pressure, better insight in soil health conditions and, ultimately, improved livelihoods through better and more inclusively accessible information (Agyekumhene, de Vries, Paassen, Schut, \& Macnaghten, 2020). They are also seen as potentially disruptive (Callum Eastwood, Ayre, Nettle, \& Dela Rue, 2019) as their potential to increase connectivity and transparency among those who have relevant applied knowledge (Fielke, Taylor, \& 


\section{Chapter 3}

Jakku, 2020) may radically change the way in which agricultural extension is organised. Many of today's digital extension services, especially those that use (smart)phones to send and collect information, target actors operating at farm or village level (e.g. smallholder farmers, extension agents). This trend assumes that widespread access to and use of mobile phones has cleared the way for phone-based extension such as SMS and IVR advisory services or disease diagnostic apps.

Despite the enduring hype and promises around digital tools in agriculture, it has been argued that we lack understanding about actual use and that current use is overestimated (Baumuller, 2016; Klerkx \& Rose, 2020; Steinke et al., 2020). For example, some interventions reportedly reached over 1 million farmers (e.g. E-Soko in Ghana, and Smart Nkunganire in Rwanda), yet of the farmers registered for those digital agriculture services an estimated $42 \%$ actually used the service and only $15-30 \%$ were truly active users (Tsan et al., 2019). Similarly, several studies point to barriers to the adoption of phone-based services, including limited added value, poor technological infrastructure, inappropriate ICT policies, and low capacity levels of (farmer) users to use the technologies (Aker et al., 2016; Ayim, Kassahun, Tekinerdogan, \& Addison, 2020; Nyamwaya Munthali et al., 2018). Hence, knowledge about the transformative capacity of digital extension is still limited (Ingram \& Maye, 2020) and research claiming evidence of the impact of digital interventions in agriculture in Africa is largely anecdotal (Tsan et al., 2019; Sulaiman V, Hall, Kalaivani, Dorai, \& Reddy, 2012).

Given the shortage of truly successful experiences, there is increasing recognition that the entry-point for studying and developing digital extension services should be the user and the specific use context in which a digital technology is used (Steinke et al., 2020; Sulaiman et al., 2012). User-centred (or human, co-creation or participatory) approaches are therefore increasingly used in the design and pilot phase of digital extension services and considered indispensable for sustainable development by some (Gonsalves et al., 2005; Ortiz-Crespo et al., 2020; Steinke et al., 2020). User-centred approaches can guide developers with designing and implementing interventions that fit with user needs and context (Steinke et al., 2020). The existing capacity of users and the digital and agricultural system can make good starting points for such a design approach. Using an ex-ante approach to assess e.g. existing agricultural information practices of intended users, communication customs, and the role of different (digital) media for sending and receiving information, can give insight in the complex environment in which a new digital extension service has to integrate and fit, and may inform about specific user features and requirements for a digital extension service 
before a design process starts. This is where this study aims to make a contribution, using a framework (User Readiness (UR) framework) that was developed with the purpose of conducting an ex-ante study into the readiness of targeted users of a digital extension service by looking at user capacity, behavior, and context. It draws on insights from the public health field, and responds to a call for an interdisciplinary approach to digital extension design, combining insights from economic, agricultural, ICT, and behavioural sciences (Fabregas et al., 2019). The used framework specifically aids assessment of current capacity of target users of a digital extension service, in our case a (smart)phone-based service and helps to understand 'user readiness'. This adds the factor of human-technology interaction to digital extension. In a development context this factor is often overlooked, however elsewhere human-technology interaction has been identified as critical to demonstrate the value and meaning of technology to farmers and other actors (Fielke et al., 2021; Ingram \& Maye, 2020). To the best of our knowledge, a framework for in-depth, quantitative, assessment of user readiness does not exist yet, especially one that can be applied to a developing countries context. Our framework puts the ex-ante capacity of target users and their context at the centre of digital innovation. A study that used a qualitative analytical framework to assess Australian farmers' user readiness appeared helpful for determining the resources and actions required to reduce (social) risks of digital development (Fielke et al., 2021). Similarly, by developing and applying the user-readiness framework, it could become possible to adapt the full digital intervention design to the real-life situation, hence moving beyond fitting a specific digital extension tool or technology to its user (like user-centred design approaches do).

For the purpose of our study we used Rwandan banana farmers and Rwanda's (digital) agricultural system as a case study. We applied our UR framework to find out whether the user readiness and the context of use meet the conditions necessary for a (smart)phone-based digital extension service to be adopted and have impact.

\subsection{Conceptual framework: An approach to study Technology User Readiness for using digital agriculture technologies}

The UR-framework follows in the footsteps of various technology assessment frameworks developed since the 1970s to assess and communicate the maturity of new technologies (Mankins, 2009). Traditionally Technology Readiness Assessments (TRA) were prospective studies that examined at the onset of a program to what extent and 


\section{Chapter 3}

in what context (e.g. laboratory setting or real-life setting) a technology had demonstrated its capacity to perform the functions for which it had been designed, often assigning a readiness level to the examined technology. Today we also see spinoffs of the original framework such as scaling readiness (Sartas, Schut, Proietti, Thiele, \& Leeuwis, 2020) and innovation readiness (Benson, 2019). However, in such assessments it is typically the technology or innovation that is evaluated for its readiness, while the user remains largely invisible. This focus on the functionality of a technology in a specific context arguably reflects a technocentric emphasis in existing readiness assessments. Yet, based on foregoing contexts, we can argue that technological readiness of a digital extension service does not guarantee adoption or impact if the users of that service are not ready too.

Conceptually, the User Readiness framework builds on general theories from the behavioural sciences that have been used to explain adoption and behaviour change in a wide range of settings, including also agriculture (see for overviews e.g. Engler, Poortvliet, \& Klerkx, 2019; Meijer, Catacutan, Ajayi, Sileshi, \& Nieuwenhuis, 2015; Mills et al., 2017). To operationalize the idea of User Readiness we employ the COM-B model of behaviour (Michie, Atkins, \& West, 2014; Michie, van Stralen, \& West, 2011) that was originally developed in the context of public health interventions, and which synthesises insights from several prominent behaviour change models (Michie et al., 2011). The COM-B model proposes that for a person to engage in a specific behaviour (B) at a moment in time, that person needs to have the physical and psychological capability (C) and the social and physical opportunity $(\mathrm{O})$ to perform that behaviour, as well as have the automatic and reflective motivation $(M)$ to do so more than any other competing behaviour at that moment (Barker, Atkins, \& de Lusignan, 2016; Michie et al., 2011). For the UR-framework we took the COM components of the original model, but instead of focusing on actual behaviour (B) we consider that the COM components together shape User Readiness (UR) which we define as the capacity of an individual or group of individual to perform a behaviour (in this case using a digital extension service). Using the COM components, we conceptualize user readiness as a quantifiable parameter that may continuously vary in time and space, and that derives its value from a set of contextually relevant variables. We propose that optimal user readiness for a digital technology lies at the intersection of the component's capability, opportunity, and motivation (Figure 6). 


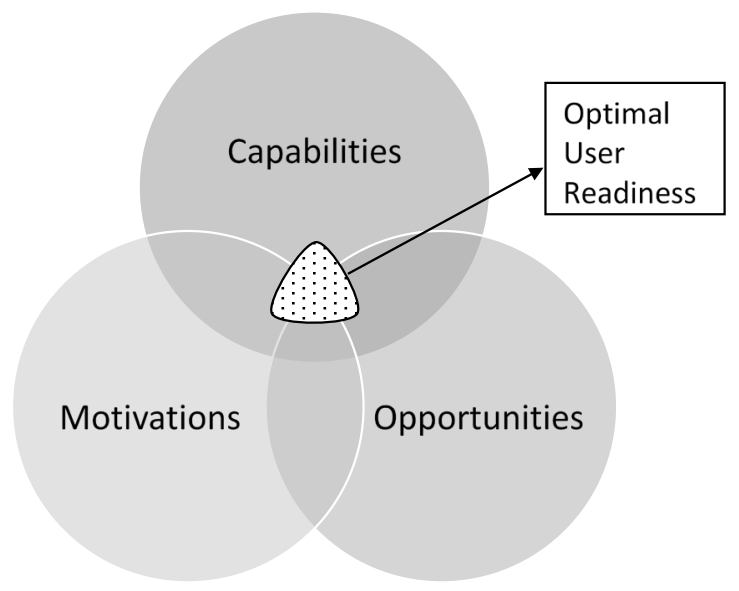

Figure 6: Schematic representation of the COM components and User Readiness (COM-UR, from here on UR framework)

Based on the original definitions of C, O, and M by Michie et al. (2011) we define capability as 'the individual's psychological and physical capacity to engage in using a digital technology or extension service.' This includes having the necessary knowledge, skills, and stamina. Opportunity is defined as 'all the factors that lie outside the individual that make the use of a digital technology or extension service possible or prompt it'. This includes contextual factors that shape accessibility, affordability, and social acceptance. Motivation is defined as 'all those brain processes that energize and direct the use of a digital technology or extension service, not limited to goals and conscious decision-making'. It includes (unconscious) habitual processes, emotional responses, as well as goals and analytically made decisions. We have translated these general definitions towards the context of digital agricultural extension (see Table 7) and used this to design a survey questionnaire with operational questions (see next page and Appendix 1). 
Table 7: Overview of UR-framework components as adapted from Michie et al. 2014 and a brief explanation with examples of their application in the context of digital extension services.

\section{Component + general definition What to consider in context of digital agricultural extension}

\section{Examples of operational categories}

\begin{tabular}{ll}
\hline Physical capability: & - What is the state of farmers' \\
Physical skills, strength, or & physical ability and skills to use \\
stamina & a digital device \\
Psychological capability: & - Education/literacy levels \\
Knowledge or psychological & - Previous experience with using \\
skills and stamina to engage in & digital technology \\
the mental process &
\end{tabular}

- Capability to use a

touchscreen on a (smart)phone

- (e)-Literacy

- Capability to use various functions in a phone

- Capability to understand interrelations between different phone functions

-Time and (financial) resources to own and use a mobile phone - Network availability

- (Economic) resources available

- (Digital) infrastructure

- Gender norms in farming communities

- Mindsets about digital technology and agricultural extension

- Social interaction in farmer communities

- Perceived government enforcement mechanisms

- Experienced norms and beliefs about ag. and digital technology

- Innovativeness of farmer

- Future goals of farmer

- Perceived needs and demands

- Expressed interests

- Organization of the (digital)
extension system
- (Economic) resources available
- (Digital) infrastructure
- Gender norms in farming
communities
- Mindsets about digital
technology and agricultural
extension
- Social interaction in farmer
communities
- Perceived government
enforcement mechanisms
- Experienced norms and beliefs
about ag. and digital technology
- Innovativeness of farmer
- Future goals of farmer

- Equal access of men, women and different age groups to own or use a mobile phone

- Cultural norm that use of digital technologies by women may bring shame on the family

- Belief that phone-based
information is trustworthy
- Intention to use an app to
retrieve agronomic advice
- Perceived barriers to adopt
digital tech.
- Perceived pressure to use an
app
- Wanting to receive
information about agriculture
- Experiencing the need to
become digitally connected
Automatic motivation Processes involving emotional reactions, desires (wants/needs), impulses, reflexes

\subsection{Materials and methods}

\subsubsection{Case study}

In order to study User Readiness, we selected a digital extension project (ICT4BXW) led by the International Institute of Tropical Agriculture that operates in Rwanda. Rwanda has a strong national vision for digital extension service delivery (MINAGRI, 2016). The ICT4BXW project aims to use citizen science and ICT to develop 
(cost)effective and scalable tools for advancing the prevention and control of Banana Xanthomonas Wilt (BXW) disease in East and Central Africa (ICT4BXW, 2018). To meet its objectives the project developed and field-tested a smartphone application called 'BXW-App'.

Our study's main focus are smallholder banana farmers in Rwanda for whom banana is a major contributor to food security. Rwanda's banana production system is diverse but overall banana is grown by $90 \%$ of households (Nsabimana et al. 2010) occupying $23 \%$ of cultivated land and contributing $28 \%$ of the country's total crop production (NISR, 2016) and both subsistence and income to smallholder farmers. Banana mats, being perennial, are an important resource in Rwanda's agricultural system and produced across a broad range of agro-ecological zones either as mono- or as intercrop. It provides an array of ecosystem services e.g. supporting soil erosion protection, in addition to food, feed, and fibre (Ocimati et al. 2020; Uwamahoro et al. 2019). The crop additionally has cultural value in Rwandan society. Similar to other staple crops in East and Central Africa, banana production is challenged by issues such as diseases, limited or unequal access to knowledge and information services, limited agronomic knowledge of farmers, and poor market infrastructure (McCampbell et al., 2018; Uwamahoro et al., 2019). These issues threaten food security and provide a disincentive for continued investment in staple crops like banana. Issues like diseases, knowledge and information access and needs are generally addressed through agricultural extension services. In this context a variety of recent extension interventions included the introduction of digital extension technologies (e.g. research led BXW-App, private sector led Viamo 3-2-1 Service (operated as *845\# in Rwanda), and government led Smart Nkunganire). While using a single case study poses limitations in terms of ability to generalize, we believe that the ICT4BXW project provides a good context to further explore the idea of user-readiness in relation to digital extension, especially smartphone-based extension. Recognizing that the findings may not be extrapolated, the insights and lessons derived may offer food for thought beyond Rwanda and banana farming system contexts. 


\subsubsection{Study area and methods}

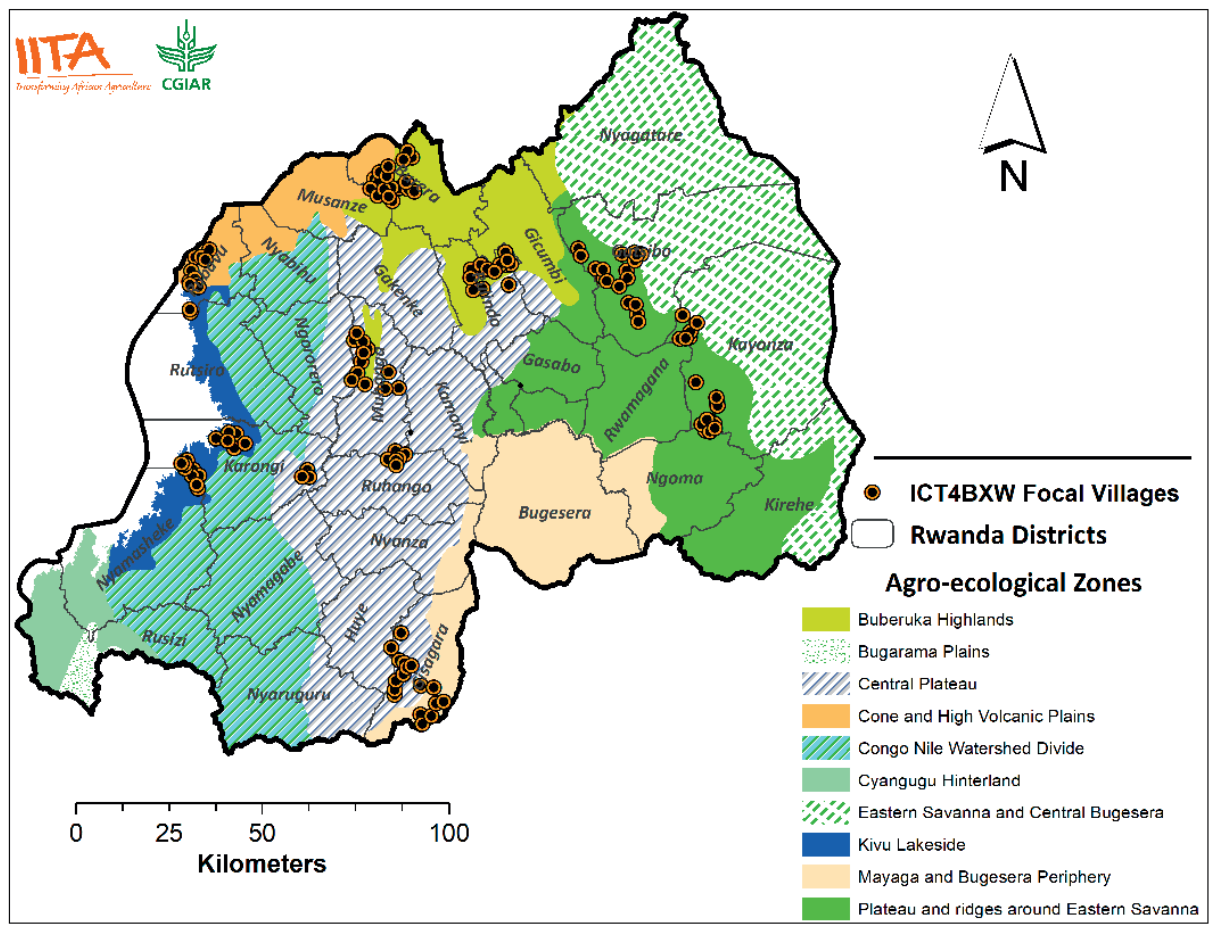

Figure 7: Overview of distribution of focal villages where farmers were surveyed.

We used a mixed methods approach for our study, including qualitative and quantitative data collection. A detailed survey was conducted to collect relevant data from banana farmers $(n=690)$ in 8 districts (Kayonza, Gatsibo, Rulindo, Burera, Rubavu, Karongi, Muhanga, Gisagara) in four provinces in Rwanda (Eastern, Northern, Western, Southern), covering all agro-ecological zones where banana is produced (Figure 7, Table 8). The survey instrument was developed for and deployed on a mobile-based digital platform (using Open Data Kit (ODK) and conducted by enumerators in the local language (Kinyarwanda). The survey included a broad range of topics related to household characteristics, general farming activities; banana production, agronomic practices, and disease management, agricultural extension and communication, and use of ICT (including phones). More specifically, it operationalized the variables of the UR framework as described in Table 7 (see for details appendix 1). Field implementation of the survey was conducted in August 2018 as a part of baseline assessment for the ICT4BXW project. To enrich our understanding of existing information exchange practices, we conducted additional surveys with farmers $(n=40)$ and farmer promoters 
(FPs) $(n=5)$ in two sectors in four villages in Kayonza district. Farmer promoters are government supported volunteers who act as extension agents at village level. Moreover, data was collated from key informant interviews with banana agronomists, stakeholders within the banana extension delivery system, and subject-matter specialists on banana and BXW disease management, in Rwanda $(n=9)$.

Table 8: Overview of respondents in banana farmer survey.

\begin{tabular}{llll} 
Variable & Indicator & $\begin{array}{l}\text { Frequency } \\
(\mathbf{n = 6 9 0 )}\end{array}$ & $\begin{array}{l}\text { Percentage } \\
(\mathbf{\%})\end{array}$ \\
\hline Gender & Male & 413 & 60 \\
& Female & 276 & 40 \\
Age & Unknown & 1 & 0.1 \\
& $16-30$ years & 60 & 9 \\
Head of household & $31-60$ years & 495 & 72 \\
\multirow{4}{*}{ Education } & 60+ years & 135 & 20 \\
& Yes & 132 & 19 \\
& No & 558 & 81 \\
& No education & 123 & 18 \\
& Primary school & 466 & 68 \\
& Lower secondary school & 71 & 10 \\
& Upper secondary general & 21 & 3 \\
District & Upper secondary technical & 1 & 0.1 \\
& Upper secondary teaching & 3 & 0.4 \\
& University Bachelor & 3 & 0.4 \\
& University Master & 2 & 0.3 \\
& Kayonza & 90 & 13 \\
& Gatsibo & 90 & 13 \\
& Rulindo & 90 & 13 \\
& Burera & 90 & 13 \\
& Rubavu & 60 & 9 \\
Karongi & 90 & 13 \\
Muhanga & 90 & 13 \\
& Gisagara & 90 & 13 \\
& & &
\end{tabular}

\subsubsection{Sampling strategy}

Districts were selected in consultation with extension delivery officers from Rwanda's Agriculture and Animal Resources Board (RAB), and with reference to data from a countrywide BXW assessment which was conducted by RAB in 2017-2018. The two selection criteria include, 1) Diversity across Rwanda's agro-ecological zones to ensure representativeness of all major banana producing zones, and 2) Different banana production typologies, to ensure that the districts represented production diversity. 
Chapter 3

Purposive sampling was conducted from 9 strata of villages that were grouped based on two criteria: (1) distance between village and district office based on a three-point scale (short, medium, large). Where distance was a weighted measurement based on true road distance and road pavement type; (2) BXW incidence severity (low, medium, high) which was determined based on reports from sector and cell agronomists together with real-time expert observations at the time of sampling. Two villages were selected from each stratum thereby considering a third criterium: Distance between villages. There had to be either a minimum distance of $5 \mathrm{~km}$ between sampled villages or a non-sampled village in between two sampled villages. This resulted in 18 selected villages for every district, except for Rubavu $(n=12)$ where no villages were sampled in the large distance strata due to absence of banana production in those areas. In each sampled village, 5 farmers from five different households were surveyed, 3 males and 2 females. Men were always surveyed by male enumerators, and women by female enumerators. Households were selected randomly, however respondents could not be neighbours.

\subsubsection{Data analysis: assessment of ex-ante User Readiness}

Robust inference of User Readiness was generated by sub-dividing the COM components in the UR framework and mapping relevant independent variables to each sub-component. The inherent value of this approach is that it offers the flexibility to incorporate as many pertinent variables as possible, to robustly and reliably quantify user readiness at individual levels, within groups, and across groups.

Mathematically this looks as follows:

$$
U R=f(\text { Capability }(a \mid b) * \text { Opportunity }(a \mid b) * \text { Motivation }(a \mid b)) \ldots \ldots . \text { Equa. } 1 a
$$

$$
U R=f\left(\text { Cphy }^{*} \text { Cpsy }^{*} \text { Mref }^{*} \text { Maut }{ }^{*} \text { Ophy }{ }^{*} \text { Osoc }\right)
$$

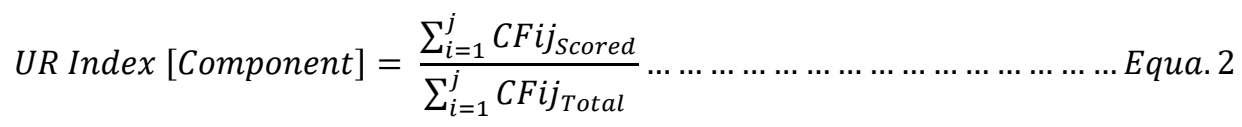

UR Index $[$ Overall $]=\sum_{n=1}^{n=j} \frac{\left(\text { TUR Index }\left[\text { Component }_{i j}\right)\right.}{n} * 100 \ldots \ldots \ldots \ldots \ldots$ Equa. 3

Where, alb denotes the partitioning of each core UR sub-component, is the score for each component factor (CF) based on the respondent's answer. is the total attainable score across the CFs within each component; Cphyis the physical capability, Cpsyis the 
psychological capability, Mrefis the reflective motivation, Maut is automatic motivation, Ophy is physical opportunity, and Osoc is social opportunity. Binary scores (0 or 1 ) were assigned to each of the 690 respondents based on their response to the questions/variables in Appendix $1{ }^{18,19}$. To avoid bias in the UR-index as a result of differences in the number of variables (ranging from 8 - 30 variables per framework sub-component) included in the framework we applied stepwise rescaling of the individual scores (by assigning equalizing weights to components). This resulted in an aggregated score for each COM component for each respondent, which was then rescaled based on relative weight for each category. Subsequently, we added the overall rescaled value to derive a continuous value of $0-1$, indicating the overall ex-ante User Readiness score per respondent. To determine the relative UR score of the sampled population, the overall respondent scores (5 classes) were reclassified and calculated based on the number of respondents in each class. Figure 1 shows a schematic representation of the theoretical optimum, where scores are closer to 1 for each of the components and a balance exists between capability, motivation, and opportunity scores.

\subsection{Results}

\subsubsection{Overall ex-ante User Readiness}

The rescaled scores for the various components of the UR framework (Figure 8) show that most of the banana farmers surveyed are limited in their physical capability, psychological capability, and physical opportunity, with average scores of $0.22,0.21$, and 0.32 respectively (with a value range between $0-1,1$ being optimum score). Approximately $85 \%$ of the respondents scored below the 0.3 in their physical capability and psychological capability, while a similar number of farmers scored less than 0.4 in their physical opportunity. In contrast, the majority of the respondents had high automatic motivation and social opportunity, with $85 \%$ and $70 \%$ respectively scoring greater than 0.7 .

\footnotetext{
${ }^{18}$ We assume that missing/incomplete responses (i.e. n/a) imply the worst/negative value.

${ }^{19}$ Note that Automatic Motivation has an inverted value of " 0 " for True and " 1 " for False because all of the variables are assessing ICT barrier
} 


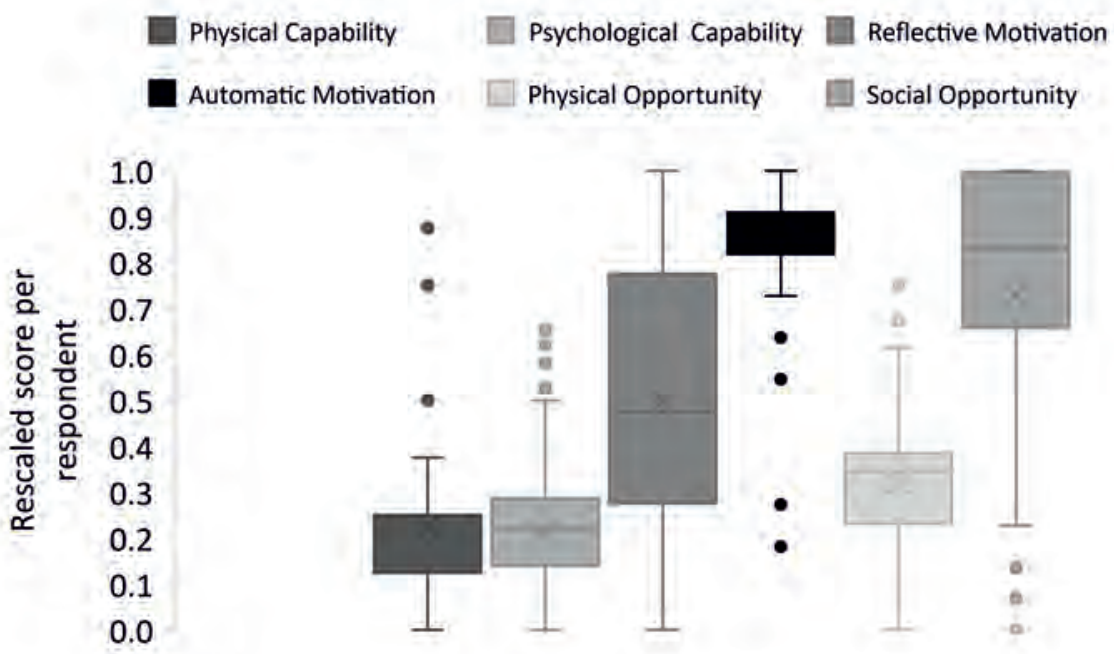

Figure 8: Calculated scores for framework sub-components among farmers based on responses to multivariate survey. The " $x$ " symbol shows the mean score.

The aggregated and standardized UR score across the sub-components show that majority of the respondents (82\%) scored between 30-60\% (Figure 9), and there was a gradual decline of the scores with the age of the respondents. Both male and female respondents are comparable in their overall UR scores, and we found no significant difference when disaggregating different age categories. Generally, the average UR score $(44.6 \%)$ was close to the median $(46.1 \%)$, with a tendency for respondents to attain lower score ranges (skewness $=-0.58$ ).

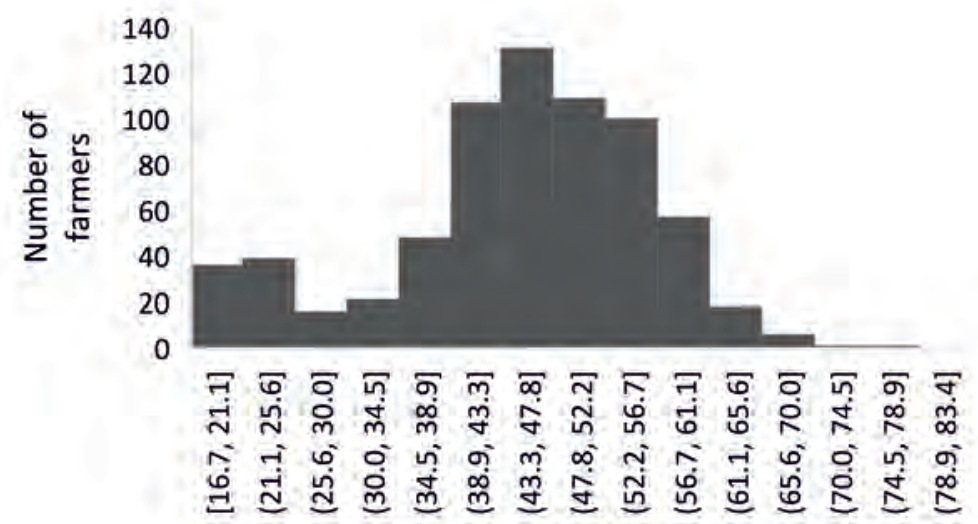

\section{Calculated UR score}

Figure 9: Distribution of ex-ante User Readiness (UR) scores of banana farmers in Rwanda. 
Further comparison of the sub-components based on selected demographic factors indicates that similar limitations characterize the respondents, notwithstanding gender, location, education, and age group (figures 10a-d). Although there is no gender-related disparity in the average scores of respondents across the sub-components (figure 10a), there are differences between studied districts, especially based on the social opportunity and reflective motivation (figure 10b). Further, the disparity gap is wider in the social opportunity and psychological capability relative to the educational level of the respondents, with farmers who had university education scoring over 10 times higher in both sub-components when compared to those who did not attend school (figure 10c). The disaggregation by age (figure 10d) showed that respondents all have high automatic motivation, but major differences are observable in their reflective motivation and social opportunity where the younger age ranges (e.g. 20-30 year olds) scored significantly higher (>50\%) than the older age ranges (e.g. $>70$ year olds).

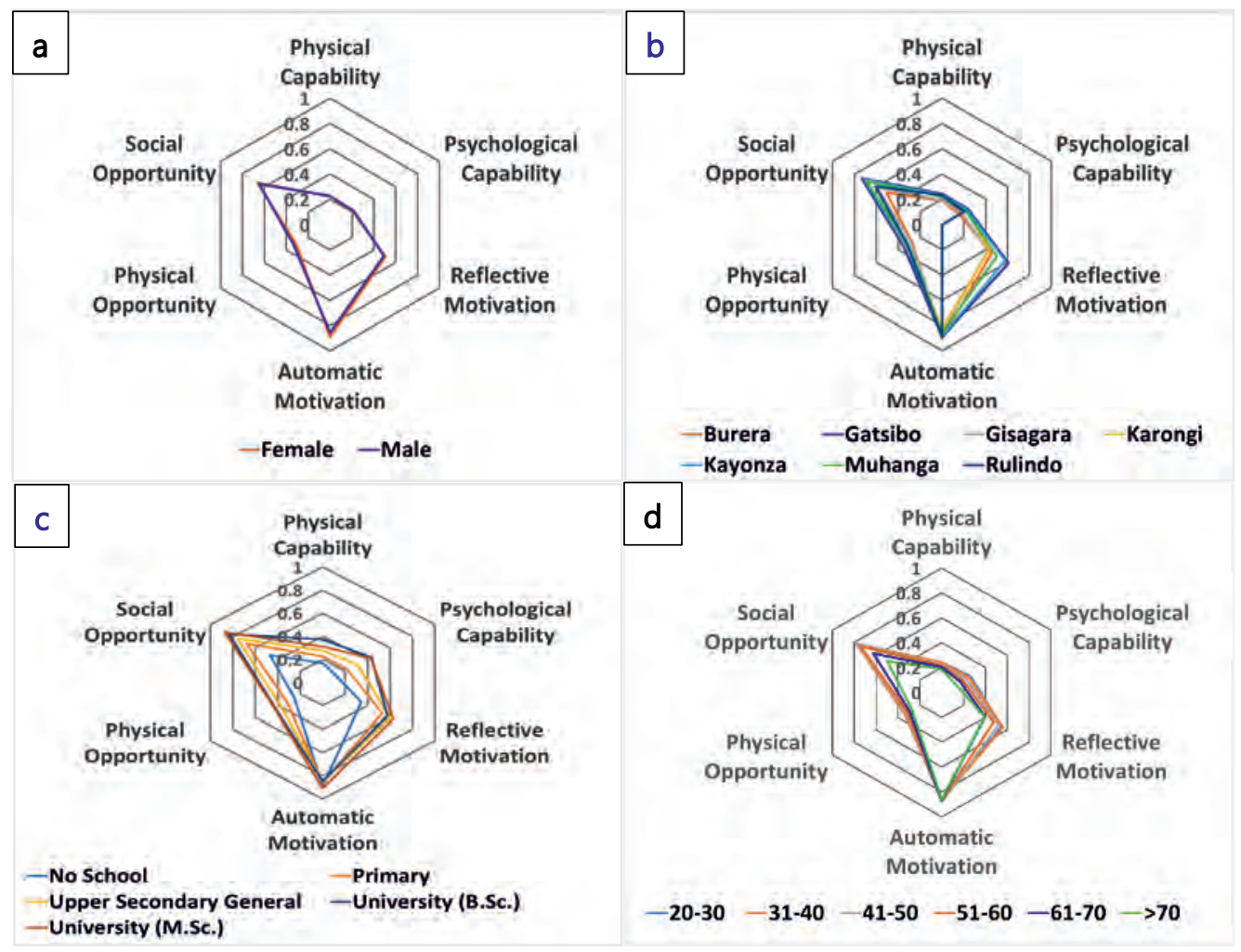

Figure 10: Average disaggregated scores for sub-components of Ex-ante User Readiness among banana farmers in Rwanda, based on gender (a), location (b), education level (c), and age group (d). 


\subsubsection{Zooming in on User Readiness variables related to digital technology access, ownership, and digital competency}

The use of ICT devices among surveyed farmers is prevalent, with approximately $80 \%$ of the respondents indicating that they have used at least one of the common devices (basic-, smartphones, radio, tv, laptop, tablet, or personal computer). Among the respondents, 4 out of every 5 farmers have used or owned basic phones and radios (67\% and $71 \%$ ownership for women and men respectively), very few (1 out of 10 farmers) have either used or owned a computer, smartphone, or feature phones. 1 out of 10 farmers also indicated that they neither own nor use any device:12\% women and $13 \%$ women do not own any ICT device (see also Figure 11). Further disaggregation of device ownership and use by gender and age indicated similarity between both male and female farmers for most devices, while younger farmers $(<45$ years old) own and use ICT devices more than older (>45years old) farmers. Thus, generally, the access and use of digital devices is limited to radio and basic phones, while about 1 out of 5 farmers indicated that they neither own nor use mobile phones. Although basic phone ownership and use among men is higher (78\%) than among women (62\%), both genders report similar (negligible) ownership of smartphones (3\%). Similarly, $37 \%$ of the female respondents noted that they do not have access to any type of phone, in contrast to $21 \%$ among men. These results especially affect the opportunity and capability scores. The low uptake of smartphones obviously impacts user readiness score for smartphone-based extension

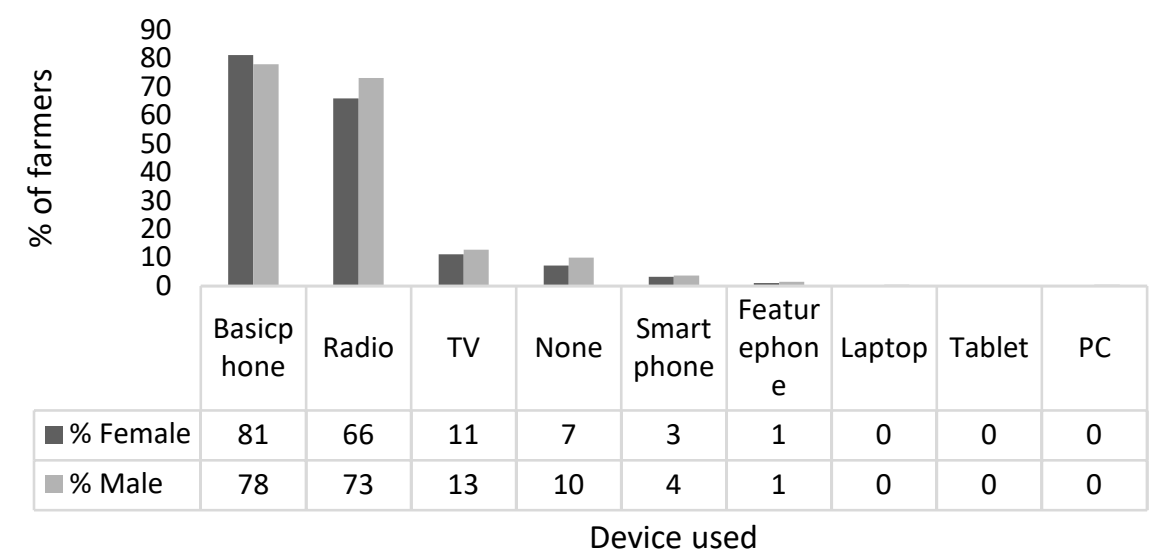

Figure 11: Digital devices that are regularly (at least once per 30 days) used by respondents. Total $n$ of sample $=690$. 


\subsubsection{Internet access and cellular services}

Our survey data showed that use of internet and internet-based services among banana farmers is very low, with less than $10 \%$ of respondents indicating that they have ever accessed internet (on their phones). This affects readiness for digital services requiring a data connection. Like phone ownership, a gender disparity exists with at least 8 out of every 10 internet users being men. Younger farmers have accessed the internet more than older ones, with $78 \%$ of respondents who have accessed internet on their phones being 50 years or younger. Almost $50 \%$ of the surveyed farmers who can access a mobile phone use it to call or use SMS at least once a day, however this is more common among the younger farmers with steady decline of usage among farmers who are older than 40 years (Figure 12). A substantial number of, especially older, farmers rarely or never make calls.

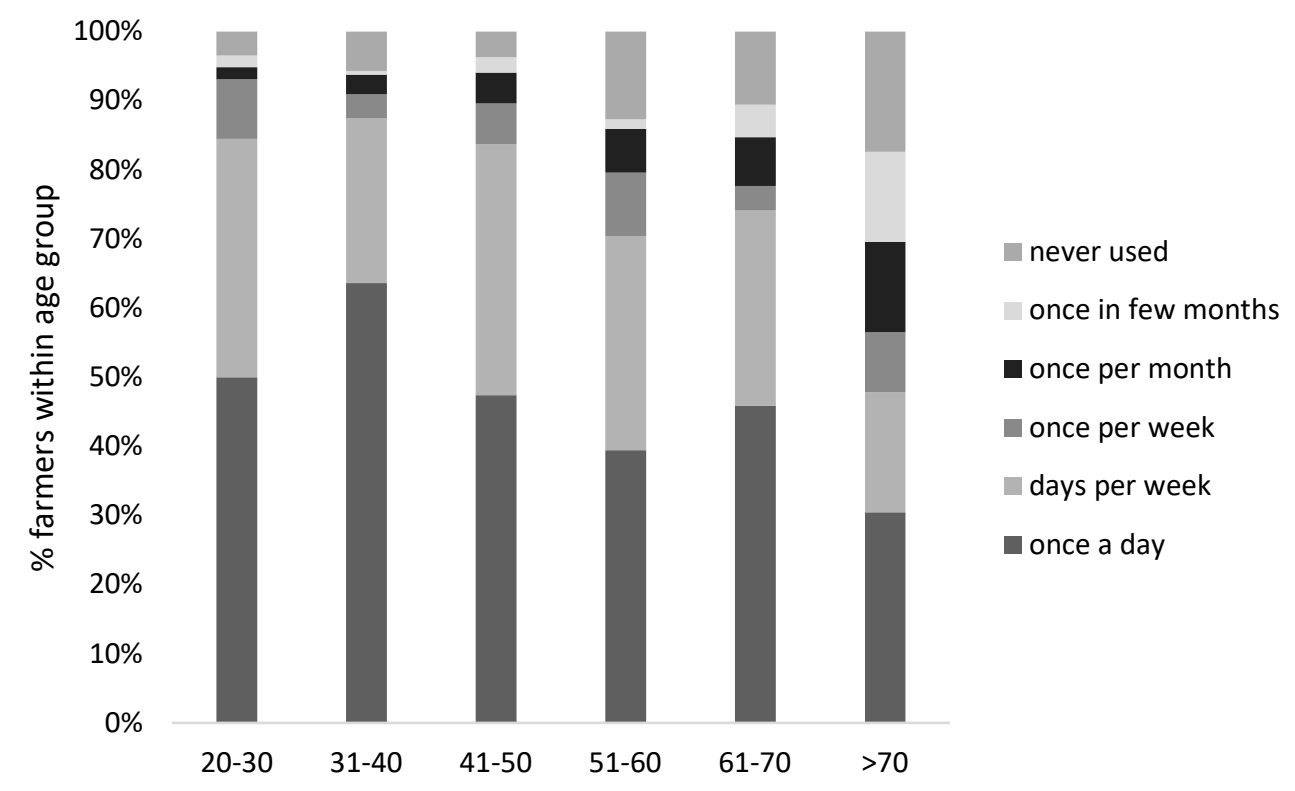

Figure 12: Phone usage for calls among surveyed banana farmers in Rwanda with access to a phone ( $n=619)$

Based on above results it appears that various demographic characteristics are linked to user readiness, suggesting that beyond addressing male-female gaps focus should be on developing farmer-focused interventions that facilitate equitable access to (basic) digital tools and extension services for diverse farmers. For example the most observable gender-related difference in UR-index (34\% in female and 39\% in male) is 
Chapter 3

associated with respondents aged 70 years and above (Figure 12). This finding can also be linked to the overall decline in UR with age. Results suggest that without additional capacity development equitable use and scaling of digital extension services, like the app developed by the ICT4BXW project, may only be achieved for a sub-group of farmers (in this case younger (male) users, mainly in the age range of 20-40 years).

\subsection{Discussion}

The aim of this study was to explore how ex-ante assessment of user readiness and use context can contribute useful insights that provide input for the development of digital extension services. We presented the UR-framework as an approach to assess current capacity of African farmers to adopt and use digital extension technologies and tools. Applying the framework for the case of smallholder banana farmers in Rwanda, we looked at the current capabilities, opportunities, and motivations of farmers. This study unravels important elements that impact readiness to adopt and use phonebased extension services, as more and more digital agricultural services are being developed and offered to African smallholder farmers.

\subsubsection{User readiness in view of the digital extension services that are developed: matches and mismatches}

The overall UR-index calculation provides a basis to understand and compare the readiness of each farmer as a potential user of digital tools/technologies for farmlevel decision-support. Most of the surveyed farmers scored low on the UR-index (modal score $=40-58 \%$ ), indicating moderate levels of readiness of the target farmers as users of digital extension services like the one developed by the ICT4BXW project for diagnostics and surveillance of BXW disease and advisory about control measures. The exploration of sub-components associated with capacity, opportunity, and motivation of the farmers provides an enriching understanding of nuanced aspects of user-readiness and adoption. For instance, at least 4 out of every 5 respondents scored $>80 \%$ in their "automatic motivation", yet, less than 2 out of every 5 scored above $50 \%$ in their individual readiness score. It was noteworthy that other sub-components (mainly those associated with opportunity and capability) had a draw-down effect on the overall readiness scores, notwithstanding the demographic of the users. The limited readiness of farmers suggests that large-scale adoption of digital extension services may not be easily achieved, particularly services that utilize advanced technologies such as smartphones. Assessing the user-readiness offers valuable information that can 
guide realistic expectations regarding the likelihood of adoption and ease of scaling among target users of a phone-based extension service.

Considering the results from this study and the type of digital extension services that are currently being developed, there is a strong basis to conclude that there is a major mismatch between the readiness of technology and the readiness of the users. Earlystage service providers often adopt low-tech tools that require functionalities on basic mobile phones, such as Short Message Service (SMS) and Unstructured Supplementary Service Data (USSD) e.g. ESOKO, M-Farm (Baumüller, 2018). Our study supports the notion that these services match the current reality and readiness of farmers in Rwanda. However, advanced digital technologies like smartphones or Internet, which are considered relatively mainstream in high-income countries and by African urban elite, remain out of reach of the majority living in rural areas in Rwanda and other developing countries (Deichmann, Goyal, \& Mishra, 2016; Mehrabi et al., 2020; Munthali, 2021). Yet, digital extension services are becoming increasingly sophisticated, including BXW-App, PlantVillage NURU (Mrisho et al., 2020), requiring phone functionalities and processing power that is only accessible in 'smart' devices. Our findings suggest that this outpaces current readiness of the users, especially relative to the opportunity and capability subcomponents, and points to a growing mismatch between the emerging digital technologies/services and the field level reality of the target users. The type of mismatch observed in Rwanda may be the result of ambitious expectations of designers, technology developers, and (project) implementing parties, combined with initial terseness of data regarding the contextual realities of the farmers. However, it appears that users who are young and educated are more promising as potential early adopters of digital tools, based on their high scores on subcomponents such as social opportunity and reflective motivation. Therefore, this cluster of users can be targeted as entry point for introducing new/advanced digital tools for adoption to accelerate development and improve livelihoods.

Further, donors continue to pursue the aspiration to introduce ever more sophisticated technologies to smallholder farming systems, e.g. Unmanned Aerial Vehicle (UAV), Artificial Intelligence (Al), blockchain. Arguably, the introduction of digital technologies that are too complex and too difficult to access, given the capacity of targeted users, is reflective of the hyped and competitive digital agriculture field, and the continuing technocentric focus in digital agriculture. This is problematic because the acceptance of new technologies is generally tied to both people's willingness and capacity to adopt 
Chapter 3

(Baumüller, 2018; Minh, Friederichsen, Neef, \& Hoffmann, 2014; Swanson, 2008). In the context of agricultural interventions in developing countries, the failure of an introduced technology due to non- or de-adoption is regularly blamed on the mindset of farmers (Murray, 2000). However, our research indicates that besides mindset, or willingness (which relate to automatic and reflexive motivations), there are a range of other dimensions that may erode people's capacity to accept a new digital technology. The method we applied brings those dimensions to light and allows for a more holistic and systematic reflection on the process of technology acceptance (or rejection). Our findings align with previous research which argues that human development (i.e. enhancing people's economic, informational, or social capabilities) rather than the ICT technology itself should be the central focus when designing and evaluating digital programs (Gigler, 2011).

\subsubsection{The mixed bag reality of digital device ownership and use}

Generally, digital device ownership or access is considered indispensable for delivery of digital content and advisory services to farmers, and this is often used as the sole benchmark for assessing digital connectivity (and divides) along rural-urban gradients, age classes, gender-classification, or socio-economic status (Trendov et al., 2019; Agyekumhene et al., 2020). Our case study results, however, show a strong contrast between near-universal access of farmers to some digital devices (radio and basic phone) on the one hand, and very poor access to other devices (such as laptops, smartphones, tablets etc.) on the other hand. For example, 75\% of our respondents reported possession of a mobile phone, but only 3\% own a smartphone. This not only indicates sub-optimal physical opportunities for users, but also that sheer penetration of mobile phones may not simply be construed as a sign of readiness for adoption of all phone-based extension services among farmers. This finding is important given that phone-based extension services targeting African farmers are increasingly deployed on smartphones (Tsan et al., 2019), with the nascent expectation of existing or rapidly emerging universal access and capability to use them. Even though farmers' possession of smartphones will almost inevitably increase, this does not guarantee overall improvement of user readiness towards optimal readiness. A relatively equitable possession of some digital devices (e.g. radio and basic or smart phones) could deceivably suggest that farmers are also well-positioned to adopt digital extension services. Although ownership of a device increases physical opportunity and psychological capability, it may not enhance the other opportunity, capability, and 
motivation factors. These together determine a user's overall capacity, and capacity in turn has been shown to affect adoption (Ayim et al., 2020; Kyobe, 2011). Thus, capacity is the sum of many factors. Some (powerful) actors in the agricultural value chain may want to protect or increase their own informational or (economic) advantages (Ayre et al., 2019; Jakku et al., 2019) possibly by obstructing the opportunities, capabilities, and motivations of others. Additional concerns for the adoption of existing or emerging digital extension services arise from the gender digital divide that we found for phone ownership and the inequal user readiness for different user groups. This shows similarity to other studies which identified farmers' education to be influential for adoption and use of digital technologies (Salemink, Strijker, \& Bosworth, 2017), age and education as determinants of smartphone adoption among German farmers (Michels et al., 2020) and age and smartphone experience as moderating factors of the performance expectancy by potential users of digital health applications (Nunes, Limpo, \& Castro, 2019). Based on these findings we argue that developers of digital interventions and services aiming to be inclusive should be especially considerate of user groups with the lowest user readiness. Within the scope of this article we explored variations in user readiness of four only four variables representing different user groups (education level, age group, gender, and geographic location), there are numerous other variables that could be considered in follow up research (e.g. income group, type of crop production system, farm size). Similarly, closer analysis of sub-component scores could be relevant to identify which (combinations of) sub-components drive the readiness index score.

Lastly, the use of radio as a means of receiving one-way communication from trusted media outlets is common among farmers still to date. Previous studies similarly found radios to be important for information provision in rural communities (Sulaiman et al., 2012; Zanello, 2012) suggesting that radio should not yet be disregarded for rapid information dissemination about agricultural challenges like BXW disease. Embedding digital technologies into existing practices and creating blends of 'digital' and 'analogue' (Burton \& Riley, 2018; Munthali, van Paassen, Lie, Leeuwis, \& van Lammeren, 2021) may be recommended especially when digital divides are a reality. A mix of new and existing practices and skills would currently respond better to needs and capacity of a larger group of users, thus improving the potential scale and impact of agricultural extension. This way, farmers who cannot (yet) access mobile phones or have low user readiness are given an opportunity to catch-up and potentially leapfrog to a more technologically advanced level (Alzouma, 2005). This would reduce the chance that 
Chapter 3

digitalization exacerbates rather than reduces inequality in agricultural development, as risk noted by (Cibangu, 2019; Trendov et al., 2019).

\subsubsection{Benefits and methodological reflections arising from the User Readiness framework}

The User Readiness framework helped to understand the major perceptions and realities of targeted users in the case study geography and highlight relevant differences related to gender and age gradients among the respondents. Beyond providing understanding of user readiness, the UR-index and individual (sub)components provide diagnostic insights about individual or collective readiness and can support the identification of appropriate interventions to improve user readiness. In alignment with Benson (2019), this UR-framework presents an ex-ante analytical approach to assess user readiness based on existing practices. Therefore, the framework may assist developers of digital extension services at the early stages of identifying the targeted users that are ready to adopt and use an envisioned digital innovation, and those who require some form of help or an alternative technology. Beyond helping with designing best-fit digital extension services, the framework supports a priori knowledge about potential adoption and outlook for scaling impacts. In this article, we applied the framework with an interest in assessing user readiness for services that require smartphone functionalities, but we are confident that the framework is equally applicable in cases of digital technologies that are more, or less, advanced. The UR-framework contributes an ex-ante, quantitative method to assess user readiness, makes a contribution to understanding the user side of digital development, and adds to an emerging body of literature that unravels what drives successful digital innovation in the agricultural sector focusing on different angles (Birner et al., 2021; Fielke et al., 2021; Parra-López et al., 2021).

We recognize three methodological limitations or concerns related to the URframework. Firstly, underlying deficiencies of one or more sub-component(s) may be masked once outcomes for sub-components are aggregated. For instance, a low(er) score on motivation may be compensated by a high(er) score on capability. Yet, the technology users (farmers) cannot attain optimal readiness to use the digital tool/technology without meeting the thresholds within each sub-component. This became evident in our case study results: Although the majority (>75\%) of the respondents had a high social opportunity and automatic motivation score $(>0.75)$ the 
maximum total UR score attained did not exceed 60\%. A high intrinsic motivation score may be a good indicator for acceptance of a digital technology but, in practice, the high score may be irrelevant if the same individual has low psychological capability to use the technology. Motivation alone is not enough for successful adoption and use yet could stimulate users to increase their capabilities. Here we follow the logic proposed by Sartas et al. (2020) who argued that specific bottlenecks (i.e. lowest scoring components) must be addressed before a user can be considered as ready to adopt a target innovation. Additionally, the lowest scoring components should inform necessary interventions to increase the likelihood of sustainable technology adoption. A second methodological limitation relates to possible biases and interviewer effects. People may tend to overemphasize their needs, demands, and willingness to accept technologies when asked about this in a survey. This may relate to respondent's general curiosity about new objects and technologies (Ainembabazi \& Mugisha, 2014), and/or the expectation that giving a positive response will satisfy the interviewer or may lead to a higher likelihood of some in-kind or financial benefit for the interviewee. The latter is a known phenomenon in the context of rural interviewees who have a vested interest to gain from participating in a study (Triomphe et al., 2013). Inflated survey results for one or more (sub)-component may result in an inflated UR-index score, or vice versa if results are deflated, negatively affecting reliability. Also, the selection of variables was guided by the extant needs within the ICT4BXW project and those regularly highlighted as important drivers of adoption and capacity (Ali, 2012; Michels, Bonke, \& Musshoff, 2019; Salemink et al., 2017), so alternative information sources or variables (which could influence farmers' motivation) were not explored or included in the framework.

Lastly, although we looked at contextual realities and how they influence individual user readiness, a limitation of our study and the UR-framework in its current form may be the dominant focus on individual or household level user readiness. This ignores that social interdependencies, social capital, and trust often play a critical role in a user's decision to accept a technology (Joffre, De Vries, Klerkx, \& Poortvliet, 2020; B. King, Fielke, Bayne, Klerkx, \& Nettle, 2019), rendering adoption as a collective rather than an individual process ( Leeuwis and Aarts, 2020). Follow up studies could explore how the influence of interaction and interdependencies between individuals and groups of individuals affects user readiness and interplays with technology and system readiness. 


\subsection{Conclusions and recommendations}

This study aimed to explore current user readiness of African farmers to adopt and use digital extension services, specifically the increasingly popular services that require smartphone functionalities. We presented the User Readiness framework as an ex-ante method to early-on assess user readiness based on capabilities, opportunities, and motivations of targeted users. The User Readiness framework was tested with a case study using data from 690 Rwandan banana farmers. Our case study findings demonstrate a mismatch between expected and realistic user readiness, especially regarding the current capabilities and opportunities of Rwandan farmers. Case study results confirm previous research that observed a need for both institutional innovation and building of local digital capacity. Findings show that ex-ante assessment of user readiness yields relevant entry-points for designing suitable digital extension projects and interventions, which may need to be less advanced than what is technologically possible.

We conclude that the User Readiness framework can provide insights regarding the capacity and needs of technology users and the context in which a digital extension service will be used. The framework complements existing readiness frameworks and ex-post methods to analyse intervention success. In contrast with technology or scaling readiness, it takes the user and his or her context rather than the technology as starting point. We believe that looking at technology, system, and user readiness and finding a sustainable balance between them is critical for digital agriculture to have positive impact in the Global South. Insights from user readiness assessments can be translated to design requirements and be used as an input for user-centred design processes. Thus, the User Readiness framework can support informed strategizing and decisionmaking about digital extension services. We recommend that developers adopt our exante approach to explore user readiness before developing a new digital extension intervention for African smallholder farmers. Although this study only looked at current readiness, using data at one particular point in time, we recommend further research into the application of the UR-framework as a longitudinal assessment method that scientists and development practitioners can use to monitor the readiness of target users in relation to specific digital technologies over time. 


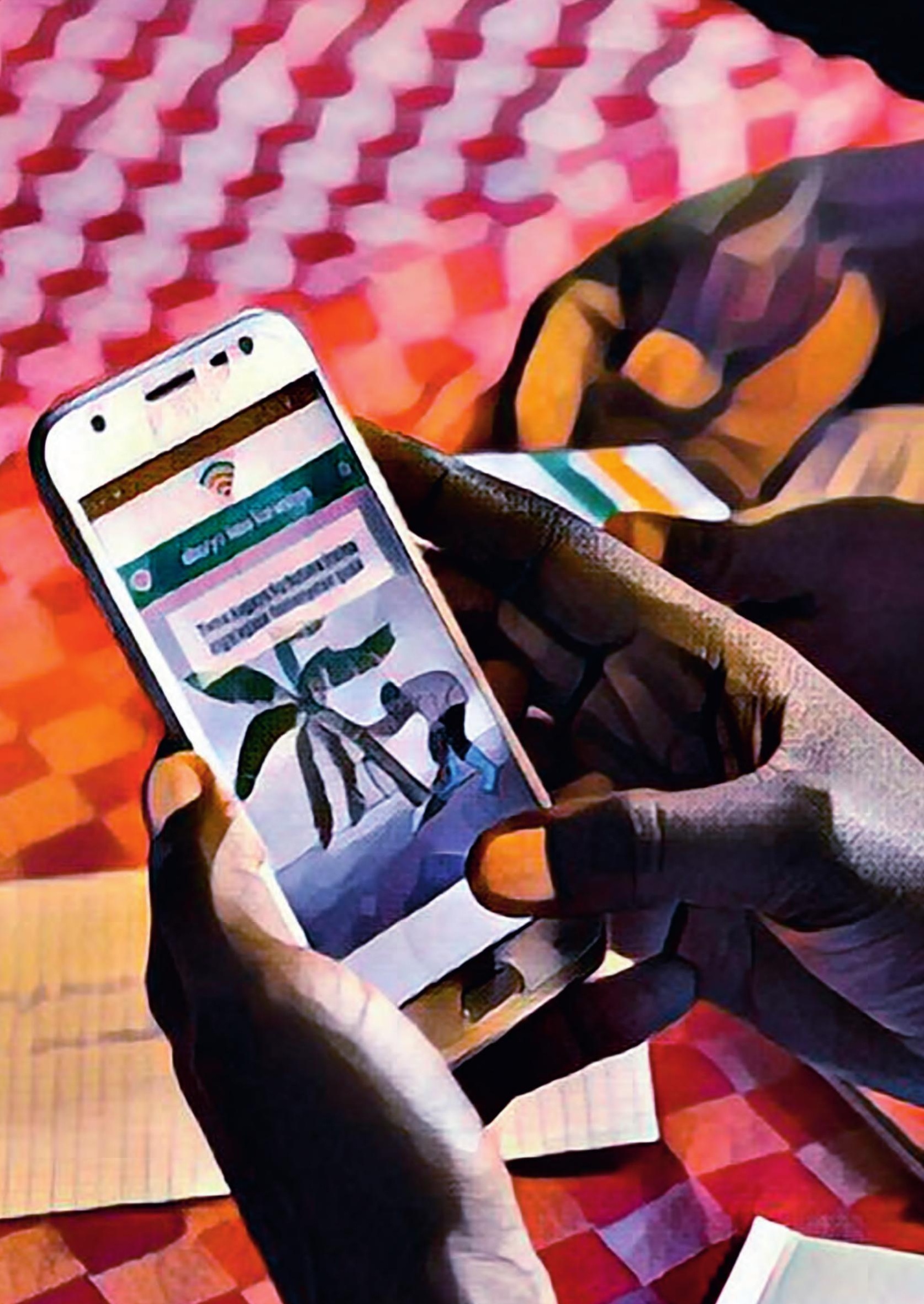




$$
\text { (a)) }
$$




\section{Good intentions in complex realities}

Challenges for designing responsibly in digital agriculture in low-income countries 


\section{Abstract}

Human-Centred Design (HCD) approaches are adopted to develop digital agriculture interventions inclusively and responsibly. Whether these approaches indeed lead to responsible designs remains unclear, especially for Low-Income Countries. Using a Rwandan case study, we contribute to debates on inclusion, technology shaping, and responsible design, studying the process of designing a digital agriculture intervention for banana disease management. The four dimensions (inclusion, anticipation, reflexivity, responsiveness) of responsible innovation and digital rights served as analytical lenses. Findings show that power relations and digital capacity negatively affect user inclusivity in design. The context in which HCD is deployed hinders anticipation, reflexivity, and responsiveness, resulting in design decisions that do not fully respect digital rights and potentially irresponsible digital technologies. Broader, long-term consequences of digital technologies should be a central consideration in design processes, while responsible innovation theory needs to become cognizant of the complex realities in which digital innovations emerge.

Chapter under review as: McCampbell, M., Schumann, C., and Klerkx, L., Good intentions in complex realities: Challenges for designing responsibly in digital agriculture in low-income countries. 


\subsection{Introduction}

Today's omnipresence of digital technologies renders into a gold rush for a share in the global digital economy (MacFeely, 2019; Tabesh, Mousavidin, \& Hasani, 2019). Digital, data-generating, technologies are a pillar of the fourth agricultural revolution, or Agriculture 4.0 (Klerkx \& Rose, 2020; David Rose \& Chilvers, 2018) with expectations that these technologies may contribute to the transformation of agricultural systems in developing countries (Barrett, 2020; Reardon et al., 2019). Discourse about digital agriculture associates it with emergent and game-changing technologies, productivity and environmental benefits (Barrett \& Rose, 2020). LowIncome Countries (LIC) and their agri-food systems present promising markets for the digital technology and agriculture industry (Lanchester, 2017; Trendov et al., 2019) and the number of active digital agriculture interventions in Low and Middle Income Countries increased from 53 in 2009 to over 700 in 2020 (GSMA, 2020). Digital agriculture comprises a whole suite of on-farm and off-farm technologies, such as precision technology, drones, and robotics. Examples include market and financial access tools, registration of farming activities, and agricultural advisory services. (Eastwood et al., 2019; Klerkx et al., 2019; Wolfert et al., 2017). This article looks specifically at tools designed to support documentation, information provision, and decision-making about agricultural (crop)systems.

Few critical studies on digital agriculture focus on LICs (Klerkx et al., 2019) and those assessing ethical and governance challenges and responsible innovation in smart farming concentrate mostly on Western countries (Bronson, 2018, 2019; Rose \& Chilvers, 2018; van der Burg et al., 2019). The influence of digital interventions on knowledge, power dependencies and inequalities, or alterations to rural livelihoods in LICs has largely been ignored (Agyekumhene et al., 2020). This is problematic since farming communities in LICs are specifically vulnerable to potential negative consequences of digital technologies, with less resources to react to changing livelihood conditions (Dearden \& Kleine, 2020). The design of digital agriculture technologies affects smallholder's digital rights, which are a translation of existing principles for protection and realization of human rights to the digital sphere (UN Systems Organizations, 2018; WSIS, 2003).

To counteract negative consequences and attend to digital rights, aspects of power, ethics, and justice should be considered early-on in technology development, and together with stakeholders (Bronson, 2019; Eastwood et al., 2017; Klerkx \& Rose, 2020; 
Rose, Wheeler, Winter, Lobley, \& Chivers, 2021). Human-Centred Design (HCD) approaches like participatory design and co-design (Steen, 2011) respond to the desire to design digital agriculture technologies (in LICs) for the user (Krell et al., 2020) and together with stakeholders (Agyekumhene et al., 2020; Kenny \& Regan, 2021; Steinke et al., 2020). Anticipated product users may get the role of 'expert of his/her experience' and participate extensively in the design process (Sanders \& Stappers, 2008). Participation of stakeholders in designing and implementing digital technologies promises reduced 'design-reality gaps' and designs that are more inclusive, and better fitting with user needs, demands, and interests (Ortiz-Crespo et al., 2020; Steinke et al., 2020). Arguably, an HCD approach supports responsible innovation in digital agriculture although discourse about responsible innovation and HCD approaches have developed in isolation. Individual studies on responsible innovation or HCD are additionally either prescriptive rather than evaluative or without LIC focus (e.g. Eastwood, Ayre, Nettle, \& Dela Rue, 2019; Steinke et al., 2020). This article fills this gap, contributing to debates on inclusion, technology shaping, and responsible design, answering the question 'How do Human-Centred Design approaches deploy responsible innovation in digital agriculture in LICS and attend to smallholder farmers' digital rights?'

Hereafter we conceptualize HCD and responsible innovation and present a digital rights framework for analysing responsibility in design processes. Next, we investigate if the design approach contributed to responsible design and attended to digital rights. Empirical data came from ICT4BXW, a project in Rwanda that developed a smartphoneapplication for banana disease management. This case study provides one example of many digital agriculture interventions in LICS, without the intention to be representative for the entire sector. However, we believe it contributes relevant insights about the practical working of HCD as a responsible design approach and implications of digital agriculture technology in relation to digital rights.

\subsection{Conceptual framework}

\subsubsection{Linking Responsible Innovation and Human-Centred Design}

Designing digital technologies comes with social and ethical responsibilities (van der Burg et al., 2019). This notion of responsibilities receives more attention standing growing recognition of the complexity and interrelatedness of digital technologies and larger digital ecosystems. A technology and what it 'is' or 'does' starts 
by how it was designed (Roeser, 2012) hence questions about conceptualization, design, and use of technologies and their positive or negative impact on societies arise (Jirotka \& Carsten Stahl, 2020) Designs reflect wants, needs, desires, norms and values of its designers (Van den Hoven, Lokhorst, \& Van de Poel, 2012; R. von Schomberg, 2011). Concepts like responsible innovation (R. von Schomberg, 2011) help to think about and take responsible, value-based choices in design processes that anticipate possible consequences of innovations, and build capacity to respond to those consequences. Von Schomberg (2011) defined responsible innovation as: "A transparent, interactive process by which societal actors and innovators become mutually responsive to each other with a view to the (ethical) acceptability, sustainability and societal desirability of the innovation process and its marketable products" (p.9). Stilgoe, Owen, \& Macnaghten (2013) identified four dimensions to responsible innovation: anticipation, inclusion, reflexivity, and responsiveness (AIRR) (Table 9). Responsible innovation has features in common with HCD approaches, like stakeholder participation, empathy for target users and context, and reflexivity on design outputs (Steen, 2012). While designing a new product, designers aim for a balance between user desirability, technological feasibility, and economic viability (Lafond \& Davis, 2016). Three broad phases together form the iterative HCD approach: (1) inspiration (the problem or opportunity for which a solution will be designed is defined and the prospective users are studied); (2) ideation (ideas are generated, developed and tested in rapid, iterative cycles); (3) implementation (further testing and refining of prototypes in a real-life context) (Steinke et al., 2020). Arguably, responsible innovation and HCD are both efforts towards achieving (morally) responsible designs (Roeser, 2012) that protect or realize moral values. In the context of digital agriculture these values are embedded in digital rights, as conceptualized hereafter. 


\section{Chapter 4}

Table 9: Overview of the four dimensions guiding responsible innovation (definitions based on Stilgoe, Owen, \& Macnaghten (2013) and Stilgoe et al., 2013 and Wittrock, Forsberg, Pols, Macnaghten, \& Ludwig, (2021) and their operationalization for an HCD approach.

\section{Dimension Definition Operationalization for HCD}

\begin{tabular}{|c|c|c|}
\hline Inclusion & $\begin{array}{l}\text { Inclusive innovation processes allow } \\
\text { stakeholders with diverging concerns } \\
\text { and perspectives to deliberate and } \\
\text { dialogue }\end{array}$ & $\begin{array}{l}\text { - Including future users in research, } \\
\text { design, decision making, and evaluation } \\
\text { - Addressing social inequalities among } \\
\text { stakeholders to foster meaningful } \\
\text { participation (e.g. access to and } \\
\text { understanding of design process, } \\
\text { project/intervention objectives) } \\
\text { HCD phase: Inspiration, Ideation, } \\
\text { Implementation }\end{array}$ \\
\hline Anticipation & $\begin{array}{l}\text { Defining the possible scenarios for and } \\
\text { consequences of innovations, and } \\
\text { considering concerns regarding these } \\
\text { consequences }\end{array}$ & $\begin{array}{l}\text { - Defining who is responsible for } \\
\text { anticipation, when, and with whom } \\
\text { present } \\
\text { - Envisioning and understanding possible } \\
\text { consequences of digital innovation with } \\
\text { stakeholders and outlining affected } \\
\text { moral-values and rights } \\
\text { - Actively anticipating possible effects } \\
\text { beyond piloting } \\
\text { HCD phase: Inspiration, Ideation, } \\
\text { Implementation }\end{array}$ \\
\hline Reflexivity & $\begin{array}{l}\text { Reflecting on activities, commitments, } \\
\text { and assumptions that shape science, } \\
\text { innovation and governance. This } \\
\text { includes the individual capacity to call } \\
\text { into question processes and results of } \\
\text { innovations }\end{array}$ & $\begin{array}{l}\text { - Making reflexivity a planned activity in } \\
\text { the timeline of the HCD process } \\
\text { - Aiming at equal capacity and } \\
\text { opportunity of all stakeholders (incl. e.g. } \\
\text { vulnerable, illiterate) to reflect on } \\
\text { assumptions and consequences of the } \\
\text { design process } \\
\text { HCD phase: Ideation, Implementation }\end{array}$ \\
\hline Responsiveness & $\begin{array}{l}\text { Changing the shape or direction of } \\
\text { digital design or intervention in response } \\
\text { to demands or values of stakeholders, } \\
\text { society, or the enabling environment } \\
\text { change, new insights etc. }\end{array}$ & $\begin{array}{l}\text { - Ensuring the means for iteration and } \\
\text { design/intervention adaptations pending } \\
\text { new insights or changes in the } \\
\text { environment (e.g. in flexible timelines } \\
\text { and budgets) } \\
\text { - Defining the scope of responsiveness - } \\
\text { what can realistically be addressed given } \\
\text { project limitations? (expectation } \\
\text { management) } \\
\text { HCD phase: Ideation, Implementation }\end{array}$ \\
\hline
\end{tabular}

\subsection{Digital rights in agriculture in LICs}

Digital rights have received considerable attention in Western settings (e.g. Australia and Europe (van der Burg, Wiseman, \& Krkeljas, 2020; Wiseman, Sanderson, Zhang, \& Jakku, 2019). Similar debates emerge for LICs, e.g. in Africa (Ayamga, 
Tekinerdogan, Kassahun, \& Rambaldi, 2020). International actors increasingly formulate guidelines and policies for digital development at global, international or organisational level, practically translating existing principles for protection and realization of human rights to the digital sphere (UN Systems Organizations, 2018; WSIS, 2003). Historically, digital rights entailed mostly the right to access (the internet), denouncing what is often referred to as the digital divide (Hernández, Earle, \& Fredlund, 2020): The gaps between the Global North and Global South, urban and rural areas, and in accessing infrastructure. Later, the digital divide concept became separated in first and second level digital divide, the former describing access to infrastructure and availability of hardware and (internet) connectivity, the latter referring to questions of digital literacy i.e. skills to operate hardware (e.g. smartphone) and software (e.g. browsing the Internet) (van Deursen \& Solis Andrade, 2018).

Digital rights mostly exist in guidelines, company policies or handbooks, while legal regulations are sparse (Wiseman, Pesce, et al., 2019) and focus on protection of the right to privacy and data security of users regarding processing of personal data on national or transnational level (e.g. GDPR in the European Union, Kenyan Data Protection Act). Hence, the ethical landscape is fragmented, occupied by voluntary standards (e.g. the FAIR Principles (Go FAIR Initiative, 2016; Wilkinson et al., 2016); Principles for Digital Development (Digital Impact Alliance, n.d.) and technical guidelines (e.g. Building for Billions (Google Developers, n.d.). A review of existing guidelines and policies resulted in a framework that informed our analysis (Table 10, see also appendix 2 for more details).

Table 10: Overview of commonly defined digital rights based on analysis of existing guidelines and policies.

\begin{tabular}{ll} 
Digital right & Definition \\
\hline $\begin{array}{l}\text { General digital rights } \\
\text { Access to }\end{array}$ & $\begin{array}{l}\text { The right of every human to } \\
\text { information } \\
\text { the services provided online in } \\
\text { an accessible language } \\
\text { Free expression }\end{array}$ \\
$\begin{array}{l}\text { Right to express oneself } \\
\text { without censorship or fear of } \\
\text { persecution based on reported } \\
\text { information or online activities }\end{array}$ \\
$\begin{array}{l}\text { Protection of personal (and } \\
\text { privacy }\end{array}$ & $\begin{array}{l}\text { non-personal or farm) data and } \\
\text { information provided by } \\
\text { individuals }\end{array}$
\end{tabular}
Guidelines and policies referring to it

GODAN Best Practices; IRPC Internet Rights and Principles; WSIS declaration

IRPC Internet Rights and Principles

All legal regulations + EU Code on

Agricultural Data Sharing; USAID Policy; Oxfam Policy; CGIAR Guidelines; UNDG Guidance Note; UN Personal Data Protection and Privacy Principles; WFP Guidelines 
Chapter 4

$\begin{array}{lll}\text { Transparent } & \text { Transparency about parties } & \text { IRPC Internet Rights and Principles; UN } \\ \text { governance and } & \text { collecting, owning, and using } & \text { Personal Data Protection and Privacy } \\ \text { accountability } & \text { data, as well as those } & \text { Principles; EU GDPR; CGIAR Guidelines; UNDG } \\ & \text { responsible for the data } & \text { Guidance Note }\end{array}$

\section{Rights recognized specifically for LICs and/or vulnerable people}

(Data) ownership \& Right of data subjects to remain control

owner and in charge of what

data is collected, by whom and for what purpose, including the option to opt-out

Access to (personal) data

Data minimization \& purpose definition

Informed consent

Protection from direct or indirect harm
Right to access (and in case of personal data correct) data at any moment in time

Use of data must be specified upon collection and further processing be limited to the agreed use cases

Free choice to consent (or not) to data collection, including receiving information about the data that is collected, by whom, and for what purpose

The act of collecting data should not negatively impact the data-originator directly or indirectly
USAID Policy; ICRC Handbook; WFP

Guidelines

GODAN Best Practices, EU GDPR, ICRC Handbook, WFP Guidelines

EU GDPR, GODAN Best Practices, ICRC Handbook, UNDG Guidance Note, WFP Guidelines

Oxfam Policy, WFP, UN Personal Data Protection and Privacy Principles, EU GDPR, USAID policy, ICRC Handbook, Oxfam Policy, CGIAR Guideline, WFP Guidelines

Oxfam Policy, EU GDPR, USAID Policy, CGIAR Guidelines, UNDG Guidance Note

\subsection{Methods}

We employed a single-case study approach (Ridder, 2017). A research problem and relevant variables for investigation were identified, however relationships between theory and variables were not formulated beforehand. The single-case design allowed to unravel the working of an HCD process in agricultural development through indepth analysis of the phenomena of interest in the context in which they emerge. The chosen approach does not allow for comparative analysis, an acceptable limitation knowing the study objectives.

\subsubsection{Case study description}

ICT4BXW is a research for development project in Rwanda led by the International Institute of Tropical Agriculture (IITA), a CGIAR research centre. We studied the project's first (piloting) phase (2018-2020). In phase 1, ICT4BXW covered 138 villages across eight districts, within four provinces. 69 project villages were intervention villages where ICT4BXW piloted a digital extension intervention for the 
control and prevention of Banana Xanthomonas Wilt disease (BXW). The project's aim was to develop a digital tool to support; inclusive access to information, efficient and cost-effective control of BXW, targeted investments in BXW management by government agencies and, ultimately, reduce loss of banana productivity and livelihood due to BXW. Human-Centred Design stood central in ICT4BXW to develop the digital tool. A Ugandan design company was hired to facilitate a participatory process, design the interface of BXW-App and a dashboard, and manage technical development of both frontend and backend. For the latter, the design company collaborated with a Dutch start-up that deploys young African software developers. Important events in the inspiration phase included a baseline survey with farmers $(n=690)$ and Farmer Promoters (FP) $(n=138)$ plus a multi-stakeholder rapid appraisal workshop. A farmer promoter (FP) is a village-level extension agent who is a farmer him-/herself. Every village in Rwanda has an FP and he/she is the last-mile actor in the country's extension system (Wennink \& Mur, 2016). For the ideation phase, four design-workshops and one e-literacy training for FPs took place. The implementation phase included an e-literacy and project-identity training for 69 FPs, user experience surveys, and (remote) support.

Main output of the design process was 'BXW-App', a digital extension service that supports diagnosis and control of BXW, gives information about banana agronomic practices, and registers local presence of BXW. BXW-App is available for free on Google Play ${ }^{\circledR}$ with English and Kinyarwanda (Rwanda's common language) language options. The app has four sections: 'What is BXW' (giving technical information about the disease), 'BXW management' (providing information about best practices for managing BXW), 'Agronomy practices' (informing about agronomic best practices for banana production), and 'Diagnostic procedure' (scouting BXW symptoms in a plot and diagnose the disease). All sections have a combination of text, illustration, and voiceover to enhance accessibility of the content for a wide variety of farmers.

BXW-App has farmer promoters as its primary users. Secondary users of the information provided, or data collected by BXW-App are farmers, researchers, and government representatives (e.g. staff of the Rwanda Agriculture and Animal Resources Development Board (RAB)).

\subsubsection{Data collection}

Empirical data was collected in the ICT4BXW project in Rwanda, mostly consisting of qualitative data. USE-surveys (Lund, 2001) were conducted with 18 farmer promoters in two project districts, Kayonza and Burera. Additionally, observational data 
was collected by following the same FPs in the field while they were using BXW-App and interacting with farmers. FPs were purposively sampled from ICT4BXW intervention villages. We conducted 9 group interviews with banana farmers (Kayonza, 18 farmers in 4 interviews) and (Burera, 27 farmers in 5 interviews) with a focus on farmer experiences with BXW-App and perceptions about privacy, (data) security, and sharing of data. Key interviews with project staff, partners and designers were conducted $(n=17)$ to learn about project organization and management, use of and understanding about the HCD method, interactions between various actors, and experiences in and perceptions about the project by various actors. Additionally, internal project documents were consulted to develop understanding about events, activities, and decisions made in ICT4BXW. Lastly, insights were gathered from observing the design process up closely, for example by attending 3 design workshops as embedded researcher.

\subsubsection{Analytical approach}

To analyse the interview and USE-survey data, we used a combination of deductive and inductive coding in ATLAS.ti ${ }^{\circledR}$. Broad themes were identified based on the conceptual framework, while specific codes were added deductively for relevant quotes. We used triangulation to verify findings from analysing interviews and survey data with observational data from the HCD process and BXW-App in use, and project reports. To create our analytical framework, we analysed the existing guidelines for digital rights (see Table 10 and Appendix 2) as well as operationalized the RRI approach (Table 9) to create a foil for evaluation of the HCD process implemented in the case study.

\subsection{Findings}

In this section we show how the design process was organized and how this structured interaction between stakeholders and design decisions. Findings are organized along the AIRR dimensions and four themes: (1) Inclusion: social roles, relations and trust; (2) Anticipation: impacts and consequences for digital rights; (3) Reflexivity: steering capacity; (4) Responsiveness: project limitations and mindset.

\subsubsection{Inclusion: Stakeholder roles, power relations and trust issues}

How people are included in the design process affects their influence on the design of the technology and technological intervention, and their ability to observe 
and control how designs respond to needs and values and, ultimately, digital rights. Beyond asking who was included in the design process, we used interview and observational data, and project documentation to analyse how different stakeholders were included in the design process. Table 11 shows who occupied which role in the ICT4BXW project.

Table 11: Stakeholders in the ICTABXW project.

\begin{tabular}{|c|c|c|c|}
\hline Stakeholder & Stakeholder interest & Project tasks & $\begin{array}{l}\text { Role in HCD } \\
\text { process }\end{array}$ \\
\hline Donor & $\begin{array}{l}\text { visible positive impact on } \\
\text { rural livelihoods and scaling }\end{array}$ & $\begin{array}{l}\text { Provide project funding } \\
\text { Monitor project log-frame } \\
\text { Grant or reject a second } \\
\text { project phase }\end{array}$ & Silent observer \\
\hline $\begin{array}{l}\text { Scientific partner } 1 \\
\text { (Project managing } \\
\text { organization) }\end{array}$ & $\begin{array}{l}\text { Scientific outputs } \\
\text { Research for development } \\
\text { impact } \\
\text { Strengthening partnership } \\
\text { with govt. } \\
\text { Showcasing organizational } \\
\text { capacity in digital } \\
\text { agriculture }\end{array}$ & $\begin{array}{l}\text { General project management } \\
\text { Implementation and control of } \\
\text { field activities } \\
\text { Monitoring and evaluation } \\
\text { Reporting to donor } \\
\text { Leading scientific activities } \\
\text { Remuneration of participants } \\
\text { Communicate project results }\end{array}$ & $\begin{array}{l}\text { Decision-maker } \\
\text { (project leader) } \\
\text { Implementer } \\
\text { (research } \\
\text { assistants) }\end{array}$ \\
\hline $\begin{array}{l}\text { Government } \\
\text { partners }\end{array}$ & $\begin{array}{l}\text { Improved, up-to-date } \\
\text { insights about BXW } \\
\text { Reduced impact of BXW on } \\
\text { production, income and } \\
\text { food security } \\
\text { Practical implementation of } \\
\text { ICT4RAg policy } \\
\text { Partnership with CGIAR } \\
\text { centres }\end{array}$ & $\begin{array}{l}\text { Future owner of BXW-App } \\
\text { Secure access to field sites and } \\
\text { actors in extension system } \\
\text { Contextualization of disease } \\
\text { information } \\
\text { Support or coordinate field } \\
\text { activities }\end{array}$ & $\begin{array}{l}\text { Decision-maker } \\
\text { (head of } \\
\text { banana } \\
\text { research } \\
\text { programme) } \\
\text { Implementer } \\
\text { (research } \\
\text { technicians) }\end{array}$ \\
\hline Scientific partner 2 & $\begin{array}{l}\text { Integration with other BXW } \\
\text { work in organization } \\
\text { Dissemination of disease } \\
\text { management approach } \\
\text { Collaboration on scientific } \\
\text { outputs }\end{array}$ & $\begin{array}{l}\text { Technical expertise and input } \\
\text { to create content for BXW- } \\
\text { App }\end{array}$ & Participant \\
\hline Design company & $\begin{array}{l}\text { Design as per client } \\
\text { demands } \\
\text { Opportunity for future } \\
\text { assignments with CGIAR } \\
\text { centres }\end{array}$ & $\begin{array}{l}\text { Lead HCD process } \\
\text { Design interface of project } \\
\text { Engage with stakeholders and } \\
\text { users }\end{array}$ & Decision-maker \\
\hline Programmer & $\begin{array}{l}\text { Technology design as per } \\
\text { client demands } \\
\text { Partnership with design } \\
\text { company } \\
\text { Opportunity for future } \\
\text { assignments with CGIAR } \\
\text { centres }\end{array}$ & $\begin{array}{l}\text { Translate interface design } \\
\text { from designer to actual } \\
\text { programmed design } \\
\text { Develop platform back-end } \\
\text { and databases } \\
\text { Adapt app and back-end } \\
\text { functionality to stakeholder } \\
\text { needs }\end{array}$ & Implementer \\
\hline
\end{tabular}


Chapter 4

\begin{tabular}{|c|c|c|c|}
\hline Sector agronomist & $\begin{array}{l}\text { Increased insight in } \\
\text { presence and management } \\
\text { of disease } \\
\text { Increased insight in } \\
\text { performance of FPs }\end{array}$ & $\begin{array}{l}\text { Participate in design } \\
\text { workshops } \\
\text { Interact with and support FPs } \\
\text { Coordinate with government } \\
\text { partner }\end{array}$ & $\begin{array}{l}\text { Participant } \\
\text { User }\end{array}$ \\
\hline Farmer promoter & $\begin{array}{l}\text { Increased insight in } \\
\text { presence and management } \\
\text { of disease } \\
\text { Improved interaction with } \\
\text { farmers } \\
\text { Improved status and trust in } \\
\text { community }\end{array}$ & $\begin{array}{l}\text { Participate in design } \\
\text { workshops (sample) } \\
\text { Attend capacity building } \\
\text { activities } \\
\text { Train other FPs about project } \\
\text { and on smartphone and app } \\
\text { use } \\
\text { Visit farmers, register them in } \\
\text { the app, run diagnostic } \\
\text { procedure in farm } \\
\text { Visit SA to upload data }\end{array}$ & $\begin{array}{l}\text { Participant } \\
\text { (sample) } \\
\text { User }\end{array}$ \\
\hline Farmer & $\begin{array}{l}\text { Improved knowledge about } \\
\text { disease } \\
\text { Increased insight in } \\
\text { presence and management } \\
\text { of disease } \\
\text { Improved interaction with }\end{array}$ & $\begin{array}{l}\text { Interact with FP } \\
\text { Visit farm with FP to run } \\
\text { diagnostic procedure } \\
\text { Register and share farm and } \\
\text { personal data in app }\end{array}$ & User \\
\hline
\end{tabular}

We identified five stakeholder roles: decision-makers, implementers, participants, users, and silent observers. Beyond anticipated users of BXW-App (e.g. FP, SA), various other stakeholders were involved in the HCD process, each with their own interests and project tasks. Inclusion of more diverse stakeholders with diverging interests affected the priority that was given to the rights and needs of users.

Findings show that those in the role of implementer were rarely in the position to take decisions. Rather, implementers, such as technicians or assistants, followed orders or did what they were paid for (programmers) by decision-makers. Nevertheless, especially technicians and assistants played an indispensable role as intermediaries between users and other stakeholders. A result of implementers being lower in the hierarchy was that not all information was (correctly) shared, got lost in 'translation', or not acted upon, which affected the projects' ability to be reflexive and responsive. Farmers were seen as users of the information provided by BXW-App, but not as users of BXW-App itself (those were FPs), and therefore not invited to participate in the design process. As a result, farmers relied on other stakeholders (e.g. FPs) to represent their interests or defend their rights. Additionally, our interview data shows that there was only partial transparency towards farmers e.g. about project objectives, the data that was collected and shared, and that farmers' understanding regarding this differed per village. For example, interviews revealed that farmers were not unequivocally 
informed that data about the presence or absence of BXW in their farm could be accessible to government officials.

Conflicting interests emerged when stakeholders debated the opportunity to use data about farmers and their farms, or FPs and their activities, for performance-surveillance purposes. Both the government partner and SAs showed interest in such data, while the project managing organization and design company rejected the idea for the purpose of BXW-App was not to be a performance-monitoring tool. Moreover, concerns existed that FPs would distrust the application if they feared being surveilled by it. FPs were never involved in decision making about this. Despite the initial reservations towards performance-monitoring, review of BXW-App's back-end showed that monitoring of an individual's performance was possible for those with the access credentials (including some actors from the government partner). Considering that these partners would eventually gain ownership over the application, combined with Rwanda's top-down structure, and existence of performance contracts for government officials, this design decision could have real consequences for individual users of BXWApp. Thus, FPs and farmers and their interests were less central than one might expect. Power relations furthermore influenced design decisions. Table 12 (next page) shows some design changes made in the ICT4BXW project and the roles influencing that change.

Table 12: Examples of design changes resulting from stakeholder engagement.

\begin{tabular}{llll} 
What changed & Original design & New design & $\begin{array}{l}\text { Main decision } \\
\text { influencer }\end{array}$ \\
\hline $\begin{array}{lll}\text { Expected role of the } \\
\text { user }\end{array}$ & $\begin{array}{l}\text { Farmers collecting } \\
\text { information about } \\
\text { disease transmission } \\
\text { for scientists (citizen } \\
\text { science) }\end{array}$ & $\begin{array}{l}\text { Information transfer to } \\
\text { farmers by scientists via } \\
\text { farmer promoters }\end{array}$ & $\begin{array}{l}\text { Decision-makers } \\
\text { (Scientific partner 1, } \\
\text { Government partner) }\end{array}$ \\
& & $\begin{array}{l}\text { Registering farmers } \\
\text { and collecting data }\end{array}$ & \\
& & $\begin{array}{l}\text { about disease presence } \\
\text { in visited farms }\end{array}$ & \\
Users of the application & Farmers, extension & Farmer promoters, & (Scientific partner 1, \\
& agents, scientists & sector agronomists & Government partner) \\
Actor responsible for & Farmer promoters, & Sector agronomists & (Scientific partner 1, \\
submitting data & (farmers) & Government partner) \\
Available information & Diagnosis, control and \\
in app & Drevention & Diagnosis, control, & Participants (FP, SA) \\
& prevention, and &
\end{tabular}


Chapter 4

Various stakeholders influenced the intervention design. FPs mainly influenced the interface and content design, especially through incremental changes contributing to usability, usefulness and usability of BXW-App. Big design changes that altered the application's nature, e.g. about the role of the user, came from decision-makers. Farmers (as end-users and data-providers today and future BXW-App users) had no direct influence on the design. Their interests should have been represented by the FPs, since FPs are also (lead)farmers themselves. Tables 11 and 12 show that FPs and, especially, farmers were in a weak position to defend their rights e.g. to transparent governance; ownership, control and access to data; informed consent; and protection from harm, because of their role as participant or user rather than decision-maker.

Despite observed transparency and power issues, farmers in group interviews expressed high levels of trust in other, more powerful actors (e.g. researchers, government) when asked about their thoughts regarding sharing information about themselves, their families, and their farms:

The government always thinks about us [i.e. looks after us]. If it introduces or gives someone permission to introduce a project it is for our good. Thus, we do not think that there are any negative impacts that can come from the fact that we have provided information to that app. (farmer, Kinunga2, Kayonza)

Asked if the provided data could be available to anyone: "[...] either way we are beneficiaries of the sharing of our information. It is for our development and that of the whole country in general." (farmer, Kinyababa, Burera).

Thus, an apparent trust in data collection existed based on the perception that those accessing the data would do something beneficial with it. With few exceptions, farmers did not demand transparency about what the data would be used for and by whom, neither clarification about their rights.

In summary, ICT4BXW attempted to be inclusive, involving a variety of stakeholders in the HCD process. However, users of BXW-App were outnumbered by other, more powerful, stakeholders and their influence on the most impactful design decisions was limited. The latter appears harmful for adherence to digital rights like the rights to access information, transparent governance and accountability, and informed consent. 


\subsection{Anticipation: Considering consequences and impact on digital rights}

Anticipation is about defining possible scenarios for and consequences of a design. Within an HCD process, anticipation is mostly visible in the inspiration and ideation phases, e.g. when designers and other stakeholders aim to discover about users and use context, and suitable designs. For our case study we indeed find that anticipation of contextual limitations (e.g. the low network coverage and high data cost in rural Rwanda) led to technical design solutions. For example, BXW-App was made accessible offline, with local storage of data, and a minimized application download size e.g. through compressing movies and illustrations. However, we find that while project leaders dealt with tangible (short-term) challenges, the responsibility for anticipating longer-term ethical issues or challenges appearing at scale was mostly passed on to the design company. When asking an interviewee from the design company if the project considered potential security issues, the response suggested that, for now, there were no such issues because of the small scale and low granularity of the data: "The way it is put in there now, it doesn't matter so much because it is all enough guesswork."

However, the same interviewee recognized that by adding information and increasing granularity this could change, e.g. the collected data could be misused to surveil data originators:

What would really be an easy step is to see if, but also for the FP, if he [i.e. the farmer] does his job." and "if the government wants more detailed information [...]. Yes, there's a danger there. For both the FP and the farmer.

Nevertheless, anticipation of possibly emerging digital rights violations was not prioritized. Since the application initially targeted a rather small number of people the perception existed that risks were limited. However, scaling of project outputs to a larger user base was desired (e.g. ICT4BXW worked with 69 FPs but planned to scale country-wide (approx. 15.000 FPs) and potentially regionally in phase 2). In absence of clear guidelines or regulations to adopt digital rights, ethical considerations became driven by personal values as the following quote from a design company interviewee illustrates:

The government would actually be perfectly fine with knowing what a farmer does with the feedback and also attach punishments to that. And that is of course the 
Chapter 4

last thing that you want. So, in the end there was some kind of a dilemma. Because it is of course all possible. But we didn't do it, because it wasn't the intention. So, you have to continue to talk. Back to the basics of 'no we want to discover patterns in the disease transmission and for that you don't have to know at an individual level what happens exactly per farm. It is about patterns at a larger scale. But well the next... I already know, the next step from the government would be to indeed individualize it.

Anticipation of the consequences of design decisions was not a participatory exercise, but rather a task of the design company. They in turn had to negotiate with stakeholders about including or omitting design features that could violate the digital rights of some users. Especially the rights to transparent governance and accountability were hereby violated, subsequently increasing risk of data security breaches and violation of rights to data privacy, or access to personal data. Additionally, informed consent from data originators is impossible without prior anticipation of potential consequences, neither can protection from direct or indirect harm be ensured.

\subsection{Reflexivity: Steering capacity in digital design}

The ability to reflect on the impact and consequences in the HCD design process depends on two crucial factors: enabling people to participate in reflection and creating space for reflection. Digital literacy (i.e. second-level digital divide) is a known limiting or enabling factor for participation. In the development and use of digital agriculture technologies this is often addressed with training e.g. by making HCD workshops simultaneously design and capacity building exercises. In the case of ICT4BXW, capacity building activities were indeed coupled with the design workshops, e.g. training participants (i.e. FPs) to operate a smartphone and BXW-App. Although user training was planned for in the project proposal, the real need for capacity building had been underestimated. Most FPs had never used a smartphone or any type of computing device before and procedures like typing or taking a picture were alien to them.

By transferring skills on how to use digital technologies, ICT4BXW addressed the second-level digital divide. However, truly meaningful participation of FPs in the design and data collection process would have required the capacity of FPs to also (partially) understand the functions and processes behind the working of digital technologies and 
data processing practices. Such requires a level of digital literacy beyond second-level literacy, allowing a user to actively and critically reflect on the digital technology in use, and would be paramount to realize rights like ownership, control and access to data, and the right to informed consent. ICT4BXW did not invest in building this digital literacy.

Another finding relates to space for reflexivity. By nature, an HCD process is iterative, and design iterations happen based on design evaluations. Review of project documents tells that indeed some necessary or desired design adaptations were noted by designers and project leaders or asked for by users. In practice however, adaptations were mostly limited to technical ones (e.g. bugs). More far-reaching design updates were postponed because of time, budget and manpower limitations, expiring contracts with the design company, and additionally used as a rationale for a second project phase.

\subsection{Responsiveness: Project limitations \& Positivist mindset}

For an HCD process to lead to a responsible, value-based digital agriculture technology, flexibility (e.g. in timelines and objectives) and awareness of product scope and limitations are necessary. In ICT4BXW budgets, timelines and deliverables were all pre-set and determined in consultation with a few stakeholders (i.e. project leader, scientific partner 2, government partner). Regarding deciding about the project scope for ICT4BXW, an interviewee from the project managing organization said:

\section{[...] when we were setting up the project, we [...] have thought out and written down many things [...]. So, I think that we then already figured out a lot conceptually and thought about 'well, how can we align this with a big problem in Rwanda? Some theme that is a hot topic and, well, that resonates well at various levels.}

This illustrates how, right from the start, much was already established e.g. developing a digital solution for a particular banana disease, partnership with the government, using mobile phone technology. This implies that technologies (e.g. mobile application) and problem definitions were fixed with limited space to alter this during the HCD process, meaning that existence of e.g. rigid funding lines and transversal topics (e.g. digital by default) directly influence the HCD process. 
Chapter 4

Responsiveness demands outlining the scope of socio-cultural issues, infrastructural limitations, or problems in agricultural production systems that a digital agriculture technology may address or cause. Rather than critical realism, we observed much optimism about the transformative capacity of digital technology in ICT4BXW: "My expectation of this project [...] is that this becomes [...] that true demonstration of what a [...] development process for digital tools should look like and what an early warning system in the future should look like." (project leader)

FPs similarly expressed technological optimism in interviews, e.g. when talking about how BXW-App and the smartphone impacted their status in communities: "[...] now that farmers see me with the smartphone, they are more interested in listening to what I tell them. Before, they used to ignore the advice [...]." (FP, Nyagafunzo, Burera) and: "[...] when I am explaining to them [i.e. farmers] while having pictures, I can speak with confidence because what I am telling is supported by the visuals in the app." (FP, Rusera, Kayonza)

These quotes suggest that the mere existence of the smartphone and BXW-App was perceived as a major benefit by FPs, creating conditions in which users are unlikely to ask critical questions about a technological design. Within this context it became possible that the project's data management plans concerned project (research) data, but did not outline policies regarding e.g. privacy, access rights, or opting out, for users of and data collected by BXW-App. Hence, in line with findings presented in the anticipation section, we observe a lack of concern about the impact of BXW-App and the data collected, and an unproductive sphere for reflexivity and responsiveness.

\subsection{Discussion}

We analysed the enactment of Human-Centred Design in one case study from Rwanda to study responsible innovation in digital agriculture in LICs and attendance to smallholder farmers' digital rights. The precise context and observations may be case study specific, nevertheless the findings provide relevant insights about and lessons for digital agriculture in LICs and contribute to larger scientific debates about digital divides and inclusion, responsible innovation, and technology shaping (e.g. H. Barrett \& Rose, 2020; Higgins \& Bryant, 2020; Rotz et al., 2019). Overall, findings indicate that usercenteredness and inclusiveness, promises inseparable from HCD approaches, only partially materialized. At surface level, it appeared that the AIRR dimensions were integrated in the HCD process. Closer analysis revealed that all that glitters is not gold: Various stakeholders were included and consulted about their needs and desires for 
interface design and application functions but power structures within and beyond the project context affected higher-level decision-making, in turn influencing safeguarding of digital rights. Moreover, enactment of the design approach lacked attention for potential broader and more long-term (negative) consequences. For example, the possibility to use BXW-App as a performance-monitoring tool was welcomed by several stakeholders without questions. It appears that our case lacked the RRI framework's anticipation and reflexivity dimensions. Arguably, this is a missed opportunity: These dimensions may have facilitated the critical thinking and deliberation with stakeholders about digital rights, aspects of power, ethics, and justice, and inequality while designing the digital agriculture intervention that others recommend (Bronson, 2019; Eastwood et al., 2017; Klerkx \& Rose, 2020; Rose, Wheeler, Winter, Lobley, \& Chivers, 2021). Hereafter, we further reflect on participation capacity, the role of power imbalances, and neglect of digital rights. We tease out broader theoretical and practical implications for responsible design in digital agriculture.

\subsubsection{The missing link - people's capacity to participate in RRI and HCD practice}

Scholarship on designing responsibly in digital agriculture has argued that HCD and RRI approaches can empower stakeholders to reflect on how to better design technologies for their particular contexts and mitigate undesirable consequences (Bronson, 2019; Ortiz-Crespo et al., 2020). Our study nuances that. Current approaches, in our case enacted through an HCD approach, will not always suffice to achieve this, echoing ideas on the need to have sufficient 'RRI readiness' (Eastwood et al., 2019). Findings showed that participation empowered stakeholders to influence the design of a digital agriculture innovation and bridge tangible design-reality gaps. But stakeholders could not always execute this power due to capacity limitations, affecting e.g. ability to anticipate or reflect on consequences of design decisions; demand for adherence to digital rights (e.g. privacy, data ownership and control, or informed consent). In view of digital capacity, one may actually question overall capacity of project stakeholders to anticipate, be reflexive, or responsive to the possible consequences of BXW-App on a higher level, or at scale. Without impeaching project and stakeholders' intentions, we think that these capacity issues may cause the observed apparent naivety and inability to fully contemplate consequences of digital technologies. This hinders effective participation. More than a shortcoming of the HCD approach, or incompetency of project implementers, we argue that these capacity 
issues are a side-effect of the inherently complex character of digital technologies. By nature, tools like BXW-App come with many 'unknowns' and 'unseens' (Klerkx et al., 2019), effectively making them technological black-boxes (Ajunwa, 2020). For stakeholders it is then innately difficult to perceive ensuing emergent effects of the technology or intervention they are designing, including potential harms. It appears that within this untransparent context, participants merely lack the comprehension to perceive and protect moral values and digital rights that are at stake. This notion expands understanding about third-level digital divides (Scheerder, van Deursen, \& van Dijk, 2017), which entails capacities needed to critically assess digital technologies and their potential impact within a broader system, and their effect on responsible design and design outputs. Neither HCD nor RRI currently provide clear guidance for coping with these intangible (future) design-reality gaps in digital agriculture and thus insufficiently build readiness to effectively enact responsible design in digital agriculture.

\subsubsection{Implications of power relations: good intentions versus on-the- ground realities}

We already know that relations between actors in digital agriculture are not neutral (Rotz et al., 2019), and that power can affect decision-making in design processes (Hyysalo \& Johnson, 2016; Sanders \& Stappers, 2008). For ICT4BXW it meant that representatives of farming communities (e.g. farmer promoters) were less powerful and thus in a weaker position as decision-makers. The different stakeholders participating in the design process were nevertheless often treated as homogenous. In doing so, the social context in which inclusion of stakeholders in decision-making takes place was ignored. Power imbalances in digital agriculture make that the powerful (e.g. donor, project managing organization) face smaller risks and bigger benefits (Cinnamon, 2020), providing little incentive to be responsible and adhere to digital rights. Simultaneously, the less powerful (e.g. farmers, farmer promoters) are poorly protected from direct or indirect harm caused by digital technologies (Mann, 2018), and lack the digital capacity and agency to demand e.g. to be informed about today's and future use of collected data. This makes the space for participation in designing a digital technology restricted and controlled by a few powerful actors. Corporate behaviour and profit, and lack of accountability structures have been blamed for this practice (Mann \& lazzolino, 2019; Taylor, 2021) but, like many other digital agriculture projects in LICS, ICT4BXW was not private sector-driven but donor funded and needed to attain 
development impact instead of profit. The same holds for the organization managing ICT4BXW: CGIAR Centres need to show both research and development impact (Cees Leeuwis, Klerkx, \& Schut, 2018). However, it appears that both in profit and not-forprofit contexts in LICs including diverse stakeholders in a design process does not solve inequality, power dependencies, or accountability issues. This contradicts the idea that responsible design approaches give participants an equal voice. In practice there may be explicit or implicit choices in responsible design processes which render them less inclusive (Klerkx \& Leeuwis, 2008) and creating responsible designs that fit with different users' needs or giving users an expert role in design is easier said than done. This has implications for the meaning of inclusivity in (debates about) RRI and HCD. We would argue that inclusivity becomes less meaningful when diverging interests and power relationships between stakeholders are not actively addressed. Hence, explicit attention for shaping optimal inclusion whilst dealing with issues such as conflicting interests is required (following Skrimizea et al., 2020; Turner et al., 2020; van Mierlo, Beers, \& Hoes, 2020).

Theoretically, digital rights frameworks could guide responsible design. But as indicated before, rights are in practice fragmented (van der Burg et al., 2020; Wiseman, Pesce, et al., 2019) and less established than general human rights. Digital rights are furthermore mostly formulated as voluntary guidelines (Sanderson, Wiseman, \& Poncini, 2018), with no unified framework to adhere to, formal obligation to adopt, or institution to appeal to. This legal fragmentation provides opportunities for cherry-picking of digital rights and 'window dressing' (L. von Schomberg \& Blok, 2019) or 'ethics washing' (Bietti, 2020; Hao, 2019): Powerful actors presenting their project and its outcomes and impact as responsible and ethical without necessarily being responsible or ethical under the hood. We wrote that at surface level ICT4BXW aimed for responsible design, yet the truth of the matter appeared different. Especially more complex rights, which are specifically important for LICs and vulnerable groups (e.g. protection from indirect harm, data purpose definitions, truly informed consent), were underrepresented. This is not to say that ICT4BXW should be considered a case of window dressing. Project managers probably had the right intentions but their implementation fell short. Nevertheless, a danger of 'false' attempts of responsible design could be that, unintendedly, the opposite is achieved: irresponsible designs. For digital agriculture in LICs this could e.g. make already vulnerable groups of people (smallholder farmers) more vulnerable or result in undesired alterations to rural societies and livelihoods. 


\subsubsection{Implications for conceptualizing responsible design}

Finally, we look at implications of our findings for conceptualizing responsible design in digital agriculture. Responsible design in digital agriculture demands asking critical questions and deliberation about potential consequences of a technology. Such sensitivity to pros and cons of technological innovation conflicts with the old belief that technology can fix all problems (Hartley, McLeod, Clifford, Jewitt, \& Ray, 2019). Ubiquitous critique on and concerns about this "technological fix thinking" in the context of digital agriculture and development exists (e.g. Birhane, 2020; Mann, 2018; Rikap \& Lundvall, 2020). Our findings confirm that this discourse still occurs in practice (Lajoie-O'malley, Bronson, van der Burg, \& Klerkx, 2020). We found technological optimism among diverse stakeholders e.g. visible in the general faith of users that BXWApp would yield positive impact. In this realm it appears that the digital (agriculture) development sector embraces responsible design approaches to deliver designs that respond to user needs and can 'do good' for people in LICs. Our concern is that practitioners may (unknowingly) use these approaches as a quick fix to structural inequality in development projects without addressing the problems underlying that inequality.

Conceptualization of responsible design approaches like HCD and RRI originates from the Global North. HCD emerged in the design sciences, aiming to develop innovations that 'work' today from a productionist and economic perspective and optimize their adoption and scale. This focus on technological feasibility and economic viability makes HCD in itself rather technocratic. Similarly, responsible innovation has been critiqued for adopting the narrow economic and technological foci of innovation (Blok \& Lemmens, 2015). In our view, the current approaches are ineffectual for developing responsible, rights-based designs in the context of digital agriculture in LICs. We follow Clapp and Ruder (2020), saying that to become truly inclusive, focused on user needs and responsibility, attention to the agricultural system and political economy in which a digital technology becomes embedded is needed. This demands an eye for both local and tangible factors and the, perhaps more intangible, system. Else, a gap remains between the levels where technologies are designed (local) and where they have impact (system). The ICT4BXW case study demonstrated the HCD approach's strength in developing a specific digital technology and planning implementation and impact for a specific (local) context. This strong focus on local context, capacity, and impact is often seen as an advantage of HCD (Steinke et al., 2020; Ayre et al., 2019; Ortiz-Crespo 
et al., 2020). Decisions by designers can nevertheless have systemic impact (Bronson, 2019) and transformative technologies require local solutions that can contribute at a larger scale (Berthet et al., 2018; Emeana, Trenchard, \& Dehnen-Schmutz, 2020). In our view, HCD gives insufficient space to anticipate possible consequences of digital technologies at scale, despite this being critical for responsible innovation and scaling (Wigboldus et al., 2016). The RRI framework does consider systemic impact yet lacks contextualization to local realities and thus cannot guide actual design of a digital agriculture technology. This limited practical applicability and the challenge to deploy it in specific organizational and national contexts has been criticized before (de Hoop, Pols, \& Romijn, 2016; Wittrock, Forsberg, Pols, Macnaghten, \& Ludwig, 2021). We observe a gap in the current framing of responsible design: Practically, short-term, tangible matters such as privacy, or inclusion in designing a digital interface are addressed, while second level issues such as data security or power dependencies are not. This has implications for anticipating broader impacts of digitalization, like redistribution of roles and responsibilities in smallholder agriculture systems or access to resources and markets (Mann, 2018), and capability to counteract those. Without attention for broader impacts, issues (e.g. regarding digital rights, (future) design-reality gaps, or inclusivity) built into locally developed technologies today will scale and solidify, affecting large numbers of people in the future (Bronson, 2018). Strong integration of the anticipation and reflexivity dimensions in design approaches, with explicit attention for systemic impact, would support better informed, more responsible design decisions. Joining Eastwood et al., (2019) we recommend clear, hands-on translations of the AIRR dimensions, contextualized for LICs and digital development, guiding analysis and evaluation of the local and system level responsibility of a design.

\subsection{Conclusion and recommendations}

This evaluative study combined RRI and digital rights lenses to study enactment of an HCD approach while developing digital agriculture technologies in LICs. Using empirical evidence from a Rwandan case study, we analysed if and how the design approach contributed to developing responsible digital agriculture innovations. The normative sociological perspective of responsible design was substantiated by adding digital rights as value input for responsible digital technologies. Evaluating a real-world design process, we identified four explanations why using HCD in LICs cannot guarantee development of responsible, rights-based designs. First, capacity limitations of participants in design processes and users of design outputs affect ability 
to critically assess design decisions. This influence has been under addressed in the literature on design approaches in digital agriculture. Second, findings suggest that unequal power distribution affects different stakeholder roles' authority over design decisions, which is in line with previous research in USA and UK (Carolan, 2018). This demands us to question if farmers (representatives) can truly be co-designers? and if inclusivity in design is an achievable when deploying HCD, especially in LICs? False inclusion looms if digital incapability and power relations are ignored. Outputs of design processes may then, unintendedly, exacerbate old or create new divides and inequalities. Third, stakeholder on all levels showed a broad technological optimism about digital technologies. Alongside aforementioned capacity limitations and power dimensions, this optimism hinders anticipation and reflexivity of consequences of a digital agriculture technology. Voluntary and fragmented guidelines for responsible, rights-based digital innovation fail to provide necessary impulse for change, instead promoting cherry-picking and 'window dressing'. We assert that anticipation and reflexivity to broader implications of using digital technologies in LIC contexts should become mandatory elements of design processes. Thus, recognition, protection, and governance of farmer's digital rights should start when designing a digital technology. Else, the 'good for all' and 'good for everything' narratives surrounding digital agriculture in LICs will continue to hinder critical thinking and challenge adoption of guidelines for responsible and rights-based design. Fourth, the local level at which the design process and decisions transpire mismatches with the systems level at which unintended consequences of digital technologies emerge. Hence, there is too little attention for and oversight of consequences emerging at scale. Here, too, we believe that critical discussion about system level outputs, pointing out stakeholders' interests as well as impact of different methodological approaches, is highly needed. Future studies could assess the validity of our findings for other digital agriculture projects in LICs, building more robust understanding about the real-world working of design processes. We also recommend further research on hands-on and conceptual integration of RRI and digital-rights in design methods to identify relations between local level design decisions and meta level consequences early-on.

Practitioners aspiring responsible design are recommended to: (1) Actively mediate between different stakeholders to address diverging interests and power inequalities and invest in digital capacity of stakeholders to make inclusion and participation meaningful. This includes investing in capacity of project staff, especially regarding 
third-level digital divides and critical thinking about technologies. (2) Make anticipation, reflexivity, and responsiveness integral elements of digital agriculture projects and design processes to foster responsible design. Scenario building exercises may help with this and support bridging third-level digital divides. (3) Public authorities are recommended to develop unified ethical and rights standards for digital agriculture that (4) recognize that local digital agriculture interventions may have systemic impacts, affecting social norms and values. Technological optimism cannot be an excuse to ignore or violate digital rights. This implies that practitioners, donors, and legislators in LICs should take responsibility for securing digital rights of all actors, especially vulnerable ones like farmers. 


$$
\begin{aligned}
& \Delta \Delta \\
& \Delta \Delta
\end{aligned}
$$




\section{A problematization of inclusion and exclusion}

Trade-offs and nuances in the digitalization of African agriculture 


\section{Abstract}

The use of digital technologies with the aim to improve African smallholder agriculture is a trend today, and expectations of the benefits and transformative capacity of these technologies are high. In practice, digitalization comes with tradeoffs, and benefits and potential harm are not equally distributed. This chapter unravels how processes of digitalization in smallholder agriculture may lead to inclusion and exclusion of people in the present or future. A broad variety of inclusion and exclusion factors are discussed across three levels: specific digital technologies; digital innovation packages; and the digital innovation system. This shows how a complex interplay between access conditions, design choices, and system complexity determine if and how inclusion and exclusion take place, at what level, for whom, and with what impact. In doing so, the chapter breaks with the normative assumption that inclusion is always positive and exclusion always negative. Instead, when it comes to the use of digital technologies in smallholder agriculture, inclusion and exclusion are more than a binary distinction between 'who is in' and 'who is out,' or what is 'good' and what is 'bad'.

This chapter is an adaptation of a book chapter that is forthcoming as: McCampbell, M., Rijswijk, K., Wilson, H., and Klerkx, L. (2021). A problematization of in- and exclusion: Tradeoffs and nuances in how digitalization affects African agricultural development, In Ludwig, D., Boogaard, B., Macnaghten, P., and Leeuwis, C. (Ed.) in; Making knowledge work: Practices and politics of inclusive development and innovation. UK: Routledge. 


\subsection{Introduction}

The use of digital technologies to enhance efficiency of production, processing, and trade, aiming to improve the profitability and sustainability of organizations and industries, has become a global trend in a wide range of industries including in African smallholder agriculture (Klerkx et al., 2019; Munthali et al., 2018). The digitalization process concerns the use of digital technologies and infrastructures in businesses, economy, and society, restructuring social and professional life through digital communication and social media (Rijswijk et al., 2020). Another important concept related to digitalization is datafication, defined as the transformation through which objects, relationships, events, and processes become data points that are machinereadable and analysable by digital technologies using data analytics, machine learning, and complex algorithms (Williamson, 2018).

A popular assumption is that digitalization is ultimately beneficial for everyone, and truly transforms agriculture (Klerkx et al., 2019). This discourse is especially commonplace in the context of digitalization efforts for humanitarian, aid and development objectives (Cinnamon, 2020; Mann, 2018), like many of the present-day digital interventions in African agriculture (Mann and lazzolino, 2019; Tsan et al., 2019). In practice, the true socio-economic impact of digitalization processes in Africa's agricultural system is yet to be seen, and recent critical analyses of digitalization in agriculture point to unequal distribution of benefits and harm (Rotz et al., 2019; Van der Burg et al., 2019). This unequal distribution relates to mechanisms of social inclusion and exclusion, terms that are generally used to organize people (or groups) according to criteria that define who is 'in' and who is 'out' (Graham and Sweller, 2011). For example, when assessing access of African farmers to weather information via a mobile phone, one could take geography, gender, age, wealth, etc. into account; but in practice, processes of inclusion and exclusion are more complex.

This chapter has the objective to unravel this complexity in digitalization processes in African smallholder agriculture in three levels: 1) access conditions in relation to a specific digital technology; 2) design choices in relation to a digital innovation package; and 3) system complexity in relation to the digital agricultural system. To date these potential causes and impacts of inclusion and exclusion are underexplored in an African smallholder agricultural context, especially when looking beyond access conditions. There is a knowledge gap about the understanding of inclusion and exclusion surrounding digitalization of agriculture in the African context. With such a focus on 
Africa, this chapter builds on lessons learned from both a Global North and South contexts, providing a broad overview of factors causing inclusion and exclusion and establishing a more nuanced discourse around inclusion and exclusion related to digital agriculture-understood as broad digitalization both on- and off-farm, e.g. in the broader value chain-and its impact on people's lives.

\subsection{Method and conceptual framing}

\subsubsection{Procedure used to select and review literature}

For the purpose of this study we conducted a non-systematic, narrative review (Ferrari, 2015) of the literature on digital agriculture with additional focus on studies from Africa (Figure 13). Purposeful sampling was used to select articles for the review, with each of this article's authors suggesting a number of publications which were then reviewed for relevance according to an analytical framework (Appendix 6). Selected publications were reviewed for 105 variables in total belonging to three broad categories and sub-categories: (1) access conditions (availability, affordability, agency and awareness, ability), (2) design choices (design related risks), (3) system complexity (technology-social organization and integration).
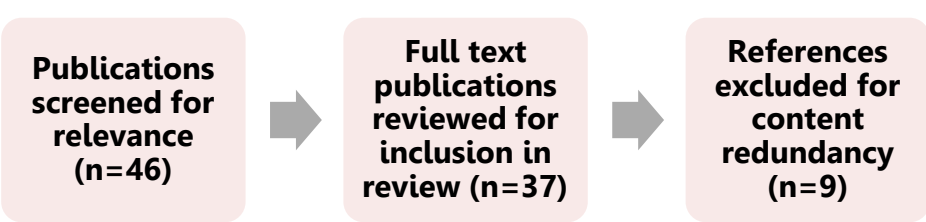
Publications included ( $n=28$, of which 4 grey literature)

\subsubsection{Conceptual framing of social inclusion and exclusion}

Notions of inclusion and exclusion in sociology address structural inequalities faced by different groups; traditionally mostly women, and also disabled, illiterate, indigenous, or (rural) poor people. Inclusiveness has long been promoted as a strategy to alleviate poverty, increase economic growth, generate employment, progress horizontal and vertical (gender) equality, and improve well-being (McKinley, 2010). In the African context, there is significant attention for inclusive development, innovation, 
and business (Opola et al. 2020; Pouw et al. 2019). Inclusion and exclusion are often used as binary distinctions that are defined by people either falling inside or outside specific social categories, and above or below specified limits (Mascareño and Carvajal, 2015). Within this context the good, expectable, and normalare attributed to inclusion, while exclusion being the negative opposite (Parsons, 1965). However, modern societies allow for a people and groups to be simultaneously included and excluded: Hence, inclusion and exclusion are not an 'either-or' matter, since no person is fully included or excluded (Mascareño and Cavajal, 2015). Stichweh and Windolf (2009) add a distinction between including exclusion and excluding inclusion, i.e. how inclusion in one group can result in (indirect) exclusion from another and vice versa. Hence, the distinction between inclusion and exclusion is more complex than a static observation of who is 'in' versus 'out' (Fitoussi and Rosanvallon, 1997) and should be approached as a process taking place within a particular social context, instead of a dichotomy between insiders and outsiders.

The thinking about inclusion and exclusion should move beyond binary terms and pay particular attention to the formation and maintenance of various kinds of power Du Toit (2004). In this regard, Sen (2000) identified unfavourable forms of inclusion; for example, as pointed out by Joseph (2014), a subordinated type in which inclusion is not evenly distributed. Another example is seen in agricultural value chains in which the profits are unevenly distributed between farmers, traders, and sellers.

Digital responses to address subordinated inclusion comprise applications that connect producers and buyers that bypass the middlemen (Aker, 2016) and e-auctions (Joseph, 2020). Unfavourable inclusion can also be illusive, so that the outcome of being included is then the same as the outcome of being excluded (Joseph, 2014). An example of illusive inclusion is when a farmer is selected to participate in a survey of a development project and expects to benefit from this. Yet, in practice the farmer never hears from this project again, nor witnesses results.

Sen's (2000) framework also recognizes constitutive, instrumental, active, and passive exclusion (and unfavourable inclusion). Constitutive exclusion has direct impact on the person excluded, such as female farmers not being invited for agronomic training and therefore not developing the same knowledge as male farmers. Instrumental exclusion leads to exclusion through causal linkages, for instance, when a farmer cannot access credit to buy inputs and equipment to increase farm production and escape poverty. Active exclusion is deliberate, as in purposely not inviting women for agronomic 


\section{Chapter 5}

training, while passive exclusion is non-deliberate and the result of social processes. In the latter case, exclusion is an unintended consequence of some decision or action, such as early-warning messages about the outbreak of a crop disease not reaching poorer farmers because they cannot afford the smartphone needed to receive the message. Nevile (2007) argues that when active forms of exclusion (or unfavourable inclusion) act as causal factors, focus should be on reasons and possible justifications for the deliberate decision to exclude. For passive forms of exclusion (or unfavourable inclusion), the focus should be on ways to mitigate unintended consequences.

\subsection{Observed mechanisms of inclusion and exclusion in digital agriculture}

Existing digital development discourse characterizes (data) inequalities as "a basic problem of inclusion/exclusion, based on the notion that inequality in diffusion of, access to, and use of data can widen development gaps between individuals, groups, and nations" (Cinnamon, 2020, p. 215), a framing that is criticised for being insufficient for explaining or addressing causes, forms, and consequences of inequalities. Hence, digital and data inclusion and exclusion always occur in a specific context. Figure 14 presents three contextual levels at which inclusion and exclusion takes place: The level of a (single) digital technology; a digital innovation package (i.e. a design of digital hardware and/or software, and the institutional arrangements to use it); and a digital agricultural system (i.e. the configuration of various rival and/or adherent and/or synergetic innovation packages and the socio-cultural context in which they need to operate).

Figure 14 illustrates how the contextual levels relate to each other. The digital technology level represents the most tangible and transparent level. Studies with an African focus have primarily concentrated on this level, studying who can and who cannot access a digital technology, and the conditions required for access. This access can be further divided into five sub-categories: Availability, affordability, awareness, abilities, and agency (Roberts \& Hernandez, 2019). 


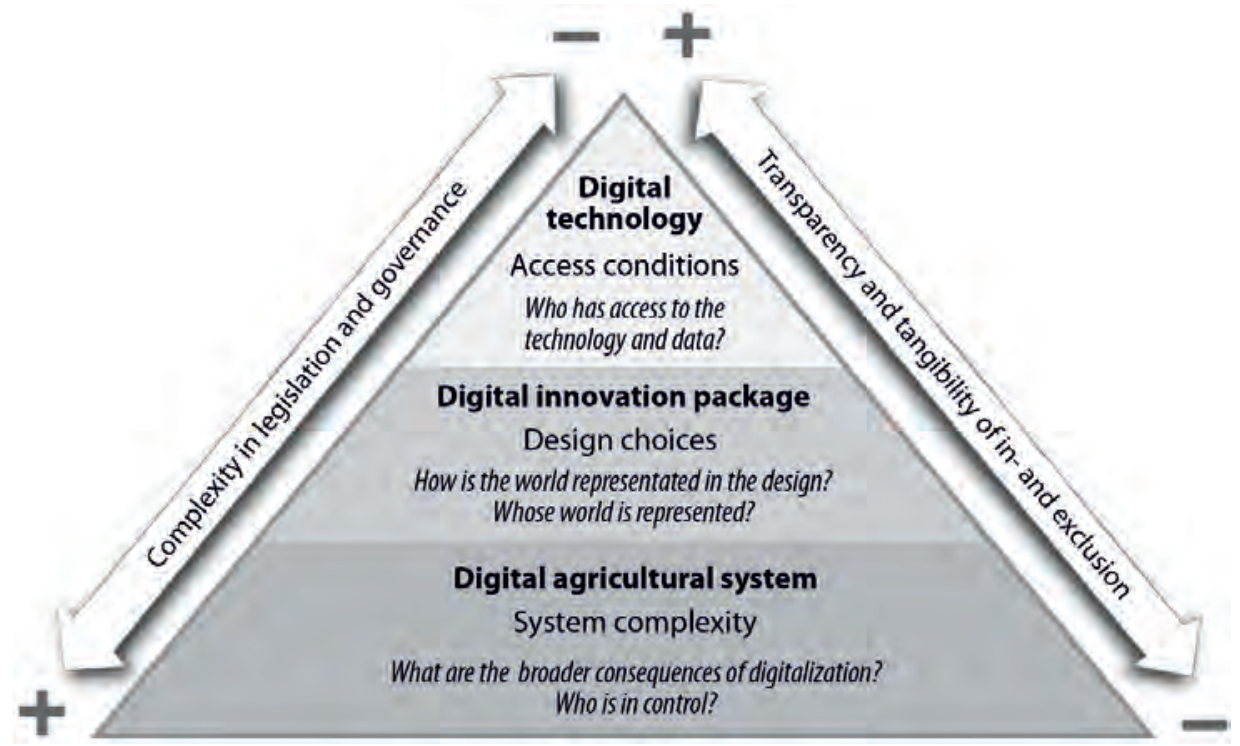

Figure 14: Relationship between the three levels at which digital and data inclusion and exclusion may appear, with increasing or decreasing complexity in the vertical axis governing the digital systems and marking how tangible and transparent inclusion and/or exclusion are.

\subsubsection{Digital technologies and access conditions: looking at digital divides}

In the following sections, we further unravel the three contextual levels introduced in the conceptual framework based on existing literature. Starting with the contextual level of digital technologies, we discuss different forms of inclusion and exclusion that together present a variety of (potential) areas of concern in relation to digital agriculture as identified in Table 13.

The advantage of focusing on a specific digital technology, and access to it, is that inclusion and exclusion are then relatively tangible and transparent. But, as seen in Figure 14, only the tip of the iceberg is then visible. Negative socio-economic impacts of digitalization have often been summarized under the umbrella of the so-called 'digital divide.' Access issues in Africa are generally recognized as key reasons for digital divides between the Africa/Global North, urban/rural, and rich/poor pairings (Trendov, 2019). This leads to social and economic marginalisation and uneven socio-economic development (Rijswijk et al., 2020; Rotz et al., 2019; Salemink et al., 2017). Thus, known factors like location, age, gender, ethnicity, wealth status, and education level, 


\section{Chapter 5}

determine access to and use of digital technologies by individuals, and they foster individuals' inclusion or exclusion to potential or assumed benefits of digitalization.

Table 13.: Overview linking the three contextual levels (digital technology; digital innovation package; digital agricultural system), forms of inclusion and exclusion that can arise, and existing or future areas of concern that were identified.

Contextual level
where inclusion and
exclusion take place.
Overarching reason
for inclusion and
exclusion at this level
Related data
inequality
Likely forms of
exclusion and
unfavourable
inclusion
Opportunities

Threats

\section{Factors influencing existence of inclusion and exclusion}

\section{Current or future areas of concern for unintended consequences and inclusion and exclusion}

\begin{tabular}{|c|c|}
\hline Specific digital technology & Digital innovation package \\
\hline Access conditions & Design choices \\
\hline Access to data & $\begin{array}{l}\text { Representation of the } \\
\text { world as data }\end{array}$ \\
\hline $\begin{array}{l}\text { Active, passive, constitutive, } \\
\text { inclusion; subordinated } \\
\text { inclusion }\end{array}$ & $\begin{array}{l}\text { Active, passive, constitutive, } \\
\text { instrumental exclusion; } \\
\text { subordinated, illusive } \\
\text { inclusion }\end{array}$ \\
\hline $\begin{array}{l}\text { Increased equal access to } \\
\text { digital technologies }\end{array}$ & $\begin{array}{l}\text { Decisions and solutions } \\
\text { that anticipate unintended } \\
\text { consequences (e.g. based } \\
\text { on fair and responsible } \\
\text { data principles) }\end{array}$ \\
\hline Digital divides; data divides & Design related risks \\
\hline
\end{tabular}

(Mostly) tangible aspects determining a person's access to a technology

Availability:

of hardware, software, data, infrastructure, rules/regulations, demand/supply Affordability: income/wealth, cost of material, value proposition, ease of use and learning Agency: autonomy, norms/values/beliefs, identity as a farmer Ability: digital literacy, general literacy, human physical ability, type of farm/geography
Digital agricultural system

System complexity

Control over data flow

Passive, instrumental exclusion; subordinated, illusive inclusion.

Establishing synergies between digital technologies and innovation packages

Digital traps: data originators or users become stuck in/with a particular system or digital technology

Risks and prospects related Socio-technical to design decisions organization and integration with the digital innovation package(s) Information overload, information quality issues, loss of human control and oversight over technology, human/animal-machine interaction, addictions, cybercrime, blurring of roles of organizations, ethical dilemmas 
Additionally, the increasing importance of data (that is, of datafication) has led to the emergence of a specific new type of divide: the data divide. The data divide refers to asymmetries between the 'data haves' and 'have-nots' (Scholz et al., 2018). According to Cinnamon (2020, p. 228), data divides matter because "access to data production and analytics in some cases actually has the reverse effect, the instantiation of new harms and the widening of inequalities."

\subsubsection{Challenges arising from digital divides}

Availability implies various forms of access: material (digital hardware, software, and data; infrastructure (required to access and use those hardware, software and data); institutional (rules and regulations); market (demand and supply); and suitability context (is the digital technology a good and fair fit for the context?). Availability of hardware, software, infrastructure, and suitable policies are outstanding issues in African countries (Ezeomah and Duncombe, 2019; Mann, 2018; Trendov, 2019;) leading mostly to passive and constitutive exclusion although active exclusion is also possible. Concerns arise that universal access and the increasing power of data in economic governance, together with the lobby of big tech companies for strategically advantageous regulation, puts African countries at risk of data extraction that benefits foreign rather than domestic economies (Mann, 2018). In such cases there is a risk of unfavourable inclusion; specifically, of subordinated inclusion.

Affordability relates to economic capacity: capital required to access digital technologies; one off or recurring material investments; and whether the technology delivers profit. Inclusion and exclusion here result from economic inequalities between farmers and farmers and other stakeholders, thus resulting in passive and constitutive exclusion. Affordability challenges may exacerbate with extremely high initial investments, or recurring expenses. Continuous investments become more problematic in case of technological lock-in and path-dependency, tying a farmer to one particular company or organization due to proprietary software, inability to access farm data without a subscription plan, or inoperability with competitive offers (Bronson, 2018). Considering the income levels of African smallholder farmers combined with general absence of loan facilities, practically any investment may be considered 'extremely high' in this context. In addition, social needs and values influence perceptions about affordability. For example, the common conception that 'time is money' in high-income countries legitimates investments in labour and time saving technologies. Most African farmer's time or labour however is considered 'for free', especially women's time, 
Chapter 5

resulting in a totally different cost-benefit calculation (Grassi, 2015). Additionally, whether investments guarantee profit return or not matters, especially in volatile markets with fluctuating agriculture produce prices (Rotz et al., 2019). These affordability issues may all result in exclusion of farmers' access to digital technologies, by definition (e.g. unable to buy a phone) or by choice (e.g. unwilling to invest in a phone).

Another issue for digital agricultural technologies in the context of African smallholder farming is users' capabilities, ease of learning and using a digital technology, and whether farmers can afford investment in additional training and resources (e.g. time, effort, physical strength). A reason for poor adoption is that farmers - especially the elderly, and females - struggle with using digital tools, particularly when smartphone based (Ezeomah and Duncombe, 2019). This relates to user ability in terms of digital and general literacy, and physical ability. Literacy is a well-known challenge in agricultural development, creating barriers for farmers with limited or no education. Digital literacy is a newer issue relating to skills and knowledge required to use digital technologies, such as using hardware and software, and making sense of data produced or received. In other words, digital technologies need to fit farmers' level of tech savviness to prevent passive and constitutive exclusion (box 2).

Agency and awareness about the socio-cultural context are less tangible issues that are often embedded in the socio-cultural make up of agricultural communities and therefore not directly observable. However, they are critical factors that influence adoption decisions and passive as well as constitutive exclusion, especially in cases of non-adoption or de-adoption, regardless of good availability, affordability, and ability of users. An example of constitutive exclusion is when it is considered socio-culturally inappropriate for a woman to use digital technologies.

Reasons for inequalities in access to digital technologies and data are not limited to observable, tangible, or seemingly individual factors (like age, gender, and wealth) but extend to more unobservable, intangible, and aggregated issues too, which as we will see in the next sections, relate to the other contextual levels of figure 1, namely. the digital innovation package, and the digital agricultural system. 
BXW-app is a smartphone application that was developed by the International Institute of Tropical Agriculture (IITA) and partners in the ICT4BXW project. The app supports Rwandan village-level extension agents with the diagnostics and monitoring of Banana Xanthomonas Wilt disease (BXW). BXW-app can moreover provide banana farmers with information about good agronomic practices. Originally the ICT4BXW project aimed to use (smart)phone technologies and citizen science to enhance control and prevention of BXW disease, working together with farmers, and the government extension services (ICT4BXW.com). Although most Rwandan banana farmers and village extension agents own a mobile phone (70\% and $94 \%$ respectively) the ownership of smartphones, necessary to access applications like BXW-app, appeared nihil (ICT4BXW, 2020). Limited smartphone ownership in combination with other access issues, like absence of electricity, cell and internet reception limitations, and poor digital literacy, were major challenges for the project. The question arose if farmers' capacity to use phone-based extension services is sufficient today. ICT4BXW is a good example of a project that overestimated the digital access in Rwanda and underestimated the complexity of developing a digital extension service that fits with the reality of and is accessible for most farmers.

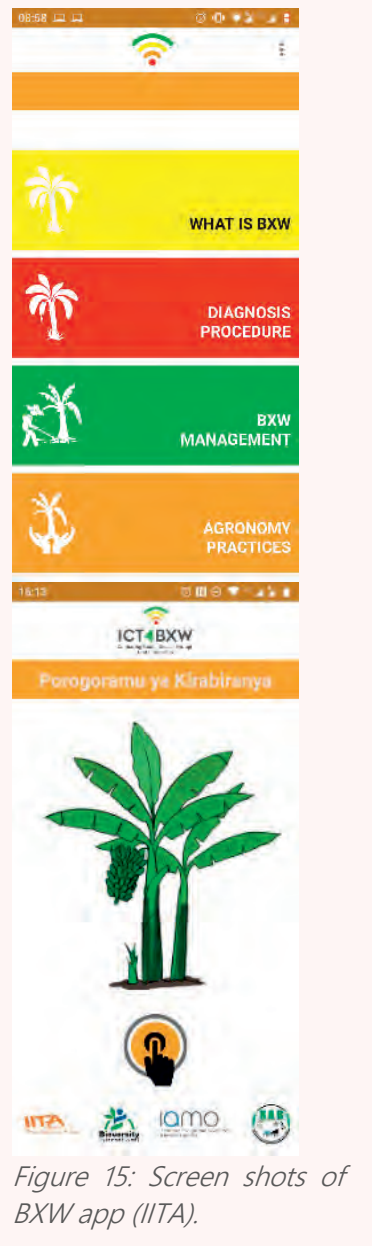

\subsubsection{Digital Innovation Packages and Design Choices: deciding about the design and anticipating design consequences}

Digital technologies and interventions are designed with a specific objective and desired outcomes in mind. Decisions about the design determine, for example the physical, front-end design (e.g. the hardware and software interface) and system or back-end design (e.g. programming languages used, location of databases, interoperability with other systems).

These design choices around digital technologies and innovation packages are always accompanied by risks, as it requires decision making about the world that the 
technology and the collected data collected represents, i.e. whose world is represented, and how is this done. These decisions alter our physical world and how we operate in it, potentially causing unequal opportunities (Cinnamon, 2020). Hence, design related impacts and intended and unintended consequences are likely, which in turn can lead to all forms of exclusion and unfavourable inclusion. Design choices are ultimately accompanied by trade-offs; saying 'yes' to one design feature usually equals saying 'no' to other features. Those trade-offs make exclusion almost inevitable as design-for-all or one-size-fits-all solutions is highly complex and oftentimes simply impossible. An example trade-off is the anticipation that progressing digitization in African agriculture will reduce demand for traditional farm-labourers, but that digitization could be a net job-creator too, offering opportunities for those with the right skills, like the many highly educated African youth (Heeks, 2020; Tsan et al., 2019). This non-deliberate loss of particular jobs is in turn an example of unequal distribution of benefits as well as instrumental and passive exclusion. Design choices should ideally anticipate unintended consequences that could become design related risks (Rijswijk et al., 2020). In this, transparency and accountability are desirable.

Designing digital innovation packages is also about distributing power among actors, with some becoming more influential than others. But how are benefits from digital technologies distributed among different actors, such as technology developers, users, data originators, and data owners (box 3)? Do design choices contribute to reducing inclusion and equal distribution of benefits, or do they create marginalization of individuals or groups? These questions relate to subordinated inclusion, e.g. one actor will benefit more from an innovation design than another.

Digital agriculture is often associated with high-tech, smart technologies and largescale, input-intensive farms. Scholars have observed that wealthier, large-scale, commercial farmers benefit more from digitalization in agriculture (Bronson, 2018). Hence digitalization may support a limited number of specific agricultural production systems at the expense of others (Bronson and Knezevic, 2016; Klerkx et al., 2019). Others argue that visions for the role of digital technologies support perpetuation of a status quo that prioritizes maximization of global agricultural production (LajoieO'Malley et al., 2020). Then again, in the absence of large numbers of commercial farms to date, current digitalization initiatives in Africa focus mostly on reaching smallholder farmers. 
The Nigerian social enterprise Hello Tractor operates in various African countries (e.g. Nigeria, Kenya) and offers a mobile booking platform that connects tractor-owners in a locality with farmers in need of tractor equipment. The company additionally sells a monitoring device that allows for remote monitoring of tractors, registering e.g. GPS data and tractor operator activity. Hello Tractor is said to have introduced the concept of 'Uber to mechanization' in developing countries (Daum, Villalba, Anidi, 2020), making tractors available to a large number of smallholder farmers. This creates a business model that allows African youth to make a living as tractor owner or operator. Hello Tractor's digital innovation package originally included tractor sales too, but they now limit themselves to the booking platform and monitoring devices. The latter are promoted as 'little black boxes' that 'glean intelligence' and 'use that information to build insights that lead to [...] marketdefining analytics (hellotractor.com).
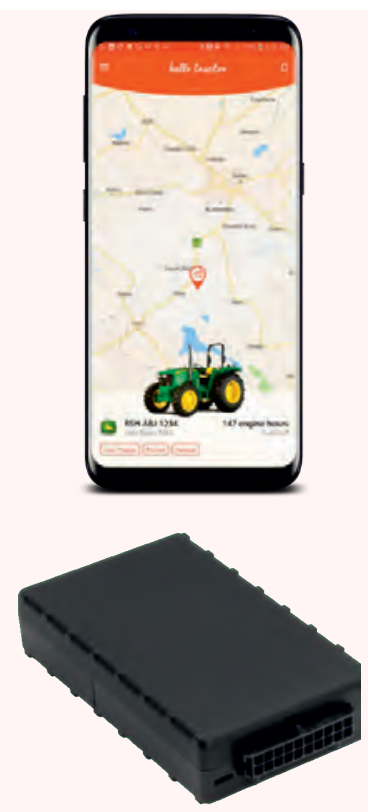

Figure 16: Left: The monitoring device (HelloTractor.com). Right: Screenshot of Hello Tractor app (Tech(runch.com).

In Nigeria, Hello Tractor established a public-private-partnership with the Nigerian Ministry of Agriculture and John Deere.This enables new tractor owners to initially lease a John Deere tractor equipped with the Hello Tractor device, and later buy that tractor at a discount (Forbes.com). The expected results of this partnership are impressive: Deploying 10.000 tractors in five years, bringing 9 million hectares of land into production, and creating 2 million direct and indirect jobs (Forbes.com). Kolk \& Ciulli (2020) see such collaborations with multinationals like John Deere as a facilitator for easy replication of the business model and supporting the spread and acceleration of (sustainability) transitions. However, the analogy of the black box monitoring device and dependency on a multinational, interested in expanding their business to the African continent also raises questions. What exactly are the commercial interests? What data is exactly collected? Who owns the data? According to Mann \& lazzolino (2019), questions like these, about what is good, what is just, and what is development should be part of public debate and rather than being decided upon by private sector actors or foreign non-profits.

The widespread use of smartphone-based applications and platforms in digitalization processes, for now, makes the socio-economic status of users less influential. 
Nevertheless, in practice wealthier or more literate farmers have the advantage of an overall larger capacity to buy fertilizers, hybrid seeds, get credit, or access digital hardware and infrastructure required to get access to information in the first place (Mann, 2018); therefore they are better able to benefit from what digital technologies have to offer. This as an example of illusive inclusion; the design of a digital technology may be inclusive for all farmers, yet they cannot all benefit from it because of the inability to truly use or act upon it.

\subsubsection{Digital agricultural systems and system complexity: Emerging mechanisms of inclusion and exclusion in digital agriculture}

In this section we cover the third level, system complexity, or the composition of elements that together make up the digital agricultural system and the sociotechnical organization within it. The digital agricultural system is complex in multiple ways: variations in crop production systems and value chains; national and international jurisdictions; the multitude of actors involved; and the ever-growing diversity of digital technologies and technological packages which may or may not be interconnected or interoperable. The complexity and motions of digital systems make prediction and visibility of different forms of inclusion and exclusion challenging.

System complexity also increases uncertainty about issues such as the quality of data and information as input and output of digital systems. A possible response is more technological integration. Integration offers opportunities for synergies and reduced complexity, yet a lack of integration can become a digital trap (Rijswijk et al., 2020). For example, a user may become stuck with a particular piece of hardware or software that is not interoperable with other items or cannot be updated. Interoperability and coupling of systems are critical. In contrast, too tight coupling of systems leads to vulnerability and potential domino effects, i.e. if one system fails, all fail. How do digital traps and domino effects relate to inclusion and exclusion? The first can result in perpetuating inclusion or exclusion: those included remain included, those excluded remain excluded. Instrumental exclusion may be the outcome of the latter because of the causal linkages between systems.

The presence of digital technologies and data-based decision-making inherently affects real-life interactions, such as between people or people and animals. Traditional human-to-human interactions become moderated or replaced by machines, changing relationships between humans and their natural, technical, and social environments and 
allowing for less empathy, trust building, and judgement of intentions and preferences (Scholz et al., 2018). In cultures where human-to-human interaction has important cultural value, like most African cultures, trust is important for acceptance of (digital) technologies (Aker et al., 2016). According to Scholz et al. (2018), data can be a disturbing variable and distractor for sharing experiences and knowledge, taking away agency from the human individual.

More concretely, digital systems rely on data input to operate. However, data inconsistency is a known problem, especially with large datasets from heterogenous sources, needing investment in rigorous efforts to reduce data noise and correct inconsistencies (Philip Chen and Zhang, 2014). Another challenge with data aggregation is the need to consider variances in how data is interpreted. Although mainstreaming interpretations enhances interoperability, it also raises the question of whether 'hybrid' interpretations are trustworthy or provide a new form of interpretative doubt (Mansour et al., 2016), and whether they support or undermine equality (box 4). For example, the outcome of interpretational mistakes may be that people are passively included or excluded, which is hard to control for and may have unforeseen consequences.

But who is responsible for those consequences? Governing digital agricultural systems is inherently difficult, especially when they are coupled or operating across-borders. Yet this also influences control over digital technologies and, more importantly, control over who uses data, where, when, and for what purposes (Cinnamon, 2020) as well as who can be held accountable. In combination with uncertainty about emerging effects of digitalization, accountability leads to various concerns about misuse of data and blurring roles and responsibilities in the digital agriculture system. Currently, roles, actors and data-owners are not clearly defined; neither are governance models, establishing who is accountable for what. Additionally, actors in the agricultural sector need to redevelop their identity and build new capacity and expertise, moving from being classical agricultural or humanitarian organizations working on crop improvement, face-to-face extension services, or emergency support to people, to designers and operators of digital platforms and systems which requires different skillsets and expertise. Within this complex and opaque environment, it is easy for all kinds of inclusion and exclusion to emerge, being at the same time difficult to anticipate. Additionally, taking action against exclusion or unfavourable inclusion may 
not be in the interest of the actors who are in control, yet institutional arrangements fall short in effectively controlling this.

\section{Box 4: CGIAR GARDIAN ecosystem and CG Labs}

The global agricultural research consortium CGIAR, through its Platform for Big Data in Agriculture, seeks to make the consortium's data resources organized and FAIR (Findable, Accessible, Interoperable, Reusable). In order to do so, they established the GARDIAN ecosystem, a platform where data resources from all consortium members and selected partners are collected, searchable and, accessible. More recently the CG Labs was added to the GARDIAN system, a data science platform that allows anyone interested in using data available in GARDIAN to (collectively) perform analyses with the data (gardian.bigdata.cgiar.org).

The effort to bring together research data and making it accessible and usable to a large audience is on the one hand applaudable. On the other hand, it leads to potential concerns. For example, GARDIAN strongly protects data security on the side of the researcher, ensuring that their data analysis work is protected. But what about the security of the data originators? Moreover, efforts were made to create shared ontologies for data available in GARDIAN. Yet, how reliable are those ontologies considering that data comes from so many sources, countries, and years? Thus, we see that although a system like GARDIAN may appear simple with its search engine at the frontend, yet what is behind it is much more complex, let alone the potential data analyses and manipulations that can be done with it.

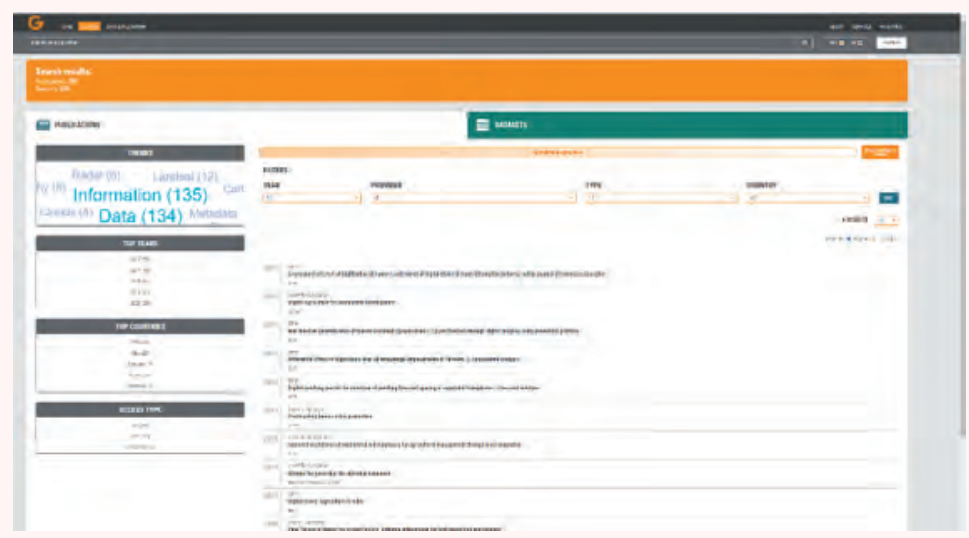

Figure 17: Screenshot showing results of a simple search query in GARDIAN for the terms 'digitalization' and 'agriculture'.

\subsection{Rethinking inclusion and exclusion for the context of digital agriculture}

The previous sections showed that as opportunities to capture unique properties about individuals, their farm, and their behaviour (habits, norms and values, likes and dislikes, recurring decisions) expand it more and more matters who you are 
and what you do, both as an individual and a company or organization. We have seen that digital technologies may lead to various mechanisms of inclusion and/or exclusion of actors and that increasingly these mechanisms may be intangible in nature (e.g. algorithmic bias, or user profiling). Intangible factors, resulting from design choices and system complexity, become powerful determinants of who is included or excluded and whether inclusion and exclusion is beneficial or harmful due to e.g. expanding access to data, aggregation of data, and capacity for data computation and manipulation. We previously noted that in relation to African agriculture focus has been biased towards access conditions, while attention for design choices and system complexity lags behind. The latter two are rarely considered, or only in form of critique-such as exclusion of actors in the design process and of actors from the benefits of data generated outputs-without offering solutions to the emerging challenges. Digital technologies meanwhile present themselves as a double-edged sword: being included may be both beneficial and harmful. Similarly, included individuals may gain agency at one contextual level, but lose it at another level.

In this chapter we unravelled the known and future impacts of digitalization processes on inclusion and exclusion in African agriculture and showed the difficulty to identify 'right' from 'wrong.' Ultimately, digitalization comes with trade-offs: people generally lack control in being included somewhere and excluded elsewhere, and vice versa. Although designers and implementers of digital technologies may anticipate many unintended consequences, some fall into the category of unknown consequences and simply cannot be predicted beforehand. Additionally, it is not always possible to control for all unintended consequences, especially when they require transformations beyond the technological design such as in the institutional or socio-cultural environment. Hence, the dichotomy of inclusion and exclusion and the inherent normative assumption that inclusion is always good and exclusion always bad demands revisiting. The perception that technology and technological progress are inherently good and needed for growth is fundamentally flawed when it comes to digital technologies. Instead, the trade-offs and unintended consequences that come with digitalization and datafication at the three contextual levels that we discussed in this chapter should receive more recognition and consideration. 

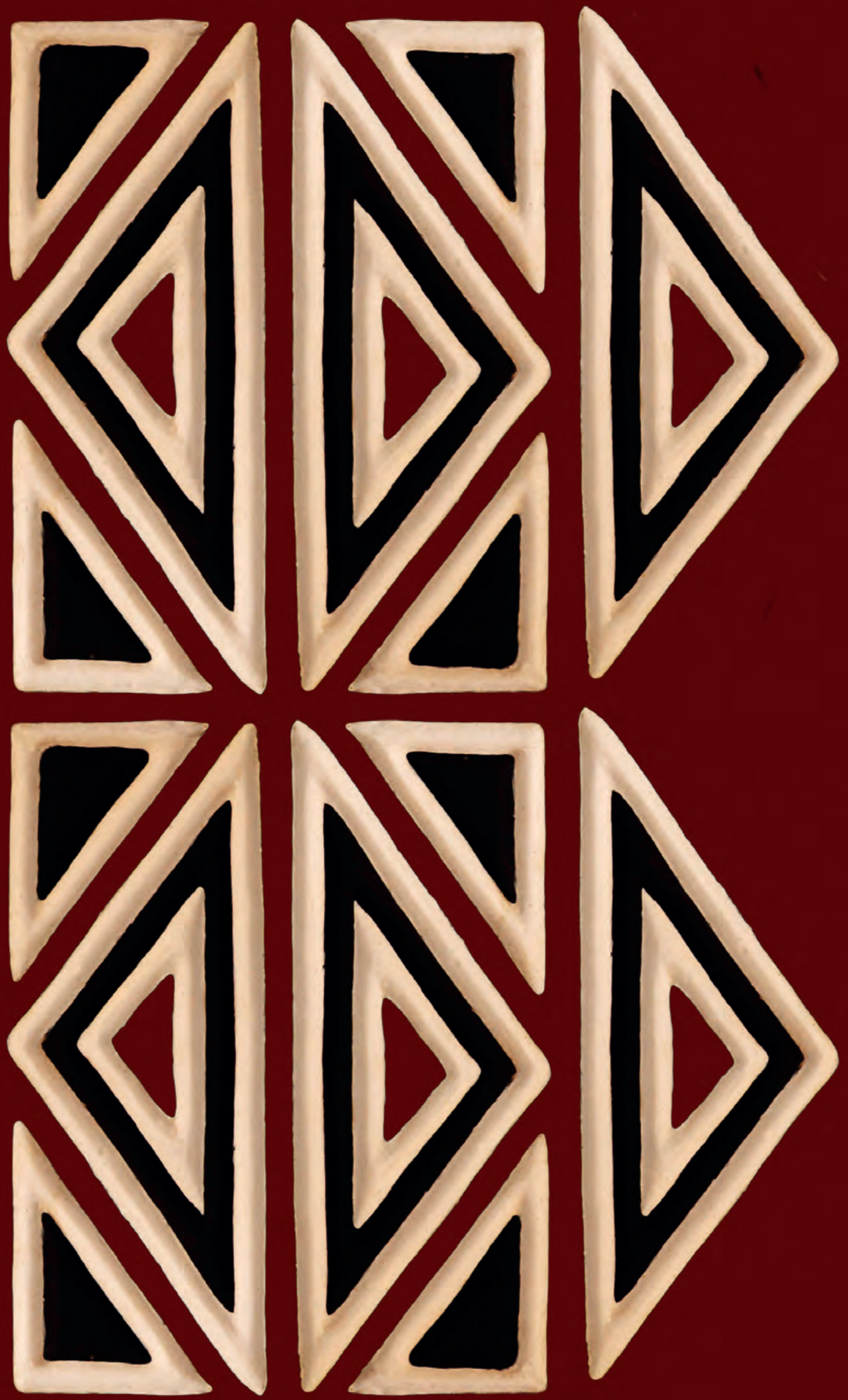


\section{Adding emergence and}

spatiality to a public-bad game to study dynamics in socio-ecological systems (Part I)

The design of Musa-game for integrative analysis of collective action in banana disease management 


\section{Abstract}

Human decision-making plays a critical and challenging role in addressing problems within socio-ecological systems (SES), such as the prevention and control of a public bad: a 'bad' that is non-rivalrous and non-excludable, causing a loss in socialwelfare of individuals and communities. Infectious diseases, in humans, animals, or plants, are examples of challenging public bads. Farmers are daily confronted with dilemmas regarding public bad management. Their decisions and actions are both the cause and effect of interactions between multiple factors and may create the risk conditions in which a public bad can occur in a SES. This article presents an experimental boardgame, Musa-game, to study the effect of individual and collective human actions on creating or preventing a public bad, and the influence of risk communication on those actions. The theoretical and methodological novelty of Musagame is that it adds attributes of SES, emergence, and spatial analysis to the study of public bads and collective action problems. Capturing emergent phenomena arising from interactions between human and non-human actors allows for building contextual understanding regarding how individual and collective actions of various entities lead to typical system outcomes (conditions that are (un)favourable to pathogens) and individual decisions about infectious disease management. To conceptualize our method, we used the case of Banana Xanthomonas Wilt disease in Rwanda. This research is published as a diptych, Part I (this article) covers the conceptualization and design of Musa-game, Part II presents findings from testing Musa-game with farmers in Rwanda and recommendations using the method.

Chapter published with minor revisions as: Galarza-Villamar, J., McCampbell, J.A., Leeuwis, C., Cecchi, F. (2021). Adding Emergence and Spatiality to a Public bad Game to study dynamics in socio-ecological systems (Part I): The design of Musa-game for integrative analysis of collective action in banana disease management. Sustainability, 2021, 13(16), 9370.

An earlier version of this work was published as: Galarza-Villamar, J., McCampbell, M., Galarza-Villamar, J.A., Leeuwis, C., Cecchi, F., Galarza-Rodrigo, J. Adding Emergence and Spatiality to a Public Bad Game within the Context of a Socio-Ecological System: Collective action to fight an infectious disease outbreak. In: Galarza-Villamar, J. 2021. Social capital, collective action, and livelihood resilience: a multidimensional approach. (Doctoral dissertation, Wageningen University). 


\subsection{Introduction}

A collective action problem occurs when the uncoordinated actions of individuals result in sub-optimal and less beneficial outcomes than coordinated actions would. In rational choice-based approaches, this problem occurs when self-interestdriven individuals fail to choose beneficial coordinated actions (Olson, 1965). Individuals' decision-making toward a good or resource that benefits everyone is influenced by social dilemmas. These are situations in which every person is better off if everyone cooperates, yet this cooperation fails due to conflicting individual interests (Dawes, Kragt, \& Orbell, 1988). In other words, it is a situation in which individual rationality leads to collective irrationality (Kollock, 1998).

Public goods (PG), such as public infrastructure or the environment, are non-excludable and non-rivalrous. Common goods (CG), such as a community forest or groundwater, are non-excludable and rivalrous. The difference is that, while the use of a public good by one individual does not affect the availability for another, the use of a common good does. The production or maintenance of a public good, or the use of a common good, is related to the prevention of a public bad (Sonnemans, Schram, \& Offerman, 1998). In 1832, Lloyd sketched out a, now famous, example: a common land with pasture where anyone may let their cattle graze (Lloyd, 1980). Each herdsman adds one more animal at a time to increase their profit. After some time, the land becomes overgrazed, and all the cattle die. Hardin (1968) called this 'the tragedy of the commons'. Although all herdsmen would prefer to have more and not less grass to feed their cattle, nobody achieves this because of self-interest-driven choices.

Following the same logic, a problem related to the prevention of a public bad is the production of a public good or sustaining a common good. As illustrated in Lloyd's example, public bads reduce benefits and have the potential to impact a significant number of people negatively because they are non-excludable and non-rivalrous (Hall \& Harper, 2019). To further illustrate this, we can use an adaptation of Lloyd's example: the cattle of a group of herdsmen graze on a common grassland. An infectious disease that is transmitted through ticks is reported in a few cattle. To reduce the risk of further disease spread, all herdsmen must treat their cattle with acaricides. However, since only a few herdsmen do this on time all the cattle become infected resulting in high mortality (Mutavi, et al 2018). Thus, although all individuals would prefer to have fewer ticks and not more, they collectively fail to achieve this because of the uncoordinated individual actions. 


\section{Chapter 6}

In both Lloyd's example and our adapted version of it, livestock is the main agricultural resource sustaining a herdsman's livelihood. In the first example, this resource is threatened by the hazard of overgrazing, in the second the spread of a tick-borne disease forms the hazard. While overgrazing relates to the overuse of a common good, the spread of the tick-borne disease relates to the management of a public bad. In a real-world context, herdsmen's decision-making is multi-factorial and more than the sum of its parts. This property is called emergence (Bonabeau, 2002). The emergent phenomena create new conditions to which actors and biophysical entities may have to adapt in a continuously evolving process. Emergence is a particular characteristic of complex adaptive systems such as socio-ecological systems (SES) (Schlüter et al., 2019).

Understanding the factors at play in human cooperation is crucial for solving collective action problems, to either produce or use a public or common good, or to prevent and control a public bad. This article presents an experimental boardgame, Musa-game, to study the role of human actions to prevent a public bad in the context of socioecological systems. The theoretical and methodological novelty of Musa-game is that it adds attributes of SES, emergence, and spatial analysis to the study of public bads and collective action problems. So far, neither classical laboratory and field experiments, nor ABM has integrated all these elements into one game-method. Hereafter, we first develop a theoretical framework to study a public bad problem in SES based on the complex-adaptive system approach (Ostrom, 2007; Ostrom, Gardner \& Walker, 1994). We adapt the original approach by integrating conceptual thinking about livelihoods, economics, and risks; to then add the operational aspects of socioecological systems in terms of emergent phenomena and spatiality. We thereafter explore how economic games and agent-based models can contribute to the study of collective action problems in SES, and their potential application for studying dynamic public bad problems. Next, we describe the case study of Banana Xanthomonas Wilt (BXW) in Rwanda which we used to develop our methodological design. This method is then presented as an experimental boardgame to study how farmers' decisionmaking (individual and collection actions) interplays with other SES factors and creates the conditions that hinder or enhance the spread of Banana Xanthomonas Wilt (BXW) disease (a public bad) in Rwanda. 


\subsection{Theoretical framework}

Agriculture sustains the livelihoods of 2.5 billion people globally (Coff et al., 2015), most of them smallholder farmers, herders, fishermen, or forest-dependent communities, who generate more than $50 \%$ of global agricultural production (Samberg, et al 2016). Agricultural livelihoods can be considered as socio-ecological systems (SES) (Rivera-Ferre, Ortega-Cerdà, \& Baumgärtner, 2013) which consist of societal and ecological subsystems that interact with one another, are complex, dynamic, and continuously evolving (Gunderson \& Holling, 2001). A SES is said to be resilient if it can absorb disturbances and respond to change through reorganization thereby maintaining its functions, structures, and evaluations, without deviation from its original pathway (Holling, 2001).

We build upon the SES framework originally introduced by Elinor Ostrom (2007) (see also Ostrom \& Cox, 2010). Its most elaborate version emphasizes both direct and feedback interactions and also integrates the role of emergent phenomena in the system. In this study, we integrate emergence in our theoretical framework, and also design a methodology based on games to operationalize it. Ostrom (2007) proposed a multilevel and nested framework to analyze the sustainability of SESs. The main subsystems in this framework are resource systems (RS), resource units (RU), governance systems (GS), and users (U). In her example, the RS is a protected park in a specified territory containing forested areas, wildlife, and water systems. The RU are the trees, wildlife, and water systems present in the park. The GS are the institutions managing the park, the specific rules related to the park's use, and how those rules are made. $U$ is the individuals using the park for their livelihoods, recreation, and other purposes. We adapted Ostrom's (2007) original framework for application to a public bad risk management situation in which the assets and units form a livelihood system, which users rely on to generate ecosystem services and make a living, is threatened (Figure 18). 


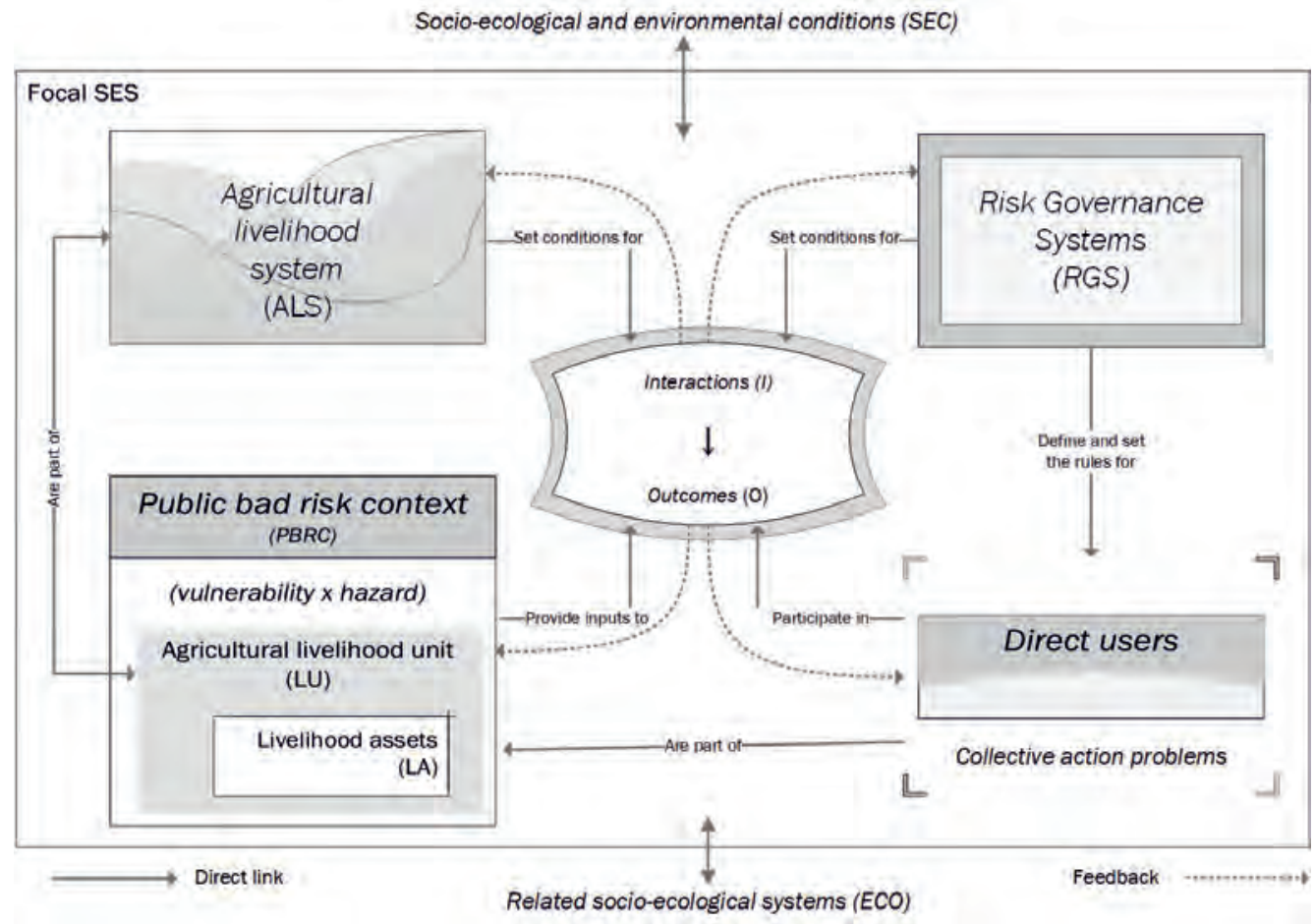

Figure 18: The core subsystems within a socio-ecological system that provide the framework for analyzing a public bad risk that threatens livelihood resilience, from a risk and collective action problem perspective. Adapted from Ostrom (2007).

Table 14 describes the framework for analyzing a public bad risk threatening livelihood resilience shown in Figure 18. The descriptions and examples are adapted from Ostrom (2007). In our framework, there is an agricultural livelihood system (ALS) in which an agricultural activity $(x)$ is the livelihood unit (LU). The direct user(s) (DU) rely on the LU to make a living in a specific territory. To produce and sustain this LU different livelihood assets (LA) are required (human, social, natural, physical, financial). Both the LA and the LU are vulnerable to different types of hazards. The covariate manifestation of the hazard (public bad risk) in the LU is strongly influenced by the DUs' collective actions to prevent and control the hazard. Those collective actions are constrained or enhanced by multiple factors (risk perspective, social dilemmas, capacity to adapt and respond). 
Table 14: Description of the components of the framework for analyzing a public bad risk threatening livelihood resilience.

\section{Components Description and example}

Agricultural livelihood

system (ALS)

Livelihood unit (LU)

Livelihood assets

Public bad risk context (PBRC)

Vulnerability

Hazard

Risk perception

Risk governance

system (RGS)

Direct users

Collective action

problems

Action Interactions (I)

and outcomes (O)

Social, economic,

ecological,

environmental, and

political conditions

(SEC)

Related socio-

ecological systems

(ECO)

Dashed arrows

Dotted-and-dashed

lines
This is represented by a specific territory where diverse agricultural livelihood activities take place, involving crops, animal husbandry, and related activities and assets that provide ecosystem services to farmers and consumers.

This is a specific agricultural activity providing ecosystem services needed to make a living, e.g. cattle for milk and meat, rice production for human consumption, maize production for human or animal feed.

Human: peoples' health and ability to work, knowledge, skills, experience;

Natural: land, water, the forest, livestock; Social: trust, mutual support,

reciprocity, ties of social obligations; Physical: tools and equipment,

infrastructure, market facilities, water supply, health facilities; Financial:

conversion of production into cash, formal or informal credit.

Conditions of vulnerability and characteristics of the hazard that hinder or limit the probability of a public bad

The vulnerability (of any system) is a function of three elements: exposure to a hazard, sensitivity to that hazard, and the capacity of the system to cope, adapt, or recover from the effect of those conditions (Turner et al., 2003).

A physical event, phenomenon, or human activity that has the potential to cause the loss of life or injuries, property damage, social and economic disruption, or environmental degradation. Its potential can be characterized by its probability (frequency) and intensity (magnitude or severity) (Blaikie, et al, 1996).

Risk perceptions are formed by common-sense reasoning, personal experiences, social communication, and cultural traditions. These are the contextual aspects that individuals consider when deciding whether or not to take a risk and selecting reduction or preventive measures (Van Asselt \& Renn, 2011; Wachinger, et al, 2013).

Rules (operational, collective-choice rules, constitutionals), property right regimes (private, public, common, mixed), network structure (centralized, noncentralized) (Van Asselt \& Renn, 2011).

Farmers and households who depend on the livelihood unit.

Coordination of responses to problems among direct users triggered by social dilemmas, risk perception, or coping capacities.

Action situations are where all the action takes place as inputs are transformed by the actions of multiple actors into outcomes (McGinnis \& Ostrom, 2014) Economic development, demographic trends, political stability, government (settlement) policies, market incentives, media organizations, the biophysical environment, and climatic conditions.

Other livelihood systems interlinked to the one in question.

These denote feedback from action situations (McGinnis \& Ostrom, 2014) These surround the focal SES and are influenced by exogenous factors, which might emerge from dynamic processes at larger or smaller scales, either inside or outside the focal SES (McGinnis \& Ostrom, 2014) 
Chapter 6

The DUs' actions continuously interact with the risk governance system, influencing and being influenced by the set of formal and informal rules and strategies to manage a public bad risk. If collective action between DUs fails, the likelihood of the risk of a public bad increases, which then impacts upon the system's interactions and outcomes, possibly leading to the emergence of a public bad risk that harms various essential LAs and LUs. The damage to the LAs and LUs in turn negatively impacts the provision of ecosystem services to the DU and, possibly, other SES.

Humans intervene in natural systems that provide ecosystem services (i.e. crop or livestock production) to people (consumers) and a livelihood to those providing those services (farmers) (Cabel \& Oelofse, 2012). A livelihood includes the capabilities, assets, and activities required for a means of living. It is resilient when people have the capacity, across generations, to sustain and improve their livelihood opportunities and wellbeing despite environmental, economic, social, and political disturbances (Tanner et al., 2015). The performance of agricultural livelihoods largely depends on the accessibility of assets (or capitals): natural, physical, human, financial, and social (Niehof \& Price, 2001). Assets are vulnerable to different kinds of hazards, such as natural, environmental or biological hazards. Infectious diseases are among the most challenging biological hazards and can affect humans, animals, and crops. Those same people, animals, or crops are also critical assets for agricultural livelihoods. Hence, livelihood resilience to biological hazards, and especially infectious diseases, is critical for the food security of smallholder farmers and the global society as a whole (FAO, 2017).

We further contextualize our framework for the context of infectious disease. There are numerous examples where our framework can support analysis of resilience to a public bad risk as a result of an infectious disease (Table 15). 


\section{Host - Livelihood units}

Public bad risk conditions (vulnerability and hazards):

Disease

Livelihood
units
Fatality/
Losses
mechanism

\section{Users risk management strategies that require coordination and cooperation}

\begin{tabular}{|c|c|c|c|c|c|}
\hline $\begin{array}{l}\text { A person } \\
\text { (labor, } \\
\text { knowledge, } \\
\text { etc.) }\end{array}$ & Malaria & $\begin{array}{l}\text { Various } \\
\text { plasmodium } \\
\text { parasites }\end{array}$ & $\begin{array}{l}\text { Transmitted by the } \\
\text { bite of the } \\
\text { anopheles } \\
\text { mosquito }\end{array}$ & $\begin{array}{l}\text { Over } 60 \\
\text { deaths per } \\
1000 \\
\text { admitted } \\
\text { in cases of } \\
\text { children } \\
\text { age }<5 \\
\text { years }\end{array}$ & $\begin{array}{l}\text { Draining of } \\
\text { standing water } \\
\text { where mosquitos } \\
\text { breed, spraying } \\
\text { living and sleeping } \\
\text { quarters, and the } \\
\text { use of bed nets } \\
\text { (Murindahabi et } \\
\text { al., 2018) }\end{array}$ \\
\hline $\begin{array}{l}\text { A person } \\
\text { (labor, } \\
\text { knowledge, } \\
\text { etc.) }\end{array}$ & Coronavirus & $\begin{array}{l}\text { SARS-CoV-2 } \\
\text { (COVID-19) } \\
\text { virus }\end{array}$ & $\begin{array}{l}\text { Person to person } \\
\text { transmission via } \\
\text { respiratory } \\
\text { droplets generated } \\
\text { by breathing, } \\
\text { coughing, } \\
\text { sneezing or, hand- } \\
\text { mediated transfer } \\
\text { from } \\
\text { contaminated } \\
\text { surfaces to mouth, } \\
\text { nose, or eyes } \\
\text { (ECDC, 2020) }\end{array}$ & $\begin{array}{l}2 \% \text { case } \\
\text { fatality } \\
\text { due to } \\
\text { alveolar } \\
\text { (Xu et al., } \\
2020 \text { ) } \\
\text { damage or } \\
\text { respiratory } \\
\text { failure }\end{array}$ & $\begin{array}{l}\text { Social distancing, } \\
\text { wearing facemasks } \\
\text { in public spaces, } \\
\text { rigorous } \\
\text { disinfection, } \\
\text { reporting } \\
\text { confirmed cases, } \\
\text { pro-active contact- } \\
\text { tracing and testing } \\
\text { of potentially } \\
\text { infected } \\
\text { individuals }\end{array}$ \\
\hline $\begin{array}{l}\text { A cow } \\
\text { (meat, milk } \\
\text { as food or } \\
\text { income) }\end{array}$ & $\begin{array}{l}\text { Tick-borne } \\
\text { diseases } \\
\text { (Babesiosis, } \\
\text { ECF, others). }\end{array}$ & $\begin{array}{l}\text { Different } \\
\text { parasites and } \\
\text { bacteria }\end{array}$ & $\begin{array}{l}\text { Different kind of } \\
\text { ticks spread the } \\
\text { diseases }\end{array}$ & $\begin{array}{l}\text { Mortality } \\
\text { rate of up } \\
\text { to } 80 \% \text { in } \\
\text { animals } \\
\text { susceptible } \\
\text { to ECF }\end{array}$ & $\begin{array}{l}\text { Tick control } \\
\text { measures } \\
\text { (vaccination, } \\
\text { applying } \\
\text { acaricides, grass } \\
\text { sward height } \\
\text { reduction), } \\
\text { resistant breeds } \\
\text { (Mutavi et al., } \\
\text { 2018) }\end{array}$ \\
\hline $\begin{array}{l}\text { Banana } \\
\text { crop } \\
\text { (banana as } \\
\text { food or } \\
\text { income) }\end{array}$ & $\begin{array}{l}\text { Banana } \\
\text { Xanthomonas } \\
\text { Wilt (BXW) }\end{array}$ & $\begin{array}{l}\text { Bacteria } \\
\text { Xanthomonas } \\
\text { vasicola pv. } \\
\text { musacearum }\end{array}$ & $\begin{array}{l}\text { Infected plant } \\
\text { material, cutting } \\
\text { tools, long- } \\
\text { distance trade, } \\
\text { soil, and vectors } \\
\text { such as birds, bats, } \\
\text { and insects }\end{array}$ & $\begin{array}{l}\text { Yield } \\
\text { losses up } \\
\text { to } 100 \% \text { if } \\
\text { control is } \\
\text { delayed }\end{array}$ & $\begin{array}{l}\text { Cultural } \\
\text { management } \\
\text { practices (male } \\
\text { bud removal, tool } \\
\text { sterilization), } \\
\text { Complete mat } \\
\text { uprooting (CMU), } \\
\text { removal of single } \\
\text { diseased stems } \\
\text { (McCampbell et } \\
\text { al., 2018) }\end{array}$ \\
\hline
\end{tabular}


Chapter 6

The spread of an infectious disease is a public bad because it is (mostly) non-excludible and non-rival. In effect, infectious diseases can affect large numbers of humans (epidemic), animals (epizootic), and plants (empathetic) and can have disastrous socioeconomic and ecological consequences. According to the disease triangle model (Scholthof, 2007), the risk of disease damage to a host is a function of the interactions between the environment, host, and pathogen. These interactions are often determined by human behaviour and responses to environmental changes. Human activities enable pathogens to disseminate and evolve, creating favourable conditions for diverse manifestations of infectious diseases (Mayer \& Piezer, 2008, p. 3-14). Generally, collective action is required to prevent and control the spread of diseases that threaten (agricultural) livelihoods and to achieve resilience.

Collective action problems are coordination problems challenged by multiple factors, including resilience, socio-economic, and risk (Meinzen-Dick, DiGregorio, \& McCarthy, 2004). Resilience stresses the importance of individuals' capacity to adapt and respond as determinants of self-organization (Berkes \& Ross, 2013). The economic perspective highlights self-interest-based choices as determinants of collective irrationality, influenced by different forms of social capital, such as trust, identity, and reciprocity (Ostrom, 1998). Lastly, risk perceptions are determinants of people's behaviour towards threats (Wachinger et al., 2013). These three factors play a critical role in risk governance. We define governance here as the actions, processes, traditions, and institutions, encompassing state and non-state actors, to bind decisions collectively, without superior authority. Risk governance, then, applies the principles of good governance to the identification, assessment, management, and communication of risks. Risk governance, involving various stakeholders, analyses and leads to the formulation of risk management strategies, which need to consider the broader legal, political, economic, and social contexts in which a risk can be managed (Van Asselt \& Renn, 2011).

\subsection{Methodological background and proposal}

Economic experiments have for decades been the most common method to test theories about social dilemmas with specific variables repeated in controlled settings. Laboratory and field experiments have been particularly useful in studying common and public goods in the context of resource and environmental issues. Experimental designs are mostly driven by behavioural and institutional concerns 
(Kurzban \& Houser, 2005). Both laboratory and field experiments involve humans as experimental subjects, in the latter case the participants are familiar with the problem being studied. Ostrom made ground-breaking contributions to collective-action research, using laboratory experiments and case studies to study the role of communication, sanctioning, and institutional rules, among other variables, for achieving collective action (Ostrom, 2006). Inspired by her work, many other researchers have carried out laboratory and field experiments in public goods (PG) and common goods (CG), with most of them keeping the production function externalities and resource dynamics simple (Ostrom, 2003). Because of those experiments we today know that individuals may contribute to the production of a PG or limit their use of a CG, due to reciprocity, trust, identity, or general pro-social behaviour (Rand \& Nowak, 2013).

Growing awareness about the human influence on biophysical systems led to the focus of collective action research shifting to socio-ecological systems (SES) perspectives, resulting in new field experimental designs to study collective action problems. For example, Cardenas et al. (2013) designed three field experiments that were framed in fishery, forestry, and irrigation systems. The major design innovation of those experiments was the introduction of the ecological complexities of social dilemmas in environmental and natural resource problems into behavioural analysis.

Although economic laboratory and field experiments still advance in their understanding of collective action problems, the interpretation of their results remains problematic. This is because individual motives are a function of social norms and other socio-ecological factors (Hagen and Hammerstein, 2006; Ostrom, 1998 and 2007; Ostrom and Ahn, 2007), putting emergence, a particular characteristic of complex adaptive systems such as an SES as a determinant of the socio-ecological outcomes the property of emergence (Schlüter et al., 2019).

An alternative method to understand human behaviour in complex systems is agentbased modelling (ABM), which has gained popularity in recent decades because of its ability to capture emergent phenomena (Bonabeau, 2002). ABM simulates simplified abstract versions of SES, representing the decision-making of autonomous computational individuals or groups of agents and their interactions with each other and with ecosystems. ABM has been used to study phenomena as diverse as traffic, markets, organizations, the diffusion of innovations, adoption dynamics, policy scenarios, and resource management. It is applied to study the interactions between 
Chapter 6

heterogeneous agents that can generate network effects, in which individual behaviour becomes non-linear, path-dependent, and based on memory, learning, and adaptation (Balbi \& Giupponi, 2009; Duffy, 2006). The behaviour of each agent is based on a situational assessment yet restricted by a specific ruleset. Despite the wide use of $A B M$ in different fields, its application in the social, political, and economic sciences is not without barriers. This is caused by human nature which comes with potentially irrational behaviour, subjective choice-making, and complex psychology, and can make the effects of the emergent processes difficult to predict or even counterintuitive (Smith \& Conrey, 2007). The main implication of this is that a given social process cannot truly be understood when studied in isolation, out of its context, or frozen in time (Castillo, et al, 2011).

The power of economic experiments and ABM lies in their capacity to simplify the complex and transform it into manageable dimensions. Both, despite their strengths, limitations, and degrees of complexity, attempt to anticipate agents' behaviour under different conditions. We believe that the limitation of economic experiments and $A B M$ can be overcome by adding a qualitative component. This can increase our understanding of context-specific motivations and provides the next methodological design step for studying problems around collective action. Clancey $(2008$, p.28) notes:

We cannot locate meaning on the text, life in the cell, the person in the body, knowledge in the brain, a memory in a neuron. Rather, these are all active, dynamic processes, existing only in interactive behaviours of cultural, social, biological, and physical environments.

To the best of our knowledge (i) neither laboratory nor field experiments have integrated emergent phenomena into their design to study collective action problems, (ii) ABM faces challenges in integrating the complexity of human behaviour into its models, and (iii) there are very few examples where economic experiments and ABM have been applied to study collective action problems to prevent and control public bads (Kurzban \& Houser, 2005; Sabzian et al., 2019). We respond to this by proposing a methodology that is a field boardgame experiment (or boardgame) that adds the attributes of an SES and its emergent phenomena. The experiment focuses on studying human cooperation under different stimuli in the prevention and control of a public bad in the context of agricultural livelihoods. 


\subsubsection{The dynamic socio-ecological (DySE) game design method}

The SES framework to analyze resilience to a public bad risk, integrates a host (the livelihood unit), the public bad risk conditions (the disease, agent, and infection mechanisms), the threat (livelihood unit losses or fatality), and the strategies (based on coordination and cooperation) to prevent and control a public bad (disease spread) into the analysis. For this research, we developed a methodology to operationalize the theoretical framework. It consists of a public good game design method that integrates emergence and spatiality: A dynamic socio-ecologic game design method. The game design method is multidimensional because it considers what I do, what others do, and what 'it' does (e.g. the vector) in a given space, time, and under certain conditions. The DySE game's purpose is to explore human behaviour and how this intertwines with socio-ecological factors surrounding behavioural decision-making.

The game mechanics include a board representing the geographical space, playing cards representing the livelihood units (humans, banana mats, cows), autonomous players (such as the disease vector or institutional actors who follow some 'real-life' rules), and the decision-makers (human players). We can understand the mechanical part of the game as the hardware where we can experiment. This allows us to test the players' behaviour (when facing a social dilemma) under different experimental treatments or scenarios (communication, incentives, punishment, etc.), over the game structure that creates emergent conditions with specific factors. The game is followed by a focus group session to explore the reasoning behind the players' actions, and the results of this are triangulated with quantitative game results. The social dilemmas (i.e. those faced by decision-makers / players), as well as the rules that govern the autonomous players, are a simplified version of the social, ecological, politicoinstitutional, and environmental rules governing real-life situations. The social dilemmas and scenarios of stimulus constitute the experimental dimension of the game and can be varied according to the research interest. The same game methodology can be calibrated and tailored to different contexts. 
Chapter 6

Table 16: Examples of application of a dynamic socio-ecologic game

\begin{tabular}{|c|c|c|c|c|}
\hline $\begin{array}{l}\text { Public bad } \\
\text { risk }\end{array}$ & What I do & $\begin{array}{l}\text { What the others } \\
\text { do }\end{array}$ & What it does & Collective impact \\
\hline Malaria & $\begin{array}{l}\text { I drain the standing } \\
\text { water where } \\
\text { mosquitos can breed }\end{array}$ & $\begin{array}{l}\text { My neighbours do } \\
\text { not drain the } \\
\text { standing water } \\
\text { where mosquitos } \\
\text { can breed }\end{array}$ & $\begin{array}{l}\text { Mosquitos breed } \\
\text { in standing water } \\
\text { close to where I } \\
\text { live and become } \\
\text { plasmodium } \\
\text { vectors }\end{array}$ & $\begin{array}{l}\text { Avoidable sickness } \\
\text { or deaths; further } \\
\text { impoverishment of } \\
\text { poor households, } \\
\text { and communities } \\
\text { (Ricci, 2012). }\end{array}$ \\
\hline COVID-19 & $\begin{array}{l}\text { I stay at home with } \\
\text { flu-like symptoms or } \\
\text { get tested for } \\
\text { COVID-19 }\end{array}$ & $\begin{array}{l}\text { My neighbour } \\
\text { goes out to the } \\
\text { supermarket with } \\
\text { flu-like symptoms } \\
\text { and is later tested } \\
\text { COVID-19 positive }\end{array}$ & $\begin{array}{l}\text { The virus spreads } \\
\text { via droplets of } \\
\text { infected saliva } \\
\text { when my } \\
\text { neighbour coughs } \\
\text { in the } \\
\text { supermarket }\end{array}$ & $\begin{array}{l}\text { Avoidable deaths: } \\
\text { potential collapse of } \\
\text { the healthcare } \\
\text { system, need for } \\
\text { collective measures } \\
\text { and law } \\
\text { enforcement } \\
\text { (Anderson, et al, } \\
\text { 2020) }\end{array}$ \\
\hline $\begin{array}{l}\text { Banana } \\
\text { Xanthomonas } \\
\text { Wilt (BXW) }\end{array}$ & $\begin{array}{l}\text { I remove banana } \\
\text { flowers and disinfect } \\
\text { my machete before } \\
\text { working in my } \\
\text { neighbours' banana } \\
\text { plantation }\end{array}$ & $\begin{array}{l}\text { My neighbour has } \\
\text { BXW infected } \\
\text { banana mats on } \\
\text { his plantation. He } \\
\text { does not remove } \\
\text { banana flowers } \\
\text { nor disinfect his } \\
\text { machete before } \\
\text { working on my } \\
\text { plantation }\end{array}$ & $\begin{array}{l}\text { The BXW } \\
\text { bacterium spreads } \\
\text { to my banana } \\
\text { plantation } \\
\text { through my } \\
\text { neighbour's } \\
\text { machete and } \\
\text { infects my } \\
\text { bananas }\end{array}$ & $\begin{array}{l}\text { Decrease of local } \\
\text { food security; } \\
\text { further } \\
\text { impoverishment of } \\
\text { poor households; } \\
\text { loss of livelihoods } \\
\text { (L. Tripathi et al., } \\
\text { 2009) }\end{array}$ \\
\hline $\begin{array}{l}\text { Gender } \\
\text { violence and } \\
\text { femicide }\end{array}$ & $\begin{array}{l}\text { I maintain a } \\
\text { relationship with my } \\
\text { partner in which } \\
\text { neither of us assaults } \\
\text { the other and we stay } \\
\text { away from substance } \\
\text { abuse. However, I } \\
\text { frequently hear my } \\
\text { neighbour is } \\
\text { assaulted. I do not } \\
\text { report this to }\end{array}$ & $\begin{array}{l}\text { My neighbour has } \\
\text { a drinking } \\
\text { problem and } \\
\text { violently assaults } \\
\text { his wife when he } \\
\text { is drunk. People in } \\
\text { the community } \\
\text { know this but shut } \\
\text { their eyes to it, } \\
\text { and do not report } \\
\text { it to authorities. }\end{array}$ & $\begin{array}{l}\text { In a drunken } \\
\text { outrage, the man } \\
\text { assassinates his } \\
\text { wife with a pistol }\end{array}$ & $\begin{array}{l}\text { Gender violence } \\
\text { becomes a public } \\
\text { health problem } \\
\text { (UNODOC, 2018); } \\
\text { abused women } \\
\text { suffer from mental } \\
\text { and physical issues; } \\
\text { large numbers of } \\
\text { women are killed } \\
\text { annually, often by a } \\
\text { (former) partner. }\end{array}$ \\
\hline
\end{tabular}


Adding emergence and spatiality to a public bad game

Table 16 shows that, in all contexts, the individuals face a social dilemma to take a determinate action. The social-dilemma might relate to an effort or money investment, as could be the case of Malaria and BXW disease, or could also be related to other more intangible aspects, such as the perception of risk or societal norms, as in the case of COVID-19 or gender violence (Bavel et al., 2020; Powell, et al, 2008). In all the examples, the sum of individual defective choices might have a negative (direct or indirect) collective impact that goes beyond the personal temporary benefit. As the purpose of simplification is to explore behaviour under specific but dynamic circumstances, there are many other influential factors in the prevention and control of the same public bad risk that might not be considered. In the next sections, we contextualize the methodology - the Musa-game - to the case of banana smallholders in Rwanda, whose production is threatened by BXW disease.

\subsubsection{Case study: Operationalization of theoretical framework to the case of BXW in Rwanda}

For the development of our method, we chose a case study that represents a typical collective action problem: the transmission of the banana disease Xanthomonas Wilt of Banana (BXW) disease by insect vectors and its management by farmers in Rwanda. In this section, we describe the BXW disease problem and the existing practices to prevent and control BXW. Based on this input we operationalized the general SES framework (Figure 18) to the case study context (Figure 19).

Banana is one of the most important crops in sustaining household food security and livelihoods in Rwanda. However, BXW, caused by the bacterium Xanthomonas vasicola pv. musacearum (formerly Xanthomonas campestris pv. Musacearum) (Studholme et al., 2020), endangers the livelihoods of millions of farmers in East and Central Africa (Tripathi et al., 2009) and can result in yield losses up to 100\%. BXW is highly transmissible and can spread rapidly through infected plant material, cutting tools, long-distance trade, and vectors such as birds, bats, and insects (Tinzaara et al., 2016). The latter become vectors of BXW when visiting a male banana flower of a diseased banana stem in search of food, after which the bacterium is transmitted to the next visited, still healthy, stem with flower. Vector mediated transmission of BXW is especially prevalent in lowland areas with high insect density (Jones, 2018), yet can be prevented if farmers comply with the cultural practice of cutting the male flower with a forked stick as soon as the last hand has developed (de-budding practice) (Tinzaara et al., 2016). 


\section{Chapter 6}

No cure exists for BXW, once the pathogen has established in a stem it will inevitably die. Complete eradication of BXW is considered impossible, however, the disease can be managed with good preventative agricultural practices and early response to disease outbreaks. Disease symptoms appear soon after infection, causing yellowing and wilting of leaves, premature ripening of fruits, brown stains in the fruit pulp, and rotting of the male flower, and eventually wilting and rotting of the entire stem. Infected plots should not be replanted with bananas for up to 6 to 8 months due to soil-borne inoculum of the pathogen (Blomme et al., 2019).

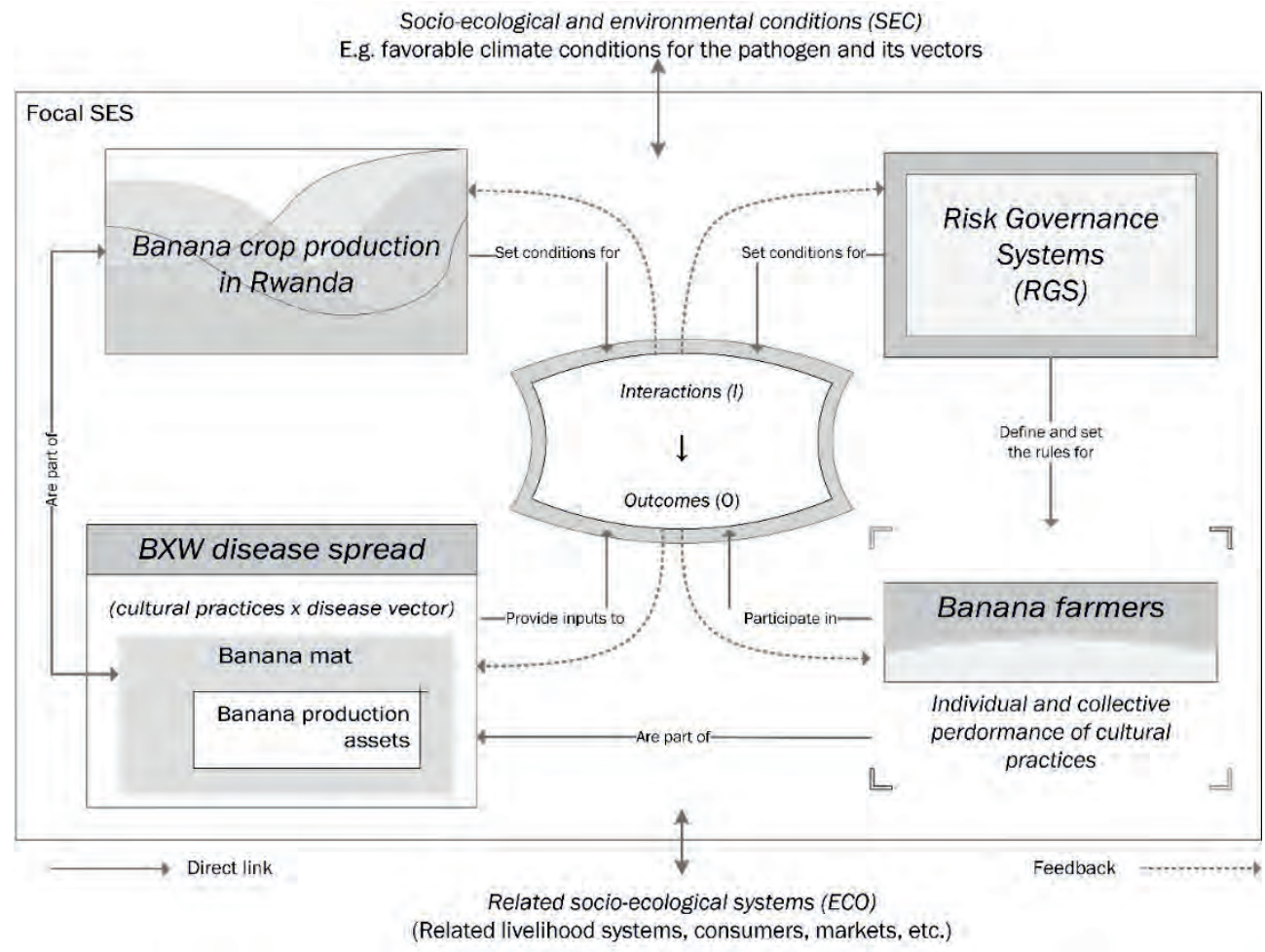

Figure 19: The core subsystems in a framework for analyzing a public bad risk (BXW disease spread) threatening agricultural livelihoods based on banana production in the context of a socio-ecological system from a risk and collective action problem perspective. Adapted from Ostrom (2009).

Provision of advice on disease prevention, control, monitoring, and response to outbreaks is the responsibility of the government agency Rwanda Agriculture and Animal Resources Board (RAB). Its current policy for BXW disease outbreaks prescribes a practice called Complete Mat Uprooting (CMU). This involves uprooting the diseased stem and all lateral stems and shoots (i.e. the entire banana mat) regardless of their infection status to reduce chances of further disease transmission. In high incidence 
cases (>70\% of the banana mats showing symptoms), the whole plantation must be uprooted (Hakizamungu et al., 2020). Although effective, CMU is also labour intensive, time-consuming, and socially costly and has therefore major implications for food and income production. It has an impact on livelihoods making farmers reluctant to comply with good BXW management practices, which is further exaggerated by perceptions of the (in)effectiveness of disease management. Some farmers hide the disease, by cutting down symptomatic stems or leaves, to avoid enforced uprooting (McCampbell et al., 2018; Uwamahoro, Berlin, Bylund, Bucagu, \& Yuen, 2019).

Regardless of the disease control practice, effective management always requires at least a combination of specific knowledge and know-how (e.g. to understand disease epidemiology, recognize disease symptoms, and uproot diseased stems), timely use of cultural prevention and control practices, and, preferably, collective action. A study in DR Congo showed the latter to be more effective for BXW control than individual action (Blomme et al., 2019). Additionally, the government needs to provide effective support mechanisms, e.g. advisory services, monitoring (Uwamahoro et al., 2019). Prevention of the spread of the disease can only be achieved (efficiently) if all the involved stakeholders work in a coordinated manner.

\subsubsection{The Musa-game: a dynamic socio-ecologic method}

In this section, we describe step-by-step the design of the experimental boardgame to evaluate farmers' performance when facing a hypothetical crop disease outbreak in different risk governance scenarios. We named this game the Musa-game ('musa' meaning banana in Kiswahili language). The Musa-game is an experimental and participatory evaluation tool, representing principles from an economic field experiment, an agent-based model, and a role game within a dynamic socio-ecological context. The main properties of the game's mechanics and arena are: (1) represent a simplified and abstract depiction of the social-ecological forces that affect farmers' risk perception (and dilemmas) and decision-making about disease management and control; (2) allow for the performance of different risk governance scenarios through specific operationalization of experimental variables for different treatments; (3) make it possible to trace the development of strategic game behaviour through the use of audio-visual data collection methods; (4) simple calculation of individual and collective outcomes (benefits and losses) immediately after the game ends; (5) achievement of common experience through facilitating post-game discussions, and; (6) collection and analysis of qualitative and quantitative data using mixed methods. 
Chapter 6

Before coming to the version of Musa-game presented in this paper we went through several iterative cycles, involving various scientists and practitioners in the design and pre-testing, to develop game mechanics and physical design. Feedback on the design was given by individuals and in group sessions. The data collection process was designed and pre-tested similarly. Real-life operationalization of the Musa-game requires the involvement of real actors faced with the social dilemma to adopt (or not) strategies to prevent or control a public bad threatening their livelihood. Individual farmers' decisions are influenced by the interplay between different farmers, other autonomous agents in the system, and environmental changes. This interplay is simultaneous as each agent plays with its individual ruleset. The game rules are a simplified version of real-world SES characteristics. To make simultaneous agent actions and system outcomes possible the experimental arena is a square-board that represents the biophysical space where actions and interactions take place. Qualitative tools, such as focus groups or in-depth interviews, are used post-experiment to better understand context-specific motivations behind peoples' decision making.

The Musa-game gives an abstract representation of the socio-ecological dynamics between a group of 4 farmers, their banana mats, the bacterial disease agent (BXW), the insect vectors transmitting the disease, and an external agent who monitors the spread of the disease. The game rules are based on the real-life context of banana production in Rwanda. As real-life banana farmers, the players are confronted with a realistic representation of the problems of collective (in)action they face when preventing disease transmission. As in real-life, complete eradication of the disease is impossible. However, minimizing the disease's impact is possible through rigorous and coordinated action. In contrast, uncoordinated action, due to behaviour driven by selfinterest, lack of capacity to respond, or poor risk perception, may devastatingly impact livelihoods. Players' profits directly relate to their game performance. The final individual and collective results depend on decisions made by individual players in combination with the influence of events in the game's socio-ecological system. In this section, we present stepwise the theory behind the experimental game design, its implementation, and the data analysis strategies.

The boardgame's mechanics, physical structure, and experimental treatments were designed based on our specific scientific interests. They could easily be adapted for other purposes or contexts and used to study other SES problems. 


\subsubsection{Operationalizing risk governance models in the game}

In the Musa-game farmers encounter a system that is governed top-down. Both the government's and farmers' goals are to minimize the risk of disease spread and preserve the continuity of banana production. Government agents determine which agricultural practices must be employed to prevent and /or respond to a disease outbreak. Players are externally organized through random assignment to a treatment group.

Based on Newman's (2001) institutional governance models, we have contextualized the dynamics between the government agents and the farmers toward the control of BXW disease, as a rational goal model as this comes closest to the reality in Rwanda today (Harrison, 2016; Van Damme, Ansoms, \& Baret, 2014). The rational goal model is oriented toward a centralized distribution of power and arrangements that create conditions for change. The state divides a problem into manageable fragments and sets goals. Power is dispersed across various agencies, and the responsibility to act is at the local level. Focus is on shorter timelines and maximisation of outputs. Performance is tightly monitored, inspected, and audited. In terms of goal setting, relationships are vertical, cascading from the government. Relationships are instrumental, pragmatic and there are efficient horizontal connections. It follows a managerial rather than bureaucratic approach (Newman, 2001).

The Musa-game aims to test farmers' cooperation when preventing or responding to a public bad risk: BXW disease. While the overall game mimics the rational goal governance model, players, who are actual banana farmers, can also self-govern the public bad risk through various risk governance strategies. For this, we used risk governance principles from Van Asselt \& Renn (2011): communication, inclusion, integration, and reflection. According to Van Asselt (2011), these should not be considered separate steps or stages but principles for each step or stage in a risk governance process. These principles create space for risk governance strategies within the complex, uncertain, and ambiguous risk contexts. As such this approach to risk governance fits with our purpose of studying a public bad risk within dynamic, emergent, and complex socio-economic systems. 


\subsection{The physical environment, and mechanics, of the Musa-game}

The Musa-game is performed on a square gameboard. Its sides are divided into six rows and six columns, resulting in a total of 36 cells. The $X$-axis has alphabetical codes from $A$ to $F$. The $Y$-axis has numerical codes from 1 to 6 . Individual squares can be identified using the $(X, Y)$ coordinates. The board is divided into 4 quadrants composed of 9 cells each, each cell representing one productive banana mat. Quadrants are identifiable through symbols: square, circle, rhombus, and triangle $(\square, 0$, $\diamond, \Delta$ ) (Figure 20). The four quadrants together represent one banana production zone (or banana farming community) in Rwanda, with each quadrant representing a banana field managed by one independent farmer.

\begin{tabular}{|c|c|c|c|c|c|c|c|c|c|}
\hline \multirow{4}{*}{$\begin{array}{l}N \\
\frac{1}{d} \\
\frac{\delta}{\sigma} \\
\frac{\pi}{L}\end{array}$} & 0 & A & B & c & D & $E$ & $\mathbf{F}$ & $\Delta$ & \\
\hline & 6 & A6 & B6 & C6 & D6 & E6 & F6 & 6 & ${ }_{0}^{2}$ \\
\hline & 5 & A5 & B5 & C5 & D5 & E5 & F5 & 5 & 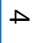 \\
\hline & 4 & A4 & B4 & C4 & D4 & E4 & F4 & 4 & \\
\hline \multirow{4}{*}{ 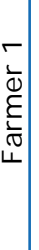 } & 3 & A3 & B3 & C3 & D3 & E3 & F3 & 3 & \\
\hline & 2 & A2 & B2 & $\mathrm{C} 2$ & D2 & E2 & F2 & 2 & 3 \\
\hline & 1 & A1 & B1 & C1 & D1 & E1 & F1 & 1 & $\omega$ \\
\hline & $\square$ & A & B & c & D & E & $\mathbf{F}$ & $>$ & \\
\hline
\end{tabular}

Banana farming community $[\mathrm{A} 1-\mathrm{F} 6]$

Figure 20: Schematic representation of the game board and the different sections of the board as shown to players. Each farmer has 9 cells e.g.: The 9 cells D4 to F6 belong to farmer 4 . Each cell contains 1 productive banana mat, e.g.: Cell D4 has 1 productive banana mat. All farmers start the game with 9 productive banana mats.

The game is facilitated by one game master and played by 4 farmers and 2 autonomous players: an insect, and a monitor (Figure 20). As a field experiment, the 4 farmers are people whose real-life livelihood depends on banana production. The movements of the autonomous players are defined randomly by throwing two dices, one with letters and one with numbers (done by the game master) or using statistical software. The combination of the letter and number corresponds with a coordinate on the board, e.g. the combination A and 4 equals the coordinate A4 on the board. The game's socio- 
ecological conditions are dynamic and defined by the decision-making of farmer players plus the autonomous actions of the insect and monitor.

Upon starting the game, each player has nine stacks of four or five cards (one stack for each cell) representing different health stages of a banana mat depending on players' decisions and locations of autonomous players (see Table 17). The different cards have different economic values, ranging from a maximum profit to a maximum loss. The two cards at the top of the stack are healthy banana mats: (1) White (value $=2600$, and (2) Green (value $=2500$ ). The next two cards are infected mats: (3) Yellow, and (4) Red. The bottom card is (5) grey card equalling a dead banana mat (value $=0$ ). The backsides of the yellow and red cards are uprooting cards (value = -500). Only cards (1), (2), (3), and (4) can be removed by the player. To eliminate the chance of a player losing all his or her banana mats in one round the cells E2, E5, B2, and B5 (the central position for each player's quadrant) have no white maximum profit card. The composition of cards at the end of the game determines the player's score, i.e. the total profit or loss made.

Table 17: Overview of cards in the game

Card

Name

\section{Health stage cards}

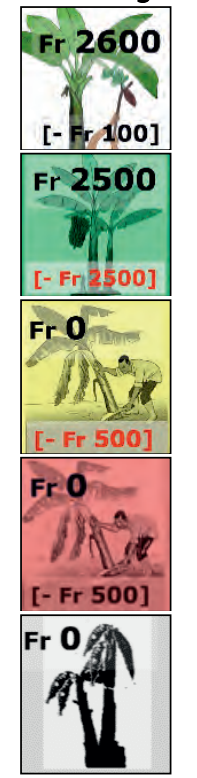

Red card

Grey card

\section{Code Description}

\author{
Yellow card \\ White card \\ 1 \\ Healthy mat with flower \\ Green card $\quad 2 \quad$ Healthy mat without flower \\ 3 \\ A BXW infected banana mat in the first disease stage. An \\ idiosyncratic institutional threat. The card value is Fr. 0
}

4

A BXW infected banana mat in the second disease stage. The card value is Fr. 0 . A covariate institutional threat. The cost of uprooting is Fr. 500

5 A dead banana mat that was not uprooted in disease stage one or two. The mat is no longer a threat. The card value is Fr. 0 


\begin{tabular}{|c|c|c|c|}
\hline-500$]$ & Yellow uproot & 31 & $\begin{array}{l}\text { The backside of the yellow uproot card appears when } \\
\text { the player decides to uproot a yellow BXW infected mat. } \\
\text { The action costs the farmer Fr. } 500 \text {. }\end{array}$ \\
\hline-500$]$ & Red uproot & 41 & $\begin{array}{l}\text { The backside of the red uproot card appears when the } \\
\text { player decides to uproot a red BXW infected mat. The } \\
\text { action costs the farmer Fr. } 500 \text {. }\end{array}$ \\
\hline
\end{tabular}

\section{Autonomous player cards}

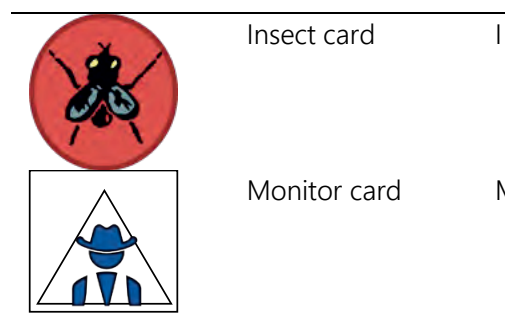

\section{Other cards}

$\begin{array}{lll}\begin{array}{l}\text { Monitor } \\ \text { intervention card }\end{array} & 6 & \begin{array}{l}\text { Monitor intervention card (uprooting activity in } \\ \text { progress). Placed on the stack after a monitor finds a } \\ \text { yellow or red card and intervenes. }\end{array}\end{array}$

Biological threat. The insect is the BXW vector and searches for nectar from a healthy mat with a flower. A visited mat becomes BXW infected and turns yellow.

M Institutional threat. The monitor represents a government agent monitoring banana mats and intervenes when a yellow or red card is found (code 3 or 4). Codes 1, 31, 41, 5, 6 do not represent an institutional threat, when the monitor inspects them there is no intervention.

yellow or red card and intervenes.

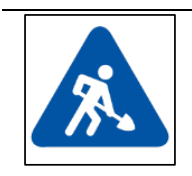

\subsubsection{Farmers: livelihood and risk}

In the game, we assume that each player relies on banana production to meet the basic weekly income needs to sustain their family's livelihood and be food secure. The behaviour of each player is triggered by the experimental setting and changing socio-ecological conditions. Each banana mat faces two threats: one biological, and one institutional. The biological threat is BXW disease, transmitted by the insect visiting a flower in search of nectar. The institutional threat is the disease control measure of the Rwandan government, existing of random visits by an extension agent whose responsibility it is to contain the disease. The monitor intervenes only when finding a diseased banana mat. Both threats are influenced by the social component, i.e. the farmer's behaviour. This translates into complying with the practice of cutting the banana flower to avoid a biological hazard (white card) or uprooting an infected mat and avoiding an institutional hazard (yellow and red cards). 
The goal of the farmer is to safeguard food security and maximize the household's livelihood. The minimum amount of money needed to be food secure is Fr. 15000. Any surplus at the end of the game represents a profit. When the game starts the player has 9 healthy banana mats, 8 with flower (white card) and 1 without a flower (green card) (Figure 21), together these represent the maximum amount of money that can be earned:

$8 \times$ Fr. $2600+1 \times$ Fr. $2500=$ Fr. 23300

The maximum profit that can be made by the player is:

Fr. $23300-$ Fr. $15000=$ Fr. 8300

Therefore:

$$
\begin{aligned}
\text { Net income }=[ & (\text { n.cards } 1 \times 2600 \mathrm{Fr} .)+(\text { n.cards } 2 \times 2500 \mathrm{Fr} .) \\
& -(\text { n.cards } 31 \times 500)-(\text { n.cards } 41 \times 500)]
\end{aligned}
$$

Individual net profit $=$ Net income - individual food security threshold

Each banana mat with a flower is at risk of BXW infection. As a preventative measure against BXW, the player can decide to cut the flower. The investment cost of cutting the flower is Fr. 100, which is represents the real-life mobility and labour effort of the farmer. After cutting, the top card becomes green (value $=$ Fr. 2500 and the mat is protected from the biological hazard.

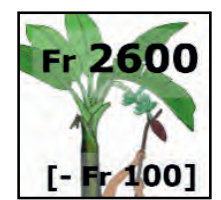

(a) WHITE: healthy mat with flower

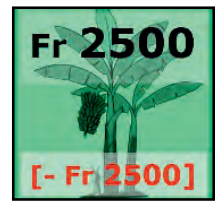

(b) GREEN: healthy mat without flower

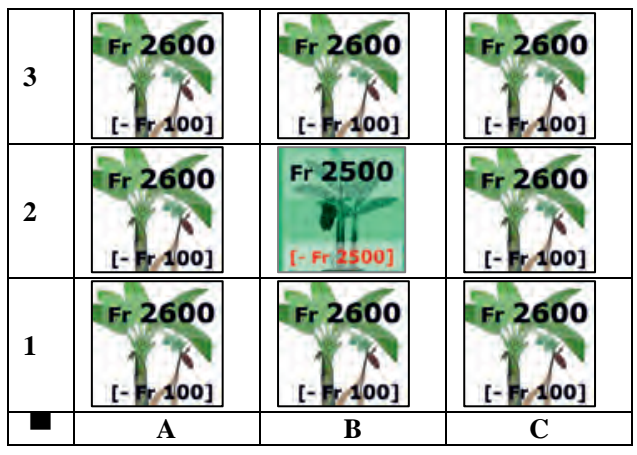

(c) initial conditions of the game per farmer 
Chapter 6

\subsubsection{The insect vector and disease progress}

The insect player card represents the autonomous insect vector that carries the BXW bacterium which causes BXW in bananas. The purpose of the insect is to find nectar in banana flowers. While doing so the insect can transmit the disease from mat to mat. In Musa-game the insect is always a carrier of BXW. The insect moves randomly in search of a flower (white card), creating the effect of emergence. The random location can be any of the game board's coordinates (A1:F6). By definition, the insect always searches for a white card. If there is no white card at a defined location, the insect moves clockwise (from the perspective of the player in whose quadrant the location is) without considering quadrant boundaries until finding a white card (Figure 22). The mat in this location becomes infected with BXW (yellow card value = Fr. 0). This is the first disease stage. In the next round, the player can decide to invest and uproot this mat (yellow uproot card, investment = Fr. 500), or not invest and let the disease progress to the second stage (red card, value = Fr. 0). In the latter scenario, uprooting is again possible in the next round (red uproot card, investment = Fr. 500). If again not uprooted, the mat dies (grey card, value Fr. 0). A mat in the first or second disease stage is an idiosyncratic institutional threat.

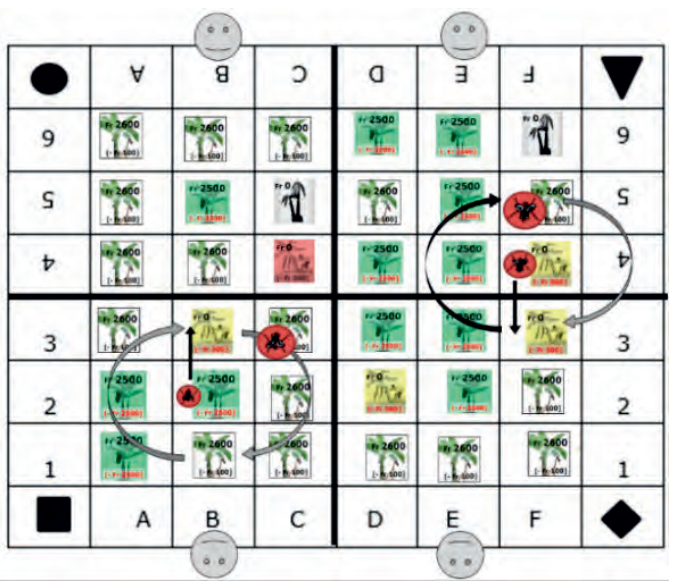

Figure 22: Schematic example of how the insect moves until it finds a white card (=with flower)

\subsubsection{The monitor}

The monitor card represents an extension agent whose responsibility it is to keep the community BXW disease-free. Every game around the monitor checks one banana mat at random, creating the effect of emergence. The random location can be any of the coordinates on the game board (A1:F6) and is also the monitor's final location 
for that round (Figure 23). The intervention takes place (or not) depending on the health status of the mat in that location. If the mat is healthy (i.e. white or green card) or dead (grey card) no action is taken. If it is diseased (yellow or red card) the control measure is performed. The control measure involves uprooting the infected mat plus, depending on infection status, all mats neighbouring the diseased mat either in that specific quadrant (yellow card) or in all quadrants (red card). In both scenarios, the neighbouring mats are uprooted regardless of their health status. Thus, six mats (belonging to one or more farmers) could be lost.

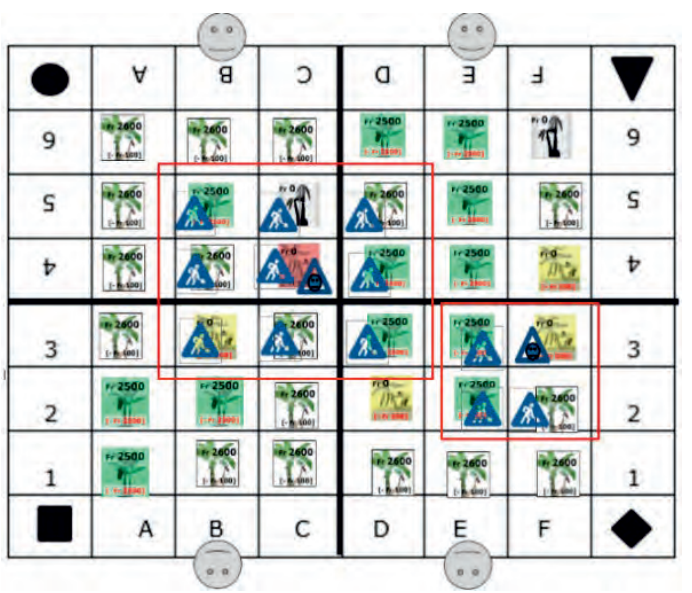

Figure 23: Intervention rules for the monitor

\subsubsection{Identifying corner solutions: fully cooperative and fully defecting playing strategies}

The most cooperative strategy is to form blocks of 9 mats from the centre of the board (Figure 24). This minimizes the potential harm to neighbour farmers if the monitor discovers an un-uprooted diseased mat. The value 0 represents the initial condition without a flower of cells B2, B5, E2, and E5. Values 1-4 represent the potential order that players could choose to cut flowers in a cooperative strategy scenario. The 3 scenarios assume the maximum investment in cutting flowers per round $(=2$ flowers/round/player). If farmers defect i.e. fail to invest in cutting flowers and/or start cutting from the centre the other players are more at risk of being harmed by a neighbour's diseased mat. 
A

\begin{tabular}{|c|c|c|c|c|c|c|c|}
\hline $\mathrm{O}$ & $\mathrm{A}$ & $\mathrm{B}$ & $\mathrm{C}$ & $\mathrm{D}$ & $\mathrm{E}$ & $\mathrm{F}$ & $\Delta$ \\
\hline 6 & 4 & 4 & 3 & 3 & 4 & 4 & 6 \\
\hline 5 & 3 & 0 & 1 & 1 & 0 & 3 & 5 \\
\hline 4 & 2 & 2 & 1 & 1 & 2 & 2 & 4 \\
\hline 3 & 2 & 2 & 1 & 1 & 2 & 2 & 3 \\
\hline 2 & 3 & 0 & 1 & 1 & 0 & 3 & 2 \\
\hline 1 & 4 & 4 & 3 & 3 & 4 & 4 & 1 \\
\hline$\square$ & A & B & C & D & E & F & $\diamond$ \\
\hline
\end{tabular}

B

\begin{tabular}{|c|c|c|c|c|c|c|c|}
\hline & A & B & C & $D$ & $E$ & $F$ & $\Delta$ \\
\hline 6 & 4 & 3 & 2 & 2 & 3 & 4 & 6 \\
\hline 5 & 4 & 0 & 2 & 2 & 0 & 4 & 5 \\
\hline 4 & 3 & 1 & 1 & 1 & 1 & 3 & 4 \\
\hline 3 & 3 & 1 & 1 & 1 & 1 & 3 & 3 \\
\hline 2 & 4 & 0 & 2 & 2 & 0 & 4 & 2 \\
\hline 1 & 4 & 3 & 2 & 2 & 3 & 4 & 1 \\
\hline$\square$ & A & B & C & D & E & F & $\diamond$ \\
\hline
\end{tabular}

C

\begin{tabular}{|c|c|c|c|c|c|c|c|}
\hline & A & B & C & D & E & F & $\Delta$ \\
\hline 6 & 4 & 4 & 3 & 3 & 4 & 4 & 6 \\
\hline 5 & 3 & 0 & 1 & 2 & 0 & 3 & 5 \\
\hline 4 & 2 & 2 & 1 & 1 & 1 & 2 & 4 \\
\hline 3 & 2 & 1 & 1 & 1 & 2 & 2 & 3 \\
\hline 2 & 3 & 0 & 2 & 1 & 0 & 3 & 2 \\
\hline 1 & 4 & 4 & 3 & 3 & 4 & 4 & 1 \\
\hline$\square$ & A & B & C & D & E & F & $\diamond$ \\
\hline
\end{tabular}

Figure 24: Disease spread scenarios (explained by quadrants) if players perform cooperative strategies A, B or C with the insect assigned randomly to one of the mats without flower in the first round.

\subsubsection{Method implementation}

Musa-game, as a DySe-game method, serves as a tool to represent the (biophysical) context in which interactions between entities take place during the experiment. These interactions create emergent conditions in a given place and time. The framing of the interactions and the rules and limitations attached to them are the outcome of design choices: experimental subjects, sampling method, variables to study, and experimental design (to review some principles for behavioural experiments and design choices, see Eckerd, 2020). The DySE-game is hence an adaptable tool that can be used to perform a variety of experiments, depending on the research interest. Examples of variables that have previously been studied concerning commons include the role of communication, gender participation, and identity (Ostrom, 2006, Rand \& Nowak, 2013). The same variables could be used in a DySE-game to evaluate the emergence and impact of new conditions in a given place and time.

For the framing and design of Musa-game we chose the variable of risk communication as our main variable of interest. Other variables may be added by integrating them into the game mechanics. For example, the effect of nudging could be studied by e.g. adding nudging cards to the game which give individual players specific disease management advice. We however advice researchers to be cautionary with adding more variables as it significantly increases the experimental design's complexity consequently the data collection, traceability, and analysis process, and error chances. With this in mind, we recommend careful consideration of the research interest and a selection of variables that concisely fit that interest, as we did with the risk communication variable. In terms of sampling, we recommend a randomized complete blocks design with oversampling to compensate for potential no-shows of sampled players. 
Traceability of the data can be challenging given that there are multiple (autonomous) players, rounds, and locations where events can emerge. Based on experiences from designing and pre-testing Musa-game we recommend as follows:

\subsubsection{Data collection method:}

A combination of paper data-entry forms to collect data in real-time and a camera set-up that records audio and video of the full game from above the game table.

- Guarding player anonymity:

The camera set-up only captures the gameboard and hands of players; no faces are visible. Players are assigned a unique identifier code to anonymize the data.

- Facilitation process:

Two facilitators per game table who speak the players' language and the language used by the researchers (e.g. English). The game is facilitated in the local language. One person takes the role of the game master, the other one is note-taker (filling data-entry forms and taking observational notes). Both conduct pre-game surveys. One game master leads the post-game discussion.

- Game protocol and training of facilitators:

A step-by-step protocol for the game is required, including instructions about the game mechanics, set-up of the game-board and data collection equipment, data management, player consent and anonymity (forms), scripted explanation of the game to be given to players. Facilitators need extensive training on the method and the philosophy behind it to become true masters of the game.

\subsection{Discussion and conclusions}

This paper presented a framework and experimental game method (Musagame) for analyzing a public bad risk that threatens livelihood resilience. It does this from a risk and collective action problem perspective, building upon Ostrom's SES framework (2009). Similar to Ostrom's framework, does our public bad adaptation of it emphasize the role of emergent phenomena in decision-making. These emergent phenomena were operationalized to the context of BXW disease management and included in the design of Musa-game. In the game, the theoretical definition of emergence is reflected by the game's entities (i.e. insect, monitor, and farmer players) and the socio-ecological rules of the system that create new conditions to which players (i.e. farmers) need to adapt via individual and collective action. The diverse interactions 


\section{Chapter 6}

between entities and their decisions give rise to the emergence of unpredictable and interdependent risk scenarios.

Games are useful tools to deal with sensitive topics (e.g. the role of self-interest, institutional arrangements, perceptions of risk, knowledge) in a self-exposed way. Scientists and practitioners participating in pre-testing the game design noted that playing Musa-game provided powerful learning about the interconnectedness of individuals' decisions, and technical disease aspects (Galarza-Villamar, 2021). The specific design features of Musa-game, e.g. addition of emergence and spatial analysis could enable us to contribute to understanding about the intertwinement of the biophysical environment and individual choices and their shaping of both individual and collective resilience. Playing a game together before a focus group discussion offers players a shared experience, triggering their thought processes around real-life situations, and collective sense-making of how individual decisions affect collective resilience (Wilkinson, 1998; and Chater and Loewenstein, 2016; in Galarza-Villamar, 2021).

Pre-test participants suggested that this kind of game could have great potential for studying and learning about various other complex problems. Although Musa-game was designed to study BXW disease management, we believe that the same method, in some adaptations, is also suitable for a variety of other complex socio-ecological problems. Examples of such problems are those in Table 2, including malaria and COVID-19. Additionally, the design of Musa-game offers opportunities to gain insight into issues regarding risk governance and communication and the kinds of interventions needed to address these issues. The next step is to field-test the method with banana farmers in Rwanda to try out practical implementation and verify if playing the game in a real-world setting indeed results in the type of data we expect based on the theoretical and conceptual design. 

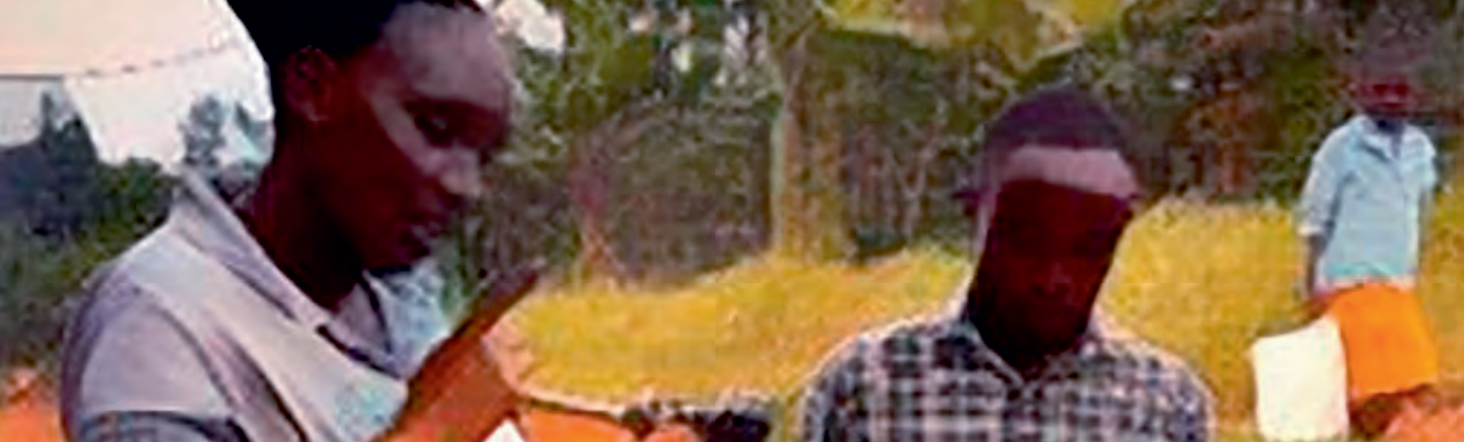


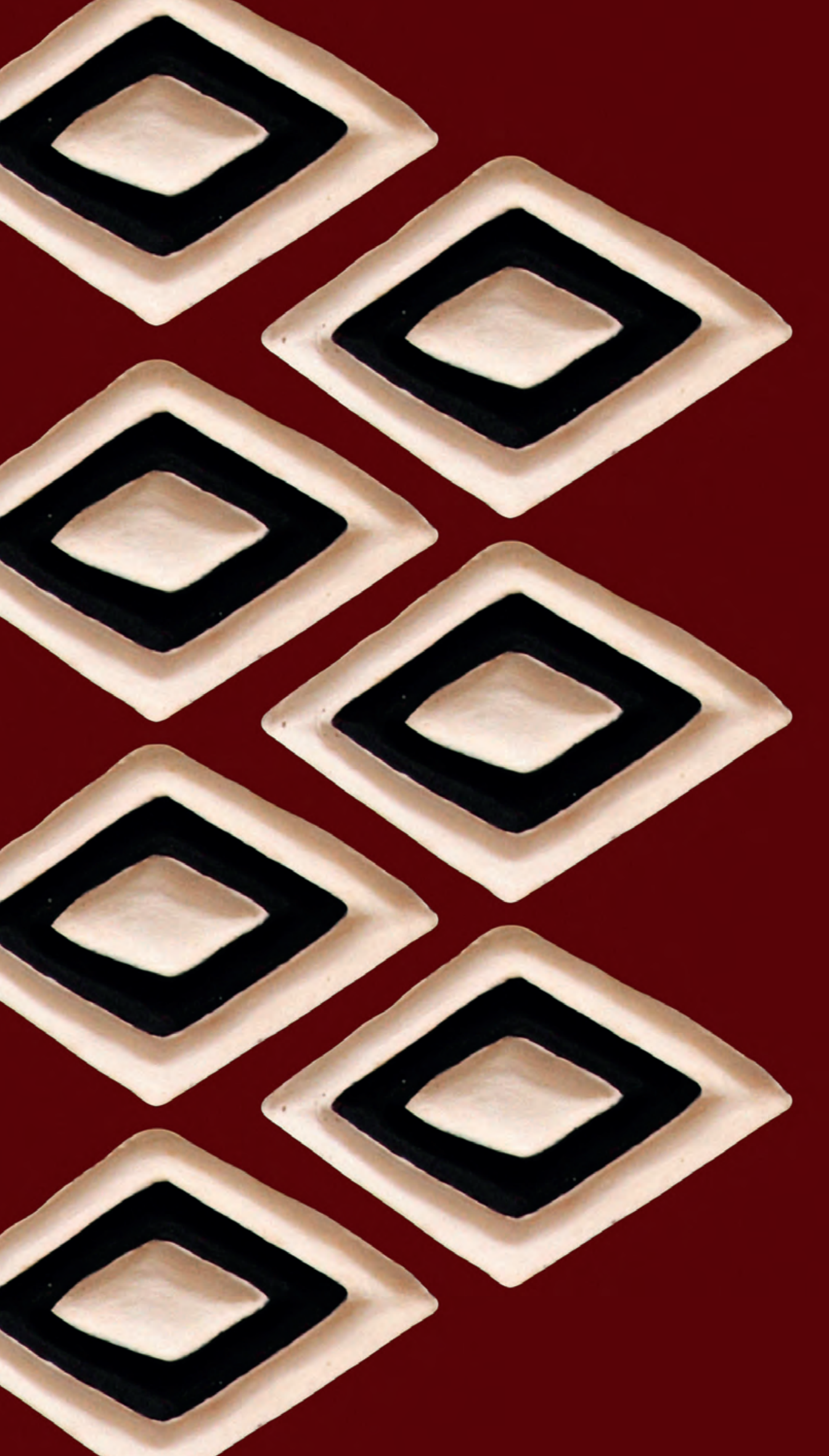


A public-bad game method to study dynamics in socio-ecological systems (Part II)

Results of testing Musa-game in Rwanda and adding emergence and spatiality to the analysis 


\section{Abstract}

This article is the second in a series of two and presents findings from fieldtesting an experimental boardgame (Musa-game) with banana farmers in four villages in Eastern Rwanda. The conceptualization and design of the Musa-game were described in Part I. Musa-game gives insights into how farmers' individual and collective decision-making and actions regarding management of a public bad interplay with other factors and characteristics of the socio-ecological system (SES). A public bad is a non-rivalrous, non-excludable issue that causes loss of social-welfare of individuals and communities. The method contributes contextual understanding about the emergence of phenomena that arise from the interactions between human and non-human actors. Musa-game was framed to study one public bad challenge in particular: the infectious crop disease Banana Xanthomonas Wilt disease (BXW). Findings increase knowhow about the emergence and governance of conditions that hinder or enhance the spread of infectious diseases like BXW. Analysis of qualitative and quantitative data suggests that individual farmers' actions are influenced by perceptions of risk, affecting both individual and collective disease management. Additionally, the used experimental treatments allowed us to evaluate the influence of communication on risk governance strategies. It appears that a combination of possession of technical knowledge about the disease, opportunities to communicate about the disease, and a collective disease management strategy gives the best individual actions and collective performance.

Chapter published with minor revisions as: Galarza-Villamar, J., McCampbell, M., Galarza-Villamar, J.A., Leeuwis, C., Cecchi, F., Galarza-Rodrigo, J. (2021). A public bad game method to study dynamics in socio-ecological systems (Part II): Results of testing Musa-game in Rwanda and adding emergence and spatiality to the analysis. Sustainability, 2021, 13(16), 9353.

An earlier version of this work was published as: Galarza-Villamar, J., McCampbell, M., Galarza-Villamar, J.A., Leeuwis, C., Cecchi, F., Galarza-Rodrigo, J. Adding Emergence and Spatiality to a Public Bad Game within the Context of a Socio-Ecological System: Collective action to fight an infectious disease outbreak. In: Galarza-Villamar, J. 2021 Social capital, collective action, and livelihood resilience: a multidimensional approach. (Doctoral dissertation, Wageningen University). 


\subsection{Introduction}

Infectious diseases are public bads because they are (mostly) non-excludable and non-rival. Therefore, infectious diseases have the potential to harm a large number of hosts (plants, animal, and humans), and the infection of one host does not reduce the available pathogens to infect other hosts (but increases its infectious potential) (Sonnemans, Schram, \& Offerman, 1998; Hall \& Harper, 2019; Mutavi, et al 2018). The socio-ecological damage caused by infectious diseases is a function of the interaction between the environment, host, and pathogen (Scholthof, 2007) and can be disastrous. Human behaviour is a critical factor in how these interactions enable pathogens to disseminate, evolve, and manifest as infectious diseases (Mayer \& Piezer, 2008, p. 314). Therefore, collective and coordinated actions are required to manage public bad risks (risk governance) like infectious diseases.

Human decisions and sense-making about such decisions are the results of dynamically intertwined factors. Thus, those decisions are not only the result but also the cause of the emergence of different scenarios (Schlüter et al., 2019; Bonabeau, 2002; Marinescu, 2013; Galarza-Villamar, 2021). In this study, our main purpose is to explore how farmer's decision-making interplays with other Socio-ecological system (SES) factors and creates conditions that hinder or enhance the spread of Banana Xanthomonas Wilt (BXW) disease (our public bad problem) in Rwanda. To do so, we test the value of integrating emergence and spatiality into the analysis by applying a dynamic socio-ecologic (DySE) game method. This method consists of a public good game integrating both emergence and spatiality in its design by considering what ' $\mathrm{l}$ ' do, what 'others' do, and what 'it' does (e.g. a disease vector) at a given geographical place, time, and socioecological conditions (see also part 1 of this article series). A detailed description of how we developed the method was given in the first article that we wrote about our work.

In this article, we limit the technical explanation of the method and conceptual thinking behind it to briefly contextualizing BXW disease using an adapted version of the SES framework (Ostrom, 2009, see also Ostrom \& Cox, 2010, Ostrom, Gardner \& Walker, 1994). Second, we field-test the framed dynamic socio-ecological (DySE) game, named the Musa-game (Musa meaning banana in Kiswahili language). It is an experimental boardgame that captures what different (human and non-human) actors [involved in the BXW socio-ecological dynamics] do, at a given place [banana farms], time (disease severity stages), and conditions (institutional management of BXW). Third, we explore 
Chapter 7

the use of spatial analytical methods to understand the dynamic relationship between the multiple playing socio-ecological factors, decision making, and resilience. To do so, we developed a computational program that includes both decisional and spatial dimensions, to assist with analyzing the game's results (inspired by principles of neighbours, connectedness, and centrality analysis, (see Sosnowska \& Skibski, 2018; Fushimi et al, 2019).

We situated our study in the context of a project, ICT4BXW, which aimed to use digital technologies and citizen science to contribute to the control and prevention of BXW in Rwanda and the East and Central African region. Using this project context, we focus on the variable of communication as a central factor affecting different actors' (inter)actions and emergent outcomes in a given space and time. By applying the Musagame and the analysis tool, we explored and reflected on what field-test findings can tell us about individual and collective action in BXW management and the effects of communication on farmers' decision-making and its implications in the broader context of (digital) communication interventions in agriculture.

\subsection{Theoretical framework}

\subsubsection{Framework for analyzing a public bad risk: an adaptation from SES framework (Ostrom 2007)}

Ostrom (2007) proposed the Socio-Ecological System framework to analyze the sustainability of socio-ecological systems. The main components of the SES framework are a set of multilevel and nested subsystems: the resource system, the resource units, the governance system, and the users. Earlier (Galarza-Villamar et al., 2021) we adapted this framework such that it can aid analysis of a public bad risk that threatens the sustainability and resilience in a livelihood system. This adaptation was made from a risk management perspective, operationalizing a public bad risk based on the hazard characteristics and vulnerability conditions. The existing governance system was furthermore framed as the set of existing rules and norms that should prevent and control the hazardous consequences of the public bad. Figure 25 portrays the different subsystems identified in the context of BXW disease in Rwanda and the interactions within the socio-ecological system. In this article, we focus on the interaction between three sub-systems: the public bad risk context, the risk governance system, and the direct users (collective action problems) which we describe in the following sections. Given the scope of this article we refer to appendix 7, and additionally to Ostrom (2009) 
and Part I (i.e. chapter 6 in this thesis) of our study for details about the original SES framework and our adapted version to explore public bad risks.

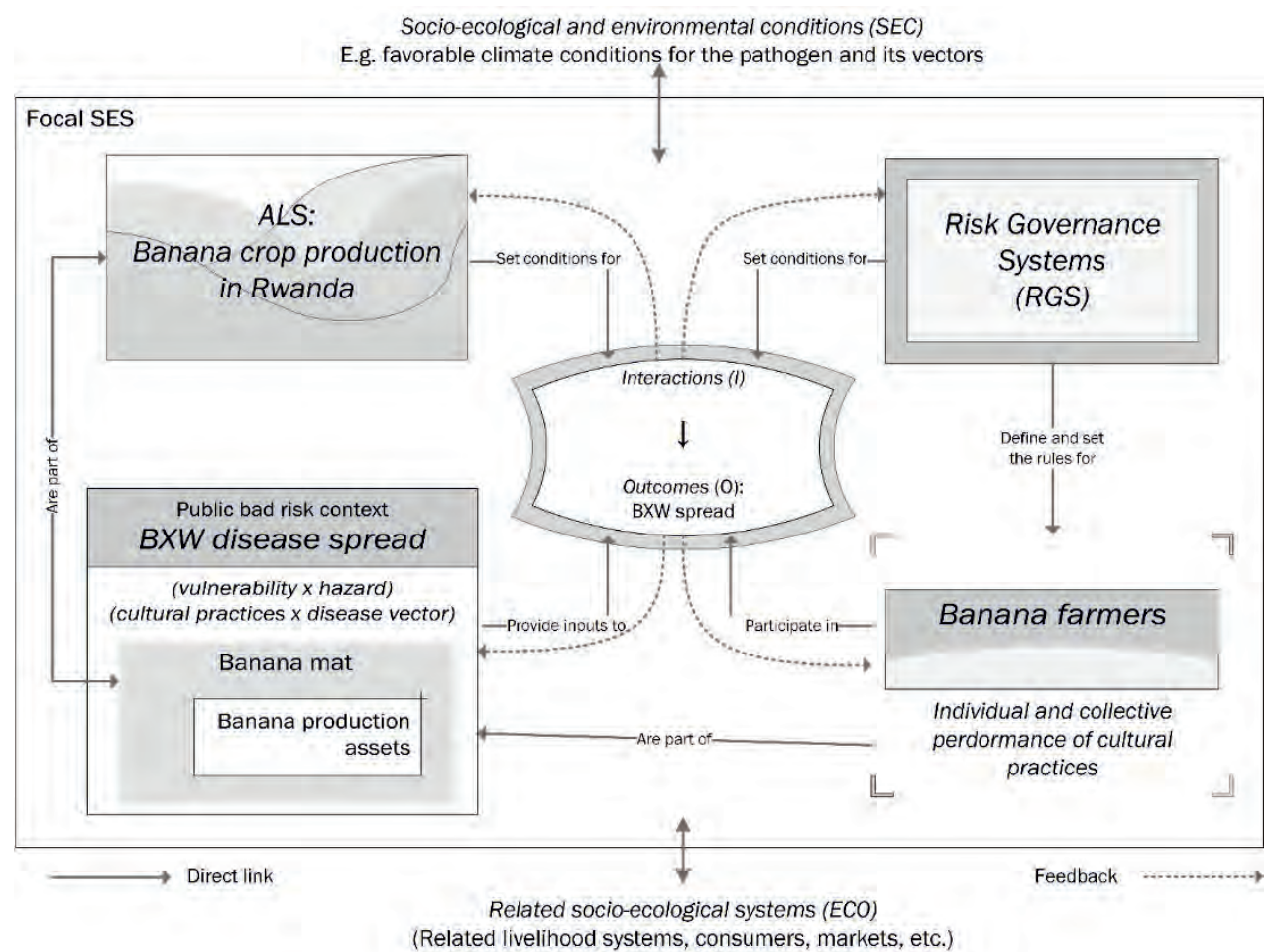

Figure 25: The core subsystems in a framework for analyzing a public bad risk (BXW disease spread) threatening agricultural livelihoods based on banana production in the context of a socio-ecological system from a risk and collective action problem perspective. Adapted from Ostrom (2009).

\subsubsection{The public bad risk governance system: BXW management in Rwanda}

Governance refers to the actions, processes, traditions, and institutions by which authority is exercised and decisions are taken and implemented. Risk governance applies the principles of good governance to the identification, assessment, management, and communication of risks. The central risk under research in this study is the spread of BXW disease in Rwanda. BXW is caused by the Xanthomonas vasicola pv. Musacearum (previously Xanthomonas campestris pv. Musacearum (Studholme et al., 2020), and has the potential to cause banana yield losses of up to $100 \%$. It is highly transmissible and can be easily spread through infected plant material, cutting tools, long-distance trade, and vectors such as birds, bats, and insects (Tinzaara et al., 2016). Vectors play an important role in disease spread, mainly through insects, birds, bats, 


\section{Chapter 7}

and cutting tools (idem). Insects, for example, become vectors when visiting a male banana flower of a diseased stem to feed on nectar

Rwanda's current policy for BXW disease outbreaks prescribes a practice called Complete Mat Uprooting (CMU). This involves uprooting the diseased stem and all lateral stems and shoots (i.e. the entire banana mat) regardless of their infection status. All uprooted material should be buried and covered with soil. Uprooting is advised to take place in an early disease stage to reduce further disease transmission. In high incidence cases ( $>70 \%$ of the banana mats showing symptoms), the whole plantation must be uprooted (Hakizamungu et al., 2020).

Although effective, CMU is also labour intensive, time-consuming, and socially costly and has therefore major implications for food and income production. It has an impact on livelihoods making farmers reluctant to comply with good BXW management practices, which is further exaggerated by perceptions of the (in)effectiveness of disease management. Some farmers hide the disease, by cutting down symptomatic stems or leaves, to avoid enforced uprooting (McCampbell et al., 2018; Uwamahoro et al., 2019). An alternative for CMU exists in the practice of Single Diseased Stem Removal (SDSR). In this case, only symptomatic infected stems, rather than entire mats, are cut, at soillevel. This method is low-cost, simple, and less labour intensive. SDSR is effective for bringing disease incidence to a minimum level, and especially suitable for smallholder farmers (Guy Blomme et al., 2021, 2017).

Regardless of the disease control practice, effective management always requires at least a combination of specific knowledge and know-how (e.g. to understand disease epidemiology, recognize disease symptoms, and uproot diseased stems), timely use of cultural prevention and control practices ( e.g. planting healthy suckers, de-budding, disinfecting farm tools, and removing infected plants) and, preferably, coordinated collective action. A study in DR Congo showed the latter to be more effective for BXW control than individual action (Blomme et al., 2019). Additionally, the government needs to provide effective support mechanisms, e.g. advisory services, monitoring (Uwamahoro et al., 2019). Hence, prevention of the spread of the disease can only be achieved (efficiently) if all the involved stakeholders work in a coordinated manner, something that comes with challenges regarding social dilemmas and effective communication strategies. 


\subsubsection{The communication variable in the context of a project}

Data for our study were collected in villages belonging to a project in Rwanda: ICT4BXW. This project piloted a smartphone application (named BXW-App) and actively engaged with village-level extension agents to support the diagnosis and control of BXW in the country. As a project, ICT4BXW is just one example of many projects today that use digital technologies (e.g. mobile phones, sensors) and services (e.g. apps supporting virtual diagnostics, reporting, and surveillance of crop pests and diseases). Sometimes (partially) replacing face-to-face communication, digital communication services provide modalities to support the coordination of complex problems, such as management and control of crop diseases. While information, e.g. about effective detection, characterization, and quantification of an infectious disease (i.e. disease surveillance) is critical to design risk management strategies, it traditionally requires a costly and bureaucratic reporting chain (Generous, Fairchild, Deshpande, Del Valle, \& Priedhorsky, 2014). Central to digital agriculture interventions is oftentimes a (smart)phone service (e.g. BXW-App in the case of ICT4BXW) that aids in the documentation and dissemination of agricultural information (Walsham, 2017) and promises to enhance efficiency and effectiveness (GSMA, 2020). An acclaimed advantage of digital services over conventional face-to-face extension is that it allows for more personalization, adapting the service to the (farm) conditions of a specific, individual farmer (Fabregas et al., 2019). This contrasts with the more one-size-fits-all character of traditional (public) agricultural extension services that are critiqued for not considering diversity among farmers and farms (Arouna et al., 2020; R. Nelson, Coe, \& Haussmann, 2016). In Rwanda for example, the provision of advice on disease prevention and control, as well as monitoring of and responding to disease outbreaks is the responsibility of Rwanda Agriculture and Animal Resources Development Board (RAB) on behalf of the Ministry of Agriculture and Animal Resources (MINAGRI). Through the country's extension system activities such as group training on agronomic practices; diagnosing, reporting, and controlling pests and diseases; and information exchange during one-on-one and community meetings are organized. Within this context, space to adapt to an individual farmer's needs is limited, something digital agricultural services promise to respond to with tailor-made information and decisionmaking support that is given directly to individual farmers. Projects like ICT4BXW focus on communication mediated through digital technologies and services themselves. Yet, our implementation of the Musa-game draw attention to other dimensions of 
communication by visualizing the human-human and human-non-human interactions on the board, and the possibility to coordinate management strategies by means of communication during the game (see also section 3 ).

\subsection{Methods}

\subsubsection{Testing the Musa-game in Rwanda and exploring data analysis methods}

The Musa-game gives an abstract representation of the socio-ecological dynamics between a group of 4 farmers, their banana mats, the bacterial disease agent $(B X W)$, the insect vectors transmitting the disease, and an external agent who monitors the spread of the disease (Galarza-Villamar et al. 2021). Being real-life banana farmers, the players are confronted with a realistic representation of the problems of collective (in)action they face when preventing disease transmission. Operationalization of the Musa-game required the involvement of real actors faced with the social dilemma to adopt (or not) strategies to prevent or control a public bad threatening their livelihood. To make simultaneous agent actions and system outcomes possible the experimental arena was a square-board that represented the biophysical space where, in real-life, actions and interactions take place. Additional (qualitative) tools, i.e. surveys and focus groups) were used pre- and post-experiment respectively to better understand context-specific motivations behind farmers' decision-making.

In April 2020 we tested the Musa-game in four villages of Kayonza district in Rwanda's Eastern province to identify possible needs for calibration and explore suitable data analysis approaches. Test games were carried out according to an experimental protocol with the support of trained research assistants speaking both the local language, Kinyarwanda, and English. In this section, we present the experimental treatments and the questions that we asked to evaluate the game design and treatments, and we then explore the qualitative and quantitative results from the test games.

\subsubsection{ICT4BXW project context}

The logistic arrangements for the field experiment test and sampling strategy were made in cooperation with the ICT4BXW project. ICT4BXW operated in 138 villages in eight districts, in four provinces, in Rwanda. 69 project villages are intervention villages where ICT4BXW piloted their smartphone application (BXW-App) and actively 
engaged with village-level extension agents (so-called farmer promoters). A farmer promoter (FP) is a village-level extension agent who is a farmer him-/herself. Every village in Rwanda has an FP and he/she is the last-mile actor in the country's Twigire Muhinzi extension system (Wennink \& Mur, 2016). An FP is elected by peer-farmers and the role is part-time and voluntary. BXW-App is a digital extension service that supports diagnosis and control of BXW (disease surveillance + early warning system), gives information about banana agronomic practices, and registers the local presence of BXW. Farmer promoters are the primary users of BXW-App. Secondary users of the information provided or data collected by BXW-App are farmers, researchers, and government representatives. ICT4BXW maintains partners with Rwandan government agencies, RAB and MINAGRI) because of those agencies' vested interest in reducing the impact of BXW as well as developing and maintaining successful digital agriculture solutions that responded to the country's policies (MINAGRI, 2016).

\subsubsection{Experimental treatments}

To contribute understanding about the emergence and governance of conditions that hinder or improve the management of a public bad, we test decisionmaking and actions of farmers toward governing a public bad risk: BXW disease. For Musa-game, we chose to develop experimental treatments grounded in the communication principle of risk governance, as a central factor that affects different actor's (inter)actions with emergent outcomes. The communication principle can be defined as meaningful interactions in which knowledge, experiences, interpretations, concerns, and perspectives are exchanged (Lofstedt, 2003 as cited in Van Asselt \& Renn, 2011) and provides a basis for governance decisions despite the possible presence of uncertainty, complexity, or ambiguity. Communication serves to share information about risks and, create networks of trust and social support to find possible ways to handle (emerging) risks (IRGC, 2010).

The three treatments are as follows: In treatment 1, players are not allowed to communicate during the game. In treatments 2 and 3, players have opportunities to communicate that allow them to exchange their interpretations of the game, technical knowledge about and experiences with BXW disease, perceptions of risk, as well as to develop an individual and/or collective risk governance strategy. In treatment 2, players were allowed to communicate before the first round of the game. This scenario is denominated as 'preventive communication' because players have not experienced the 


\section{Chapter 7}

disease in the game yet. In treatment 3, players were given two communication opportunities: once before the first round (similar to treatment 2), and once in between rounds three and four (see also Table 19). The latter communication opportunity scenario is denominated as 'responsive communication' since it occurs when players are experiencing the spread of the disease and need to respond to the associated threats. Therefore treatment 3 is a preventive-responsive communication scenario.

From a methodological-analytical perspective, the test sought to explore:

- If the emergence of an event (throughout the game rounds) and its representation at a given place (the board) influence players' decision-making (toward prevention and control of the disease, or institutional consequences of failing to do this) and vice-versa?

- If intertwined human and non-human dynamics influence the creation of unfavourable collective conditions, either from the disease itself (death of the banana mat) or other associated ones (compulsory uprooting of infected mats performed by monitors)?

- If and how spatial analysis can contribute to the interpretation of the data collected through the Musa-game?

From the perspective of an experiment on risk governance, focusing on the principle of communication and its role in governing a public bad, the test sought to explore:

- If there is a difference in collective and individual performance in terms of net profit in the different treatments?

- If having previous knowledge of BXW disease management affects collective and individual performance in terms of net profit?

- If risk perceptions influence participants' playing strategies for the prevention and/or control of a public bad risk such as BXW disease?

- If the experimental findings can inform digitalized disease management and communication strategies?

From a game mechanics design and contextualization perspective, the test also raised the following questions.

- Is the Musa-game easy to understand and attractive to play for actual farmers?

- Does the Musa-game sufficiently capture the real-life decisions about dilemmas related to the prevention and control of BXW disease? 
The Musa-game test sessions had two phases: In the first phase, farmers played the game for up to 7 rounds. In the second phase, players were involved in a focus group discussion. The quantitative and qualitative data were processed for spatial analysis. The dependent variables for analysis were the individual and collective profits, and the players' preferences to take risk management actions such as either cutting 2 flowers or uprooting one infected mat (Table 18). The spatial dimension of such decisions was considered by both tracing the position on the board and the round in which actions were taken.

Table 18: Dependent, independent and controlled variables of the Musa-game experiment

\begin{tabular}{lll} 
Dependent variables & Independent variables & Controlled dynamic variables \\
\hline Individual profit outcome & Risk communication: none; & Farmer game rules \\
Collective profit outcome & preventative; responsive; & Insect vector game rules \\
Decision to cut male flower (0 or & preventative and responsive. & Monitor inspection game rules \\
2 flowers per round) & & Rules in the progression of the \\
Decision to either cut male & & disease through the progress of \\
flower (0 or 2 per round) or & & time. \\
uproot one infected mat. & &
\end{tabular}

\subsubsection{Sample}

Test game villages were sampled based on the criteria location, agricultural activity, and reachability. The sample is not and was not intended to be representative since its purpose is limited to test experimental design, game design, and contextual coherence. A total of 48 male and female banana farmers participated in the test sessions, 12 farmers per session, with three individual games played per session. Farmers were randomly selected from a pool of 30 farmers per village whose names had been provided by the village leader or village extension agent. An over-sampling strategy was used to resolve potential no-show issues. For each session 16 farmers were sampled, 12 players, 4 reserves. In case a player farmer did not show he/she was replaced with a person from the reserve list. Reserves present but not needed as players were allowed to observe the game for learning purposes but not to contribute to the game or interact with the players.

To explore the effect of existing knowledge on BXW disease management on performance we included two types of villages in our test sample: (1) those recently exposed to a BXW knowledge intervention and (2) those not exposed to a BXW knowledge intervention. Of the four villages, three (36 farmers) were villages that had 


\section{Chapter 7}

interventions from the ICT4BXW project (intervention status - a). This project operated in Rwanda and developed and piloted a digital extension application specifically targeting BXW prevention and control. In these villages, the extension agent had received training about $B X W$ through the project and used the extension application, and it could be expected that farmers had been exposed to the extension agent's knowledge about BXW. One village (12 farmers) was an ICT4BXW control village where no previous project interventions had taken place (control status - b) (Table 19). Each participant gave informed consent and agreed to participate in the Musa-game.

Table 19: Overview of sample used in the test experimental game.

\begin{tabular}{|c|c|c|c|c|c|c|}
\hline Treatment & Boards & Description & Village & $\begin{array}{l}\text { Part of ICT4BXW } \\
\text { project } \\
\text { intervention }\end{array}$ & $\begin{array}{l}\text { Code } \\
\text { Treatment/ } \\
\text { ICT4BXW/ } \\
\text { board }\end{array}$ & $\begin{array}{l}\mathrm{N} . \\
\text { players }\end{array}$ \\
\hline T1.a & $\begin{array}{l}\text { Board 1, } \\
\text { Board 2, } \\
\text { Board 3. }\end{array}$ & Non comm. & Muzizi & Yes (a) & $\begin{array}{l}\text { T1.a.b1 } \\
\text { T1.a.b2 } \\
\text { T1.a.b3 }\end{array}$ & 12 \\
\hline T2.a & $\begin{array}{l}\text { Board 1, } \\
\text { Board 2, } \\
\text { Board } 3 .\end{array}$ & $\begin{array}{l}\text { Preventive } \\
\text { comm. }\end{array}$ & Kamajigija & Yes (a) & $\begin{array}{l}\text { T2.a.b1 } \\
\text { T2.a.b2 } \\
\text { T2.a.b3 }\end{array}$ & 12 \\
\hline T3.а & $\begin{array}{l}\text { Board 1, } \\
\text { Board 2, } \\
\text { Board } 3 .\end{array}$ & $\begin{array}{l}\text { Preventive } \\
\text { and } \\
\text { responsive } \\
\text { comm. }\end{array}$ & Kinunga II & Yes (a) & $\begin{array}{l}\text { T3.a.b1 } \\
\text { T3.a.b2 } \\
\text { T3.a.b3 }\end{array}$ & 12 \\
\hline T3.b & $\begin{array}{l}\text { Board 1, } \\
\text { Board 2, } \\
\text { Board 3. }\end{array}$ & $\begin{array}{l}\text { Preventive } \\
\text { and } \\
\text { responsive } \\
\text { comm. }\end{array}$ & Butimba II & No (b) & $\begin{array}{l}\text { T3.b.b1 } \\
\text { T3.b.b2 } \\
\text { T3.b.b3 }\end{array}$ & 12 \\
\hline Total & $\begin{array}{l}12 \text { boards; } \\
12 \text { games }\end{array}$ & 3 treatments & 4 villages & & & 48 \\
\hline
\end{tabular}

\subsubsection{Procedure}

Each treatment was tested with a game session taking approximately 2 hours. In each session, three games were played with 4 players each. Every game table had two research assistants, one game master, and one notetaker. The gameboards and their components (e.g. cards) were placed on separate tables. For each session, a sticker with a unique identifier code was placed on each of the four gameboard quadrants with each identifier being randomly assigned to a participant. A camera was attached to a tripod with a horizontal arm to video-record the game (Figure 26 and Figure 27). This overhead setup only recorded the boards and the players' hands during the game 
rounds, guaranteeing player anonymity. As part of the informed consent, players consented to the session being video and audio recorded.

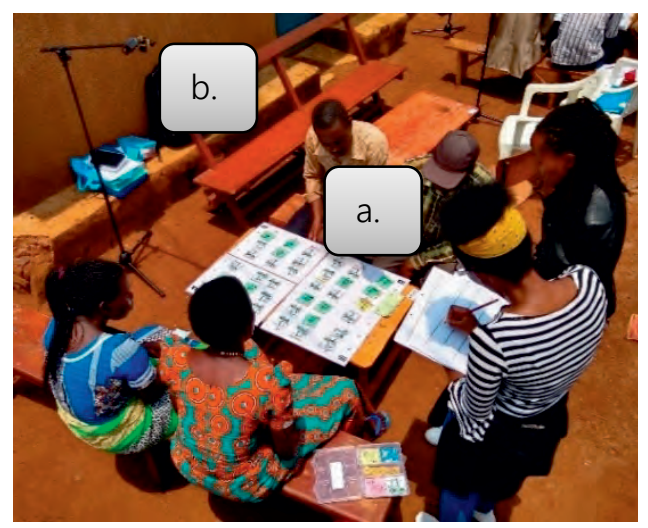

Figure 26 Test session in Kayonza. In the picture, four farmers are playing the boardgame (a) while being recorded (b).

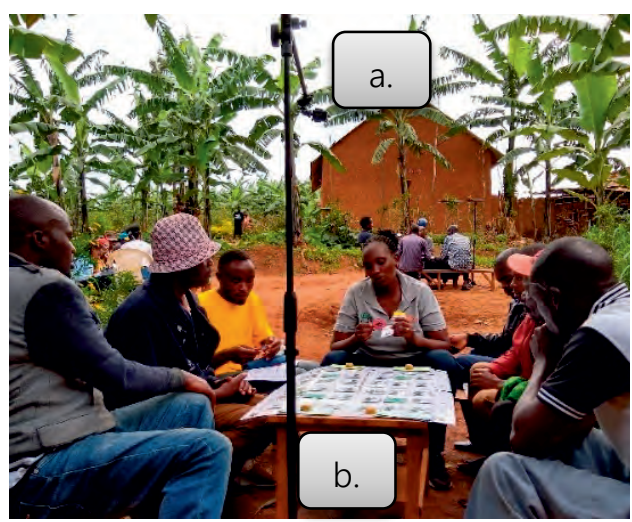

Figure 27 Test session in Kayonza with 3 groups of players with a distance between the game tables. Separate video equipment (a) and game kits (b) were used for each table

After welcoming a participant, a research assistant would lead them to the seat matching his or her identifier. Once all players were seated the session started with a general introduction about the Musa-game (e.g. BXW disease, the research project, and the objective of the game test). The research assistants then explained the rules of the game in Kinyarwanda, supporting their explanations with demonstrations on the actual board. Participants had the opportunity to play one trial round and ask questions or for clarifications afterward. Thereafter the game started following the specified treatment protocol.

For each test-game the coordinates of both monitor and insect were assigned randomly in advance, using statistical software, and equal for every session. In every round, the farmers first decided if and which action they should take. After that, the game master announced the location of first the monitor and then the insect and placed it in the right cell on the board. In each round, the assistant read aloud the position on the board where the monitor and insect card will visit. The players only know where the insect and monitor will visit after they have made their decisions. The notetaking research assistant meanwhile filled a paper-based form to track the farmer/players' actions, the monitor's and insect's locations, and the intermediate game outcomes. The video and audio recordings of the session were used as a backup to the hand-written data. 
Chapter 7

\subsection{Results and analysis}

In this section, we explore the test game results, both quantitatively and qualitatively. First, we assess game acceptance, game vs real-life practices, and perceptions about the different treatments. We then look at how results from the Musagame may inform us about individual and collective benefits and possible relationships between benefits and individual decisions regarding what action to choose, and where to spatially perform that action. Lastly, the section looks at learning effects. Given the small sample size and the exploratory nature of the analysis, we do not perform any inferential statistical analysis but use descriptive statistics and descriptive spatial analysis.

\subsubsection{Participants receptivity to the Musa-game}

The responses from the banana farmers who played the Musa-game showed that it was well-received and mostly understood by players. Participants expressed gratitude for the game's learning effect: "Before we'd cut flowers and even uproot the infected bananas but without knowing the reasons why we do that. But after playing this game we understand the importance of cutting flowers and uprooting the infected banana mats"(T3.b.b2).

We also found evidence of social learning mechanisms, especially regarding fighting BXW collectively: "This game taught us about the way that we should work together with our neighbours when fighting BXW" (T2.a.b3); and "After playing this game, I recognize that a better way to eradicate $B X W$ disease is to collaborate with my fellow banana farmers by advising each other" (T3.b.b2).

Participants perceived the game as a fun way to learn about BXW disease by playing the game and interacting with their peers. A farmer noted that: "The game was fun, and [it was] interesting to understand what was happening and why" (T2.a.b1).

Farmers mentioned that playing the Musa-game helped them to understand the consequences of their actions: "The game was amazing, and we have seen that it is better to prevent BXW disease because if we don't do it, we lose our investment too" (T2.a.b2). Others acknowledged the importance of working together: "The game showed me that working together is very important in fighting BXW"(T1.a.b1).

Farmers reported that the Musa-game equipped them with relevant skills: "Honestly I am happy that you gave use these priceless skills on the importance of cutting banana 
flowers. I wish you could come as many times as you can and teach us more" (T1.a.b1) and said that they wanted to share this knowledge with other farmers: "What / get after playing this game, I am going to teach all of these good lessons to my neighbours so that we can work together in combating BXW disease" (T2.a.b2); and: "What I can give as an advice is that you need to reach out to every banana farmer in the country, to make them understand how to prevent this dangerous disease and the importance of working together" (T1.a.b1).

From a disease management perspective, participants mentioned learning from both the Musa-game rules and discussions with their peers: "What / learned [...] is to share ideas as neighbours by reminding each other to visit each other's fields more often. In addition, [...] / learned [...] that we should invest in protecting our banana fields" (T3.a.b3). Some participants were unaware that the BXW could be transmitted by insects and therefore had not prioritized cutting flowers in their fields: "[...] / learned that BXW disease is caused by an insect, this has led me to decide to wake-up early every day to visit my field and cut flowers" (T3.b.b2).

Farmers agreed that the Musa-game is a helpful tool to develop a better understanding of both the disease and the impact that individual actions can have for collective benefit:

$B X W$ is a very bad disease which can cause a big loss, not only to an individual farmer but also to the whole village and our country. In order to solve the problem of BXW disease, it is better to mobilize our fellow farmers [...] through village meetings (T3.a.b2).

Moreover, the importance of preventative actions for protecting fields and livelihoods became clear: "What I learned from this game is that we should cut flowers early and uproot the diseased mats immediately" (T1.a.b3); and: "What I observed through this game is that if we don't protect our fields from BXW it will cause poverty" (T3.b.b3).

\subsubsection{Participants' perception of how the game's representation of decision dilemmas to prevent and control BXW disease accorded with real-life.}

Participants accounted that BXW disease is a recurring issue in their life: "The game tells me how to fight BXW and this is a real problem that I have been fighting with for four years" (T1.a.b2). They also related the game context to their real-life 
Chapter 7

experiences with BXW disease prevention and control: "... in this game those who did not invest in protection faced losses. The same happens in real-life, if you don't invest in protecting your field then you lose" (T3.a.b1).

The FGD data gives insight into participants' knowledge about cultural practices used to prevent BXW transmission. For example, most players were aware of the practice of cutting the flower: "The decisions about cutting flowers and uprooting the diseased mats that I had to take in the game were the same as the ones I'm used to taking in real-life" (T3.b.b3). Others cope differently with diseased mats in real-life: "I'm used to cutting the diseased mat and leaving it in the field, not to uprooting it." (T2.a.b3).

Some participants displayed knowledge about other disease infection mechanisms and prevention practices:

I can also get infected by using infected tools like hoes, machetes, or get infected by my neighbour who has BXW in his field" (T2.a.b3), and: "IIn real-life] I have also observed that even bananas which have no flowers are also infected by BXW. So since you are researchers, I would like you to take this into consideration too" (T3.a.b3).

Farmers who played in one of the two different game treatments with communication (T2-T3) told us that the risk communication style during the game differed from reallife:

The style of communication during the game was not the same as the one we use in real life, because when you meet someone, the only thing you tell him is if you have been infected by BXW. [...] we never discuss together the measures we should take to fight this disease. But during the game, I was able to discuss and share with my neighbours the measures that we can take to fight this disease together (T3.a.b3).

Participants experienced this communication as providing an opportunity to learn from others and develop strategies to fight BXW together:

"We also discuss about BXW in real-life but there is a small difference, [in real-life] we might see our neighbour's field infected by BXW but do nothing to help, but during the game, we discussed [...] what we should do"(T2.a.b3).

Farmers playing the non-communication treatment (T1) thought that communication was crucial to taking better decisions: "I wished to share ideas with my friends. I even 
whispered but you caught me and stopped me" (T1.a.b1). According to T1 players communication would not only allow them to make better individual decisions but also collectively respond to a common threat: "I think that if we'd had a chance to discuss during the game, I would not have been infected by BXW because we would take action together to fight this disease" (T1.a.b3).

\subsubsection{Overall game performance}

Figure 28 shows the results from all 12 boards in terms of net profits. In 100\% of the games, collective food security and some net profit from banana production were achieved. Individually, only one player, in T3.b, ended the game with net debt and became food insecure. The mean average is similar for all games, ranging between Fr.4000 and Fr.4650 for 10 out of the 12 games. Hence, descriptively we observe no significant profit differences between the treatments.

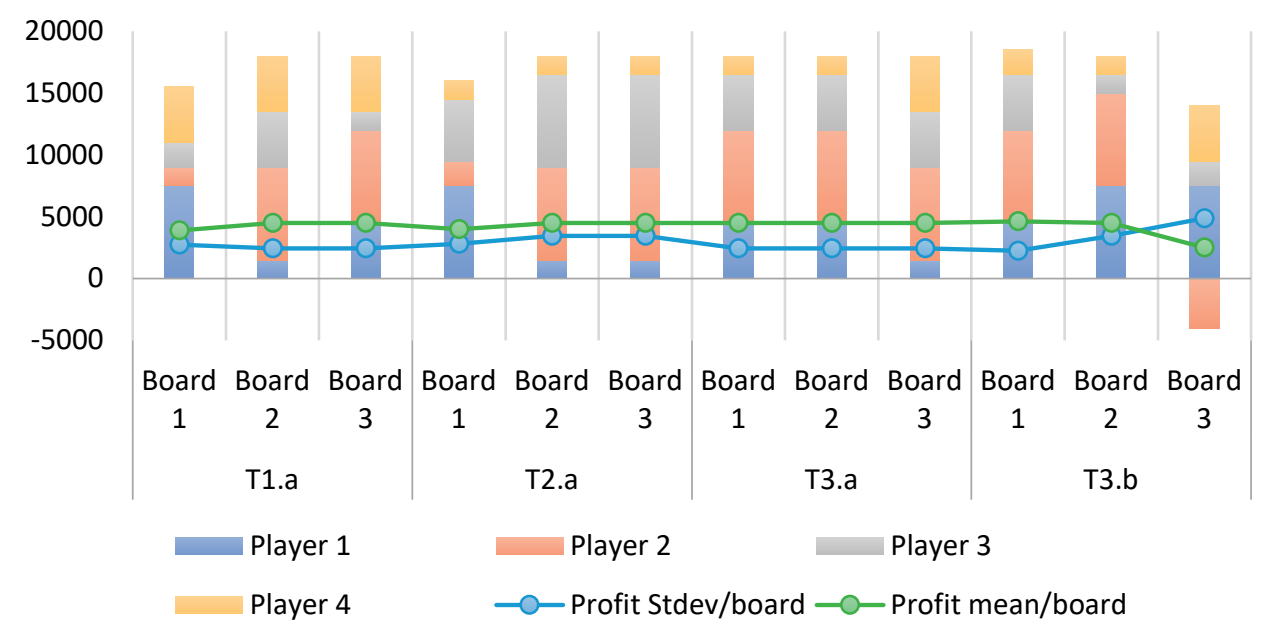

Figure 28 Game results in terms of profits per player, per board (4 players/board), per treatment (3 boards/treatment). The blue line shows the profit standard deviation per board. The green line shows the mean profit per board.

Figure 29 provides information about differences in the actions that players prioritized in the different treatments. In T1.a and T3.a none of the farmers ended the game with cards representing a risk for themselves or their neighbours (i.e. yellow or red cards). In T2.a and T3.b, some players ended the game while there was still a disease threat (i.e. a yellow and red card in T3.b and a yellow card in T2.a). 


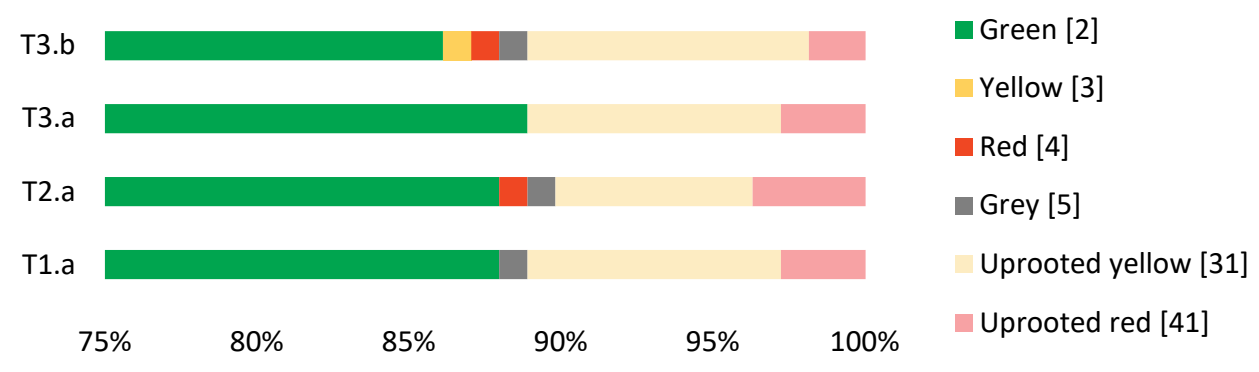

Figure 29 Percentage of the type of cards on the board at the end of the game which determined players profits: green card [healthy mat without flower - code 2], yellow card [BXW infected mat, first disease stage - code 3], red card [BXW infected mat, second disease stage - code 4], Grey card [dead mat - code 5], Uprooted yellow card [code 31], Uprooted red card [code 41].

\subsubsection{Spatial locations of decision-making: Decisions about where to cut flowers}

Since the Musa-game is played on a board there is a spatial dimension to players' decision-making. Each player shares their quadrant's inner border with the other three players. However, the game instructions did not inform players about what would (hypothetically) be adjacent to the outer borders of their quadrant. The hypothesis is that farmers who decide to take preventive (cut flower) or responsive (uproot diseased mat) action nearer to the inner border (= their fellow players) show more cooperative behaviour than farmers who take actions nearer to the outer border. This because the game rules informed players that their actions can have consequences for both themselves and their fellow players. For data analysis purposes we transcribed the original notation of the board locations from letters and numbers to just numbers (Figure 30). Locations 1 to 5 adjoin the 4 players, 9 is the location furthest from the board's centre, and 6-8 sit in between. 
Player 2
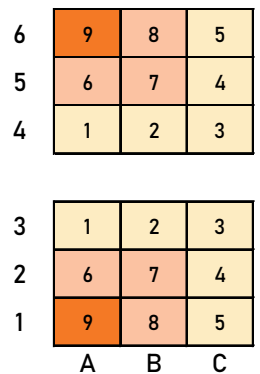

Player 1
Player 4

\begin{tabular}{|l|l|l|}
\hline 5 & 8 & 9 \\
\hline 4 & 7 & 6 \\
\hline 3 & 2 & 1 \\
\hline
\end{tabular}

\begin{tabular}{|l|l|l|}
\hline 3 & 2 & 1 \\
\hline 4 & 7 & 6 \\
\hline 5 & 8 & 9 \\
\hline D & E & F
\end{tabular}

Player 3

Figure 30 Game board map: players' positions and mat locations for data processing purposes.

Figure 31 shows the board locations where players cut flowers to prevent BXW transmission in each round. In all four treatments players cut flowers in locations 4, 5 , 8 , and 9 in round 1 , which are mainly outer border locations. The mats in those locations never got infected. Location 3 (the most central) was cut in the first two rounds mainly by farmers in T3.a, the treatment with farmers exposed to knowledge about BXW in real life and with two opportunities to communicate during the game. Only in T3.b (groups with two communication opportunities, that do not belong to the ICT4BXW project) did none of the players cut flowers in the most central locations (1-5), while it took until round 4 before the central location (3) was cut.

Although players in T3.a and T3.b had the same communication opportunities there were differences in the flower-cutting locations between rounds. The players in T3.a had been exposed to knowledge about the disease in real-life and this may have influenced their ability to communicate about prevention and control practices and work out a (spatially) more cohesive game strategy. 


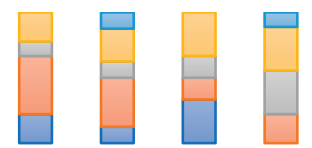

T1.a T2.a T3.a T3.b 6
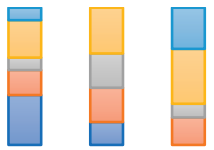

T1.a T2.a T3.a T3.b

9
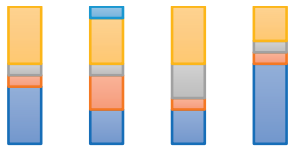

T1.a T2.a T3.a T3.b

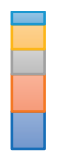

At the start of the game the mat in this position was without flower for all players.

8
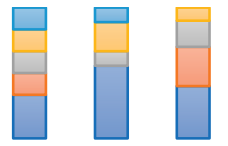

T1.a T2.a T3.a T3.b
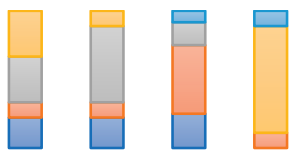

T1.a T2.a T3.a T3.b

4

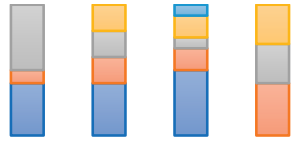

T1.a T2.a T3.a T3.b

5

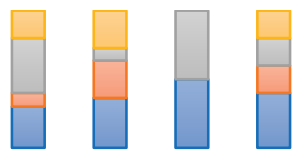

T1.a T2.a T3.a T3.b

aRound $1 \quad \square$ Round 2 aRound 3 aRound $4 \quad \square$ Round 5 aRound 6 aRound 7

Figure 31: Proportion of decisions to cut flowers taken in the 9 board locations in each game round. The figure is presented like a players' section of a board from the perspective of player 1 (see Figure 12). Each segment is numbered from 1 to 9, corresponding with locations. Locations 1-5 are the board's inner borders. Location 3 is the most central. Location 9 is the board's outer corner. The bar diagrams within each segment show the proportion of flowers cut in each round per treatment. E.g. in round 1 (light blue colour) many flowers were cut in position 9, the location farthest from the board's centre, and only a few in position 3, the most central location. Location 7 does not show data because all players started the game with a mat without a flower in that position.

\subsubsection{Spatial distance-based decision-making analysis: the Musa analysis tool}

To retrieve the results presented in the following sub-sections, a computational programme, called the Musa analysis tool, was developed to assist with analyzing our dataset which includes both decisional and spatial dimensions. The Musa analysis tool was developed using the programming language C Sharp (C\#) and its task is to perform different spatial analyses based on distances and relate those to game decisions. The software assumes a uniform distance of $1 \times 1$ unit between the banana mats (positioned 
in a segment), and its point of interest is in the central position of each segment (Figure 32 and Figure 33).

The distance between two random points $A$ and $B$ is given by:

$$
D=\sqrt{\left(P I_{A x}-P I_{B x}\right)^{2}+\left(P I_{A y}-P I_{B y}\right)^{2}},
$$

where $\mathrm{PI}$ is the position of interest for calculation measured from the centre of each segment.

Likewise, all the distances measured during the experiment correspond to the distances between a PI (Point of Interest) of a segment, corresponding to the player's actions, and another $\mathrm{PI}$ of a second segment, corresponding to a direct value of the board at that instant of time (Game Round), or the Pc position (Center position). These measurements were normalized to a scale of values between 0 and 1 , which will mean a value of 0 for positions outside the board and 1 for positions where specific actions are taken (figure 32 and figure 33).

The distance given in values between 1 and 0 , will be called the normalized distance or Dn, and will be given by $\boldsymbol{D} \boldsymbol{n}=\frac{(\boldsymbol{D m}-\boldsymbol{D})}{\boldsymbol{D} \boldsymbol{m}}$, where $\mathrm{Dm}$ will be the value of the maximum possible distance between two ends of the board. For calculations where the only reference is the Central Position $(\mathrm{Pc})$, the Dm will be half the diagonal of the board. For practical purposes, it should be emphasized that during the real measurements, for normalized distance (Dn) the closed values of 1 and 0 will not be represented (See appendixes for detailed information on the software methodology). 


\begin{tabular}{|l|l|l||l|l|l|}
\hline 0,0 & 0,1 & 0,2 & 0,3 & 0,4 & 0,5 \\
\hline 1,0 & 1,1 & 1,2 & 1,3 & 1,4 & 1,5 \\
\hline 2,0 & 2,1 & 2,2 & 2,3 & 2,4 & 2,5 \\
\hline 3,0 & 3,1 & 3,2 & 3,3 & 3,4 & 3,5 \\
\hline 4,0 & 4,1 & 4,2 & 4,3 & 4,4 & 4,5 \\
\hline 5,0 & 5,1 & 5,2 & 5,3 & 5,4 & 5,5 \\
\hline
\end{tabular}

$$
\begin{gathered}
D=\sqrt{((0+0.5)-3)^{2}+((1+0.5)-3)^{2}} \\
=2.91
\end{gathered}
$$

Figure 32 Distance calculation between a random point $(0,1)$ and PC (Central Position). Notation for each segment is given in coordinates $X, Y$.

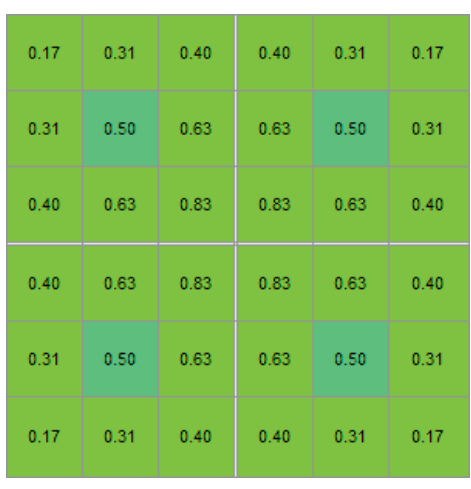

Figure 33 Example of the initial board situation in the Musa analysis tool. It shows the values of the Normalized Distance (Dn) for each segment surrounding the Central Position $(P C)$ of all types of mat's states (healthy, infected, intervened, or dead) for a standard board in the initial round.

\subsubsection{The relationship between the decision to cut flowers and the minimum distance to a neighbour's mat without flower}

Figure 34 shows the relationship between the proportion of flowers that players cut and the minimum distance to a neighbour's mat without flowers (green card). The closer the flower cutting action is to a neighbour's green card, the closer the distance value will be to 1 . The graph shows, in intervals of 0.1 distance units, the proportion of actions taken at distances between 0.1 and 0.9 . It can be observed that in the complete sample, indifferent of treatment, the decision to cut a flower in round 1 started at a distance of 0.5 (in relation to the nearest green card). It thus appears that participants' flower-cutting actions were not oriented toward forming clusters of green cards in the center on the board but dispersed in directions closer to the board's outer borders.

As the games progress the number of green cards on the board can be expected to increase. Therefore, in round 5 we can see that flower-cutting decisions all happen at distances of 0.7 and above (i.e. close to a neighbour's green card). 


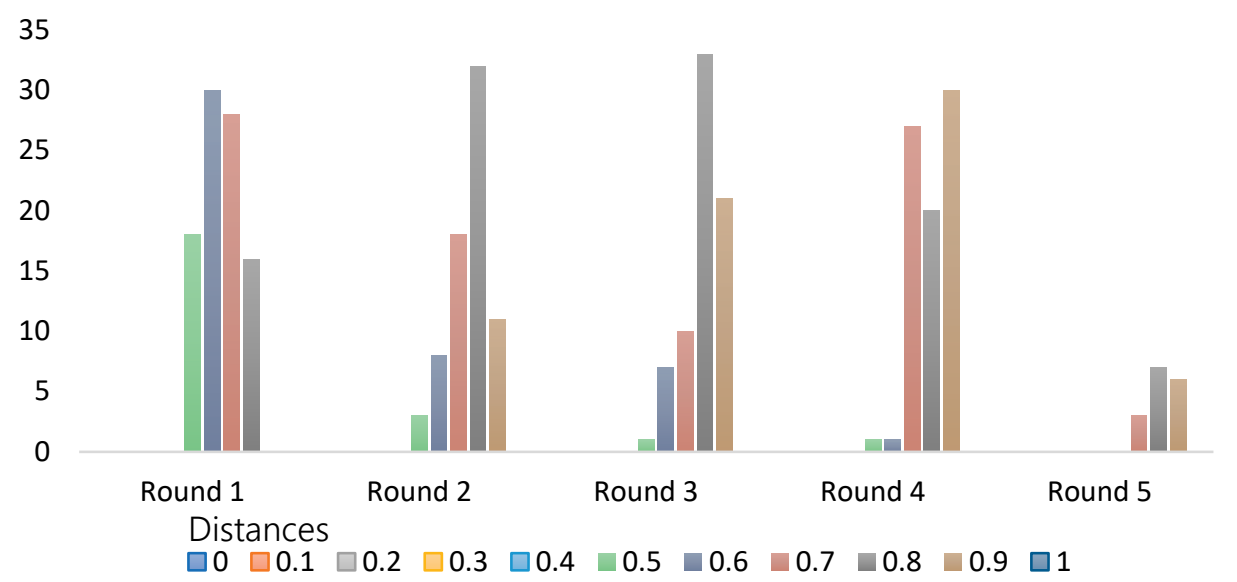

Figure 34 Number of flower-cutting decisions versus the minimum distance to a neighbour's mat without flower. Distances are shown in intervals of 0.1 , from 0 to 1 . The distance closest to 1 represents the shortest distance to a neighbour's mat without a flower.

When asked about the action to cut flowers during the FGD, participants agreed that cutting as many flowers as possible was the best preventative game strategy: "I cut flowers because when the insect that spreads the disease arrives and finds that the bananas are protected, it will leave and infect where the bananas are not protected" (T3.b.b3) and that a regular reminder is desired: "[...] it is always good to keep reminding our neighbours to cut banana flowers in their field" (T2.a.b2).

\subsubsection{The decision to uproot yellow or red mats versus the minimum distance to a neighbour's healthy mat with or without flower}

Although cutting flowers close to where neighbours also cut flowers did not appear to be a priority for players, uprooting diseased mats did. Even though the monitor did not intervene in any of the game sessions, there was a general perception of risk regarding the monitor finding an infected mat:

I was afraid that if the monitor came and found that there was a disease in my mat it would have been necessary for me to uproot other bananas near the sick one. But I was lucky enough to get rid of it before he arrived"(T3.a.b1);

And "I feared that the monitor might come and punish me for infecting my neighbours' bananas" (T3.a.b2). 


\section{Chapter 7}

Figure 35 shows the proportion of yellow cards that were uprooted and the distance to a healthy mat (with or without flower, white or green card). The nearer a player's yellow card is to a neighbour's healthy mat, the closer the distance value is to 1 . Positions over 0.8 are the immediate neighbours' locations. Overall, we observe no actions at distances below 0.7 . If we relate this to the locations where players cut flowers (with a tendency to cut far from neighbours), it implicitly tells us that most mats vulnerable to disease infection (= white cards) were located near the centre of the board. Thus, if one of those mats becomes BXW infected (yellow card) it is located close to healthy mats and therefore more of a collective threat for all players.

Players in T1.a and T3.a uprooted infected mats more often than they cut the flowers. FGD data confirmed that for those playing in T3.a uprooting infected mats was the main strategy

We uprooted mats of infected bananas to protect the remaining bananas in the field as we have realized that if we do not uproot early the banana might turn to red which can be dangerous not only in my field but also for my neighbours" (T3.a.b2).

These players prioritized uprooting diseased mats over profit-making: "Although some of us did not get much profit we have at least managed to uproot the infected mats". They also worked together to minimize overall losses: "We tried to work together as a team so that no-one would suffer a loss"(T3.a.b2). Players in T1.a uprooted yellow mats $100 \%$ of the time when they were in a position of 0.7 from a neighbour's healthy mat and $67 \%$ of the time when they were in a position or 0.9 distance from a neighbour's healthy mat. Players in T3.a uprooted yellow mats $60 \%$ and $100 \%$ of the times when they had them in the same positions. In T2.a and T3.b, the action of uprooting yellow mats decreased to less than $71 \%$ when infected mats were located more than 0.8 distance from healthy mats. This means that some players let their yellow mats progress to red (second disease stage) and that T3.b players, in contrast to those in T3.a. prioritized cutting flowers over uprooting infected mats "I cut all the male flowers in my field and uproot later" (T3.b.b2). 
T3.a

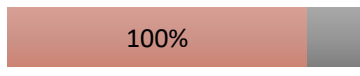

$60 \%$

$83 \%$

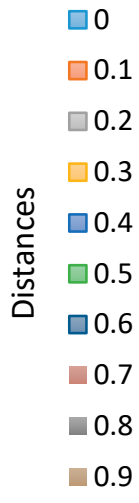

$\square 1$

Figure 35 Stacked bars showing the proportion of uprooted yellow mats in relation to the minimum distance to a neighbour's healthy mat with or without flower. Distances are between 0 and 1 , in intervals of 0.1. Distance closest to 1 represents the shortest distance to a neighbour's mat with/without a flower. E.g. players in T3.b uprooted a yellow mat $71 \%$ of the times that it was located at a 0.9 distance from a neighbour's healthy mat. This means that the remaining $29 \%$ of yellow mats became a red mat in the next round, if not found by the monitor.

Of the mats progressing from yellow to red (Figure 36), players in T3.a uprooted $100 \%$ of the time that a mat progressed to red, and these were located at an average distance of 0.8 distance to a neighbours' healthy mat. In all other treatments, the decision of uprooting a red mat was under 75\%, meaning that the players allowed the disease to progress from a red to a dead stage (grey card). While not uprooting a yellow mat was a risk for the individual player, not uprooting a red mat put all the players at risk of uprooting if it was found by the monitor. Players in T3.b., who were not part of the ICT4BXW project intervention, took the highest collective risk. 
T3.a

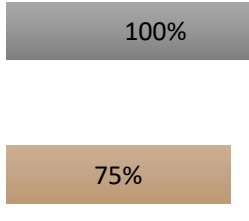

$100 \%$

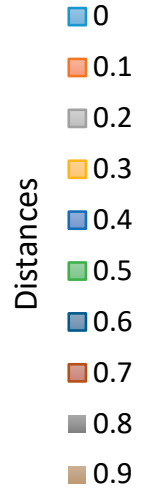

T3.b

$50 \%$

$67 \%$

$\square 1$

Figure 36 Stacked bars showing the proportion of uprooted red mats in relation to the minimum distance to a neighbour's healthy mat with or without flower. Distances are between 0 and 1, in intervals of 0.1 . Distance closest to 1 represents the shortest distance to a neighbour's mat with/without a flower. E.g. players in T3.b uprooted a yellow mat 50\% of the times that it was located at a 0.9 distance from a neighbour's healthy mat. This means that the remaining $50 \%$ of yellow mats died in the next round, if not found by a monitor.

\subsubsection{Decisions about cutting flowers and the distance to an infected mat and the outer border}

We also explored the relationship between the decision to cut flowers and the distance to 2 different variables: distance to the outer border (distance toward 0), and distance to the nearest infected mat (yellow or red) of a neighbour (distance toward 1). If the player decided to cut a flower closer to the outer border rather than closer to the nearest infected mat of a neighbour, the value is closer to zero. If the player cuts a flower closer to the infected mat, the distance is closer to 1. In Figure 37 we see that $66 \%$ of players cut the flowers closer to the border, and only under $10 \%$ cut flowers in positions near a neighbour's infected mat. These results suggest that players preferred to invest in cutting flowers in positions the farthest from an infected mat. The fact that most farmers decide to cut flowers in positions 0.2 distant to the border (close to the outer border, far from the neighbour's infected mat), suggests that most infected mats are located toward the centre of the board. 
$70 \%$
$60 \%$
$50 \%$
$40 \%$
$30 \%$
$20 \%$
$10 \%$
$0 \%$

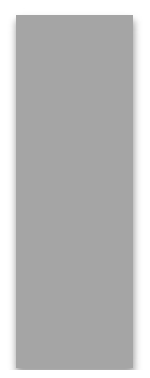

0.2

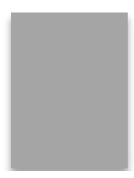

0.4
0.6

Figure 37: Decision to cut flowers in relation to the distance to the outer border and infected mats. The Xaxis shows the distances between the outer border (toward 0) and an infected mat (toward 1). The $Y$-axis shows the proportion of cutting flowers in between both variables (outer border and infected mat).

\subsubsection{Exploring the usefulness of neighbours' analysis}

We used the Average Nearest Neighbour Distance tool available in ArcGIS to perform exploratory analysis and calculate the expected mean distance between each feature and its nearest neighbour's location. The feature, in this case, represents the location of a banana mat and its nearest neighbour's mat where a player took an action (either cutting the flower or uprooting an infected mat). The expected distance is based on a hypothetical random distribution with the same number of features covering the same total area (ArcGis, n.d.). To make this analysis possible, we gave a hypothetical geographical coordinate to each location, with a homogeneous distance in metres between features. The purpose of this analysis was to explore the relationship between the progression of the distance between actions taken over time and a player's net income. Our assumption is that the larger the distance in the first rounds, the less cooperative a player's actions (= farther away from the board's centre), resulting in lower, or more unequal, individual net incomes.

We tested this analytical method comparing T2.a and T3.a. As previously described, players in T2.a had one communication opportunity before the start of the game (preventive), and players in T3.a, had a communication opportunity before the first round (preventive), and after the third round (responsive). Players involved in both treatments belong to a group of farmers that are part of the ICT4BXW project, which provides them with training in BXW management. In Table 20a, we see that the mean net incomes are very similar, although the income per player varied. Players 1 and 4 in game T2.a. made a net income of 16500 Fr., while players 2 and 3 ended the game with 


\section{Chapter 7}

a net income of $22500 \mathrm{Fr}$. In T3.a, the variation among players' net income was less, with 3 out of 4 players gaining net incomes of between 19500 and 22500 .

In Table 20b, the board locations where the action took place are shown progressively from round 1 to round 5 . The numbers (from 1 to 5 ) shown in each square denote the round where the action was taken. The actions were either to cut flowers or to uproot an infected mat. We see that players 1 and 4 from T2.a, with the lowest net incomes, initially chose to take these actions in more distant locations but that they became closer to the centre as the game progressed. The final actions of those players (round 5) were in the board's central locations. Players in T3, in contrast, starting from round one took actions closer to the center of the board and ended the game toward the outer border of the board, hence working in a closest to furthest distance order.

In Table 20c, we relate the expected mean distance between the location where actions were taken (features) in each round to the standard deviation of the net income across rounds. Looking at T2.a, we can see that the lower the distance among the positions where the actions were taken toward the game's end (round 5), the higher the standard deviation of the net income (3464 Fr.). In T2.a, the distance among action-taken positions remained dispersed up to round 4 and did not show a trend. In T3.a, we see that the distances increased steadily as the game progressed, resulting in a lower standard deviation of net incomes (2449 Fr). These differences (in trends) between the treatments might be related to players in T2.a not having a communication opportunity between the rounds. This meant that players in T2.a players did not exchange any information that could have contributed to the emergence of a different strategy once the game started.

In public bad management terms, the results suggest that more communication opportunities contribute to better collective management of risks. Secondly, they suggest that collective action in risk management can create socio-ecological conditions for a more equal distribution of benefits. 

(28)

$a$

\begin{tabular}{c|cccccc|cccc} 
T2.a & $r 1$ & $r 2$ & $r 3$ & $r 4$ & & T3.a & $r 1$ & $r 2$ & $r 3$ & $r 4$ \\
\hline P1 & 23100 & 20300 & 19800 & 17000 & & $P 1$ & 23100 & 20300 & 19800 & 19600 \\
P2 & 23100 & 22900 & 22700 & 22500 & & $P 2$ & 23100 & 22900 & 22700 & 22500 \\
P3 & 23100 & 22900 & 22700 & 22500 & & $P 3$ & 23100 & 22900 & 20100 & 19600 \\
P4 & 20500 & 20000 & 17200 & 17000 & & $P 4$ & 20500 & 20000 & 19800 & 17000 \\
Mean & 22450 & 21525 & 20600 & 19750 & & Mean & 22450 & 21525 & 20600 & 19675 \\
Sum & 89800 & 86100 & 82400 & 79000 & & Sum & 89800 & 86100 & 82400 & 78700 \\
Stdv. & 1300 & 1592 & 2647 & 3175 & & Stdv. & 1300 & 1592 & 1407 & 2247
\end{tabular}

$b$

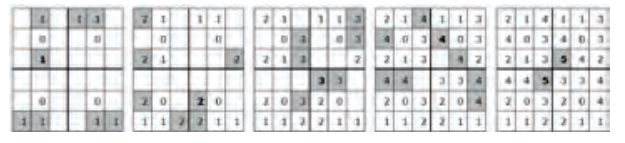

C $\quad 140.00$

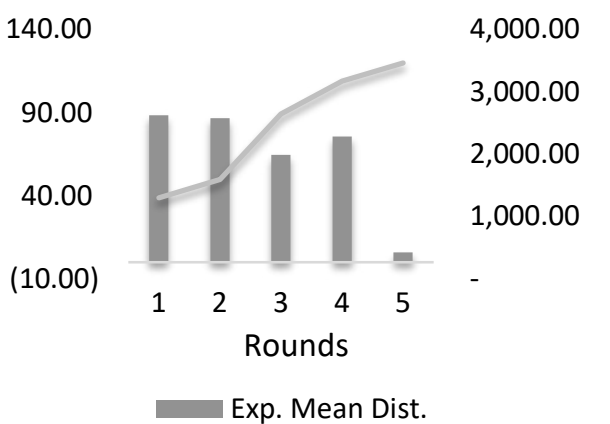

Exp. Mean Dist.
140.00

90.00

40.00

$(10.00)$

$4,000.00$

$3,000.00$

$2,000.00$

$1,000.00$

$\begin{array}{lllll}1 & 2 & 3 & 4 & 5\end{array}$

Rounds

Exp. Mean Dist.

\subsection{Discussion and conclusions}

\subsubsection{The emergent phenomena and spatial analysis to better understand public bad risks}

This paper built upon Ostrom's SES framework (2009), a framework for analyzing a public bad risk threatening livelihood resilience, from a risk and collective action problem perspective and presented results from field-testing an experimental boardgame: Musa-game. The game method emphasizes the role of emergent phenomena in decision-making, which were operationalized for the context of BXW disease management in Rwanda. With Musa-game we successfully added the element of emergence to the study of public bad risks and can show how various interactions between entities (i.e. players, insect vector, monitor) and their individual decisions, and rules of the socio-ecological system give rise to unpredictable and interdependent risk 
scenarios. The combination of autonomous players, emergence, and spatial analysis in Musa-game elicited a metacognitive experience for players. Individual players (farmers) needed to adapt to the emerging conditions through individual and collective actions towards coordination of the disease risk. By tracing the data about the what, where, and when, of player's management decisions, we were able to better understand how decisions shape the public bad risk in different circumstances. Through the Musa-game, we traced data showing the BXW disease prevention and control decisions that players took. We also looked at the timing (game rounds) and locations (on the game board) of those decisions. The analysis allowed us to link, through spatial analysis, decisionmaking and risk scenarios that emerged from the decisions of players, together with actions of autonomous entities (insect and monitor). The potential causal relations we identified helped us to develop hypotheses about the decisions made in different communication scenarios.

\subsubsection{The influence of knowledge and communication}

Exploring the number of decisions to cut flowers closer to the outer border or a neighbour's infected mat, we found that over $60 \%$ preferred to cut flowers in mats that were further from a neighbour's infected mat. FGD data suggest that farmers perceived proximity to a sick mat as high risk:

Although I was in the favourable condition of not being infected by BXW in my field because I cut my flowers frequently, I feel like I still risked BXW infecting in my field because my neighbours had BXW disease in their field" (T3.b.b2).

This suggests that farmers fear making an unworthy investment (cutting flowers) near an infected mat. Farmers experienced uncertainty about whether their neighbour would choose to uproot their infected mats, or to cut more flowers: Even though / already cut all my flowers I was still afraid because the neighbours still had BXW in their field (T3.a.b1). Additionally, at least some participants knew that disease transmissions patterns other than insects exist, albeit these were not included in the game: "I can also get infected through using infected materials like hoes, machetes, or get infected by my neighbour who has BXW in his field" (T2.a.b3). Therefore, cutting flowers near a neighbour's infected mat presented a higher investment risk since, if not uprooted, that disease mat could be visited by the monitor resulting in loss of both mat and investment. Thus, risk perceptions about infected mats and the neighbour's decisions about uprooting probably contributed to sustaining the dispersed strategy. 
The game strategy adopted by participants was similar across all treatments. However, we found that over time the strategy changed in groups that had both previous knowledge about disease management (as a result of being an ICT4BXW intervention village) and multiple opportunities to communicate (treatment 3 ) and became more cooperative. Players from T3.a had some previous knowledge of BTW disease management and had two communication opportunities during the game. A farmer said: "If there was no communication, I would not know what measures I should take, and the result would have been a big loss"(T3.a.b3). These game tables had the highest proportion of uprooting of yellow mats during the game and uprooted $100 \%$ of the red mats. Although they initially started cutting flowers closer to the outer border, this changed from round 2 onwards, when players started cutting flowers closer to their neighbours (Figure 31).

Although participants in T3.b also had two communication opportunities, their management strategy for preventing disease spread was the least effective. This was the only game in which one player ended up in debt. The playing strategy was focused on the outer borders, and the games ended with more infected mats in the yellow and red stages, representing a collective risk. The relationship between the number of infected mats uprooted and the distance to a neighbour's healthy mat was the lowest (see Figure 35 and Figure 36).

One difference between groups T3.a and T3.b was previous disease knowledge. Participants in T3.b were not involved in the extension service programme that provided training in BXW disease management since they were an ICT4BXW project control village. The result suggests that absence of, or incorrect, information has the potential to create greater collective risks.

\subsubsection{Reflection on the Musa-game method}

\subsubsection{The observed phenomena in the game}

Based on the quantitative and qualitative results, we observed that most players, in all of the treatments, started the game by cutting flowers from the outer borders. We interpret this strategy as a non-cooperative one since it creates conditions that increase collective risk. But why did farmers choose this strategy? When explaining the game's rules and structure the research assistants explained that the monitor would randomly visit one mat in each round. Players were not told where the monitor came from or where he/she would go after visiting a mat. Yet FGD data suggests that farmers assumed that the monitor watched their actions from somewhere, even when the 
Chapter 7

monitor card was not yet played: "I felt I was at a high risk because the monitor was somewhere watching or circulating"(T1.a.b1). Therefore, players tried to first satisfy their need to decrease the threat of the monitor if he/she would watch their poor performance on disease management. This suggests that farmers supplemented the information gaps with their personal experiences about (disease) monitoring in reallife. This is not unlikely given the high level of social control and hierarchical structure of Rwandan society, where any person might report about events in their community to a local leader or extension agent. Thus, monitoring is not a foreign concept to farmers. Additionally, we know from reports of extension staff that farmers sometimes 'hide' diseased bananas by being more rigorous in their agronomic practices in places that are visible from the road or close to houses, in an attempt to be seen as a 'good farmer'.

Since the players started the game by cutting flowers mostly toward the outer border, mats in the most central locations were vulnerable to infection by insects for a longer period. The strategies for cutting flowers varied across the treatments. For example, players in T3.a tried to satisfy both the need to show good agronomic performance to outsiders and decrease collective risk. They cut one flower near the border and one flower near the center. By contrast, players in T3.b focused their flower cutting in locations toward the board's outer border. This (initially) individual strategy created a collective risk and mats in more central positions started to get infected over time.

\subsubsection{Reflection on the game's results}

Our study results suggest that for effective collective management of public bad risks a farmer needs to have both the right knowledge and the opportunity to build a collective strategy. This finding aligns with Damtew et al. (2020), who found that the provision of technical information about disease managerial practices alone can have a counterproductive effect on disease management decisions. On the other hand, a combination of both information provision and opportunities for communication and internal governance can lead to better decision-making.

Risk perception appears a critical factor. Participants in this study designed their playing strategies based on their perceptions of risk, either from the fear to be found underperforming by the monitor 'watching them from somewhere', or the possibility that their neighbours do not take actions that reduce the collective risk. Consequently, the sum of the individual decisions to take actions closer to the board's outer border 
not only created a collective risk but, in some cases, also became a self-defeating decision. Thus, the completeness and quality of the information provided matter. In the absence of complete and trustworthy information, self-defeating strategies may be created, especially when the decisions are taken in a vacuum without consultation, and deliberation, with peers. COVID-19 is one example where the influence of misinformation (or a lack of information) and inaccurate risk perceptions. The rapid diffusion of misinformation and poor individual knowledge resulted in the adoption of counterproductive disease prevention practices at both individual and collective levels. For instance, a resident in the U.S. died after consuming chloroquine (use to clean aquariums) to cure COVID-19, fake news that spread through social media. Conspiracy theories spread on social media have also been harmful by undermining public health messages (Barua et al., 2020; Pennycook et al., 2020)

\subsubsection{The learning effect of playing together}

Our study results suggest that the lack of a collective strategy based on knowledge has the potential to create self-defeating strategies, and new collective threats. However, we also found that playing was an effective and powerful learning tool. Participants repeatedly expressed their sense of gratitude and excitement because they learned both about technical aspects of the disease as well as interdependencies and collective action requirements. Our findings align with Tafesse et al. (2020) who found a need for learning approaches that support the diffusion of both technical disease aspects as well as giving attention to the existence of interdependencies and needs for collective action. Given the feedback that we received from farmers, our method meets those characteristics in that it lets farmers actively experience their interdependence while also teaching them technical disease information. Hence, besides being an experimental tool, the Musa-game has potential as a learning tool that could be implemented by researchers and practitioners.

\subsubsection{Implications for communicating about public bad problems}

The Musa game allowed us to explore the multidimensional causalities behind decision-making and their emergent outcomes. The mechanics of the game elicited farmers to learn and experience a complex reality in a simplified setting. Different forms of communication and deliberation opportunities (treatments) triggered players to make sense of their decisions and motivations at both individual and collective levels. These factors influenced decision-making and the outcomes in different 


\section{Chapter 7}

communication treatments. Our findings suggest that collective [coordinated] actions are challenged by more than just social dilemmas. We found that, besides social dilemmas, players' coping capacity and risk perception shape the collective capability to organize the prevention and control of BXW in a coordinated way (Table 21). Those groups with the most opportunities to communicate performed better. Players reported learning from each other, jointly evaluating risks, and making agreements. Group communication hence appears critical providing a space for deliberation and collective sense-making and creating conditions necessary to reach consensus on a strategy and come to collective action.

Table 21: The three factors influencing collective action to prevent and control BXW disease in the Musa game.

\begin{tabular}{l|l} 
Social dilemma & $\begin{array}{l}\text { Players (farmers) face the dilemma of either taking a preventive/control action } \\
\text { (investment) against BXW, which could potentially harm themselves and others. } \\
\text { The dilemma, shaping actions, includes when (game-round) and where (location } \\
\text { on the gameboard) to act. }\end{array}$ \\
Risk perception & $\begin{array}{l}\text { Players' perceived risk of disease infection and punishment (monitor) influences } \\
\text { the decision about when and where to act. }\end{array}$ \\
Coping capacity & $\begin{array}{l}\text { Players' decisions to act (accurately and timely) are influenced by resource } \\
\text { availability, especially capital, information, and knowledge. }\end{array}$
\end{tabular}

Recent experimental findings by Cieslik et al., (2021) from Ethiopia show that a digital service can provide a platform for peer-to-peer communication that facilitates collective action and contributes to catalyzing development impacts, provided that farmers had a prior understanding of their interdependence. In real-life, the power of peer-to-peer communication in study results from Ghana, showing that social media group aided rapid communication about the emerging fall-army-worm issue (Nyamwaya Munthali, 2021). Yet, when we look at how digital services in agriculture are generally designed, we come to an interesting, yet concerning, conjecture. Supposed key benefits of digital agriculture services over traditional face-to-face services are that they improve access to timely and accurate information (Fabregas, Kremer \& Schilbach, 2019) and ca be tailor-made for individual farmers and farms. As a result, services specifically built to support documenting and dissemination information about agricultural problems are targeting individual decision-making (Trendov et al., 2019; Van Der Waals, Denner, Van Rij, \& Korsten, 2003). Yet, in light of our findings and those by Damtew et al. (2020), which inform us that addressing complex agricultural problems demands collective sense-making and action to prevent them from becoming public 
bads, we observe an emerging issue. Although we do agree that more targeted information provisioning to individuals may enhance timeliness and accuracy for single farmers, we believe that it may simultaneously reduce space for deliberation and collective decision-making. Focusing on the individual alone, without being informed about or strategize with fellow farmers reduces opportunities for collective sensemaking. Our concern is that tailor-made advice given to individual farmers and the preceding actions may conflict with collective needs and that the sum of actions can result in worse collective performance towards the prevention of a public bad. Knowing about this potential negative impact of digitally mediated communication is relevant for projects like ICT4BXW and policymakers. Although more research is necessary, we advise that digital agriculture interventions targeting complex problems and public bad management consider the need for collective sense-making and deliberation either by protecting existing or creating new (digital) opportunities that foster tailor-made communication but then in a collective setting.

\subsubsection{Outlook for dynamic socio-ecologic games}

Looking at our findings we conclude dynamic socio-ecologic games (DySE), like Musa-game, can yield rich and insightful data. Using a boardgame we were able to model a public bad risk as SES with its biophysical and institutional characteristics and could experiment with a social-dilemma regarding risk management using communication treatments. The presented social dilemma gave players a temporary shared experience, while the addition of a qualitative method, i.e. FGD, allowed respondents to make sense of their decisions and relate to real-life practices used to maintain livelihood resilience. This supports researchers in interpreting the meaning of the quantitative game data. Additionally, it appears that games like Musa-game provide promising interactive learning tools. The ability to visualize human-human and human-non-human interactions and dependencies are particularly valuable for learning. To be conclusive about the effectiveness of DySE-games, experiments need to be conducted at scale. With a larger sample, the test-findings and hypotheses presented in this article could be verified. Secondly, with a larger sample more in-depth analyses, e.g. comparing data from different age and gender groups or different geographic locations, would become possible. Studying the influence of age and gender on communication behaviour, decision-making, individual and collective performance is especially interesting, given that, for example, women have historically had less access to information and knowledge. While this exclusion of women has so 
Chapter 7

far been mostly addressed as an individual issue, the DySE-games may shed a different light on this. Last, we recommend further research on the interplay between real-life experiences and practices of farmers, the decisions they take while playing, and the basis on which those decisions are made. For future applications, opportunities for digitizing DySE-games could be explored. A digital version would simplify game implementation and create a more controlled experimental environment, thus reducing error chances. A digital game would also provide more options for visualization and collective sense-making within the game environment. The level of digital literacy of players may be a barrier however and hence needs to be assessed and considered beforehand. 


\section{$=$ \\ I

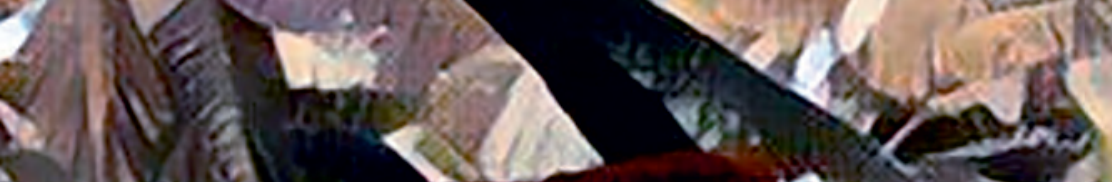

17 1. $10 \times 12$ in
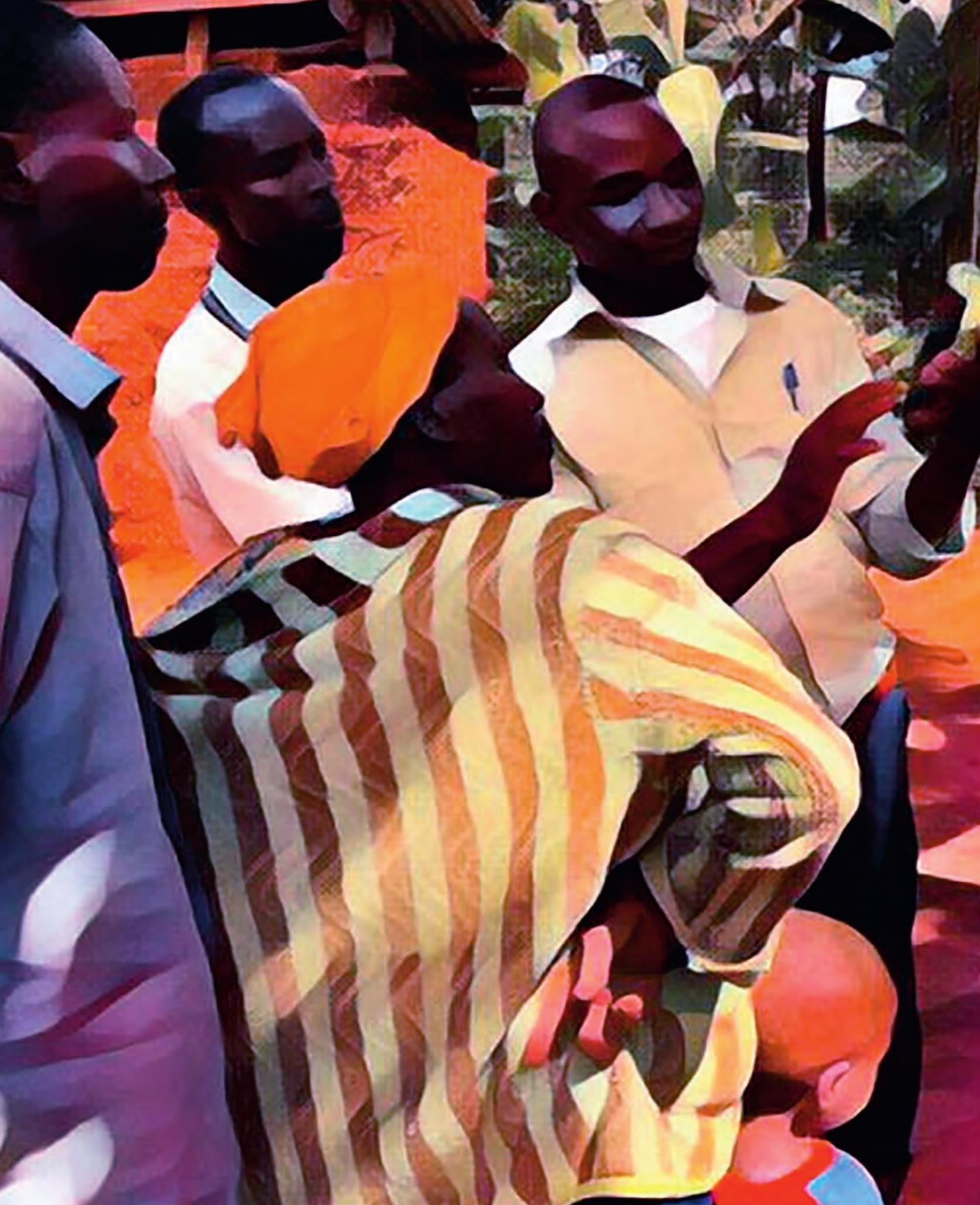



\section{Discussion and synthesis}




\subsection{Prelude}

The six empirical chapters presented in this study give a holistic account of how digital agriculture technologies, services, and interventions for agricultural advisory and decision support, especially phone-based services, are designed, by whom, and with what objectives and outcomes. My geographic focus was on Africa with case studies from Rwanda. Beyond the focus on the design process itself, the research aimed to unravel what (future) impact digitalization may have on the information and knowledge, and communication about complex agricultural problems such as crop diseases. All in all, I aimed to conduct a critical reality check with this research, with the objective to observe and understand what is there beyond what meets our eyes. This has resulted in a multi-facetted dissertation which approached the topic of interest from different angles (see also Figure 1 and figure 4 in chapter 1 ) and that responds to the need for social science research that moves beyond the discourse used by international organizations, donors, and policymakers and looks at what happens on the ground (Gatti \& Visser, 2020).

In the diagnostic phase of the study, I first zoomed in on the problem context and unravelled the complex agricultural problem for which a digital advisory and decision support service would later be developed (in the intervention phase): Banana Xanthomonas Wilt disease, to learn what makes a problem complex and find out how digital technologies and services may contribute to addressing such problems (chapter 2). After that, I developed a framework for ex-ante assessment of user readiness in chapter 3, which helped to build understanding about the (mis)match between digital capacity of targeted users and the digital technologies and services that are developed and employed. With this chapter I focused on three layers: digital technology or service, users, and the digital innovation ecosystem. These same layers were explored in the two chapters that followed thereafter. For the study's intervention phase (chapter 4), I studied from up-close the participatory design approach through which a digital agriculture application for advisory and decision support (BXW-App) was designed, and assessed the objectives of this process, who participated, and the outcomes of the chosen approach. Based on chapters 3 and 4, it became clear that inclusion and inclusivity are important, yet complicated, concepts in the context of digitalization in African smallholder farming systems. To learn more in-depth about what shapes inclusion (and exclusion) in this context, a literature review was conducted (chapter 5). Another in-depth exploration of the potential implications of digitalization for the 
management of complex agricultural problems and public bad prevention was presented in chapters 6 and 7. In this phase of the research I returned to analyzing the problem context. Through the Musa-game I was able to study human decision-making about Banana Xanthomonas Wilt management in a game environment and to learn how emergence, spatiality, communication, and knowledge affect farmers' behaviour. In chapter 7, I additionally reflected on how the characteristics of digital technologies and services fit with the type of communication, decisions, and actions that are needed to contain complex agricultural problems.

I use this final chapter to summarize and synthesize key findings from the empirical chapters and broader contributions of this research. First, I present chapter findings in relation to the study's research questions (section 8.2). This is followed by a discussion of the wider implications of these findings for scientific and societal debates (section 8.3) with at the end of each sub-section recommendations for research, policymaking and practitioner work. Thereafter, in section 8.4, I reflect on the implementation of the research and my role as a researcher. The thesis ends in section 8.5 with a final reflection that captures the study's main lessons and take-home messages.

\subsection{A research journey into digital agriculture advisory and decision support in an African context}

The research' primary foci were Rwanda and Africa in general, although knowledge and experiences from elsewhere in the Global South and North were often guiding me on my research journey, providing information, inspiration, and critical reflection. The engagement with my case study, the ICT4BXW project offered a unique opportunity to study the making and piloting of a digital advisory and decision support service for the management of a crop disease from up close. The overall study followed a chronological order and consisted of three phases; diagnostics phase (chapters 2 and 3), intervention phase (chapter 4), and deep-dive phase (chapters 5-7). Each of the chapters looked at one or more levels (i.e. digital tools, users, (collective action) problem context, digital innovation ecosystem) and provided input to answer the following research questions:

1. What factors and processes within a participatory design approach shape the design-choices and actual design of digital agriculture advisory and decision support services? 
Chapter 8

2. How does the capacity of users and other actors influence readiness for developing and using digital agriculture advisory and decision support services?

3. What factors shape inclusion and exclusion in digitalization processes in African smallholder agriculture?

4. How may (digital) communication strategies affect farmers' individual and collective performance in crop disease management practices and preventing a public bad?

I now first respond to each of these questions, using chapter findings. Based on the answers to the sub-research questions I can respond to the study's main question: What factors and processes shape the design and use of digital agricultural advisory and decision support services that are developed for addressing complex agricultural problems in Africa? This, I will do in section 8.3, when I discuss the overarching findings of my research and their theoretical, practical, and policy implications. Each sub-section starts with a theoretical discussion and ends with recommendations for policy and practice.

\subsubsection{The factors and processes that shape design-choices and outcomes of a participatory design process}

\section{Limitations to participation}

To answer the first research question, I analysed how a real-life design process, which used a Human Centred Design approach, was enacted. The case of the ICT4BXW project in Rwanda allowed me to collect observational and qualitative field data and to develop insights about the design process and the emerging outcomes of that process. Most of the findings that pertain to this research question are presented in chapter 4. Starting point is the observation that participatory design approaches (alternatively referred to as Human-Centred-Design (HCD), co-creation, co-design, responsible design), are increasingly cited as a preferred approach to design 'digital technology for good' and somehow presented as a silver bullet (Kenny \& Regan, 2021; Ortiz-Crespo et al., 2020; Steinke et al., 2020). This comes with big expectations (e.g. inclusivity and overcoming digital divides, designs that meet needs and demands of users, improved adoption (Berthet et al., 2018; Cerf et al., 2012; Macken-Walsh, 2019). However, the relation between the approach used to design and implement a service and the adoptability of the resulting digital service was this far under researched. In response to this, chapter 4 analyses the enactment of an HCD process during which BXW-App 
was developed and in which village extension agents, among others, participated. I did this, for example, by looking at the power, and influence of diverse stakeholders on the design, project limitations, and the implications of design choices for how 'responsible' the design process and outputs are. The case study findings show that participatory approaches are in practice no panacea. Although users were included in the design process, their influence on the design was mostly limited to the visible design, e.g. interface, content. Decisions about the back-end, anticipation or reflection on tradeoffs and consequences of design choices, etc. were not made by users but by project managers. Feedback from users in the pilot-phase of BXW-App was only partially incorporated, depending on e.g. project objectives and resource availability. The research showed that stakeholders participating in a participatory design process take up diverse roles, and each stakeholder brings his/her interests, values, and power into the design process and the design of a digital advisory or decision support service. These dynamics are also known to exist in traditional extension systems (Cook, Satizábal, \& Curnow, 2021). The participatory process itself does not remove these dimensions e.g. by giving equal power to every stakeholder. Hence, a design process, even when said to be inclusive or participatory, is not neutral. Decisions about the design of an intervention or digital service are influenced by power and politics, an issue that has been raised by scholars before (Holeman \& Kane, 2020; Park \& Humphry, 2019) and that can lead to false assumptions and predictions about the local context and realities of users (Krauss, 2021) or result in questionable decisions that overlook the interests of certain, less powerful, actors (Bronson, 2018; Rotz et al., 2019). I discuss the implications of power and politics for the design of a digital service in more detail later, in section 8.3.2.

\section{A Global North approach transferred to a Global South context}

Another finding is that popular participatory approaches, such as Human Centred Design (HCD), have a strong focus on the local (use) context and perceived user needs, while anticipation of and reflexivity on potential long-term and more systemic impacts or digital rights such as privacy, security, or informed consent do not receive much attention. What may play a role in this is that an approach like HCD has its origin in the design sciences and was developed in and for the Global North. The approach should help to develop (technological) products that found the 'sweet spot' between economic viability, technological feasibility, and user desirability, and would therefore have a high chance of adoption and market success. The same approach is 
Chapter 8

today used in the (agricultural) development sector in the Global South where it is implemented without real adaptation. The context in which many digital agriculture interventions and services that target Africa and the Global South are developed provides another factor that influences design choices and outcomes. In many cases digital advisory and decision support services are developed in a project setting and depend on donor funding. Most of these projects furthermore come with strict timelines and set deliverables. These factors all affect the amount of flexibility within the design process and the ability to develop services that are truly responsive to the needs and demands of users or the use context. Hence, arguably, beyond adapting the digital innovation to the local (use) context and user needs it is necessary to adapt the design approaches themselves, such that they become more appropriate for the specific context of digitalization in the Global South and a donor funded project setting (Doezema, Ludwig, Macnaghten, Shelley-Egan, \& Forsberg, 2019; Klerkx, Seuneke, de Wolf, \& Rossing, 2017)

\section{Upholding responsibility in a fragmented and voluntary landscape}

I furthermore analyzed if principles for responsible design and digital rights are upheld in design choices and the outcomes of design processes. Again, the ICT4BXW project was used as a case study, while we also evaluated the wide variety of guidelines, principles, and codes of conduct for digital rights and responsible digital innovation that exist today (chapter 4). I found that a lot of fragmentation is created since so many organizations and governmental bodies develop guidelines, principles, and codes of conduct. Additionally, these frameworks are almost always voluntary (and hence not legally binding) and often lack local contextualization. As a result, there is no clear incentive to adhere to these regulations when designing or implementing a digital service, or to anticipate on and be reflexive to the consequences of the digital service and corresponding intervention. Moreover, it is almost impossible for users to demand so without excluding themselves from using the service. The findings moreover suggest that the latter is exacerbated by power relationships and capacity limitations of stakeholders. Hence, the case study showed that in practice guidelines and principles are not consciously considered, except for privacy, while there is also a lack of transparency from developers and implementers about rights and responsibility towards users and other stakeholders. I analyzed the relation between design and responsibility again in chapter 5 . This time the specific focus was on inclusion and exclusion within and caused by digital agriculture. The literature review showed that 
exclusion or involuntary inclusion are often a side-effect or trade-off of certain decisions made in the design phase. An observed issue is that in the context of digitalization this inclusion or exclusion may be invisible, while it can also have long-term impact or create path-dependency. One of the discussion points is that side-effects may have long-term impact, and that this impact is not always tangible.

\subsubsection{Capacity as a determining factor for users' ability to use digital agriculture technologies and services}

In chapter 1 I identified that capacity in the context of digital agriculture in the Global South had primarily been approached at the level of the user, assessing capacity and capacity building needs of farmers and extension agents, yet that other capacity limitations were under researched. I have tried to respond to this gap in this thesis, as I explain later when summarizing findings from chapter 4. I did however first explore the capacity theme at the level of farmer in the diagnostic phase (chapter 3) by studying the current capacity of farmers to use digital technologies and services. The novelty of this part of the research is that it used an ex-ante approach, so assessing capacity before the development of an intervention. For this I developed the User Readiness (UR) framework (building on the COM-B model (Michie, Atkins, \& West, 2014; Michie, van Stralen, \& West, 2011) and used it to conduct and an ex-ante assessment of current information and communication practices and farmer readiness to use digital (phonebased) agricultural extension services. User readiness is a metric to understand capacity as a synergistic sum of motivational, opportunity, and capability sub-dimensions. Our ex-ante assessment showed that a mismatch exists between the anticipated user and use (the fictional farmer that digital interventions and services are designed for) and the real-life user and use (surveyed Rwandan farmers in the study). For example, the adoption and use of more advanced digital hardware and software is negligible among study farmers (represented by low capability and opportunity UR-scores), while the access to and use of basic phones and radio are high among both men and women. It thus did not come as a surprise that user readiness for more high-tech digital technologies and services is overall low, age and gender having practically no influence. However, projects targeting smallholder farmers are developing services that require more advanced hardware like smartphones. This leads to concerns about digital interventions and services that do not fit with the capacity of their anticipated users and hence non- or de-adoption. Differences between user groups are visible when zooming in on sub-dimensions, e.g. women's access and ownership is lower than man's resulting 


\section{Chapter 8}

in lower opportunity scores. The findings of chapter 3 show that both the overall user readiness index (i.e. capacity) and readiness scores on sub-dimensions influence users' readiness to use digital agriculture technologies and services. This makes user readiness (representing the capacity of the user) an important metric to consider when developing digital agriculture services, besides technology readiness (representing the capacity of the technology and scaling readiness (representing the capacity of the system).

\section{Capacity also affects users' participation and influence in a participatory design process}

In chapter 4, I studied capacity again, but then with a focus on the capacity of stakeholders to make meaningful contributions in a participatory design process. The case study findings suggest that the capacity of users (i.e. village level extension agents/ farmer promoters) who participated in the Human Centred Design process in the ICT4BXW project was limited. For example, most users had never used digital hardware or service that was more advanced than a basic phone or SMS. I also found low capacity of users, as well as farmers and other stakeholders, to anticipate or be reflexive on the potential reach of data collected by the service developed by ICT4BXW or if it mattered if data access was open or restricted. Farmers and extension agents thought local, while data does not stick to boundaries. Our findings showed that those participating in the HCD process and those interacting with the service (BXW-App), cannot anticipate or reflect on the consequences of design choices. This affects their participation in the design process and how much influence they can have on the digital service that is being developed. Our findings also showed that less powerful stakeholders (e.g. farmers, extension agents) have no monopoly on capacity limitations, scientists, practitioners, and government representatives involved in the project similarly lacked the psychological capability to grasp the trade-offs and potential consequences of design choices. In the absence of the capability dimension stakeholders cannot make informed decisions about the design and use of digital services. In other words, it appears that capacity influences how responsible and ethical digital services are, and that failing to consider capacity of diverse stakeholders in the system may result in irresponsible designs. This can in turn lead to exclusion, negative livelihood impact, or other unintended consequences. 


\subsubsection{Inclusion and exclusion are more nuanced than a simple binary 'in' or 'out'}

As emphasized in chapter 1, science to inclusion and digital divides in the context of agriculture had this far mainly focused on access to specific technologies or services and expressed a desire to include every individual. I have been more critical and comprehensive in this dissertation analyzing the issue at multiple levels. In the diagnostic phase of the research (chapter 3) I found that user readiness (or absence thereof) in combination with the choice of digital technology and service design could affect digital divides and improve or reduce inclusion for diverse user groups. In the discussion of chapter 3, I argue that a mismatch between user readiness and the digital agriculture technology or service offered to farmers can widen existing divides or cause the exclusion of new user groups. What inclusivity means in the context of digital agriculture in a smallholder farming context returned as a thematic focus in chapter 3 , where I looked at the inclusion of diverse stakeholders in the design process and assessed to what extent inclusion led to influence and meaningful contributions. I showed that achieving inclusivity is not as straightforward as its often presented. In practice, inclusivity is interlinked with capacity and power relationships. This means that people may be included in the design process yet lack the capacity or power to influence the design of the digital service and intervention. Hence, inclusion does not automatically result in inclusivity or power neutrality. Inclusion needs to be more than simply being present for it to be meaningful. Stakeholders who are participating in a design process also ned to be able to influence decisions, including decision beyond the interface or content design of a service. Secondly, and this directly links with the previous section, participants need to have the capacity to understand what they are designing and what the impact of their own and others' design choices may be locally or globally, short- or long-term.

With the above in mind, I further unravelled how digitalization in African farming systems can cause inclusion and exclusion at different levels in the digital ecosystem and what impacts this may have. As such, chapter 5 presented the results of a literature review that unravels the mechanisms behind inclusion and exclusion. This part of the study did not only look at what (tangible) in- and exclusion mean today, in relation to e.g. access to specific digital technologies, services or solutions, but also at higher-level, less tangible, or future processes of in- and exclusion. I found that, within the context of digitalization in the Global South, inclusion and exclusion are primarily debated in 
Chapter 8

relation to people's access to technologies or services. However, positive and negative impact of digitalization on people plays out at various levels and is not necessarily time or place based. Inclusion and exclusion are not restricted to the level of the digital technology, factors at the level of the digital innovation package or digital agricultural system can be cause for inclusion or exclusion too. At these levels the processes causing inclusion and exclusion can become less tangible and there may be a delay before people are confronted with their inclusion or exclusion. Another finding is that inclusion and exclusion can be perpetuating or path-dependent, while there may also be lock-in or stacking effects. Based on these findings I dismiss the rationale used in digital and agricultural development in which inclusion is always good and aimed for as if it were a holy grail, and exclusion always bad and to be avoided. Inclusion and its causes and impacts is much more nuanced than a simple 'in' or 'out' and is not by definition good and beneficial. Similarly, exclusion is not always bad and detrimental and may become a blessing in disguise in the context of digitalization.

\subsubsection{Digital communication may affect performance in crop disease management and public bad prevention}

The potential role of digital communication in the form of advisory, decision support, and space for deliberation and strategy making was assessed in chapters 2, 6, and 7. By contributing understanding about how digitalization may or may not make knowledge exchange and decision-making processes more effective I respond to the gap in the literature regarding how the design of a digital service may affect knowledge exchange and decision-making about complex agricultural problems. The first chapter in this line (chapter 2), takes a diagnostics approach and looks at digitalization from an opportunity perspective. Chapters 6 and 7 present and test an experimental game method that provides novel insights into the importance of working together when addressing complex and public bad problems. The two chapters analyse what the results from a game experiment can tell about the impact of different communication strategies on individual and collective performance of farmers and the prevention of a public bad. In the discussion section of chapter 7 I examine what the experimental findings can tell us about best-fit strategies for supporting collective action and prevention of a public bad and assess how these strategies compare with the digital advisory and decision support services that are currently being developed. 


\section{How digital services could support the management of a complex problem like Banana Xanthomonas Wilt disease}

Using a systems analysis approach, chapter 2 assessed the complex problem of Banana Xanthomonas Wilt (BXW) disease. The research studied the context of BXW disease, considering this disease as a typical example of a vector-based disease that forms a complex agricultural problem in Africa and can become a public bad. Findings show that when addressing BXW, the academic and practice focus has been mostly on the biophysical and technological dimensions of the system, while the social, cultural, economic, institutional, and political dimensions are often overlooked. Another finding is that knowledge of and information exchange between different actors in the system is generally insufficient. To address complex problems a holistic approach is required, yet because of the strong technological focus in the case of BXW the socio-cultural and institutional dimensions are being overlooked. Combined with challenges with (timely) availability of (accurate) data, information, knowledge, and stakeholder connectivity, this narrow focus causes BXW to persist or reoccur. Data, information, knowledge, and connectivity related interventions (i.e. digital advisory or decision support services) could contribute to resolving this complex problem. For example, a digital platform could support farmers to exchange information and knowledge with peers or other stakeholders. Additionally, digital technologies and services could support with making real-time data, contextualized information, and knowledge available across the system. A digital service could also support with the dissemination of information about e.g. suitable disease management practices. This way the farmer may be given more options to prevent or control BXW and choose the one that fits best with his/her needs. Lastly, by creating more open and multi-way communication within the system, digital communication could support collective action.

\section{What we can learn about decision-making from playing an experimental game with banana farmers}

The lessons learned from the diagnostic phase of the research provided input for the design of Musa-game, an experimental boardgame, that is presented in chapter 6. Based on the notion that complex problems like vector diseases in crops can become a public bad and need to be governed, a method was developed to study individual and collective action in relation to the governance of BXW. In this way I was able to study the interplay between socio-cultural and biophysical dimensions and human decision-making about disease management, as well as the role of communication. The 


\section{Chapter 8}

findings from a pilot with Musa-game in Rwanda are presented in chapter 7. A first finding was that, besides being an experimental game, Musa-game turned out to be an effective and powerful learning tool or serious game too. Interview results showed that farmers learned about BXW, interdependencies, and the value of collective action, while also enjoying this approach to learning which differs from conventional trainerfarmer approaches.

How individual and collective action decisions influence individual and collective results in disease prevention and control was investigated through the data from the field-test. Results show that collective action is more effective than individual action. However, most players used a non-cooperative strategy, thereby increasing both individual and collective risk and reducing collective performance in the game. The Musa-game experiment included different experimental treatments with communication being the dependent treatment variable. A relation between the treatment and player behaviour in the game was found. The difference in behaviour did influence both individual and collective game results. It appeared that, for best performance, farmers need both the right knowledge (timely, accurate, relevant for their context) and the opportunity to develop a collective disease management strategy. The latter demands opportunities to communicate, which create space for deliberation and collective sense-making.

This chapter also contains a reflection on the implications of a shift to digital communication (e.g. using mobile phones, apps) for (collective) decision-making. Findings suggest that digital services could help with collective learning and sensemaking, providing the right knowledge at the right time. They could also help to make interactions and interdependencies (human-human and human-non-human) more tangible to farmers. In line with previous findings by others (Cieslik et al., 2021; Damtew et al., 2020), the experimental findings suggest that digital technologies and services could act as intermediaries that create a virtual space for deliberation, strategy building, and sense-making, and connecting farmers and potentially farmers and other actors. This may support collective action towards preventing and/or containing a public bad problem like BXW disease. Mainstream social media platforms could be digital platforms that play such an intermediary role, although they are not specifically targeting agriculture and many of them come with concerns about data ownership and use, and privacy. In that sense, a platform that is custom-made for African smallholder farmers and honours digital rights may be more suitable. However, many of the services built specifically for agricultural advisory or decision support target farmers individually 
and provide no or limited opportunities for two- or multi-way interaction. In the discussion of chapter 7, I argue that this is a potential risk. Although tailor-made advice may be beneficial to the individual farmer in the short-term, it conflicts with the need for larger-scale governance and collective action when governing complex agricultural problems such as crop diseases. I see this insight as an important theoretical contribution of the thesis and return to it in section 8.3.3.

\subsection{The research findings in a broader perspective: Contributions of the thesis to the scientific debate on digital agriculture}

As can be seen from the above chapter summaries and synthesis, the findings of this thesis contribute new insights about the use of participatory approaches, digital capacity, inclusivity, and potential impact of digitalization on complex agricultural problems and collective action problems. The study findings hence respond to the gaps in the literature on digital agriculture advisory and decision support in an African context which I identified in sections 1.3.1-1.3.4 in the dissertation's first chapter. I use the remaining sections of this discussion chapter to look at the broader and overarching research contributions of my research and links with existing scientific knowledge. I do this based on the chapter findings discussed in section 8.2, the above research topics, and the scientific gaps and debates identified in chapter 1.

\subsubsection{Participatory and responsible design in digital agriculture}

In section 8.2.1, I referred back to literature introduced in the first chapter of this dissertation to summarize why participatory design approaches have become popular in digital agriculture and the expectations that come with the use of these approaches. In short, participatory design approaches are used to improve understanding about the context in which users (e.g. farmers) take decisions or use information, and what needs and demands for (technological) support farmers have, with ultimately the goal to improve adoption of digital agricultural advisory and decision support services (Rose et al., 2018). The research results in this thesis, especially those from the ICT4BXW case study, reveal that a rather uncritical perception of technology exists among donors, implementers, and users, in which digital technologies and services are generally perceived as 'good' and 'glamorous'.

However, the way in which digital agriculture interventions and services are designed, and by and for whom they are designed, affects the outputs of the design process. This 
Chapter 8

in turn influences whether these outputs indeed lead to outcomes and impact that are good or may, in contrast, do harm now or in the future. This has implications for the contribution that can be expected in terms of e.g. addressing complex problems such as crop pests and diseases. Below I discuss what the research findings taught me about this, and what this implies for theory.

\section{Do participatory approaches yield better outcomes when used for designing digital agriculture services? That is still not clear.}

As introduced in chapter 1, section 1.2.2, both in science and practice the entrypoint for digital agriculture in a Global South and African context have been the digital technologies and services themselves, rather than their (anticipated) users or the use context (i.e. agricultural and communication systems and the complex agricultural problems that digital services aim to address). This has resulted in a plethora of work conducting ex-post assessments of 'what is out there' and problematizing adoption, use, and adaptation of those technologies and services (e.g. Aker, Ghosh, \& Burrell, 2016; Fawole \& Olajide, 2012; Nakasone, Torero, \& Minten, 2014). In contrast, the user and use context, with the exemption of the many studies addressing digital divides (e.g. Aker, 2011; Alabi, 2016; Mwombe, Mugivane, Adolwa, \& Nderitu, 2014) and design with and for users only later gained attention. The findings in this thesis align with those of scholars who argue that digital technologies and services have to be adapted to the context of smallholder agriculture, low income countries, rural communities, and other contextual limitations (e.g. Aker \& Ksoll, 2016; Haworth et al., 2018; Rose et al., 2018)20 and that participatory approaches may support with this (Kenny \& Regan, 2021; OrtizCrespo et al., 2020; Rose et al., 2018; Steinke et al., 2020). As chapters 4 and 5 show, how digital interventions and services are designed may have a positive influence (e.g. participation of users in the design process, better fit with context), but it may just as well be negative. The ICT4BXW case showed that potential negative consequences were largely overlooked in the design process, which may have created a recipe for disappointing results and unwanted side-effects. The research findings illustrate this for example with the mismatch between limited user-readiness and the development of

${ }^{20}$ In practice, this will often also require that the technologies or services are 'untechnified', i.e. reducing their complexity, removing more high-tech features, and indeed adapting the technology to the users and use conditions. This links with established concepts such as frugal innovation (Mann, 2018), appropriate technology (Lwoga \& Sangeda, 2019), appropriation of technologies (Glover, Sumberg, \& Andersson, 2016; Glover, Sumberg, Ton, Andersson, \& Badstue, 2019) and tinkering (Higgins, Bryant, Howell, \& Battersby, 2017) which all call for adaptation of the technology to the farming and farmer circumstances. 
smartphone-based services for smallholder farmers in chapter 3, and the lack of anticipation on potential consequences of design choices (e.g. the option to make a performance-surveillance platform of BXW-APP) in chapter 4.

The research findings hence show that participatory design approaches are no panacea. This is not to say that they do not yield better outcomes in any way. The case results show how the participatory process attracted diverse stakeholders and that they could all somehow influence the design of BXW-App even though most stakeholders, especially users, could only influence decisions about the visible design, i.e. the interface and content. This did result in adaptations to the design which made it more (socioculturally) appropriate for the users and use context (e.g. voice explanations, offline operational, interaction between farmer promoters and sector agronomists). The design workshops in which farmer promoters, sector agronomists, and government representatives participated also helped to observe the large need for (digital) capacity building early on and the project was able to partially facilitate this. Another benefit is that users were actively engaged and approached as future owners (government representatives) and ambassadors (farmer promoters) of the project. This may have a positive impact on their feeling of ownership and hence sustainability of project outputs and outcomes, although I was not able to verify this through my research.

And yet, the participatory approach did not provide a solution to all challenges. In this regard I found that the context in which digital agriculture is 'done' in the Global South (i.e. primarily led by NGOs and (international) organizations and (social) enterprises and start-ups that depend on donor funding) is far from ideal for a participatory design approach and digital innovation because of the lack of flexibility. This has previously been critiqued for systems change in agricultural extension in general as well (Bentley et al., 2020; Cees Leeuwis, Klerkx, et al., 2018), and my research findings show that this is no different for digital advisory and decision support. The ICT4BXW project was clearly bound by project objectives and donor expectations and this affected capacity to respond to user feedback, flexibility to adapt the design of the digital intervention and the digital service (BXW-App) that resulted from the participatory design process. Meanwhile, the participatory approach itself has not been adapted to this context, it is primarily a copy-paste of an approach that gave good results for commercial product development in the Global North that is now utilized for development in the Global South even scholars for some time already argue that methods and techniques used 


\section{Chapter 8}

to design and implement digital technologies in the Global South must be adapted to that specific context (Heeks, 2009; van Reijswoud, 2009).

Something else that the participatory design process did not truly change is that funders, developers, and implementers of digital interventions tend to focus on the technology rather than the user, e.g. trying to fit users to technologies, instead of technologies or services to users (which aligns with the term 'misconfigured innovations' that Fraser (2021) used to refer to specific solutions to specific problems that lack integration with the broader system). For example, in chapter 3 I showed the mismatch between the low user-readiness of Rwandan banana farmers and the advanced services that international organizations want to develop for them. Thus, my research findings indicate a clear discrepancy between what scholars suggest as the preferred way to approach digital transformation in agriculture (i.e. problem-driven and open to diverse transition pathways and the reality on the ground (i.e. narrowly defined options, technology/solution-driven) (Klerkx \& Rose, 2020; Lajoie-O'Malley et al., 2020; Rijswijk et al., 2021; Rose \& Chilvers, 2018). I observed a similar discrepancy in relation to design thinking principles and the principles for digital development (Cerf et al., 2012; Dearden \& Rizvi, 2008; Waugaman, 2016). Making the technology and not the user or the complex agricultural problem the entry-point for a digital intervention invites funders or developers to search for problems that they can fit to (ready-made) solutions, rather than designing a solution to a real-life problem. In such a context there is very little space for participation and influence of users and other stakeholders in the design process and it further reduces flexibility to anticipate the consequences of a service, be reflexive on trade-offs and side-effects of design-choices, or adapt to local context and conditions.

\section{From hype to realism: The need to manage expectations of digitalization in African agriculture}

In the introduction chapter I referred to digital agriculture as a hype that comes with big promises about outcomes and impact (Richard Heeks \& Shekhar, 2019; lazzolino, 2021b) and that there exists an almost religious belief in especially data and data generating technologies (Harari, 2017). In the run-up to the 2021 UN Food Systems summit the conviction that information deficiency has been the reason for despair in the Global South and that digitalization and access to data can change everything for the better are present, as this statement from the UN Secretary-General for the 2021 Food systems summit and president of AGRA exemplifies: "The scarcity of high-quality, 
timely agricultural data is directly complicating countries' plans for economic growth and efforts to reduce poverty" 21 .

However, this thesis showed that data and digitalization are no silver bullets when it comes to solving complex problems in agriculture. The experiences with Musa-game and the ICT4BXW case study demonstrate that digital technologies and services themselves will not solve present day challenges like climate change, infectious diseases, food and nutrition security, population growth, inequality, etc. Basically, all that digitalization can do is aid and mediate. But it is up to us humans to choose if and how we want digital technologies and services to contribute to the management of complex agricultural problems (and this may require us to entirely rethink digitalization and digital innovation (see also Fraser, 2021; Wittman, James, \& Mehrabi, 2020). For example, an advisory and decision support service could help to build trust within the agricultural system (e.g. like in ICT4BXW between farmers and farmer promoters) but could in contrast also reduce or even exacerbate trust issues. Similarly, a service may encourage collective decisions and actions, or instead foster individual choices (I return to this in section 8.3.3). A lot depends on how and what technology or service is designed, by whom, with what objectives, outcomes and impact, and how transparent the process is. For example, many services could be used for multiple purposes, e.g. the case of BXW-app in chapter 4 showed how the application was built as a disease diagnostics and monitoring and crop information system, but with a few simple tweaks the same app could be used for (performance) surveillance. With this finding, the study shows how easy it is to adapt an application that is primarily helpful for farmers and extensionists and turn it into something that is primarily helpful for a government or private actors. Discussing the broader implications of this malleability (Williams \& Edge, 1996) is beyond the scope of this thesis, yet it is easy to see the link with surveillance capitalism (Zuboff, 2015, 2019) and digital colonialism (Ávila Pinto, 2018; Birhane, 2020; Schopp et al., 2019) which provoke that dynamics of capitalist accumulation become embedded in the designs of digital technologies, services, and interventions and digitalization is utilized to construct a world with reduced uncertainty and contingency and that is hence more predictable and controllable (Fraser, 2021). This takes me to my

\footnotetext{
${ }^{21}$ Quartz Africa: https://qz.com/africa/2001970/a-lack-of-basic-agricultural-data-holds-african-countriesback/?utm_source=email\&utm_medium=africa-weekly-brief\&utm_content=4c129977-a8ff-11eb-aa271afc0a360faf
} 
Chapter 8

next discussion point: what makes digital innovations different from other technological innovation processes?

\section{Digitalization demands us to rethink how we conceptualize innovation processes}

In chapter 1, I explained that digital innovations have certain unique affordances compared to other technological innovations. The thesis shows how some of those affordances determine the transformative capacity of digital technologies and services in agriculture. Later in this discussion I debate what the research findings from chapters 1, 6 and 7 can tell us about how the information, communication, collaboration and coordination affordances may affect decision-making and collective action about complex agricultural problems. In this section I want to discuss what the removal of time, place, and traditional hierarchical restrictions in the agricultural and communication systems by digital technologies and services means for how design should be approached. It is important to realize that the absence of time and place boundaries is really a unique property of digital innovations and the transformations they may cause. It means, for example, that the hardware part of a digital service (e.g. a phone) may be in the hands of its user, but the software part (e.g. the application or data) is not. Generally, all it takes is a click on a button to send data into 'the cloud', i.e. a server, somewhere on the planet, owned by some company, and accessible by some specified individuals or publicly. The transboundary nature of data also means that a farmer or extensionist can throw away his/her phone, delete an application, or withdraw from a project, yet there is no guarantee that the data about him/her or his/her farm will be gone too. The products produced by digital technologies and services, data, are there to stay somewhere in some form. Based on this I want to argue that in the context of digital technologies and services, more than with other technological innovations, the visible frontend of the hardware and software is less important than the less tangible, sometimes even hidden, back-end. Digitalization changes dynamics in agricultural innovation and knowledge systems. Established conceptual thinking about innovations and knowledge is not always valid when it comes to digitalization, and thus needs rethinking. I showed this for inclusion in chapter 5 and for knowledge exchange and decision making about complex problems in chapters 6 and 7, while others demonstrated it for topics such as governance and legislation (Cinnamon, 2020; van der Burg et al., 2020; Wiseman, Pesce, et al., 2019), or for responsibility (Bronson, 2018; Rijswijk et al., 2021). Yet there is still a world to explore and research. Future research 
could look back, reflect and learn, with the objective to develop a vision for responsible digitalization. In the next section I discuss my own findings about responsible design and innovation.

\section{Responsible design and innovation and responsibility in digital agriculture}

Concerns raised by critical scholars in the regard to the digital innovation ecosystem and e.g. socio-economic, socio-cultural, and ethical consequences of digital technologies and services as discussed in chapter 1 (section 1.3.4) are important and create necessary awareness about, for example, who drives digitalization in smallholder agriculture (Birner et al., 2021), shifting power relations and potential concentration of power and (data) ownership in the Global North (Mann, 2018; Mann \& Iazzolino, 2019), and new forms of (digital) colonialism (Abebe et al., 2021; Birhane, 2020). The same counts for those voicing issues about ethics, responsibility, and formalization of responsible and rights-based design and use of digital technologies (Ferris \& Rahman, 2016; Lajoie-O'Malley et al., 2020; van der Burg et al., 2020; Wiseman, Pesce, et al., 2019). However, this far, such academic work has not managed to trickle down to fieldlevel, i.e. to where digital technologies and services are used and people are likely to feel any negative consequences. Neither did it reach the conference halls and boardrooms where the decisions about funding allocation, project objectives, and intervention and service designs are taken. This thesis contributes to filling this gap, especially through chapters 3 and 4, by analyzing what happens on the ground in terms of drivers of digitalization, power relations, and rights-based and responsible design. The study gives a rare glimpse into the design process and on-ground decisions that determine the effects that digital technologies and services have both on the ground (today) and in the broader digital innovation ecosystem (tomorrow). Unfortunately, the study shows that, while the dark sides of digitalization, its transformative capacity, and broader socio-political, -cultural, and -economic implications are a point of discussion in science and policy today, this can still be overlooked or ignored in the process of designing technologies and services today. The notion that digitalization can undeniably come with unintended consequences and, sometimes ugly, side-effects (e.g. security breaches, privacy scandals, biased algorithms, use of persuasion for morally questionable means) contrasts with opportunistic views about the transformative capacity of digital innovations (Fraser, 2021; Hanson et al., 2020; Hanson \& Heeks, 2020). Based on my research findings I support the idea that responsibility 


\section{Chapter 8}

should be a continuous concern (Rijswijk et al., 2021) and that anticipation, reflexivity, and responsiveness are necessary to catch unintended consequences early on, continuously adapt designs to emerging demands, and enable responsible diffusion and scaling of digital innovations (Bronson, 2019; Klerkx \& Rose, 2020; Wigboldus et al., 2016). To facilitate this, and reduce that the consequences of digitalization are in reallife overlooked, conceptual thinking about responsible innovation and responsible design should be operationalized to the real-life conditions of the Global South and digital agriculture and become better integrated with the approaches used to design digital innovations.

\section{New research themes regarding distribution of power and responsibility}

Today the field is also increasingly populated by local and international tech start-ups and attracting investments from the private sector. Some of these investments are coming from the big tech and ag tech companies (Birner et al., 2021), seeking to expand their markets to those previously untapped (Mann \& lazzolino, 2019). The luring issue with these new investors is that they are not challenged by the limitations that the public and non-profit sectors face (e.g. resource and time restrictions, fixed objectives, see also the earlier discussion in section 8.2.1). Critical scholars furthermore argue that these new actors may not enter the sector for the right reasons (Mann, 2018). This raises new research questions about the broader implications of how the digital agriculture field and digital innovation ecosystem are organized: e.g. Can profit making and 'doing good' go together in a responsible and sustainable way? Can and should anything be done to govern the large private conglomerates that enter the field of digital agriculture? If yes, then what, and how? How could guidelines and frameworks for Responsible Research and Innovation and digital (human) rights inform responsibilisation in the field? How can users truly become designers of the technologies and services that that target them?

In this context it would be interesting to look at newly emerging concepts and frameworks, many of which do not target agriculture specifically. For example, responsible data22, and data stewardship (Carroll et al., 2020; GovLab, 2020) The latter

\footnotetext{
${ }^{22}$ Which has taken a flight in 2020 and 2021, when discussions regarding digital vaccination passports debates about responsible data use and rights of people started to pop-up. Interesting initiatives include: https://www.theengineroom.org/projects/responsible-data/; https://responsibledata.io/; and https://bigdata.cgiar.org/responsible-data-guidelines/
} 
has much in common with previous work on brokerage in agricultural innovation systems (Hermans, Stuiver, Beers, \& Kok, 2013; Klerkx \& Leeuwis, 2009). Along the same lines, Goshalia, McDonogh, Mhlanga, \& Sewchurran, (2021) introduce the 'puppeteering' role for Internet of Things (IOT), defining it as someone who helps organizing the digital ecosystem and actors in it in such a way that all stakeholders can realize value from it. This role may best be played by the technology-owner so that they can co-create and generate jointly-developed power to capture and distribute value. Yet other initiatives explore alternative data governance strategies, often building on common good models in which communities become owners and guardians of data and decide who gains access and for what purpose ${ }^{23}$. Further research could explore what lessons from this existing and emerging work are valid for the context of digitalization in African agriculture.

\section{Policy and practice implications for participatory and responsible design}

The agricultural development sector was generally late in embracing digital technologies and services (e.g. the health and education sectors did this sooner) and the same holds true for acknowledging that there may be (unanticipated, unintended, and unwanted) negative side-effects to digitalization and datafication. Research and policymaking respond to this with high-level analyses and guidelines and policies (GODAN, 2019; Wiseman, Pesce, et al., 2019). But this does not address the issue at the local-level, and hence, as this thesis shows, these issues have not yet been integrated in the approaches used to design digital advisory and decision support services. The thesis findings indicate that decisions regarding ethics, digital rights, and responsibility should be high on the agenda right from day 0 , when the project or product proposal is developed. Only then would it be possible to anticipate potential trade-offs, negative consequences, and conflicts of interest a priori and in a truly participatory way. This

\footnotetext{
${ }^{23}$ See for example this report by Katya Abazajian for Mozilla Insights which explores alternative ways of governing digital ecosystems:

https://assets.mofoprod.net/network/documents/Ecosystem_Landscape_Analysis_SL8oRqo.pdf or this working paper by Jeet Singh for IT for Change that explores how Ostrom's work to propose that data and digital intelligence are approaches as common pool resources, with common property regimes: https://datagovernance.org/files/research/ITFC_Parminder_Data_Commons___Paper_2.pdf In academia focusing, primarily focusing on a US context, scholars study if digital personal data could become personal assets (Birch, Chiappetta, \& Artyushina, 2020; Birch, Cochrane, \& Ward, 2021) as a response to digital rentiership (defined as "the construction and extraction of value through the technoeconomic extension of ownership and/or control over assets" (Birch \& Cochrane, 2021)) by Big Tech companies.
} 


\section{Chapter 8}

means that responsibility, inclusivity, and digital rights or justice should be central values when designing digital advisory and decision support services and be internalized in the design process to prevent digital green-/responsible-/ethicswashing (Bietti, 2020; Laufer, 2003; L. von Schomberg \& Blok, 2019). Ultimately, more emphasis should be put on consideration of the values that stakeholders want to protect: the philosophy behind Value Sensitive Design (Aizenberg \& van den Hoven, 2020; van de Poel, 2013; Van den Hoven et al., 2012) may be a useful addition to current design approaches, as also proposed by others (Van den Hoven et al., 2012; van der Burg et al., 2019) since it takes social values as a starting point in contrast with Human Centred Design which starts from the more rational technological, economic, and social needs and demands.

On a more practical level, practitioners should ask themselves if the design of a digital advisory or decision support service can be truly user-centred if not the user, but the technology is the entry-point of the design process. A related question that practitioners should ask to the people whom they aim to target with a digital intervention (i.e. the users) before initiating another digital agriculture project is if what they (e.g. farmers, extension agents) need is indeed another digital service, or if there is another, more suitable, solution to their problem (lazzolino, 2021a).

Looking at the institutionalization of participatory design approaches, I argue that it is important to invest in development of human skills and capacities that are currently absent within many international organizations, and to work towards projects that offer more flexibility in terms of time, resource allocation, and expected outputs, outcomes, and impact. The current setting in which digital agriculture projects in an agricultural development setting depend on donor funding and 3-5-year windows is unsuitable for a digital innovation process. This recommendation links to the research topic on the emerging role of private sector actors which are advantaged here.

The institutionalization of designing digital innovations together with stakeholders additionally requires practitioners and policymakers to think about responsibility and accountability: i.e. who should be held accountable if the design process and the resulting outputs lead to negative outcomes and impact?

Building on the previous recommendation, there is need for consolidation of guidelines, policies, codes of conduct etc. such that the interest and incentives to adopt them, and motivation to build the necessary capacity to do so, is essential to internalize ethics, responsibility, and inclusivity into the designs of digital agriculture technologies 
and services and build responsible digital innovation ecosystems. Current guidelines and codes of conduct do not hold in court and can only steer public opinion and create awareness, however development of more formal enforcement structures may be required.

\subsubsection{Capacity for and inclusivity in the context of digitalization in the Global South and African agriculture}

\section{Gaps in the capacities of users and other stakeholders in the digital innovation ecosystem}

Earlier, in section 8.3.1, I already debated the techno optimistic view which I found to be existent across stakeholders, at all levels in ICT4BXW (hence both among users and farmers whose data was collected and among those developing the services to collect the data). The results from applying the user-readiness framework and studying the design process in ICT4BXW additionally showed a general lack of digital literacy, including e.g. the capacity to understand what digital technologies can do or what data can be (used for). These findings add more nuanced insights about digital literacy and user-readiness and add a Global South and responsible design perspective to existing theoretical thinking about digi-grasping in relation to digital agriculture in the Global North (Dufva \& Dufva, 2019; Fielke et al., 2021; Rijswijk, Klerkx, \& Turner, 2019) that provides understanding about the interplay between design approaches, design decisions, and digital literacy and stakeholder capacity, and transformative capacity. Additionally, it fits with ideas about the relation between digital agency, power and equality, and outcomes and access to the outcomes and opportunities from digital agriculture (Ayre et al., 2019).

This far researchers studying digital agriculture in the Global South had primarily focused on first and second level digital literacy, i.e. the capacity to use a technology (Benson, 2019; Deen-Swarray, 2016; Kleine, 2013). My research findings suggest that the limited digital literacy and capacity to question digitalization makes that those developing a service may not perceive a need for responsible design (chapter 4) (e.g. a design that adheres to digital rights like privacy, protection from harm, options to opt out). On the other hand, those who may be negatively affected by irresponsible design choices, e.g. farmers and extension agents, lack the digital literacy to grasp that their interaction with a digital advisory or decision support service today may have unwanted consequences for them tomorrow. It shows that digital literacy is more complex and 
nuanced than e.g. if someone knows how to use a mobile phone. The findings also show that digital literacy is low among all stakeholders engaged in digital agriculture in Africa and that this limits capacity to recognize ethical concerns and respond to those concerns with responsible designs. This finding corresponds with others who call for joint learning and capacity building on digital agriculture (Ayre et al., 2019)

Beyond digital literacy, this research also contributed novel understanding about locallevel capacity more generally, in terms of user-readiness (chapter 3) and clearly showed that a mismatch between users and the digital technologies and services is possible when the capacity of users across several dimensions is not considered before designing a product. Given the current user-readiness I concluded in chapters 2 and 3 that a hybrid communication approach would currently be most suitable to avoid unwanted exclusion and enlarging digital divides among farmers. This recommendation is in line with recommendations by several other scholars (i.e. combining various 'old' and 'new' communication technologies) (Birner et al., 2009; Munthali et al., 2021; Steinke et al., 2020; Sulaiman et al., 2012). My recommendation for a hybrid approach is mostly motivated by low user-readiness, especially on the opportunity sub-component (chapter 3), digital divides and inequality in the system, and general lack of infrastructure to justify a fully digital extension system right now. I have another motivation too, which I will address later in section 8.3.3.

\section{A more nuanced view on inclusion and exclusion}

As discussed in chapter 5, the more complex the digital innovation ecosystem becomes the more difficult it is to anticipate different forms of in-/exclusion and their impact on people's livelihoods, and it is unrealistic to think that all mechanisms of inclusion and exclusion can be known beforehand. Another example that supports this argument, is the case described by lazzolino (2021) on the social cost of giving Kenyan smallholder farmers access to financial services. While initially this led to more inclusion, over time the resultant was diminished access to financial services and increased vulnerability for those who lacked the capacity to pay off their debts. In other words, short-term inclusion can result in long-term exclusion. The thesis shows that it is critical to look beyond access and use and focus on understanding trade-offs (opportunities and threats, benefits and losses, short-term and long-term impact, local vs global impact etc.) of design decisions about individual technologies and services, digital innovation packages, and the digital innovation ecosystem. This thesis contributes a more nuanced and critical view on in- and exclusion in the context of digital agriculture 
in Africa and counters the techno optimistic vision that everyone needs to be included. Considering the findings from chapters 3, 4 and 5, it seems fair to say that design-forall (John Clarkson \& Coleman, 2015; Macagnano \& Greeff, 2007) remains a myth in the context of digitalization, and that inclusion of everyone, as advocated by some (Mehrabi et al., 2020), is probably unwanted and should not be the goal. Earlier, van Mierlo et al., (2020) similarly argued that a participatory process can lead to both an 'opening up' and 'closing down' (i.e. increase or decrease) to diversity in perspectives and that inclusion as such is no panacea for opening up innovation processes. In line with this I use the final paragraph of this section to make some points about inclusion in participatory design.

In the discussion of chapter 4 I argued that inclusion of users can render meaningless if they are not given the power to influence all facets of the product and intervention design. Additionally, I argued that capacity is a determining factor for how meaningful inclusion in a design process is. The above paragraphs on capacity have explained the link between digital literacy and the capacity to demand for a responsible design. This more critical perspective on inclusion in participatory design processes differs from the common prescriptive view in digital development to date (e.g. by Kenny \& Regan, 2021; Ortiz-Crespo et al., 2020; Steinke et al., 2020), since it questions the contribution of participatory approaches to making innovation processes inclusive, responsive to input from users (and hence more democratic), and reducing design-reality-gaps. For example, my research findings suggest that capacity imbalances between stakeholders (e.g. farmer promoter versus project implementer) and within stakeholder groups (e.g. younger and older farmer) create a disbalance in power relations and degrees of power (I introduced the issue with power relations earlier in section 8.2.2). This notion is in correspondence with critique that although participatory approaches promise to make design democratic, at their core they protect a status quo in which some actors are at merit to take decisions for users and that participation is always restricted (Iskander, 2018). As long as such issues are not addressed, the powerful can become more powerful (as they have better capacity to influence decisions such that they are beneficial to them) regardless of the approach used to design a digital innovation. In turn digital divides, power imbalances, or design-reality gaps may not, as promised, be reduced (Cinnamon, 2020; Hayes, Miscione, Silva, \& Westrup, 2013; Ortiz-Crespo et al., 2020; Thapa \& Hatakka, 2017) but exacerbate. 
Chapter 8

\section{New research themes on capacity and inclusion}

In terms of topics for further research, I observe opportunities to investigate how digital literacy and capacity building can become more strongly integrated in design processes. In line with this, research could establish if and how improved capacity and digital literacy of users participating in design processes affects the needs and demands that they articulate for digital technologies and services. In addition to this, it could be assessed if enhanced capacity and literacy improve how meaningful participation of users in design processes is, i.e. if it improves real inclusion and the power and capacity to influence decision-making.

Another theme for further research is the capacity of stakeholders across the digital agriculture innovation ecosystem. As discussed above, until now research has primarily focused on the capacity and literacy of users and other local actors, while my research findings indicate that this is a broader issue that needs addressing. It would be interesting to investigate suitable approaches to building capacity across the ecosystem, and the type of infrastructure needed to facilitate this also in the longer term.

\section{Policy and practice implications for capacity and inclusivity}

Digital literacy needs to be put more broadly and extensively on the agenda, especially when a digital advisory or decision support service demands users to share personal data. In line with this Baumüller \& Addom (2020) write: "Any use of personal data will have to go hand-in-hand with well-developed data protection rules, awareness campaigns and digital literacy training, in particular for the poor and marginalized who may be less informed about associated risks". Not only should locallevel users (e.g. farmers, extensionists) be trained in how to use services, there should be attention for third-level capacity building as well (as emphasized in chapter 4). Furthermore, capacity building should focus on the capacity needs of all stakeholders, across the digital innovation ecosystem.

Related to the above recommendation, there is need to build infrastructure and capacity beyond the hardware and tangible design (i.e. beyond what meets the eye). This requires thinking about the digital innovation ecosystems that are desired; for whom and whose benefits these ecosystems are designed and implemented; and what could be considered acceptable outcomes and impact of digital transformation. To do this, the aforementioned third-level digital capacity is required, as well as consideration 
of responsible design and digital rights frameworks before and throughout the design process (see also my next recommendation).

The focus should shift more towards a-priori and ex-ante anticipation of capacity/userreadiness among diverse stakeholders and potential bottlenecks to responsible innovation (e.g. regarding the capacity to raise social and ethical concerns about digitalization) before and while designing a digital service for agriculture. It has been claimed that early anticipation of consequences could improve design capacity, e.g. by involving diverse stakeholders (Rijswijk et al., 2021), improving the capacity to 'grasp' the digital technology or service and its impacts (Dufva \& Dufva, 2019; Fielke et al., 2021) and in turn, enabling stakeholders to determine the moral responsibilities and accountabilities of a wide range of actors for the consequences of digitalization, i.e. responsibilisation (Rijswijk et al., 2021).

\subsubsection{Complex agricultural problems as a collective/connective action problem}

\section{Musa-Game results in perspective: Digitalization and addressing complex problems or public bads}

Complex agricultural problems are problems that, as we could learn from chapter 1, are embedded in and intertwined with all dimensions of the agricultural system and for which there is no quick fix. Hence, these problems are never just biophysical or technological in nature and require a suite of solutions encompassing all dimensions of the system (Markham, 2009; Schut et al., 2014; see also section 1.3.3 in chapter 1). Digitalization itself is not changing the characteristics of complex problems, it can only mediate in various ways, like improving communication between actors in the system, enhancing access to accurate and timely communication etc. (see chapter 1).

For example, there is evidence that digitalization in agriculture improves access to (timely, reliable) information (Ingram \& Maye, 2020; Wolfert et al., 2017) and thus responds to the primary affordance of provision of information (Heeks, 2018). However, when it comes to the promised options for two-way and multi-way communication, hence the affordances of connection, collaboration, and coordination (see chapter 1 , section 1.1 for definitions of those) the research findings from chapters 4 and 7 paint a different picture, For example, ICT4BXW aimed to develop a platform for citizen science and disease monitoring that provided options for two-way communication. In practice, 
Chapter 8

BXW-app offers primarily a tool to register farmers and their farms, monitor presence of BXW disease in their farm, and provide them with information. The two-way communication element is absent in the application since it lacks an option for farmers or extension agents to communicate through the application with peers or other actors in the system. Observing the properties of other applications, it becomes apparent that many agricultural advisory and decision support services lack features that allow for connection and collaboration, while the coordination affordance is primarily available for those with access to the back-end of the service (e.g. allowing these actors to strategize based on large-scale data).

Reflecting on what agricultural advisory and decision support services afford users to do with them, I can see a link with what scholars and practitioners bring forward as another affordance that set digital services apart from traditional, face-to-face service: individualization. The fact that digital technologies and services make it possible to provide users with individual, personalized advice and information is applauded in the sector (Birner et al., 2021; Fabregas et al., 2019). This is indeed a wonderful element since it moves away from the 'one-size-fits-all' approach, which so often has been critiqued for not considering diversity among farmers and farms (Arouna et al., 2020; Giller et al., 2011; R. Nelson et al., 2016; Sanyang, Taonda, Kuiseu, Coulibaly, \& Konaté, 2015; Schut, Leeuwis, \& Thiele, 2020; Triomphe et al., 2014), to a more tailor-made approach. An added benefit of is that it is user-specific and therefore the information becomes excludable and difficult to share (Birner et al., 2021). The generic advice given by blanket services on the other hand is non-excludable and easily sharable. Thus service-developers and owners of tailor-made services have more profit-making opportunities (Birner et al., 2021), despite the higher initial development cost and relatively low capability or willingness to pay (Baumüller, 2018). However in the case of complex problems that require collective action (like BXW) because in such cases having access to just personalized, individual information is insufficient as it leaves one blind about what happens around them (e.g. fellow farmers and farmers in the community) and miss an opportunity to learn from others, and know what others are doing and where they are standing in terms of preventing or controlling the problem (i.e. the disease). Thus, although personalized information may be beneficial to a farmer in general, it does create a barrier for collective learning, deliberation, and action. Studies with farmers in Ghana and Ethiopia similarly showed the importance of combining information with deliberation and collective sense-making. The study in Ghana with a phone-based service providing farmers with weather forecasts revealed 
that the information became usable when farmers could share and discuss the information among each other, which they did through face-to-face interaction (Sarku, 2021). In Ethiopia, a game-experiment showed that decision-making about disease prevention improved and resulted in more collective action and better individual and collective results when farmers could communicate and deliberate about management strategies (Cieslik et al., 2021; Damtew et al., 2020). As I will also further discuss in the next section, digitalization may threaten collective action and public bad management, when targeting individual instead of collective action and/or replacing existing spaces for deliberation and sense making. But before going in-depth, I first want to discuss about how digitalization may (or may not) affect perceptions about complex problems. I do this based on the findings from chapter 7 .

\section{Communicating about public bad problems in a digital age: The things that may get lost in digitization}

The hype surrounding digital agriculture means it is easy to be carried away by all the opportunities that digital technologies have to offer and to think that everything from the past was bad and needs to be replaced with something new. But, as I also elaborated in the introduction chapter and in section 8.2.4 of this chapter, there has this far been limited attention for how transformations to the ways in which people communicate and receive information may impact the governance of complex agricultural problems for better or worse. In the previous section on inclusion and capacity (section 8.3.2) I joined scholars who advocate for a hybrid communication approach in which diverse (digital) communication technologies are combined, to support inclusivity. Here, I want to add another motivation for combining 'old', face-toface communication and extension practices with 'new' digital practices, based on chapter 7 findings. The motivation is that both means of communication bring their own unique selling points to the table. Indeed, face-to-face communication and extension has its limitations, e.g. having timing and accuracy issues, being inefficient, often depending on too few extension agents, and lacking opportunities to tailor information to the needs of individuals ((Davis, Babu, \& Ragasa, 2020; Spielman, Ekboir, Davis, \& Ochieng, 2008), see also chapter 1). Digital technologies certainly have their benefits when it comes to these factors, being faster, accurate, up-to-date, and giving a range of opportunities for customization. Then why does digital extension so far not live up to the expectations? I believe that the findings of this dissertation lead us in the right direction by pointing out that there is something beautiful in face-to-face 


\section{Chapter 8}

communication that digital extension currently does not offer: It brings people together, and creates a space for deliberation, conflict management, and sensemaking. Both science and practice pay very little attention to the fact that very often the link between the 'old' and the 'new' system is missing, while this may be the way we have to go. Instead of aiming to eventually replace face-to-face, human interaction between groups of interdependent farmers with digital, technology-mediated interaction between an individual and a machine the aim should be to bring the two systems together such that they can form a synergy.

When it comes to the digital advisory and decision support services currently available or being developed, it appears that many of them are first and foremost diagnostic, monitoring, or performance surveillance tools (as was the case with BXW-App). The promise of facilitating easy, multi-way, interaction between farmers, extension agents, and other actors in the system is not met (see chapter 4). Instead, and considering what I wrote in the previous paragraph, I am concerned that the current services may reduce rather than enhance connectivity, especially farmer-to-farmer connectivity, and cause users to shift to alternative (social-media) platforms and commercial applications because of the option to connect with multiple actors in real-time. Findings by e.g. Munthali et al. (2021) support the latter.

Another recognized benefit of these platforms over face-to-face communication is that they remove physical boundaries (Eichler Inwood \& Dale, 2019; Richard Heeks, 2020a). For example, a farmer's or extension agent's communication options are no longer limited to who lives within walking or motorbike-ride distance from the homestead, farm, or extension office. One can basically connect with anyone, anywhere, at any time. The question is if this is always necessary or useful when it comes to public bad problems that have local impact. In my view, proven forms of, analogue, connectivity, e.g. community meetings, can be more effective and appropriate to support with the local management of a complex problem when enough information and knowledge are available, and deliberation is necessary. Hence, this could be another argument in favour of bringing digital and analogue communication and extension together into hybrid, synergetic intervention strategies that combine established and new perspectives on knowledge and innovation management in the context of complex agricultural problems (Ingram \& Maye, 2020). 


\section{Could the logic of collective action change under influence of digitalization?}

In the previous section I wrote that since digital services may foster individualization and personalization, farmers may develop the perception that they can solve problems individually. For example, targeted information provision without any feedback about what fellow-farmers are confronted with, or what decisions or actions fellow farmers take to manage a complex problem, can create the perception that these problems can successfully be managed at an individual level, in isolation of and unaffected by others. However, understanding the mechanisms behind complex problems (see chapter 1 and chapter 6 ) I argue that this perception would likely be incorrect. The properties of the complex problem itself and the need to address it collectively do not change when information provision or communication about that problem becomes targeted to and contextualized to individuals. Put in a broader perspective, it is possible to say that individualization and personalization, as brought forward by digitalization, fits with a neoliberal way of thinking about individualism in which 'I am responsible for myself and my own well-being'. It means that my thriving is a personal achievement, something that I likely want to protect. Alternatively, if I fail it is my own fault, and those who are more well-off may not want to share their merit with me when I struggle. This conceptualization of individualism is contrasting with an alternative formula in which individualism means the individual responsibility to do the right thing for the common good. In other words: 'If my individual actions help me to succeed, it will in turn also help the collective be better off'. The latter conceptualization fits much better with how African culture, or smallholder farmer communities for that matter, traditionally function. This philosophy that highly values the relationships and interdepence between people, called Ubuntu ${ }^{24}$, is widely spread across Africa (Boogaard \& van Norren, 2021). Considering the findings from testing Musa-Game in Rwanda, I am concerned that the introduction of digital technologies into rural communities may transform the traditional African concept of individualism. This concern is coherent with literature that critiques the neoliberal focus of digitalization processes in the agricultural sector (some only focusing on the Global North) (Brooks, 2021; Carolan, 2018, 2020; Fraser, 2021; Gras \& Cáceres, 2020; Rotz et al., 2019). The

\footnotetext{
24 Ubuntu is a Bantu language word that translates to 'humanity' or 'human generosity' (in Kinyarwanda) and is also often interpreted as meaning 'I am because we are' and in philosophical terms refers to 'the belief in a universal bond of sharing that connects all humanity'. Other African languages know words with similar meaning e.g. 'utu' in Kiswahili.
} 
Chapter 8

effect of this transformation may be that the notion of how others (e.g. fellow farmers) are doing and whether and how one farmer's individual actions are affecting the collective. In such a context an individual is not confronted with the broader implications of his/her actions, and hence also not emotionally or socially hurt by them.

\section{New research themes on how digitalization affects communication about and management of complex agricultural problems}

The above discussion regarding the potential pros and cons of using digital innovations in the context of complex agricultural problems is based on the findings from one case experiment applied to one case study. The insights that I was able to gain from it were nevertheless very interesting and point out new avenues for research. As also written in chapter 7, future research could conduct Musa-game at a larger-scale or conduct a similar game for a different complex problem. Additionally, it would be interesting to implement this type of game-experiment using digital devices (e.g. mobile phones) to play the game and to communicate (similar to what Damtew et al. (2020) did in Ethiopia), this could give more insight in the role of communication while it would also help to reduce the need for facilitation and chances of data errors in the experiment.

In regard to the possible implications of personalized information provision through digital services, as discussed above, further research could set up experiments with diverse digital interventions and measure their impact on knowledge and information exchange, deliberation, individual and collective decision-making and actions and, ultimately, the complex problem itself in real-life and over a longer period of time., Another topic that could be explored is if conceptual thinking about common- and public goods and public bads can be applied to digitalization itself. This research could explore the applicability of common good theory in the context of digital agriculture and agricultural Big Data, which links to the emerging works on common and public data (Taylor, 2021), and drivers of digital development (Birner et al., 2021), and if and how a common or public good can become a public bad in this context.

In the final sections of this dissertation I want to reflect on the research, including the study's strengths, limitations, and my role as a researcher. I finish in section 8.5 with a final reflection. 


\subsection{Reflection on the research}

\section{Methodological contributions}

This thesis contributed a framework that supports ex-ante assessment of userreadiness (chapter 3), a second framework to assess if ethics, rights, and responsibility are considered in design (chapter 4), and an experimental method that can be used as serious game as well (Musa-game, chapters 6 and 7). The User-Readiness framework provided relevant entry-points about capacity (=readiness) of users and the innovation ecosystem that can inform the design digital ag. projects and interventions and specific services, and complements similar readiness frameworks that were developed for the Global North and use a qualitative approach (e.g. digi-MAST (Fielke et al., 2021), that focus on the technology (e.g. technology readiness (Kobos, Malczynski, Walker, Borns, \& Klise, 2018), or the technology and innovation ecosystem combined (e.g. scaling readiness (Sartas, Schut, Proietti, Thiele, \& Leeuwis, 2020), and frameworks that facilitate anticipation of unknown impacts of digitalization by assessing socio-cyber-physical relations (Rijswijk et al., 2021).

The thesis also contributed a novel way to asses a participatory design approach by adding ethics, responsible research and innovation, and digital rights to the assessment. In doing so, I brought higher-level conceptual thinking about what would entail a responsible design to the local-level where participatory approaches are implemented and designs are being made. This way I was able to gain many insights about the factors and processes that shape the design of a digital advisory service and the implications of design decisions.

A third methodological contribution is the Musa-game, which adds emergence and spatiality to the study of a complex agricultural problem and public bad problem and has been contextualized to the socio-ecological system that belongs to banana production in Rwanda. What is also novel about this method is that it combines qualitative and quantitative methods to match understanding from the controlled environment of the experimental game with real-life experiences of players.

\section{Limitations of the research}

There are a couple of limitations to my research which I briefly capture here. First, much of the research is based on two case studies: Banana Xanthomonas Wilt and the ICT4BXW project, i.e. one complex agricultural problem and one participatory 


\section{Chapter 8}

design process that resulted in a digital advisory and decision support service. The single case approach used in for example chapters 3 and 4, means that it is difficult to say which findings are unique to the specific case and which can be extrapolated to other cases as well, i.e. the external validity may be limited. I have tried to be transparent about these limitations in each of the empirical chapters. Where possible, I used literature to compare my findings with those of others and to observe how the research findings were conflicting, complementing, or confirming what was already known.

A second limitation is that the research zooms in on the context and conditions at one point in time (chapters 4, 3, and 7) or over a longer time-period (chapter 4), capturing the conditions at that moment. It would have been interesting to, for example, conduct another user readiness assessment after some time or after BXW-App had been introduced to see if and how readiness adapts. Similarly, it was outside the scope of this thesis to measure how BXW-App performed after the pilot period and if it affects, for example, disease management practices of farmers and extensionists, communication between actors at local level, strategies at national level, etc. Now that there is a second phase of the ICT4BXW project there may be opportunities for other researchers to do this.

The study contributed new knowledge about three thematic clusters (Klerkx et al., 2019): adoption, uses, and adaptation (chapters 3, 4, and 5); how digitalization may affect knowledge and innovation systems (chapters 2, 6, and 7); and power, ownership, privacy and ethics (chapters 3, 4, and 5). The remaining two clusters (economics and management of digitalized agriculture; and effects of digitalization on farmer identity, skills, and farm work) remained largely outside the scope of the study. Studying these 'bigger picture' and 'future of farming' themes would have required a different lens and different study approach, e.g. more longitudinal, more experimental, and more at a meta-level. I chose to primarily focus on processes at a local level, zooming in on the digital technologies and services, users, and problem context, and explore how local level experiences and perceptions could be linked to concepts and frameworks that are normally used higher up in the system (e.g. RRI, data rights). However, due to the study set-up discussed above I cannot say anything conclusive about my research findings in relation to more global socio-economic, -cultural, or -political processes.

Chapter 7 emerged as a compromise. In my original research design, I would have conducted a full experiment with Musa-game in Rwanda and collect a large amount of data. This data should have had enough statistical power to test hypotheses and would 
have allowed me to present the results from chapter 7 with more certainty about their validity. This work was unfortunately affected by the outbreak in Covid-19, which forced me to put the fieldwork on hold in March 2020. A longer-term lock-down and travel restrictions in Rwanda made it impossible to return to the sampled fieldsites within an acceptable time period.

A more practical limitation is that I am a white, European woman who was born and raised in the Global North. Hence, unconsciously, I may have brought some (Eurocentric) researcher biases into the research interventions or the way in which I interpret my data (Boogaard, 2019). Additionally, during my research I often relied on Rwandan enumerators and translators to collect and translate the data. I have worked with very talented and committed people but cannot guarantee that some details got lost in translation. Additionally, even though I had already lived and worked in Rwanda and Africa for several years before starting this $\mathrm{PhD}$ research, I cannot deny that the fact that I am a umuzungu ${ }^{25}$ woman with a different cultural background may have influenced my research. To cope with these limitations, I have verified my observations with Rwandan colleagues or research assistants on many occasions which I think was quintessential to interpret the data and observations.

Lastly, I want to briefly discuss my position as an action researcher. In the introduction chapter I mentioned that I was in the unique position to study the case of ICT4BXW from the very beginning, while it was still in a proposal development stage. This gave me the opportunity to get very close to the project, events, and the people implementing the project. Without this it would not have been possible to gain the insights that I used to write chapter 4. The chosen research approach came with challenges that have been described in literature on action research too (Kock, 2004): objectivity, contingency, and control. A limitation of the embedded position is that it may have been difficult to always be objective and to not let my personal biases get involved in the analyses of my data. This, in turn, may have affected the internal validity of the research. I have tried to address this issue, for example by validating my findings with those of others and by working with co-authors who were not involved in the ICT4BXW project and could be considered as neutral outsiders. I have also tried to be as transparent as possible with project staff and partners about my position as an embedded researcher who studied the project itself, the approaches it used, and the

\footnotetext{
${ }^{25}$ Kinyarwanda term originating from the Kiswahili word Mzungu that means 'wanderer' and which is commonly used thorughout East and Central Africa to refer to a foreigner, usually with a white or light coloured skin.
} 
Chapter 8

people implementing them. The nature of the research also reduced the amount of control that I had as a researcher and made that I sometimes had to adapt to unforeseen circumstances.

\subsection{Final reflection}

This conclusion section marks the end of my research journey. The six empirical chapters of this dissertation gave a multi-facetted overview of digital agriculture in the context of Africa and the Global South more generally, with specific focus on advisory and decision support services and how design (choices) influence what a digital technology or service 'is' and 'does' and for whom. The thesis shows that the power and potential of digital technologies and services are undeniable, and that digitalization is here to stay. We have reached a point where the digital technologies themselves and whether they are ready for deployment from a technological perspective is not the issue. The time has come to look at what is needed to make them work for all humans. It is time to figure out how all the promises about the transformative capacity of digital technologies and services can be made reality so that they can contribute to true positive change.

If I must mention one general thing that this thesis shows, it is that the impact of a digital agriculture technology or service, on agricultural systems in general and people specifically, is largely determined by how that technology or service was designed. During the design process all the critical decisions about what the technology or service is and does are made. In the introduction chapter I wrote how a picture of a smiling Kenyan woman formed the inspiration for my research The study findings show that hidden behind that individual picture are many photographs of creative designers, sweating programmers, overly optimistic project managers, demanding donors, overburdened extension agents, and struggling farmers, all trying to make sense of complex problems that they are trying to solve. All those people make choices, and it are those choices that determine which implications digital agriculture has for the Kenyan woman and millions of her fellow farmers or, in the case of ICT4BXW, for the farmer promoters who are expected to use BXW-App. Based on my research findings, I have come to understand that the people developing apps and other digital services generally do so with the right intentions. Nevertheless, my findings and other literature suggest that many advisory and decision support services fail in their ambitions. My research sheds light on reasons for those failures from perspective of how they were 
designed. It links the struggle of digital services to live up to their promises to techno optimism and unrealistic expectations, limited user-readiness and capacity limitations in general across the digital innovation ecosystem, power relationships that challenge true inclusivity in participatory design processes, which all limit the capabilities, opportunities, and motivations to observe and cope with and design for the real-world complexity of developing digital technologies and services for African agriculture.

Admittedly, the more knowledge I gained about digitalization, and the transformative impact that digitalization has on people, their livelihoods, and their socio-cultural systems; the increasing power of data and algorithms; and the role of a few dominant (big tech) actors in the sector, the more I came to question my own initial optimism about digital agriculture and the opportunities that it would bring for smallholder farmer communities. My techno-optimistic view became techno-skepticism for some time, and it took a while before that became techno-realism. Now, at the end of my research, I have developed a more critically realistic view on digital agriculture and the social and political implications of digital development and transformations. I can again believe that digital innovations triggers or contributes to positive transformations in agricultural systems and can support with improving the resilience, livelihoods, and equal access of vulnerable groups, like smallholder farmers. Yet, I clearly see the potential dark sides of digital innovation too. Scientists, development practitioners, donors, and policymakers have a responsibility to try to minimize the negative consequences of digitalization processes in agriculture in the Global South. Additionally, they should consider the complex problem, and the type of decisionmaking and action that it requires, more carefully. For this it is not enough to look at individual digital innovations in isolation of their users and use context. Digital innovations belong to larger digital innovation ecosystems, which in turn are embedded in agricultural innovation systems and hence systems thinking is necessary to grasp the consequences of digitalization.

Through my research I have come to appreciate the ideas behind responsible innovation and responsible design, concepts that invite scientists, developers, designers, implementers, and users to anticipate and reflect on technological and social development. Reflexivity may still be difficult when it comes to digitalization in a Global South context, as I also concluded in chapter 4. Simply put, we know that the impact is going to be large, but we are not (yet) very good at predicting where, when, and whom will be affected. It can still take years for this to change. However, a lot can be learned already about impacts of digitalization processes in a Global North context, in the 
Chapter 8

context of agriculture, in other sectors, and in general. From that lessons can be learned that with contextualization and appropriation could be useful for an African and smallholder farming setting. Doing this with honest intentions and in a transparent way may change various stakeholders' perception of digitalization, like this thesis research did for me. Based on my research I am confident that the key to success is in the design, and in approaching digital agricultural advisory and decision support services, digital interventions, and digital innovation ecosystems more holistically and responsibly. 


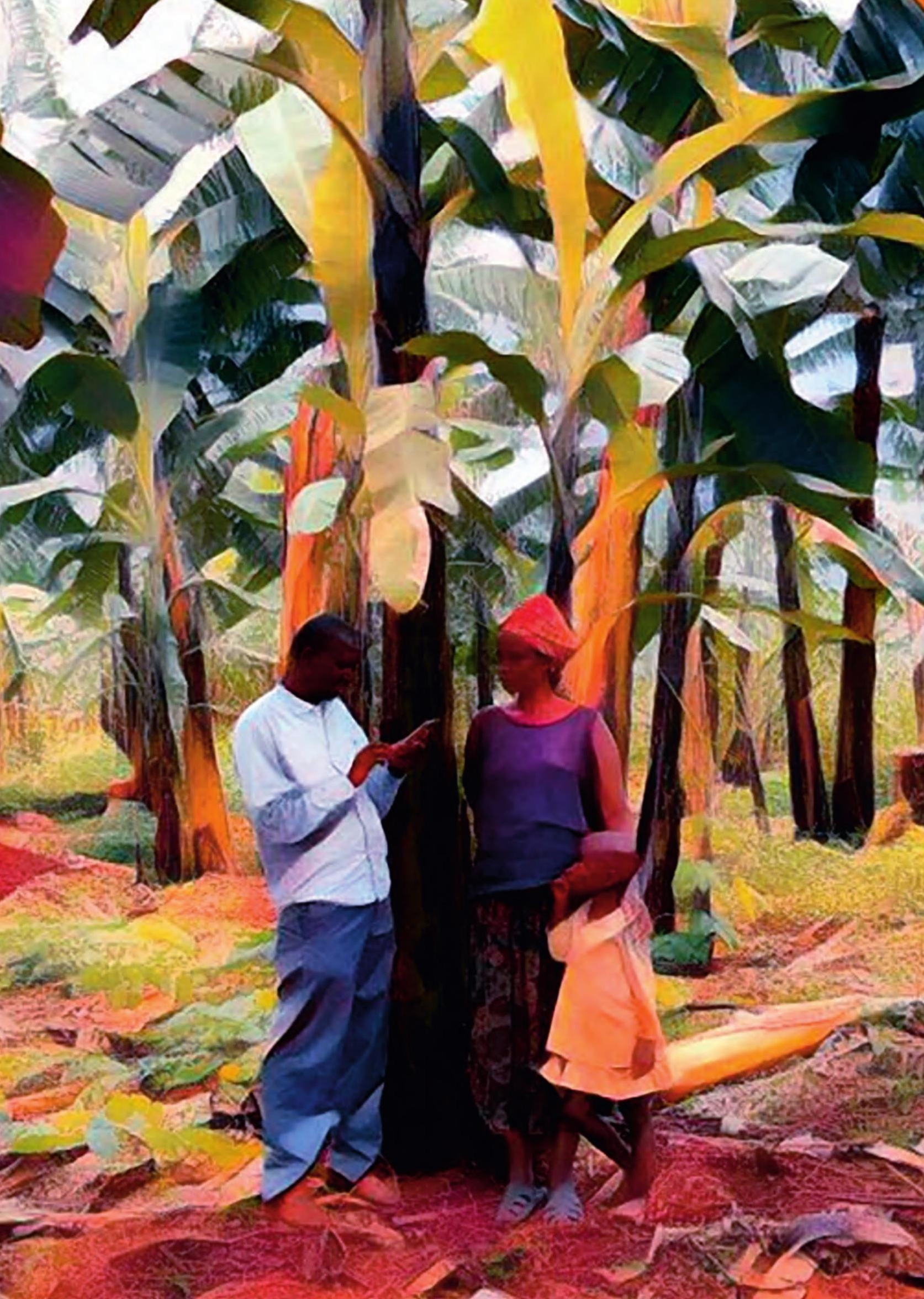




\section{References}

Abebe, R., Aruleba, K., Birhane, A., Kingsley, S., Obaido, G., Remy, S. L., \& Sadagopan, S. (2021). Narratives and counternarratives on data sharing in Africa. In FAccT 2021 - Proceedings of the 2021 ACM Conference on Fairness, Accountability, and Transparency (pp. 329-341). New York, NY, USA: Association for Computing Machinery, Inc. https://doi.org/10.1145/3442188.3445897

Ackoff, R. L. (1999). From Data to Wisdom. In Ackoff's best: his classic writings on management (pp. 170 172). New York: John Wiley \& Sons.

African Union. (2019). African Leaders Redefine the Future through Digital Transformation. Retrieved December 12, 2019, from https://au.int/en/pressreleases/20190211/african-leaders-redefine-futurethrough-digital-transformation

Agyekumhene, C., de Vries, J. R., Paassen, A. van, Schut, M., \& MacNaghten, P. (2020). Making Smallholder Value Chain Partnerships Inclusive: Exploring Digital Farm Monitoring through Farmer Friendly Smartphone Platforms. Sustainability, 12(11), 4580. https://doi.org/10.3390/su12114580

Agyekumhene, C., de Vries, J. R., van Paassen, A., Macnaghten, P., Schut, M., \& Bregt, A. (2018). Digital platforms for smallholder credit access: The mediation of trust for cooperation in maize value chain financing. NJAS - Wageningen Journal of Life Sciences, 86-87, 77-88. https://doi.org/10.1016/j.njas.2018.06.001

Ainembabazi, J. H., \& Mugisha, J. (2014). The Role of Farming Experience on the Adoption of Agricultural Technologies: Evidence from Smallholder Farmers in Uganda. Journal of Development Studies, 50(5), 666-679. https://doi.org/10.1080/00220388.2013.874556

Aizenberg, E., \& van den Hoven, J. (2020). Designing for human rights in Al. Big Data \& Society, 7(2), 205395172094956. https://doi.org/10.1177/2053951720949566

Ajani, E. N. (2014). Promoting the Use of Information and Communication Technologies (ICTs) for Agricultural Transformation in Sub-Saharan Africa: Implications for Policy. Journal of Agricultural and Food Information, 15(1), 42-53. https://doi.org/10.1080/10496505.2013.858049

Ajunwa, I. (2020). The "black box" at work. Big Data \& Society, 7(2), 205395172096618. https://doi.org/10.1177/2053951720938093

Aker, J. C. (2011). Dial "A" for agriculture: A review of information and communication technologies for agricultural extension in developing countries. Agricultural Economics, 42(6), 631-647. https://doi.org/10.1111/j.1574-0862.2011.00545.x

Aker, J. C. . b, \& Ksoll, C. . d. (2016). Can mobile phones improve agricultural outcomes? Evidence from a randomized experiment in Niger. Food Policy, 60, 44-51. https://doi.org/10.1016/j.foodpol.2015.03.006

Aker, J. C., Ghosh, I., \& Burrell, J. (2016). The promise (and pitfalls) of ICT for agriculture initiatives. Agricultural Economics (United Kingdom), 47, 35-48. https://doi.org/10.1111/agec.12301

Alabi, O. O. (2016). Adoption of information and communication technologies (ICTs) by agricultural science and extension teachers in Abuja, Nigeria. Journal of Agricultural Education, 57(1), 137-149.

Alavi, M., \& Leidner, D. E. (2001). Review: Knowledge Management and Knowledge Management Systems: Conceptual Foundations and Research Issues. MIS Quarterly, 25(1), 107. https://doi.org/10.2307/3250961

Aleke, B. ., Ojiako, U. ., \& Wainwright, D. W. . (2011). ICT adoption in developing countries: Perspectives from small-scale agribusinesses. Journal of Enterprise Information Management, 24(1), 68-84. 
https://doi.org/10.1108/17410391111097438

Ali, J. (2012). Factors affecting the adoption of information and communication technologies (ICTs) for farming decisions. Journal of Agricultural and Food Information, 13(1), 78-96.

https://doi.org/10.1080/10496505.2012.636980

Alzouma, G. (2005). Myths of digital technology in Africa: Leapfrogging development? Global Media and Communication, 1(3), 339-356. https://doi.org/10.1177/1742766505058128

Arouna, A., Michler, J. D., Yergo, W. G., \& Saito, K. (2020). One Size Fits All? Experimental Evidence on the Digital Delivery of Personalized Extension Advice in Nigeria. American Journal of Agricultural Economics, ajae.12151. https://doi.org/10.1111/ajae.12151

Ávila Pinto, R. (2018). Digital sovereignty or digital colonialism? . SUR - International Journal on Human Rights, 15(27), 15-27.

Ayamga, M., Tekinerdogan, B., Kassahun, A., \& Rambaldi, G. (2020). Developing a policy framework for adoption and management of drones for agriculture in Africa. Technology Analysis \& Strategic Management, 1-18. https://doi.org/10.1080/09537325.2020.1858047

Ayim, C., Kassahun, A., Tekinerdogan, B., \& Addison, C. (2020). Adoption of ICT innovations in the agriculture sector in Africa: A Systematic Literature Review. Wageningen.

Ayre, M., Mc Collum, V., Waters, W., Samson, P., Curro, A., Nettle, R., ... Reichelt, N. (2019). Supporting and practising digital innovation with advisers in smart farming. NJAS - Wageningen Journal of Life Sciences, 90-91, 100302. https://doi.org/10.1016/j.njas.2019.05.001

Barker, F., Atkins, L., \& de Lusignan, S. (2016). Applying the COM-B behaviour model and behaviour change wheel to develop an intervention to improve hearing-aid use in adult auditory rehabilitation. International Journal of Audiology, 55(sup3), S90-S98. https://doi.org/10.3109/14992027.2015.1120894

Barrett, C. B. (2020). Overcoming Global Food Security Challenges through Science and Solidarity. American Journal of Agricultural Economics, ajae.12160. https://doi.org/10.1111/ajae.12160

Barrett, C. B. (2021). Overcoming Global Food Security Challenges through Science and Solidarity. American Journal of Agricultural Economics, 103(2), 422-447. https://doi.org/10.1111/ajae.12160

Barrett, C. B., Benton, T. G., Cooper, K. A., Fanzo, J., Gandhi, R., Herrero, M., ... Wood, S. (2020, December 1). Bundling innovations to transform agri-food systems. Nature Sustainability. Nature Research. https://doi.org/10.1038/s41893-020-00661-8

Barrett, H., \& Rose, D. C. (2020). Perceptions of the Fourth Agricultural Revolution: What's In, What's Out, and What Consequences are Anticipated? Sociologia Ruralis, soru.12324. https://doi.org/10.1111/soru.12324

Baumuller, H. (2016). Are mAgriculture applications living up to expectations? A critical review of empirical evidence and methodologies. In Proceedings of the 5th International Conference on M4D Mobile Communication Technologyfor Development.

Baumüller, H. (2016). Agricultural service delivery through mobile phones: Local innovation and technological opportunities in Kenya. In Technological and Institutional Innovations for Marginalized Smallholders in Agricultural Development. https://doi.org/10.1007/978-3-319-25718-1_9

Baumüller, H. (2018). The Little We Know: An Exploratory Literature Review on the Utility of Mobile PhoneEnabled Services for Smallholder Farmers. Journal of International Development, 30(1), 134-154. https://doi.org/10.1002/jid.3314 


\section{References}

Baumüller, H., \& Addom, B. K. (2020). The Enabling Environments for the Digitalization of African Agriculture. In D. Resnick, X. Diao, \& G. Tadess (Eds.), Resakks annual trends and outlook report. IFPRI.

Bennett, W. L., \& Segerberg, A. (2012). THE LOGIC OF CONNECTIVE ACTION. Information Communication and Society, 15(5), 739-768. https://doi.org/10.1080/1369118X.2012.670661

Benson, T. (2019). Digital innovation evaluation: User perceptions of innovation readiness, digital confidence, innovation adoption, user experience and behaviour change. BMJ Health and Care Informatics, 26(1). https://doi.org/10.1136/bmjhci-2019-000018

Bentley, J. W., Naziri, D., Prain, G., Kikulwe, E., Mayanja, S., Devaux, A., \& Thiele, G. (2020). Managing complexity and uncertainty in agricultural innovation through adaptive project design and implementation. Development in Practice. https://doi.org/10.1080/09614524.2020.1832047

Berthet, E. T., Hickey, G. M., \& Klerkx, L. (2018). Opening design and innovation processes in agriculture: Insights from design and management sciences and future directions. Agricultural Systems, 165, 111115.

Bietti, E. (2020). From ethics washing to ethics bashing: A view on tech ethics from within moral philosophy. In FAT* 2020 - Proceedings of the 2020 Conference on Fairness, Accountability, and Transparency (pp. 210-219). Association for Computing Machinery, Inc. https://doi.org/10.1145/3351095.3372860

Birch, K., Chiappetta, M., \& Artyushina, A. (2020). The problem of innovation in technoscientific capitalism: data rentiership and the policy implications of turning personal digital data into a private asset. Policy Studies, 41(5), 468-487. https://doi.org/10.1080/01442872.2020.1748264

Birch, K., \& Cochrane, D. T. (2021). Big Tech: Four Emerging Forms of Digital Rentiership. Science as Culture, 1-15. https://doi.org/10.1080/09505431.2021.1932794

Birch, K., Cochrane, D., \& Ward, C. (2021). Data as asset? The measurement, governance, and valuation of digital personal data by Big Tech. Big Data \& Society, 8(1), 205395172110173. https://doi.org/10.1177/20539517211017308

Birhane, A. (2020). Algorithmic Colonization of Africa. Journal of Law, Technology and Society, 17(2), 389409. https://doi.org/10.2966/scrip.170220.389

Birner, R., Daum, T., \& Pray, C. (2021). Who drives the digital revolution in agriculture? A review of supplyside trends, players and challenges. Applied Economic Perspectives and Policy. https://doi.org/10.1002/aepp.13145

Birner, R., Davis, K., Pender, J., Nkonya, E., Anandajayasekeram, P., Ekboir, J., ... Cohen, M. (2009). From Best Practice to Best Fit: A Framework for Designing and Analyzing Pluralistic Agricultural Advisory Services Worldwide. The Journal of Agricultural Education and Extension, 15(4), 341-355. https://doi.org/10.1080/13892240903309595

Biruma, M., Pillay, M., Tripathi, L., Blomme, G., Abele, S., Mwangi, M., ... Eden-Green, S. (2007). Banana Xanthomonas wilt: a review of the disease, management strategies and future research directions. African Journal of Biotechnology, 6(8), 953-962.

Blok, V., \& Lemmens, P. (2015). The Emerging Concept of Responsible Innovation: Three Reasons Why It Is Questionable and Calls for a Radical Transformation of the Concept of Innovation. In B. J. Koops, I. Oosterlaken, H. Romijn, T. Swierstra, \& J. van den Hoven (Eds.), Responsible Innovation 2: Concepts, Approaches, and Applications (pp. 19-35). https://doi.org/10.1007/978-3-319-17308-5

Blomme, G., Ocimati, W., Sivirihauma, C., Lusenge, V., Bumba, M., \& Ntamwira, J. (2019). Controlling Xanthomonas wilt of banana: Influence of collective application, frequency of application, and social 
factors on the effectiveness of the Single Diseased Stem Removal technique in Democratic Republic of Congo. Crop Protection, 118, 79-88.

Blomme, Guy, Dusingizimana, P., Ntamwira, J., Kearsley, E., Gaidashova, S., Rietveld, A., ... Ocimati, W. (2021). Comparing effectiveness, cost- and time-efficiency of control options for Xanthomonas wilt of banana under Rwandan agro-ecological conditions. European Journal of Plant Pathology, 1-15. https://doi.org/10.1007/s10658-021-02258-z

Blomme, Guy, Jacobsen, K., Ocimati, W., Beed, F., Ntamwira, J., Sivirihauma, C., ... Karamura, E. (2014). Finetuning banana Xanthomonas wilt control options over the past decade in East and Central Africa. European Journal of Plant Pathology, 139(2), 265-281. https://doi.org/10.1007/s10658-014-0402-0

Blomme, Guy, Ocimati, W., Sivirihauma, C., Vutseme, L., Mariamu, B., Kamira, M., ... Ntamwira, J. (2017). A control package revolving around the removal of single diseased banana stems is effective for the restoration of Xanthomonas wilt infected fields. European Journal of Plant Pathology, 149(2), 385400. https://doi.org/10.1007/s10658-017-1189-6

Bloomberg, J. (2018, April 29). Digitization, Digitalization, And Digital Transformation: Confuse Them At Your Peril. Retrieved June 7, 2021, from https://www.forbes.com/sites/jasonbloomberg/2018/04/29/digitization-digitalization-and-digitaltransformation-confuse-them-at-your-peril/?sh $=45 \mathrm{~d} 0385 \mathrm{f} 2 \mathrm{f} 2 \mathrm{C}$

Boogaard, B. K. (2019). The relevance of connecting sustainable agricultural development with African philosophy. South African Journal of Philosophy, 38(3), 273-286. https://doi.org/10.1080/02580136.2019.1648124

Boogaard, B., \& van Norren, D. (2021). "Development" perspectives from the Global South: Learning from Ubuntu and Buen Vivir philosophies. In D. Ludwig, B. Boogaard, P. Macnaghten, \& C. Leeuwis (Eds.), The Politics of Knowledge in Inclusive Development and Innovation (1st ed.). Routledge.

Bouwmeester, H., Heuvelink, G. B. M., \& Stoorvogel, J. J. (2016). Mapping crop diseases using survey data: The case of bacterial wilt in bananas in the East African highlands. European Journal of Agronomy, 74, 173-184. https://doi.org/10.1016/j.eja.2015.12.013

Breitenbach, M. C. (2013). Telecentres for sustainable rural development: Review and case study of a South African rural telecentre. Development Southern Africa, 30(2), 262-278.

Bronson, K. (2018). Smart Farming: Including Rights Holders for Responsible Agricultural Innovation. Technology Innovation Management Review, 8 (2).

Bronson, K. (2019). Looking through a responsible innovation lens at uneven engagements with digital farming. NJAS - Wageningen Journal of Life Sciences, 90-91, 100294. https://doi.org/10.1016/j.njas.2019.03.001

Brooks, S. (2021). Configuring the digital farmer: A nudge world in the making? Economy and Society. https://doi.org/10.1080/03085147.2021.1876984

Bruce, T. J. A. (2016). The CROPROTECT project and wider opportunities to improve farm productivity through web-based knowledge exchange. Food and Energy Security, 5(2), 89-96. https://doi.org/10.1002/fes3.80

Burton, R. J. F., \& Riley, M. (2018). Traditional Ecological Knowledge from the internet? The case of hay meadows in Europe. Land Use Policy, 70, 334-346. https://doi.org/10.1016/j.landusepol.2017.10.014

Buytaert, W., Zulkafli, Z., Grainger, S., Acosta, L., Alemie, T. C., Bastiaensen, J., ... Zhumanova, M. (2014). Citizen science in hydrology and water resources: opportunities for knowledge generation, ecosystem service management, and sustainable development. Frontiers in Earth Science, 


\section{References}

2(October), 1-21. https://doi.org/10.3389/feart.2014.00026

Carbonell, I. M. (2016). The ethics of big data in big agriculture. Internet Policy Review, 5(1). https://doi.org/10.14763/2016.1.405

Carolan, M. (2018). 'Smart' Farming Techniques as Political Ontology: Access, Sovereignty and the Performance of Neoliberal and Not-So-Neoliberal Worlds. Sociologia Ruralis, 58(4), 745-764. https://doi.org/10.1111/soru.12202

Carolan, M. (2020). Digitization as politics: Smart farming through the lens of weak and strong data. Journal of Rural Studies. https://doi.org/10.1016/j.jrurstud.2020.10.040

Carroll, S. R., Garba, I., Figueroa-Rodríguez, O. L., Holbrook, J., Lovett, R., Materechera, S., ... Hudson, M. (2020). The CARE principles for indigenous data governance. Data Science Journal, 19(1), 1-12. https://doi.org/10.5334/DSJ-2020-043

Cerf, M., Jeuffroy, M.-H., Prost, L., \& Meynard, J.-M. (2012). Participatory design of agricultural decision support tools: taking account of the use situations. Agronomy for Sustainable Development, 32(4), 899-910. https://doi.org/10.1007/s13593-012-0091-z

Cibangu, S. K. (2019). Marginalization of indigenous voices in the information age: a case study of cell phones in the rural Congo*. Information Technology for Development. https://doi.org/10.1080/02681102.2019.1647403

Cieslik, K., Cecchi, F., Assefa Damtew, E., Tafesse, S., Struik, P. C., Lemaga, B., \& Leeuwis, C. (2021). The role of ICT in collective management of public bads: The case of potato late blight in Ethiopia. World Development, 140, 105366. https://doi.org/10.1016/j.worlddev.2020.105366

Cieslik, K. J., Leeuwis, C., Dewulf, A. R. P. J., Lie, R., Werners, S. E., van Wessel, M., ... Struik, P. C. (2018). Addressing socio-ecological development challenges in the digital age: Exploring the potential of Environmental Virtual Observatories for Connective Action (EVOCA). NJAS - Wageningen Journal of Life Sciences, 86-87, 2-11. https://doi.org/10.1016/j.njas.2018.07.006

Cinnamon, J. (2020). Data inequalities and why they matter for development. Information Technology for Development, 26(2), 214-233. https://doi.org/10.1080/02681102.2019.1650244

Cioffo, G. D., Ansoms, A., \& Murison, J. (2016). Modernising agriculture through a 'new' Green Revolution: the limits of the Crop Intensification Programme in Rwanda. Review of African Political Economy, 43(148), 277-293. https://doi.org/10.1080/03056244.2016.1181053

Clapp, J., \& Ruder, S. L. (2020). Precision technologies for agriculture: Digital farming, gene-edited crops, and the politics of sustainability. Global Environmental Politics, 20(3), 49-69. https://doi.org/10.1162/glep_a_00566

Coad, A., Nightingale, P., Stilgoe, J., \& Vezzani, A. (2020). Editorial: the dark side of innovation. Industry and Innovation, 1-11. https://doi.org/10.1080/13662716.2020.1818555

Cook, B. R., Satizábal, P., \& Curnow, J. (2021). Humanising agricultural extension: A review. World Development, 140, 105337. https://doi.org/10.1016/j.worlddev.2020.105337

Crowe, S., Cresswell, K., Robertson, A., Huby, G., Avery, A., \& Sheikh, A. (2011). The case study approach. BMC Medical Research Methodology, 11(1), 1-9. https://doi.org/10.1186/1471-2288-11-100

d.school Stanford University. (2018). Design Thinking Bootleg.

Damtew, E., Leeuwis, C., Struik, P. C., Cecchi, F., van Mierlo, B., Lie, R., ... Cieslik, K. (2020). Communicative interventions for collective action in the management of potato late blight: evidence from a framed field game experiment in Ethiopia. Food Security, 1-17. https://doi.org/10.1007/s12571-020-01120-0 
Daum, T., Villalba, R., Anidi, O., Mayienga, S. M., Gupta, S., \& Birner, R. (2020). Uber for Tractors? Opportunities and Challenges of Digital Tools for Tractor Hire in India and Nigeria. SSRN Electronic Journal. https://doi.org/10.2139/ssrn.3526918

Davis, K., Babu, S., \& Ragasa, C. (2020). Agricultural Extension: Global Status and Performance in Selected Countries. IFPRI.

de Hoop, E., Pols, A., \& Romijn, H. (2016). Limits to responsible innovation. Journal of Responsible Innovation, 3(2), 110-134. https://doi.org/10.1080/23299460.2016.1231396

Dearden, A., \& Kleine, D. (2020). Interdisciplinarity, self-governance and dialogue: the participatory process underpinning the minimum ethical standards for ICTD/ICT4D research. Information Technology for Development. https://doi.org/10.1080/02681102.2020.1840321

Dearden, A., \& Rizvi, H. (2008). Participatory IT Design and Participatory Development: A comparative review. PDC'08: Experiences and Challenges, Participatory Design Conference, 1-11.

Deen-Swarray, M. (2016). Toward Digital Inclusion: Understanding the Literacy Effect on Adoption and Use of Mobile Phones and the Internet in Africa. Information Technologies \& International Development, 12(2), 29-45.

Deichmann, U.a, Goyal, A. ., \& Mishra, D. . (2016). Will digital technologies transform agriculture in developing countries? Agricultural Economics (United Kingdom), 47, 21-33. https://doi.org/10.1111/agec.12300

Deichmann, Uwe, Goyal, A., \& Mishra, D. (2016). Will digital technologies transform agriculture in developing countries? Agricultural Economics (, 47, 21-33. https://doi.org/10.1111/agec.12300

Digital Impact Alliance. (n.d.). Principles for Digital Development. Retrieved February 5, 2021, from https://digitalprinciples.org/

Doezema, T., Ludwig, D., Macnaghten, P., Shelley-Egan, C., \& Forsberg, E. M. (2019). Translation, transduction, and transformation: expanding practices of responsibility across borders. Journal of Responsible Innovation, 6(3), 323-331. https://doi.org/10.1080/23299460.2019.1653155

Dufva, T., \& Dufva, M. (2019). Grasping the future of the digital society. Futures, 107, 17-28. https://doi.org/10.1016/j.futures.2018.11.001

Duncombe, R. A. (2014). Understanding the Impact of Mobile Phones on Livelihoods in Developing Countries. Development Policy Review, 32(5), 567-588. https://doi.org/10.1111/dpr.12073

Dwivedi, Y. K., Hughes, D. L., Coombs, C., Constantiou, I., Duan, Y., Edwards, J. S., ... Upadhyay, N. (2020). Impact of COVID-19 pandemic on information management research and practice: Transforming education, work and life. International Journal of Information Management, 55, 102211. https://doi.org/10.1016/j.jijnfomgt.2020.102211

Eastwood, C., Klerkx, L., Ayre, M., \& Dela Rue, B. (2019). Managing Socio-Ethical Challenges in the Development of Smart Farming: From a Fragmented to a Comprehensive Approach for Responsible Research and Innovation. Journal of Agricultural and Environmental Ethics, 32(5-6), 741-768. https://doi.org/10.1007/s10806-017-9704-5

Eastwood, C., Klerkx, L., \& Nettle, R. (2017). Dynamics and distribution of public and private research and extension roles for technological innovation and diffusion: Case studies of the implementation and adaptation of precision farming technologies. Journal of Rural Studies, 49. https://doi.org/10.1016/j.jrurstud.2016.11.008

Eastwood, Callum, Ayre, M., Nettle, R., \& Dela Rue, B. (2019). Making sense in the cloud: Farm advisory 


\section{References}

services in a smart farming future. NJAS - Wageningen Journal of Life Sciences. https://doi.org/10.1016/j.njas.2019.04.004

Eichler Inwood, S. E., \& Dale, V. H. State of apps targeting management for sustainability of agricultural landscapes. A review, 39 Agronomy for Sustainable Development § (2019). Springer-Verlag France. https://doi.org/10.1007/s13593-018-0549-8

Eisenhardt, K. M., \& Graebner, M. E. (2007). Theory building from cases: Opportunities and challenges. Academy of Management Journal, 50(1), 25-32. https://doi.org/10.5465/AMJ.2007.24160888

El Bilali, H., \& Allahyari, M. S. (2018, December 1). Transition towards sustainability in agriculture and food systems: Role of information and communication technologies. Information Processing in Agriculture. China Agricultural University. https://doi.org/10.1016/j.inpa.2018.06.006

Emeana, E. M., Trenchard, L., \& Dehnen-Schmutz, K. (2020). The Revolution of Mobile Phone-Enabled Services for Agricultural Development (m-Agri Services) in Africa: The Challenges for Sustainability. Sustainability, 12(2), 485. https://doi.org/10.3390/su12020485

Engler, A., Poortvliet, P. M., \& Klerkx, L. (2019). Toward understanding conservation behavior in agriculture as a dynamic and mutually responsive process between individuals and the social system. Journal of Soil and Water Conservation, 74(4), 74A-80A. https://doi.org/10.2489/jswc.74.4.74A

European Innovation Partnership for Agricultural Productivity and Sustainability. (2012). Code of conduct on agricultural data sharing by contractual agreement. EIP-AGRO.

European Parliament of the Council of European Union. (2016, April). Regulation (EU) 2016/679 . European Union.

Ezeomah, B., \& Duncombe, R. (2019). The role of digital platforms in disrupting agricultural value chains in developing countries. In IFIP Advances in Information and Communication Technology (Vol. 551, pp. 231-247). Springer New York LLC. https://doi.org/10.1007/978-3-030-18400-1_19

Fabregas, R., Kremer, M., \& Schilbach, F. (2019). Realizing the potential of digital development: The case of agricultural advice, 1-9. https://doi.org/10.1126/science.aay3038

FAO. (2017). The future of food and agriculture: Trends and challenges. Rome: FAO.

Fawole, O. P., \& Olajide, B. R. (2012). Awareness and use of information communication technologies by farmers in Oyo State, Nigeria. Journal of Agricultural \& Food Information, 13(4), 326-337.

Ferris, L., \& Rahman, Z. (2016). Responsible Data in Agriculture.

Fielke, S. J., Garrard, R., Jakku, E., Fleming, A., Wiseman, L., \& Taylor, B. M. (2019). Conceptualising the DAIS: Implications of the 'Digitalisation of Agricultural Innovation Systems' on technology and policy at multiple levels. NJAS - Wageningen Journal of Life Sciences.

https://doi.org/10.1016/j.njas.2019.04.002

Fielke, S. J., Taylor, B. M., Jakku, E., Mooij, M., Stitzlein, C., Fleming, A., ... Vilas, M. P. (2021). Grasping at digitalisation: turning imagination into fact in the sugarcane farming community. Sustainability Science, 16(2), 677-690. https://doi.org/10.1007/s11625-020-00885-9

Fielke, S., Taylor, B., \& Jakku, E. (2020). Digitalisation of agricultural knowledge and advice networks: A state-of-the-art review. Agricultural Systems. https://doi.org/10.1016/j.agsy.2019.102763

Fradera, R., Slawson, D., Gosling, L., Lakeman-Fraser, P Makuch, K., Makuch, Z., Madani, K., ... Haklay, M. (2015). Explorinig the nexus through citizen science (think piece series No. 10).

Franklin, M., Bodle, R., Hawtin, D., \& Moreira, M. (2019). The charter of human rights and principles for the 
internet.

Fraser, A. (2021). 'You can't eat data'?: Moving beyond the misconfigured innovations of smart farming. Journal of Rural Studies. https://doi.org/10.1016/j.jrurstud.2021.06.010

Frison, E., \& Sharrock, S. (1998). The economic, social and nutritional importance of banana in the world. In Bananas and food security. Proceedings of an international symposium held in Douala, Cameroon (p. 2135).

Frogdesign. (2012). Collective Action Toolkit.

Gatti, F., \& Visser, O. (2020, May). Digitalizing agriculture in Africa: promises and risks of an emerging trend . Retrieved June 13, 2021, from https://issblog.nl/2020/05/15/eadi-iss-series-digitalizing-agriculturein-africa-promises-and-risks-of-an-emerging-trend-by-fabio-gatti-and-oane-visser/

Generous, N., Fairchild, G., Deshpande, A., Del Valle, S. Y., \& Priedhorsky, R. (2014). Global Disease Monitoring and Forecasting with Wikipedia. PLoS Computational Biology, 10(11), e1003892. https://doi.org/10.1371/journal.pcbi.1003892

Gent, D. H., Mahaffee, W. F., McRoberts, N., \& Pfender, W. F. (2013). The Use and Role of Predictive Systems in Disease Management. In VanAlfen, NK (Ed.), ANNUAL REVIEW OF PHYTOPATHOLOGY, VOL 51 (Vol. 51, pp. 267-289). https://doi.org/10.1146/annurev-phyto-082712-102356

GIE. (2019). Global Development Innovation Landscape Q2 2019.

Gigler, B. S. (2011). Informational Capabilities:The Missing Link for the Impact of ICT on development (ETransform Knowledge Platform).

Giller, K. E., Tittonell, P., Rufino, M. C., Van Wijk, M. T., Zingore, S., Mapfumo, P., ... Corbeels, M. (2011). Communicating complexity: Integrated assessment of trade-offs concerning soil fertility management within African farming systems to support innovation and development. Agricultural Systems, 104(2), 191=203.

Glover, D., Sumberg, J., \& Andersson, J. A. (2016). The adoption problem; or why we still understand so little about technological change in African agriculture. Outlook on Agriculture, 45(1), 3-6. https://doi.org/10.5367/oa.2016.0235

Glover, D., Sumberg, J., Ton, G., Andersson, J., \& Badstue, L. (2019). Rethinking technological change in smallholder agriculture. Outlook on Agriculture, 48(3), 169-180. https://doi.org/10.1177/0030727019864978

Go FAIR Initiative. (2016). FAIR Principles. Retrieved February 5, 2021, from https://www.go-fair.org/fairprinciples/

GODAN. (2019). Vision and Strategic Plan for a Collective Action on Empowering Farmers through Equitable Data Sharing Vision.

Gomez, R. (2020). The failed promise of leCT for development: Aunt Ofelia replies to her letter 20 years later. The Electronic Journal of Information Systems in Developing Countries. https://doi.org/10.1002/isd2.12153

Gonsalves, J., Becker, T., Braun, A., Campilan, D., De Chavez, H., Fajber, E., ... Vernooy, R. (2005). Participatory Research and Development for Sustainable Agriculture and ... - Google Books. CIP, IDRC.

Google Developers. (n.d.). Building for Billions . Retrieved February 5, 2021, from https://developers.google.com/billions 


\section{References}

Goshalia, C., McDonogh, J., Mhlanga, P., \& Sewchurran, K. (2021). The Puppeteer behind the scenes: Toward understanding ecosystem leadership mechanisms to grow loT in South Africa. Electronic Journal of Information Systems in Developing Countries. https://doi.org/10.1002/isd2.12183

GovLab. (2020). Wanted: Data Stewards. (Re-)defining the roles and responsibilities of data stewards for an age of data collaboration.

Gras, C., \& Cáceres, D. M. (2020). Technology, nature's appropriation and capital accumulation in modern agriculture. Current Opinion in Environmental Sustainability, 45, 1-9.

https://doi.org/10.1016/j.cosust.2020.04.001

Green, S., Chandrasekharan, S., Schwegmann, C., Cohen, J., Sullivan, C., Raftree, L., ... Getachew, N. (2019). Considerations for Using Data Responsibly at USAID.

GSMA. (2019). Connected Women: The mobile Gender Gap Report 2019.

GSMA. (2020). Digital Agriculture Maps 2020: State of the Sector in Low and Middle-Income Countries.

GSMA, \& Frogdesign. (n.d.). mAgri Design Toolkit: User-centered design for mobile agriculture.

Hakizamungu, L., Rukundo, P., Muhigirwa, J. C., Mukamuhirwa, F., Umfuyisoni, J., Uzayisenga, B., \& Kalisa, J. P. (2020, December). Pest Management Decision Guide: Banana Xanthomonas Wilt (BXW). CABI Plantwise.

Hanson, K. T., Shaw, T. M., Puplampu, K. P., \& Arthur, P. (2020). Digital transformation: A connected and "disrupted" Africa. In International Political Economy Series (pp. 295-305). Palgrave Macmillan. https://doi.org/10.1007/978-3-030-40647-9_14

Hanson, W., \& Heeks, R. (2020). Impact of ICTs-in-Agriculture on Rural Resilience in Developing Countries (Development Informatics Working Paper Series No. 84). Manchester.

Hao, K. (2019, December 27). In 2020, let's stop Al ethics-washing and actually do something. MIT Technology Review.

Harari, Y. N. (2017). Dataism Is Our New God. New Perspectives Quarterly, 34(2), 36-43. https://doi.org/10.1111/NPQU.12080

Hartley, S., McLeod, C., Clifford, M., Jewitt, S., \& Ray, C. (2019). A retrospective analysis of responsible innovation for low-technology innovation in the Global South. Journal of Responsible Innovation, 6(2), 143-162. https://doi.org/10.1080/23299460.2019.1575682

Haworth, B., Biggs, E., Duncan, J., Wales, N., Boruff, B., \& Bruce, E. (2018). Geographic Information and Communication Technologies for Supporting Smallholder Agriculture and Climate Resilience. Climate, 6(4), 97. https://doi.org/10.3390/cli6040097

Hayes, N., Miscione, G., Silva, L., \& Westrup, C. (2013). Theorising development and technological change. Info Systems Journal, 23, 281-285. https://doi.org/10.1111/isj.12014

Heeks, R. (2009). The ICT4D 2.0 Manifesto: Where Next for ICTs and International Development? (Development Informatics Working Paper No. 42). Development Informatics Working Paper Manchester: Centre for Development Informatics; 2009. Working Paper No. 42. Manchester: Centre for Development Informatics.

Heeks, Richard. (2018). Information and communication technology for development (ICT4D) (1st ed.). Abingdon, New York: Routledge.

Heeks, Richard. (2020a). ICT4D 3.0? Part 1-The components of an emerging "digital-for-development" paradigm. The Electronic Journal of Information Systems in Developing Countries, 1-15. 
https://doi.org/10.1002/isd2.12124

Heeks, Richard. (2020b). ICT4D 3.0? Part 2-The patterns of an emerging "digital-for-development" paradigm. The Electronic Journal of Information Systems in Developing Countries. https://doi.org/10.1002/isd2.12123

Heeks, Richard, \& Shekhar, S. (2019). Datafication, development and marginalised urban communities: an applied data justice framework. Information, Communication \& Society, 22(7), 992-1011. https://doi.org/10.1080/1369118X.2019.1599039

Heiskanen, E., Hyysalo, S., Kotro, T., \& Repo, P. (2010). Constructing innovative users and user-inclusive innovation communities. Technology Analysis \& Strategic Management, 22(4), 495-511. https://doi.org/10.1080/09537321003714568

Hemphill, T. A. (2019). 'Techlash', responsible innovation, and the self-regulatory organization. Journal of Responsible Innovation, 6(2), 240-247. https://doi.org/10.1080/23299460.2019.1602817

Hermans, F., Stuiver, M., Beers, P. J., \& Kok, K. (2013). The distribution of roles and functions for upscaling and outscaling innovations in agricultural innovation systems. Agricultural Systems, 115, 117-128. https://doi.org/10.1016/j.agsy.2012.09.006

Hernández, S. M., Earle, C. B., \& Fredlund, L.-Å. (2020). A Methodology for Addressing the Second-Level Digital Divide. In Responsible Design, Implementation and Use of Information and Communication Technology (Vol. 12067 LNCS, pp. 331-337). Springer. https://doi.org/10.1007/978-3-030-45002-1_28

Higgins, V., \& Bryant, M. (2020). Framing Agri-Digital Governance: Industry Stakeholders, Technological Frames and Smart Farming Implementation. Sociologia Ruralis, 60(2), 438-457. https://doi.org/10.1111/soru.12297

Higgins, V., Bryant, M., Howell, A., \& Battersby, J. (2017). Ordering adoption: Materiality, knowledge and farmer engagement with precision agriculture technologies. Journal of Rural Studies, 55, 193-202. https://doi.org/10.1016/j.jrurstud.2017.08.011

Hinings, B., Gegenhuber, T., \& Greenwood, R. (2018). Digital innovation and transformation: An institutional perspective. Information and Organization, 28(1), 52-61.

https://doi.org/10.1016/j.infoandorg.2018.02.004

Holeman, I., \& Kane, D. (2020). Human-centered design for global health equity. Information Technology for Development, 26(3), 477-505. https://doi.org/10.1080/02681102.2019.1667289

Hussain, S. A. (2016). ICT4Agriculture lessons learned from developing countries. A systematic review protocol. In ACM International Conference Proceeding Series (Vol. 03-06-June, pp. 1-4). New York, New York, USA: Association for Computing Machinery. https://doi.org/10.1145/2909609.2909636

Hyysalo, S. (2012). Accumulation and Erosion of User Representations or How is Situated Design Interaction Situated. In Phenomenology, Organizational Politics, and ICT Design: The Social Study of Information Systems (pp. 196-220). IGI Global.

Hyysalo, S., \& Johnson, M. (2016). User Representation: A Journey Towards Conceptual Maturation. In S. Hyysalo, T. E. Jensen, \& N. Oudshoorn (Eds.), The New Production of Users: Changing innovation collectives and involvement strategies (first, pp. 75-100). New York: Routledge, Taylor \& Francis. https://doi.org/10.4324/9781315648088-3

lazzolino, G. (2021a, March 25). What about the crates? Rethinking digital farming in Kenya . Retrieved April 21, 2021, from https://blogs.lse.ac.uk/africaatlse/2021/03/25/what-about-crates-rethinking-digitalfarming-agriculture-agritech-kenya/ 


\section{References}

Iazzolino, G. (2021b, April 8). The digital advance into rural Kenya has a social cost for a new type of farmer. Retrieved April 21, 2021, from https://blogs.lse.ac.uk/africaatlse/2021/04/08/digital-advance-intorural-kenya-has-social-cost-new-type-farmer-entrepreneur/

Iazzolino, G., \& Mann, L. (2019, March 29). Harvesting data: Who benefits from platformization of agricultural finance in Kenya? - Developing Economics. Retrieved October 6, 2020, from https://developingeconomics.org/2019/03/29/harvesting-data-who-benefits-from-platformizationof-agricultural-finance-in-kenya/

IDEO.org. (2015). The Field Guide to Human-Centered Design.

Ingram, J., \& Maye, D. (2020). What Are the Implications of Digitalisation for Agricultural Knowledge? Frontiers in Sustainable Food Systems, 4, 66. https://doi.org/10.3389/fsufs.2020.00066

Irwin, A. (1995). Citizen science: A study of people, expertise and sustainable development. Routledge. https://doi.org/10.1177/017084069701800109

Iskander, N. (2018, September). Design Thinking is fundamentally conservative and preserves the status quo. Harvard Business Review.

Islam, M. S., \& Grönlund, A. (2011). Bangladesh calling: Farmers' technology use practices as a driver for development. Information Technology for Development, 17(2), 95-111. https://doi.org/10.1080/02681102.2010.526093

ISO. (2010). ISO 9241-210 Ergonomics of human-system interaction - Part 210: Human-centred design for interactive systems.

Jakku, E., Taylor, B., Fleming, A., Mason, C., Fielke, S., Sounness, C., \& Thorburn, P. (2019). "If they don't tell us what they do with it, why would we trust them?" Trust, transparency and benefit-sharing in Smart Farming. NJAS - Wageningen Journal of Life Sciences, 90-91.

https://doi.org/10.1016/j.njas.2018.11.002

Jalbert, K., \& Kinchy, A. J. (2016). Sense and Influence: Environmental Monitoring Tools and the Power of Citizen Science. Journal of Environmental Policy \& Planning, 18(3), 379-397. https://doi.org/10.1080/1523908X.2015.1100985

Jasanoff, S. (2002). New modernities: Reimagining science, technology and development. Environmental Values, 11(3), 253-276. https://doi.org/10.3197/096327102129341082

Jirotka, M., \& Carsten Stahl, B. (2020). The need for responsible technology. https://doi.org/10.1016/j.jt.2020.100002

Joffre, O. M., De Vries, J. R., Klerkx, L., \& Poortvliet, P. M. (2020). Why are cluster farmers adopting more aquaculture technologies and practices? The role of trust and interaction within shrimp farmers' networks in the Mekong Delta, Vietnam. Aquaculture, 523, 735181.

https://doi.org/10.1016/j.aquaculture.2020.735181

Jogo, W., Karamura, E., Tinzaara, W., Kubiriba, J., \& Rietveld, A. (2013). Determinants of Farm-Level Adoption of Cultural Practices for Banana Xanthomonas Wilt Control in Uganda. Journal of Agricultural Science, 5(7). https://doi.org/10.5539/jas.v5n7p70

John Clarkson, P., \& Coleman, R. (2015). History of inclusive design in the UK. Applied Ergonomics, 46(PB), 235-247. https://doi.org/10.1016/j.apergo.2013.03.002

Jones, D. R. (2018). Handbook of Diseases of Banana, Abacá and Enset (Second). Boston: CABI.

Kabunga, N. S., Dubois, T., \& Qaim, M. (2011). Information Asymmetries and Technology Adoption: The Case of Tissue Culture Bananas in Kenya. Courant Research Centre: Poverty, Equity and Growth - 
Discussion Papers.

Kamande, M., \& Nafula, N. (2016). The Welfare Effects of ICTs in Agricultural Markets: A Case of Selected Countries in East Africa (AGRODEP working paper series).

Karamura, E., Osiru, M., Blomme, G., Lusty, C., \& Picq, C. (2005). Developing a regional strategy to address the outbreak of banana Xanthomonas wilt in East and Central Africa. In Proceedings of the Banana Xanthomonas Wilt Regional Preparedness and Strategy Development Workshop (pp. 36-39). Kampala (Uganda): INIBAP, Montpellier.

Kenny, U., \& Regan, A. (2021). Co-designing a smartphone app for and with farmers: Empathising with endusers' values and needs. Journal of Rural Studies, 82, 148-160. https://doi.org/10.1016/j.jrurstud.2020.12.009

Kindred, D. (2015). Effective exchange between practice and research - using farmer networks to enable researchers to learn. In Association of Applied Biologists/Food and Energy Security conference, Knowledge exchange: from research to the food supply chain. Lancaster, U.K.: University of Lancaster.

King, A. (2017). Technology: The Future of Agriculture. Nature, 544(7651), S21-S23. https://doi.org/10.1038/544S21a

King, B., Fielke, S., Bayne, K., Klerkx, L., \& Nettle, R. (2019). Navigating shades of social capital and trust to leverage opportunities for rural innovation. Journal of Rural Studies, 68, 123-134. https://doi.org/10.1016/j.jrurstud.2019.02.003

Klapwijk, C. J., Bucagu, C., Wijk, M. T. Van, Udo, H. M. J., Vanlauwe, B., Munyanziza, E., \& Giller, K. E. (2014). The ' One cow per poor family ' programme: Current and potential fodder availability within smallholder farming systems in southwest Rwanda. Agricultural Systems, 131, 11-22. https://doi.org/10.1016/j.agsy.2014.07.005

Kleine, D. (2013). Technologies of Choice?: ICTs, Development, and the Capabilities Approach, (March 2012), 267. https://doi.org/10.1080/19452829.2013.875737

Klerkx, L. (2019). Social science on digitalization in agriculture-established and emerging strands of work and future avenues.

Klerkx, L., Jakku, E., \& Labarthe, P. (2019). A review of social science on digital agriculture, smart farming and agriculture 4.0: New contributions and a future research agenda. NJAS - Wageningen Journal of Life Sciences, 90-91, 100315. https://doi.org/10.1016/j.njas.2019.100315

Klerkx, L., \& Leeuwis, C. (2008). Institutionalizing end-user demand steering in agricultural R\&D: Farmer levy funding of R\&D in The Netherlands. Research Policy, 37(3), 460-472.

Klerkx, L., \& Leeuwis, C. (2009). Establishment and embedding of innovation brokers at different innovation system levels: Insights from the Dutch agricultural sector. Technological Forecasting and Social Change, 76(6), 849-860. https://doi.org/10.1016/j.techfore.2008.10.001

Klerkx, L., \& Rose, D. (2020). Dealing with the game-changing technologies of Agriculture 4.0: How do we manage diversity and responsibility in food system transition pathways? Global Food Security, 24(December 2019), 100347. https://doi.org/10.1016/j.gfs.2019.100347

Klerkx, L., Seuneke, P., de Wolf, P., \& Rossing, W. A. H. (2017). Replication and translation of co-innovation: The influence of institutional context in large international participatory research projects. Land Use Policy, 61, 276-292. https://doi.org/10.1016/j.landusepol.2016.11.027

Kobos, P. H., Malczynski, L. A., Walker, L. T. N., Borns, D. J., \& Klise, G. T. (2018). Timing is everything: A 


\section{References}

technology transition framework for regulatory and market readiness levels. Technological Forecasting and Social Change, 137, 211-225.

https://doi.org/https://doi.org/10.1016/j.techfore.2018.07.052

Kock, N. (2004). The three threats of action research: A discussion of methodological antidotes in the context of an information systems study. Decision Support Systems, 37(2), 265-286. https://doi.org/10.1016/S0167-9236(03)00022-8

Krauss, K. E. M. (2021). Demonstrating critically reflexive ICT4D project conduct in rural South Africa. Information Technology for Development, 1-28. https://doi.org/10.1080/02681102.2021.1928588

Krell, N. T., Giroux, S. A., Guido, Z., Hannah, C., Lopus, S. E., Caylor, K. K., \& Evans, T. P. (2020). Smallholder farmers' use of mobile phone services in central Kenya. Climate and Development, 1-13. https://doi.org/10.1080/17565529.2020.1748847

Kubiriba, J., Karamura, E. B., Jogo, W., Tushemereirwe, W. K., \& Tinzaara, W. (2012). Community mobilization: A key to effective control of banana xanthomonas wilt. Journal of Development and Agricultural Economics, 4(5), 125-131. https://doi.org/10.5897/JDAE11.098

Kuner, C., \& Massimo, M. (2020). Handbook on data protection in humanitarian action.

Kyobe, M. (2011). Investigating the key factors influencing ICT adoption in South Africa. Journal of Systems and Information Technology, 13(3), 255-267. https://doi.org/10.1108/13287261111164844

Lafond, A., \& Davis, N. (2016). The Use of Design Thinking in MNCH Programs: A Case Study of the Care Community Hub (CCH) Pilot, Ghana. Arlington.

Lajoie-O'Malley, A., Bronson, K., van der Burg, S., \& Klerkx, L. (2020). The future(s) of digital agriculture and sustainable food systems: An analysis of high-level policy documents. Ecosystem Services, 45, 101183. https://doi.org/10.1016/j.ecoser.2020.101183

Lanchester, J. (2017, August 17). John Lanchester · You Are the Product. London Review of Books.

Laufer, W. S. (2003). Social Accountability and Corporate Greenwashing. Journal of Business Ethics, 43(3), 253-261. https://doi.org/10.1023/A:1022962719299

Leeuwis, C. (1993). Of computers, myths and modelling : the social construction of diversity, knowledge, information, and communication technologies in Dutch horticulture and agricultural extension.

Leeuwis, Cees, \& Aarts, N. (2020). Rethinking Adoption and Diffusion as a Collective Social Process: Towards an Interactional Perspective BT - The Innovation Revolution in Agriculture: A Roadmap to Value Creation. In H. Campos (Ed.), The Innovation Revolution in Agriculture (pp. 95-116). Cham: Springer International Publishing. https://doi.org/10.1007/978-3-030-50991-0_4

Leeuwis, Cees, Cieslik, K. J., Aarts, M. N. C., Dewulf, A. R. P. J., Ludwig, F., Werners, S. E., \& Struik, P. C. (2018). Reflections on the potential of virtual citizen science platforms to address collective action challenges: Lessons and implications for future research. NJAS - Wageningen Journal of Life Sciences, 86-87(1. Leeuwis C, Cieslik KJ, Aarts MNC, Dewulf ARPJ, Ludwig F, Werners SE, et al. Reflections on the potential of virtual citizen science platforms to address collective action challenges: Lessons and implications for future research. NJAS-Wageningen J Lif), 146-157. https://doi.org/10.1016/j.njas.2018.07.008

Leeuwis, Cees, Klerkx, L., \& Schut, M. (2018). Reforming the research policy and impact culture in the CGIAR: Integrating science and systemic capacity development. Global Food Security, 16, 17-21. https://doi.org/http://dx.doi.org/10.1016/j.gfs.2017.06.002

Leeuwis, Cees, \& van den Ban, A. W. (2004a). Communication for rural innovation : rethinking agricultural 
extension. (A. W. van den Ban, Ed.) (3rd ed.). Oxford: Blackwell Science.

Leeuwis, Cees, \& van den Ban, A. W. (2004b). Knowledge and perception. In A. W. van den Ban (Ed.), Communication for Rural Innovation: Rethinking Agricultural Extension (3rd ed., pp. 94-116). Oxford: Blackwell Science.

Loh, Y. A. C. (2015). Approaches to ICT for development (ICT4D): vulnerabilities vs. capabilities. Information Development, 31(3), 229-238. https://doi.org/10.1177/0266666913513198

Lund, M. (2001). Measuring usability with the USE questionnaire. Usability Interface, 8(2), 3-6.

Lwoga, E. T., \& Sangeda, R. Z. (2019). ICTs and development in developing countries: A systematic review of reviews. The Electronic Journal of Information Systems in Developing Countries, 85(1). https://doi.org/10.1002/isd2.12060

Macagnano, V., \& Greeff, M. (2007). Universal Design for $\mathrm{HCl}$ in a developmental context: myth or reality? The South African example. In HCl International 2007 (p. 6). Bejing, China.

MacFeely, S. (2019). The Big (data) Bang: Opportunities and Challenges for Compiling SDG Indicators. Global Policy, 10(S1), 121-133. https://doi.org/10.1111/1758-5899.12595

Macken-Walsh, Á. (2019). Multi-actor co-design of extension interventions: paradoxes arising in three cases in the Republic of Ireland. The Journal of Agricultural Education and Extension, 25(3), 245-265. https://doi.org/10.1080/1389224X.2019.1604390

Malabo Montpellier Panel. (2019). BYTE BY BYTE Policy Innovation for Transforming Africa's Food System with Digital Technologies .

Mankins, J. C. (2009). Technology readiness assessments: A retrospective. Acta Astronautica, 65, 1216-1223.

Mann, L. (2018). Left to Other Peoples' Devices? A Political Economy Perspective on the Big Data Revolution in Development. Development and Change, 49(1), 3-36. https://doi.org/10.1111/dech.12347

Mann, L., \& lazzolino, G. (2019). See, Nudge, Control and Profit: Digital Platforms as Privatized Epistemic Infrastructures.

Markham, R. (2009). Managing diseases and pests of banana: The way ahead? Acta Horticulturae, 828, 417427.

McCampbell, M., Schut, M., Van den Bergh, I., van Schagen, B., Vanlauwe, B., Blomme, G., ... Leeuwis, C. (2018). Xanthomonas Wilt of Banana (BXW) in Central Africa: Opportunities, challenges, and pathways for citizen science and ICT-based control and prevention strategies. NJAS - Wageningen Journal of Life Sciences, 86-87, 89-100. https://doi.org/10.1016/j.njas.2018.03.002

Mehrabi, Z., McDowell, M. J., Ricciardi, V., Levers, C., Martinez, J. D., Mehrabi, N., ... Jarvis, A. (2020). The global divide in data-driven farming. Nature Sustainability. https://doi.org/10.1038/s41893-02000631-0

Meijer, S. S., Catacutan, D., Ajayi, O. C., Sileshi, G. W., \& Nieuwenhuis, M. (2015). The role of knowledge, attitudes and perceptions in the uptake of agricultural and agroforestry innovations among smallholder farmers in sub-Saharan Africa. International Journal of Agricultural Sustainability, 13(1), 40-54. https://doi.org/10.1080/14735903.2014.912493

Michels, M., Bonke, V., \& Musshoff, O. (2019). Understanding the adoption of crop protection smartphone apps - An application of the Unified Theory of Acceptance and Use of Technology (No. 1905). Gottingen.

Michels, M., Fecke, W., Feil, J. H., Musshoff, O., Pigisch, J., \& Krone, S. (2020). Smartphone adoption and use 


\section{References}

in agriculture: empirical evidence from Germany. Precision Agriculture, 21(2), 403-425. https://doi.org/10.1007/s11119-019-09675-5

Michie, S, Atkins, L., \& West, R. (2014). The behaviour change wheel: A guide to designing interventions. London: Silverback Publishing.

Michie, Susan, van Stralen, M., \& West, R. (2011). The behaviour change wheel: A new method for characterising and designing behaviour change interventions. Implementation Science, 6(1), 42. https://doi.org/10.1186/1748-5908-6-42

Milan, S. (2020, October 20). Techno-solutionism and the standard human in the making of the COVID-19 pandemic. Big Data and Society. SAGE Publications Ltd. https://doi.org/10.1177/2053951720966781

Mills, J., Gaskell, P., Ingram, J., Dwyer, J., Reed, M., \& Short, C. (2017). Engaging farmers in environmental management through a better understanding of behaviour. Agriculture and Human Values, 34(2), 283-299. https://doi.org/10.1007/s10460-016-9705-4

MINAGRI. (2016). National ICT4RAg Strategy (2016-2020). Kigali.

MINECOFIN. (2013). Rwanda Vision 2020; revised 2012. Retrieved May 21, 2015, from http://www.minecofin.gov.rw/fileadmin/templates/documents/NDPR/Vision_2020_.pdf

MINECOFIN. (2020). Vision 2050. Kigali.

Minh, T. T., Friederichsen, R., Neef, A., \& Hoffmann, V. (2014). Niche action and system harmonization for institutional change: Prospects for demand-driven agricultural extension in Vietnam. Journal of Rural Studies, 36, 273-284. https://doi.org/10.1016/j.jrurstud.2014.09.008

MINICT. (2019). ICT Hub Strategy 2024: rwanda's roadmap to becoming a leading ICT Hub in Africa. Kigali.

Misaki, E., Apiola, M., Gaiani, S., \& Tedre, M. (2018). Challenges facing sub-Saharan small-scale farmers in accessing farming information through mobile phones: A systematic literature review. The Electronic Journal of Information Systems in Developing Countries, 84(4). https://doi.org/10.1002/isd2.12034

Morozov, E. (2013). To save everything, click here: The folly of technological solutionism. Public Affairs.

Mramba, N., Rumanyika, J., Apiola, M., \& Suhonen, J. (2017). ICT for Informal Workers in Sub-Saharan Africa: Systematic Review and Analysis.

Mrisho, L., Mbilinyi, N., Ndalahwa, M., Ramcharan, A., Kehs, A., McCloskey, P., ... Legg, J. (2020). Evaluation of the accuracy of a smartphone-based artificial intelligence system, PlantVillage Nuru, in diagnosing of the viral diseases of cassava. BioRxiv, 2020.01.26.919449. https://doi.org/10.1101/2020.01.26.919449

Mulozi, D. (2008). Telecentres: knowledge sharing in rural Africa. Rural 21, 42(6), 23-25.

Munthali, N, van Paassen, A., Lie, R., Leeuwis, C., \& van Lammeren, R. (2021). Ghanaian farmers' choice of inofrmation sources and use of mobile technology in managing a new pest - fall armyworm. In Innovation intermediation in a digital age: broadening extension service delivery in Ghana. Wageningen University.

Munthali, Nyamwaya. (2021). Innovation intermediation in a digital age: broadening extension service delivery in Ghana. Wageningen University.

Munthali, Nyamwaya, Leeuwis, C., van Paassen, A., Lie, R., Asare, R., van Lammeren, R., \& Schut, M. (2018). Innovation intermediation in a digital age: Comparing public and private new-ICT platforms for agricultural extension in Ghana. NJAS - Wageningen Journal of Life Sciences, 86-87, 64-76. https://doi.org/10.1016/j.njas.2018.05.001 
Murray, P. (2000). Evaluating participatory extension programs: challenges and problems. Australian Journal of Experimental Agriculture, 40, 519-526. https://doi.org/10.1071/EA99079

Mutchler, L. A., Shim, J. P., \& Ormond, D. (2011). Exploratory Study on Users' Behavior: Smartphone Usage. In AMCIS 2011 Proceedings. Detroit, Michigan.

Mwangi, M., \& Nakato, V. (2009). Key factors responsible for the xanthomonas wilt epidemic on banana in East and Central Africa. Acta Horticulturae, 828, 395-404.

https://doi.org/10.17660/ActaHortic.2009.828.41

Mwombe, S. O. L. . b, Mugivane, F. I. ., Adolwa, I. S. ., \& Nderitu, J. H. . (2014). Evaluation of Information and Communication Technology Utilization by Small Holder Banana Farmers in Gatanga District, Kenya. Journal of Agricultural Education and Extension, 20(2), 247-261. https://doi.org/10.1080/1389224X.2013.788454

Nagendra, H., \& Ostrom, E. (2012). Polycentric governance of multifunctional forested landscapes. The Commons Journal.

Nakasone, E, Torero, M., \& Minten, B. (2014). The power of information: The ICT revolution in agricultural development. Annual Review of Resource Economics, 6(1), 533-550. https://doi.org/10.1146/annurevresource-100913-012714

Nakasone, E., Torero, M. (2016). A text message away: ICTs as a tool to improve food security. Agricultural Economics (United Kingdom), 47, 49-59. https://doi.org/10.1111/agec.12314

Nakato, G. V., Beed, F., Bouwmeester, H., Ramathani, I., Mpiira, S., Kubiriba, J., \& Nanavati, S. (2016). Building agricultural networks of farmers and scientists via mobile phones: case study of banana disease surveillance in Uganda. Canadian Journal of Plant Pathology, 38(3), 307-316. https://doi.org/10.1080/07060661.2016.1230149

Namyenya, A., Daum, T., Rwamigisa, P. B., \& Birner, R. (2021). E-diary: a digital tool for strengthening accountability in agricultural extension . Information Technology for Development, 1-27. https://doi.org/10.1080/02681102.2021.1875186

Ndayihanzamaso, P., Niko, N., Niyongere, C., Bizimana, S., Nibasumba, A., Lepoint, P., ... Karamura, E. (2016). Distribution, incidence and farmers knowledge of banana Xanthomonas wilt in Burundi. African Journal of Agricultural Research, 11(38), 3615-3621. https://doi.org/10.5897/AJAR2016.11210

Nelson, C. (2010). Don't mourn, organize. Journal of International Development, 22, 674-692. https://doi.org/10.1002/jid.1719

Nelson, R., Coe, R., \& Haussmann, B. I. G. (2016). Farmer Research Networks As a Strategy for Matching Diverse Options and Contexts in Smallholder Agriculture. Experimental Agriculture, 1-20. https://doi.org/10.1017/S0014479716000454

Niko, N., Ndayihanzamaso, P., \& Lepoint, P. (2011). First report of Banana Xanthomonas Wilt (Xanthomonas campestris pv. musacearum) in Burundi. Bujumbura. Burundi.

Nižetić, S., Šolić, P., López-de-Ipiña González-de-Artaza, D., \& Patrono, L. (2020). Internet of Things (IoT): Opportunities, issues and challenges towards a smart and sustainable future. Journal of Cleaner Production, 274, 122877. https://doi.org/10.1016/j.jclepro.2020.122877

Nkuba, J., Tinzaara, W., Night, G., Niko, N., Jogo, W., Ndyetabula, I., ... Karamura, E. (2015). Adverse impact of Banana Xanthomonas Wilt on farmers' livelihoods in Eastern and Central Africa. African Journal of Plant Science, 9(7), 279-286. https://doi.org/10.5897/AJPS2015.1292

Nunes, A., Limpo, T., \& Castro, S. L. (2019). Acceptance of Mobile Health Applications: Examining Key 


\section{References}

Determinants and Moderators. Frontiers in Psychology, 10. https://doi.org/10.3389/fpsyg.2019.02791

Nyaga, J. M., Onyango, C. M., Wetterlind, J., \& Söderström, M. (2021). Precision agriculture research in subSaharan Africa countries: a systematic map. Precision Agriculture, 1-20. https://doi.org/10.1007/s11119-020-09780-w

Ocimati, W., Nakato, G. V., Fiaboe, K. M., Beed, F., \& Blomme, G. (2015). Incomplete systemic movement of Xanthomonas campestris pv. musacearum and the occurrence of latent infections in xanthomonas wilt-infected banana mats. Plant Pathology, 64(1), 81-90. https://doi.org/10.1111/ppa.12233

Ocimati, W., Ssekiwoko, F., Karamura, E., Tinzaara, W., Eden-Green, S., \& Blomme, G. (2013). Systemicity of Xanthomonas campestris pv. musacearum and time to disease expression after inflorescence infection in East African highland and Pisang Awak bananas in Uganda. Plant Pathology, 62(4), 777785. https://doi.org/10.1111/j.1365-3059.2012.02697.x

Okeke, M., Nwalieji, H., \& Uzuegbunam, C. (2015). Emerging Role of Information Communication Technologies in Extension Service Delivery in Nigeria: A Review | Journal of Agricultural Extension. Journal of Agricultural Extension, 19(1).

Okello, J. J., Kirui, O., Njiraini, G. W., \& Gitonga, Z. M. (2012). Drivers of use of information and communication technologies by farm households: the case of smallholder farmers in Kenya. Journal of Agricultural Science (Toronto), 4(2), 111-124.

Olson, M. (1965). Logic of Collective Action: Public Goods and the Theory of Groups (Harvard economic studies v. 124). Harvard University Press.

Onyango, C. M., Nyaga, J. M., Wetterlind, J., Söderström, M., \& Piikki, K. (2021, February 1). Precision agriculture for resource use efficiency in smallholder farming systems in sub-saharan africa: A systematic review. Sustainability (Switzerland). MDPI AG. https://doi.org/10.3390/su13031158

Ortiz-Crespo, B., Steinke, J., Quirós, C. F., van de Gevel, J., Daudi, H., Gaspar Mgimiloko, M., \& van Etten, J. (2020). User-centred design of a digital advisory service: enhancing public agricultural extension for sustainable intensification in Tanzania. International Journal of Agricultural Sustainability, 1-17. https://doi.org/10.1080/14735903.2020.1720474

Ostrom, E. (2000). Collective Action and the Evolution of Social Norms. Journal of Economic Perspectives, 14(3), 137-158.

Oxfam. (2015). Responsible Program Data Policy.

Park, S., \& Humphry, J. (2019). Exclusion by design: intersections of social, digital and data exclusion. Information Communication and Society, 22(7), 934-953. https://doi.org/10.1080/1369118X.2019.1606266

Parra-López, C., Reina-Usuga, L., Carmona-Torres, C., Sayadi, S., \& Klerkx, L. (2021). Digital transformation of the agrifood system: Quantifying the conditioning factors to inform policy planning in the olive sector. Land Use Policy, 108, 105537. https://doi.org/10.1016/j.landusepol.2021.105537

Phillipson, J., Lowe, P., Proctor, A., \& Ruto, E. (2012). Stakeholder engagement and knowledge exchange in environmental research. Journal of Environmental Management, 95(1), 56-65. https://doi.org/10.1016/j.jenvman.2011.10.005

Pigford, A. A. E., Hickey, G. M., \& Klerkx, L. (2018). Beyond agricultural innovation systems? Exploring an agricultural innovation ecosystems approach for niche design and development in sustainability transitions. Agricultural Systems, 164, 116-121. https://doi.org/10.1016/j.agsy.2018.04.007

Porciello, J., Coggins, S., Otunba-Payne, G., \& Mabaya, E. (2021a). A Systematic Scoping Review: How are 
farmers using digital services in low- and middle-incom countries?

Porciello, J., Coggins, S., Otunba-Payne, G., \& Mabaya, E. (2021b). Key messages and findings: How are farmers using digital services in low- and middle-income countries?

Poteete, A. R., Janssen, M., \& Ostrom, E. (2010). Working together: collective action, the commons, and multiple methods in practice. Princeton University Press.

Poulton, C., Dorward, A., \& Kydd, J. (2010). The Future of Small Farms: New Directions for Services, Institutions, and Intermediation. World Development, 38(10), 1413-1428.

https://doi.org/10.1016/j.worlddev.2009.06.009

Powell, A. (2017). CABI's innovative use of technology, data, and knowledge transfer to reduce crop losses in the developing world. Food and Energy Security, 6(3), 94-97. https://doi.org/10.1002/fes3.113

Privacy International. (2020, March 3). 2020 is a crucial year to fight for data protection in Africa. Retrieved May 24, 2021, from https://privacyinternational.org/long-read/3390/2020-crucial-year-fight-dataprotection-africa

Qiang, C. Z., Kuek, S. C., Dymond, A., \& Esselaar, S. (2011). Mobile Applications for Agriculture and Rural Development. World Bank, (May), 120.

https://doi.org/http://siteresources.worldbank.org/INFORMATIONANDCOMMUNICATIONANDTECH NOLOGIES/Resources/MobileApplications_for_ARD.pdf

Qureshi, S. (2020). Why Data Matters for Development? Exploring Data Justice, Micro-Entrepreneurship, Mobile Money and Financial Inclusion. Information Technology for Development, 26(2), 201-213. https://doi.org/10.1080/02681102.2020.1736820

Reardon, T., Echeverria, R., Berdegué, J., Minten, B., Liverpool-Tasie, S., Tschirley, D., \& Zilberman, D. (2019). Rapid transformation of food systems in developing regions: Highlighting the role of agricultural research \& innovations. Agricultural Systems, 172, 47-59. https://doi.org/10.1016/j.agsy.2018.01.022

Reeder, R. H., Muhinyuza, J. B., Opolot, O., Aritua, V., Crozier, J., \& Smith, J. (2007). Presence of banana bacterial wilt (Xanthomonas campestris pv. musacearum) in Rwanda. Plant Pathology, 56(6), 1038. https://doi.org/10.1111/j.1365-3059.2007.01640.x

Regan, Á. (2019). 'Smart farming' in Ireland: A risk perception study with key governance actors. NJAS Wageningen Journal of Life Sciences. https://doi.org/10.1016/j.njas.2019.02.003

Reis, J., Amorim, M., Melão, N., Cohen, Y., \& Rodrigues, M. (2020). Digitalization: A Literature Review and Research Agenda (pp. 443-456). Springer, Cham. https://doi.org/10.1007/978-3-030-43616-2_47

Ridder, H. G. (2017). The theory contribution of case study research designs. Business Research, 10(2), 281305. https://doi.org/10.1007/s40685-017-0045-z

Rijswijk, K., Klerkx, L., Bacco, M., Bartolini, F., Bulten, E., Debruyne, L., ... Brunori, G. (2021). Digital transformation of agriculture and rural areas: A socio-cyber-physical system framework to support responsibilisation. Journal of Rural Studies. https://doi.org/10.1016/j.jrurstud.2021.05.003

Rijswijk, K., Klerkx, L., \& Turner, J. A. (2019). Digitalisation in the New Zealand Agricultural Knowledge and Innovation System: Initial understandings and emerging organisational responses to digital agriculture. NJAS - Wageningen Journal of Life Sciences, 90-91, 100313. https://doi.org/10.1016/j.njas.2019.100313

Rikap, C., \& Lundvall, B.-Å. (2020). Big tech, knowledge predation and the implications for development. Innovation and Development, 1-28. https://doi.org/10.1080/2157930X.2020.1855825

Roberts, T., \& Hernandez, K. (2019). Digital Access is not Binary: The 5'A's of Technology Access in the 


\section{References}

Philippines. The Electronic Journal of Information Systems in Developing Countries. https://doi.org/10.1002/isd2.12084

Roeser, S. (2012). Emotional Engineers: Toward Morally Responsible Design. Science and Engineering Ethics, 18(1), 103-115. https://doi.org/10.1007/s11948-010-9236-0

Rose, David C, Parker, C., Fodey, J., Park, C., Sutherland, W. J., \& Dicks, L. V. (2018). Involving stakeholders in agricultural decision support systems: Improving user-centred design. International Journal of Agricultural Management, 6, 80-89. https://doi.org/10.5836/ijam/2017-06-80

Rose, David Christian, \& Chilvers, J. (2018). Agriculture 4.0: Broadening Responsible Innovation in an Era of Smart Farming. Frontiers in Sustainable Food Systems, 2, 87. https://doi.org/10.3389/fsufs.2018.00087

Rose, David Christian, Wheeler, R., Winter, M., Lobley, M., \& Chivers, C. A. (2021). Agriculture 4.0: Making it work for people, production, and the planet. Land Use Policy, 100, 104933. https://doi.org/10.1016/j.landusepol.2020.104933

Rotz, S., Duncan, E., Small, M., Botschner, J., Dara, R., Mosby, I., ... Fraser, E. D. G. (2019). The Politics of Digital Agricultural Technologies: A Preliminary Review. Sociologia Ruralis, 59(2). https://doi.org/10.1111/soru.12233

Royakkers, L., Timmer, J., Kool, L., \& van Est, R. (2018). Societal and ethical issues of digitization. Ethics and Information Technology, 20(2). https://doi.org/10.1007/s10676-018-9452-x

Rumanyika, J., Apiola, M., Mramba, N. R., Oyelere, S. S., \& Tedre, M. (2021). Mobile technology for street trading in Tanzania: A design science research approach for determining user requirements. Electronic Journal of Information Systems in Developing Countries. https://doi.org/10.1002/isd2.12176

Salemink, K., Strijker, D., \& Bosworth, G. (2017). Rural development in the digital age: A systematic literature review on unequal ICT availability, adoption, and use in rural areas. Journal of Rural Studies, 54, 360371. https://doi.org/10.1016/j.jrurstud.2015.09.001

Sanders, E., \& Stappers, P. J. (2008). Co-creation and the new landscapes of design. Co-Design, 4(1), 5-18. https://doi.org/10.1080/15710880701875068

Sanderson, J., Wiseman, L., \& Poncini, S. (2018). What's behind the ag-data logo? An examination of voluntary agricultural-data codes of practice. International Journal of Rural Law and Policy, (1). https://doi.org/10.5130/ijrlp.1.2018.6043

Sanyang, S., Taonda, S. J.-B., Kuiseu, J., Coulibaly, N., \& Konaté, L. (2015). A paradigm shift in African agricultural research for development: the role of innovation platforms. International Journal of Agricultural Sustainability, 5903(October), 1-27. https://doi.org/10.1080/14735903.2015.1070065

Sara, R. (2019). Guidelines for Managing PII in the Research Project Data Lifecycle. CGIAR Platform for Big Data in Agriculture.

Sarku, R. (2021). Making weather information services usable to support adaptive decision-making in farming in Ghana. Wageningen University, Wageningen.

Sartas, M., Schut, M., Proietti, C., Thiele, G., \& Leeuwis, C. (2020). Scaling Readiness : Science and practice of an approach to enhance impact of research for development. Agricultural Systems, 183(May), 102874. https://doi.org/10.1016/j.agsy.2020.102874

Scheerder, A., van Deursen, A., \& van Dijk, J. (2017). Determinants of Internet skills, uses and outcomes. A systematic review of the second- and third-level digital divide. Telematics and Informatics, 34(8), 
1607-1624. https://doi.org/10.1016/j.tele.2017.07.007

Schimpf, M., \& Diamond, E. (2020). Digital Farming: Can digital farming really address the systemic causes of agriculture's impact on the environment and society, or will it entrench them? . Brussels.

Scholz, R. W., Bartelsman, E. J., Diefenbach, S., Franke, L., Grunwald, A., Helbing, D., ... Pereira, G. V. (2018). Unintended side effects of the digital transition: European scientists' messages from a propositionbased expert round table. Sustainability (Switzerland), 10(6), 2001.

https://doi.org/10.3390/su10062001

Schopp, K., Schelenz, L., Heesen, J., \& Pawelec, M. (2019). Ethical questions of digitalization in the Global South. TATuP Zeitschrift Für Technikfolgenabschätzung in Theorie Und Praxis, 28(2), 11-16. https://doi.org/10.14512/tatup.28.2.s11

Schut, M., Klerkx, L., Rodenburg, J., Kayeke, J., Hinnou, L. C., Raboanarielina, C. M., ... Bastiaans, L. (2014). RAAIS: Rapid Appraisal of Agricultural Innovation Systems (Part I). A diagnostic tool for integrated analysis of complex problems and innovation capacity. Agricultural Systems, 132, 1-11. https://doi.org/10.1016/j.agsy.2014.08.009

Schut, M., Leeuwis, C., \& Thiele, G. (2020). Science of Scaling: Understanding and guiding the scaling of innovation for societal outcomes. Agricultural Systems, 184(August), 102908.

https://doi.org/10.1016/j.agsy.2020.102908

Schut, M., Rodenburg, J., Klerkx, L., van Ast, A., \& Bastiaans, L. (2014). Systems approaches to innovation in crop protection. A systematic literature review. Crop Protection, 56, 98-108. https://doi.org/10.1016/j.cropro.2013.11.017

Schut, M., van Paassen, A., Leeuwis, C., \& Klerkx, L. (2014). Towards dynamic research configurations : A framework for reflection on the contribution of research to policy and innovation processes. Science and Public Policy, 41(August 2013), 207-218. https://doi.org/10.1093/scipol/sct048

Shimwela, M. M., Ploetz, R. C., Beed, F. D., Jones, J. B., Blackburn, J. K., Mkulila, S. I., \& van Bruggen, A. H. C. (2016). Banana xanthomonas wilt continues to spread in Tanzania despite an intensive symptomatic plant removal campaign: an impending socio-economic and ecological disaster. Food Security, 8(5), 939-951. https://doi.org/10.1007/s12571-016-0609-3

Skog, D. A., Wimelius, H., \& Sandberg, J. (2018). Digital Disruption. Business and Information Systems Engineering, 60(5), 431-437. https://doi.org/10.1007/s12599-018-0550-4

Skrimizea, E., Lecuyer, L., Bunnefeld, N., Butler, J. R. A., Fickel, T., Hodgson, I., ... Young, J. C. (2020). Sustainable agriculture: Recognizing the potential of conflict as a positive driver for transformative change. In Advances in Ecological Research (Vol. 63, pp. 255-311). Academic Press Inc. https://doi.org/10.1016/bs.aecr.2020.08.003

Sonnemans, J., Schram, A., \& Offerman, T. (1998). Public good provision and public bad prevention: The effect of framing. Journal of Economic Behavior and Organization, 34(1), 143-161. https://doi.org/10.1016/S0167-2681(97)00042-5

Spielman, D. J., Ekboir, J., Davis, K., \& Ochieng, C. M. O. (2008). An innovation systems perspective on strengthening agricultural education and training in sub-Saharan Africa. Agricultural Systems, 98(1), 1-9. https://doi.org/10.1016/j.agsy.2008.03.004

Steen, M. (2011). Tensions in human-centred design. CoDesign, 7(1), 45-60. https://doi.org/10.1080/15710882.2011.563314

Steen, M. (2012). Human-centered design as a fragile encounter. Design Issues, 28(1), $72-80$. https://doi.org/10.1162/DESI_a_00125 


\section{References}

Steinke, J., van Etten, J., Müller, A., Ortiz-Crespo, B., van de Gevel, J., Silvestri, S., \& Priebe, J. (2020). Tapping the full potential of the digital revolution for agricultural extension: an emerging innovation agenda. International Journal of Agricultural Sustainability, 1-17. https://doi.org/10.1080/14735903.2020.1738754

Stilgoe, J., Owen, R., \& Macnaghten, P. (2013). Developing a framework for responsible innovation. Research Policy, 42, 1568-1580. https://doi.org/http://dx.doi.org/10.1016/j.respol.2013.05.008

Studholme, D. J., Wicker, E., Abrare, S. M., Aspin, A., Bogdanove, A., Broders, K., ... Bull, C. T. (2020). Transfer of Xanthomonas campestris pv. arecae and X. campestris pv. musacearum to X. vasicola (Vauterin) as $X$. vasicola pv. arecae comb. nov. And X. vasicola pv. musacearum comb. nov. And description of X. vasicola pv. vasculorum pv. nov. Phytopathology, 110(6), 1153-1160. https://doi.org/10.1094/PHYTO-03-19-0098-LE

Sulaiman V, R., Hall, A., Kalaivani, N. J., Dorai, K., \& Reddy, T. S. V. (2012). Necessary, But Not Sufficient: Critiquing the Role of Information and Communication Technology in Putting Knowledge into Use. The Journal of Agricultural Education and Extension, 18(4), 331-346. https://doi.org/10.1080/1389224X.2012.691782

Swanson, B. E. (2008). Global Review of Good Agricultural Extension and Advisory Service Practices. Rome.

Tabesh, P., Mousavidin, E., \& Hasani, S. (2019). Implementing big data strategies: A managerial perspective. Business Horizons, 62(3), 347-358. https://doi.org/10.1016/j.bushor.2019.02.001

Tafesse, S., van Mierlo, B., Leeuwis, C., Lie, R., Lemaga, B., \& Struik, P. C. (2020). Combining experiential and social learning approaches for crop disease management in a smallholder context: a complex socioecological problem. Socio-Ecological Practice Research, 2(3), 265-282. https://doi.org/10.1007/s42532-020-00058-z

Taylor, L. (2021). Public Actors Without Public Values: Legitimacy, Domination and the Regulation of the Technology Sector. Philosophy and Technology. https://doi.org/10.1007/s13347-020-00441-4

Thapa, D., \& Hatakka, M. Understanding ICT in ICT4D: An Affordance Perspective, Proceedings of the 50th Hawaii International Conference on System Sciences (2017) § (2017). Hawaii International Conference on System Sciences. https://doi.org/10.24251/hicss.2017.316

Thapa, D., Sein, M. K., \& Sæbø, Ø. (2012). Building collective capabilities through ICT in a mountain region of Nepal: where social capital leads to collective action. Information Technology for Development, 18(1), 5-22. https://doi.org/10.1080/02681102.2011.643205

Tinzaara, W., Karamura, E. B., Kubiriba, J., Ochola, D., Ocimati, W., Blomme, G., \& Ssekiwoko, F. (2016). The banana Xanthomonas wilt epidemic in east and central Africa: Current research and development efforts. Acta Horticulturae, 1114, 267-274. https://doi.org/10.17660/ActaHortic.2016.1114.36

Tinzaara, W., Karamura, E., \& Kubiriba, J. (2014). The banana Xanthomonas wilt epidemic in east and central Africa: current research and development efforts. In 1114 International Horticultural Congress on Horticulture: Sustaining Lives, Livelihoods and Landscapes (IHC2014) (pp. 267-274).

Trendov, N. M., Varas, S., \& Zeng, M. (2019). Digital technologies in agriculture and rural areas - Status report.

Triomphe, B., Floquet, A., Kamau, G., Letty, B., Vodouhe, S. D., Ng'ang'a, T., ... Hocdé, H. (2013). What Does an Inventory of Recent Innovation Experiences Tell Us About Agricultural Innovation in Africa? Journal of Agricultural Education and Extension, 19(3), 311-324.

https://doi.org/10.1080/1389224X.2013.782181

Triomphe, B., Waters-Bayer, A., Klerkx, L., Schut, M., Cullen, B., Kamau, G., \& LeBorgne, E. (2014). Innovation 
in smallholder farming in Africa: recent advances and recommendations. In International Workshop on Agricultural Innovation Systems in Africa (AISA), 29-31 May 2013, Nairobi, Kenya (p. 229). Montpellier: CIRAD.

Tripathi, J. N., Ntui, V. O., Shah, T., \& Tripathi, L. (2021). CRISPR/Cas9-mediated editing of DMR6 orthologue in banana ( Musa spp.) confers enhanced resistance to bacterial disease. Plant Biotechnology Journal. https://doi.org/10.1111/pbi.13614

Tripathi, L., Mwangi, M., Aritua, V., Tushemereirwe, W. K., Abele, S., \& Bandyopadhyay, R. (2009). Xanthomonas Wilt: A threat to Banana Production in East and Central Africa. Plant Disease, 93(5). https://doi.org/http://dx.doi.org/10.1094/PDIS-93-5-0440

Tsan, M., Totapally, S., Hailu, M., \& Addom, B. (2019). The Digitalisation of African Agriculture Report 20182019.

Turner, J. A., Horita, A., Fielke, S., Klerkx, L., Blackett, P., Bewsell, D., ... Boyce, W. M. (2020). Revealing power dynamics and staging conflicts in agricultural system transitions: Case studies of innovation platforms in New Zealand. Journal of Rural Studies, 76, 152-162. https://doi.org/10.1016/j.jrurstud.2020.04.022

Tushemereirwe, W. K., Okaasai, O., \& Kubiriba, J. (2006). Status of banana bacterial wilt in Uganda. African Crop Science Journal, 14(2), 73-82.

Tushemereirwe, W., Kangire, A., Smith, J., Ssekiwoko, F., Nakyanzi, M., Kataama, D., ... Karyaija, R. (2003). An outbreak of bacterial wilt on banana in Uganda. InfoMusa, 12(2), 6-8.

UN Development Group. (2017). Data privacy, ethics, and protection: Guidance note on big data for achievement of the 2030 agenda.

UN Systems Organizations. (2018). Personal data protection and privacy principles.

Uwamahoro, F., Berlin, A., Bylund, H., Bucagu, C., \& Yuen, J. (2019). Management strategies for banana Xanthomonas wilt in Rwanda include mixing indigenous and improved cultivars. Agronomy for Sustainable Development, 39(2), 22. https://doi.org/10.1007/s13593-019-0569-z

Valkenburg, G. (2020). Consensus or Contestation: Reflections on Governance of Innovation in a Context of Heterogeneous Knowledges. Science, Technology and Society, 25(2), 341-356. https://doi.org/10.1177/0971721820903005

Van Asten, P. J. ., Gold, C. ., Okech, S. H. ., Gaidashova, S. ., Tushemereirwe, W. ., \& De Waele, D. (2004). Soil quality problems in East African banana systems and their relation with other yield loss factors. InfoMusa, 13, 20-25.

Van Damme, J., Ansoms, A., \& Baret, P. V. (2014). Agricultural innovation from above and from below: Confrontation and integration on Rwanda's Hills. African Affairs, 113(450), 108-127. https://doi.org/10.1093/afraf/adt067

Van De Gevel, J., Van Etten, J., \& Deterding, S. (2020). Citizen science breathes new life into participatory agricultural research. A review. Agronomy for Sustainable Development, 40(35). https://doi.org/10.1007/s13593-020-00636-1/Published

van de Poel, I. (2013). Translating Values Into Design. In D. P. Michelfelder (Ed.), Philosphy and Engineering: Reflections on Practice, Principles and Process (Vol. 15). Dordrecht: Springer Science and Business Media LLC. https://doi.org/10.1007/978-94-007-7762-0

Van den Hoven, J., Lokhorst, G. J., \& Van de Poel, I. (2012). Engineering and the Problem of Moral Overload. Science and Engineering Ethics, 18(1), 143-155. https://doi.org/10.1007/s11948-011-9277-z 


\section{References}

van der Burg, S., Bogaardt, M. J., \& Wolfert, S. (2019). Ethics of smart farming: Current questions and directions for responsible innovation towards the future. NJAS - Wageningen Journal of Life Sciences, (December 2018), 1-10. https://doi.org/10.1016/j.njas.2019.01.001

van der Burg, S., Wiseman, L., \& Krkeljas, J. (2020). Trust in farm data sharing: reflections on the EU code of conduct for agricultural data sharing. Ethics and Information Technology, 1-14. https://doi.org/10.1007/s10676-020-09543-1

Van Der Waals, J. E., Denner, F. D. N., Van Rij, N., \& Korsten, L. (2003). Evaluation of PLANT-Plus, a decision support system for control of early blight on potatoes in South Africa. Crop Protection, 22(6), 821828. https://doi.org/10.1016/S0261-2194(03)00049-8

van Deursen, A., \& Solis Andrade, L. (2018). First- and second-level digital divides in Cuba: Differences in Internet motivation, access, skills and usage. First Monday, 23. https://doi.org/10.5210/fm.v23i8.8258

van Mierlo, B., Beers, P., \& Hoes, A.-C. (2020). Inclusion in responsible innovation: revisiting the desirability of opening up. Journal of Responsible Innovation, 7(3), 361-383. https://doi.org/10.1080/23299460.2020.1780409

van Reijswoud, V. (2009). Appropriate ICT as a Tool to Increase Effectiveness in ICT4D: Theoretical considerations and illustrating cases. The Electronic Journal of Information Systems in Developing Countries, 38(1), 1-18. https://doi.org/10.1002/j.1681-4835.2009.tb00272.x

Vanlauwe, B., Coyne, D., Gockowski, J., Hauser, S., Huising, J., Masso, C., ... Asten, P. Van. (2014). Sustainable intensification and the African smallholder farmer. Current Opinion in Environmental Sustainability, 8, 15-22. https://doi.org/10.1016/j.cosust.2014.06.001

Vial, G. (2019). Understanding digital transformation: A review and a research agenda. Journal of Strategic Information Systems, 28(2), 118-144. https://doi.org/10.1016/j.jsis.2019.01.003

von Schomberg, L., \& Blok, V. (2019). Technology in the Age of Innovation: Responsible Innovation as a New Subdomain Within the Philosophy of Technology. Philosophy and Technology. https://doi.org/10.1007/s13347-019-00386-3

von Schomberg, R. (2011). Towards Responsible Research and Innovation in the Information and Communication Technologies and Security Technologies Fields. Publication Office of the European Union, Luxembourg. https://doi.org/10.2777/58723

Vurro, M., Bonciani, B., \& Vannacci, G. (2010). Emerging infectious diseases of crop plants in developing countries: Impact on agriculture and socio-economic consequences. Food Security, 2(2), 113-132. https://doi.org/10.1007/s12571-010-0062-7

Wakunuma, K. (2019). Power as an ethical concern in the Global South's digital transformation. TATuP Zeitschrift Für Technikfolgenabschätzung in Theorie Und Praxis, 28(2), 29-34. https://doi.org/10.14512/tatup.28.2.s29

Walsham, G. (2017). ICT4D research: reflections on history and future agenda. Information Technology for Development, 1102(May), 1-24. https://doi.org/10.1080/02681102.2016.1246406

Wang, B., Schlagwein, D., Cecez-Kecmanovic, D., \& Cahalane, M. C. (2020). Beyond the factory paradigm: Digital nomadism and the digital future(s) of knowledge work post-COVID-19. Journal of the Association for Information Systems, 21(6), 1379-1401. https://doi.org/10.17705/1jais.00641

Waugaman, A. (2016). From principle to practice: Implementing the principles for Digital Development. Washington, DC.

Weber, E. P., \& Khademian, A. M. (2014). Wicked Problems, Knowledge Capacity Builders in Network 
Challenges, Settings and Collaborative. Public Administration Review, 68(2), 334-349. https://doi.org/10.1111/j.1540-6210.2007.00866.x

Wennink, B., \& Mur, R. (2016). Twigire Muhinzi Reflection Paper. Kigali.

Wigboldus, S., Klerkx, L., Leeuwis, C., Schut, M., Muilerman, S., \& Jochemsen, H. (2016, September 1). Systemic perspectives on scaling agricultural innovations. A review. Agronomy for Sustainable Development. Springer-Verlag France. https://doi.org/10.1007/s13593-016-0380-z

Wilkinson, M. D., Dumontier, M., Aalbersberg, Ij. J., Appleton, G., Axton, M., Baak, A., ... Mons, B. (2016). The FAIR Guiding Principles for scientific data management and stewardship. Scientific Data, 3(1), 1-9. https://doi.org/10.1038/sdata.2016.18

Williams, R., \& Edge, D. (1996). The social shaping of technology. Research Policy, 25(6), 865-899. https://doi.org/10.1016/0048-7333(96)00885-2

Williamson, B. (2018, March 17). 10 definitions of datafication (in education). Retrieved June 8, 2020, from https://codeactsineducation.wordpress.com/2018/03/17/10-definitions-datafication/

Wiseman, L., Pesce, V., Zampati, F., Sullivan, S., Addison, C., \& Drolet, J. (2019). Review of codes of conduct, voluntary guidelines and principles relevant for farm data sharing (ICT for agriculture No. 1). Wageningen.

Wiseman, L., Sanderson, J., Zhang, A., \& Jakku, E. (2019). Farmers and their data: An examination of farmers' reluctance to share their data through the lens of the laws impacting smart farming. NJAS Wageningen Journal of Life Sciences, 90-91. https://doi.org/10.1016/j.njas.2019.04.007

Wittman, H., James, D., \& Mehrabi, Z. (2020). Advancing food sovereignty through farmer-driven digital agroecology. International Journal of Agriculture and Natural Resources, 47(3), 235-248. https://doi.org/10.7764/ijanr.v47i3.2299

Wittrock, C., Forsberg, E.-M., Pols, A., Macnaghten, P., \& Ludwig, D. (2021). Conclusion to the Book BT Implementing Responsible Research and Innovation: Organisational and National Conditions. In C. Wittrock, E.-M. Forsberg, A. Pols, P. Macnaghten, \& D. Ludwig (Eds.) (pp. 115-120). Cham: Springer International Publishing. https://doi.org/10.1007/978-3-030-54286-3_9

Wolfert, S., Ge, L., Verdouw, C., \& Bogaardt, M.-J. (2017). Big Data in Smart Farming - A review. Agricultural Systems, 153, 69-80. https://doi.org/https://doi.org/10.1016/j.agsy.2017.01.023

Wood, B. A., Blair, H. T., Gray, D. I., Kemp, P. D., Kenyon, P. R., Morris, S. T., \& Sewell, A. M. (2014). Agricultural Science in the Wild: A Social Network Analysis of Farmer Knowledge Exchange. PLoS ONE, 9(8), e105203. https://doi.org/10.1371/journal.pone.0105203

World Bank Group, \& China Development Bank. (2017). Leapfrogging. Leapfrogging: The Key to Africa's Development? World Bank, Washington, DC. https://doi.org/10.1596/28440

World Food Programme. (2016). WFP Guide to Personal Data Protection and Privacy.

World Summit on the Information Society. (2003, December). WSIS: Declaration of Principles. World Summit on the Information Society.

Wright, H. J., Ochilo, W., Pearson, A., Finegold, C., Oronje, M., Wanjohi, J., ... Rumsey, A. (2016). Using ICT to Strengthen Agricultural Extension Systems for Plant Health. Journal of Agricultural \& Food Information, 17(1), 23-36. https://doi.org/10.1080/10496505.2015.1120214

Xie, L., Luo, B., \& Zhong, W. (2021). How are smallholder farmers involved in digital agriculture in developing countries: A case study from China. Land, 10(3), 1-16.

https://doi.org/10.3390/land10030245 


\section{References}

Xin, J. ., \& Zazueta, F. . (2016). Technology trends in ICT - Towards data-driven, farmer-centered... Agricultural Engineering International: CIGR Journal, 18(4), 275-279.

Yirgou, D., \& Bradbury, J. F. (1968). Bacterial Wilt of Enset (Enset ventricosum) Incited by Xanthomonas musacearum sp. n. Phytopathology, 58, 111-112.

Yirgou, D., \& Bradbury, J. F. (1974). A Note on Wilt of Banana Caused by the Enset Wilt Organism Xanthomonas musacearum. East African Agricultural and Forestry Journal, 40(1), 111-114.

Zanello, G. (2012). Mobile phones and radios: effects on transactions costs and market participation for households in Northern Ghana. Journal of Agricultural Economics, 63(3), 694-714.

Zewge, A., \& Dittrich, Y. (2017). Systematic Mapping Study of Information Technology for Development in Agriculture (The Case of Developing Countries). The Electronic Journal of Information Systems in Developing Countries, 82(1), 1-25. https://doi.org/10.1002/j.1681-4835.2017.tb00602.x

Zuboff, S. (2015). Big other: Surveillance capitalism and the prospects of an information civilization. Journal of Information Technology, 30(1), 75-89. https://doi.org/10.1057/jit.2015.5

Zuboff, S. (2019). Surveillance Capitalism and the Challenge of Collective Action. New Labor Forum, 28(1), 10-29. https://doi.org/10.1177/1095796018819461 


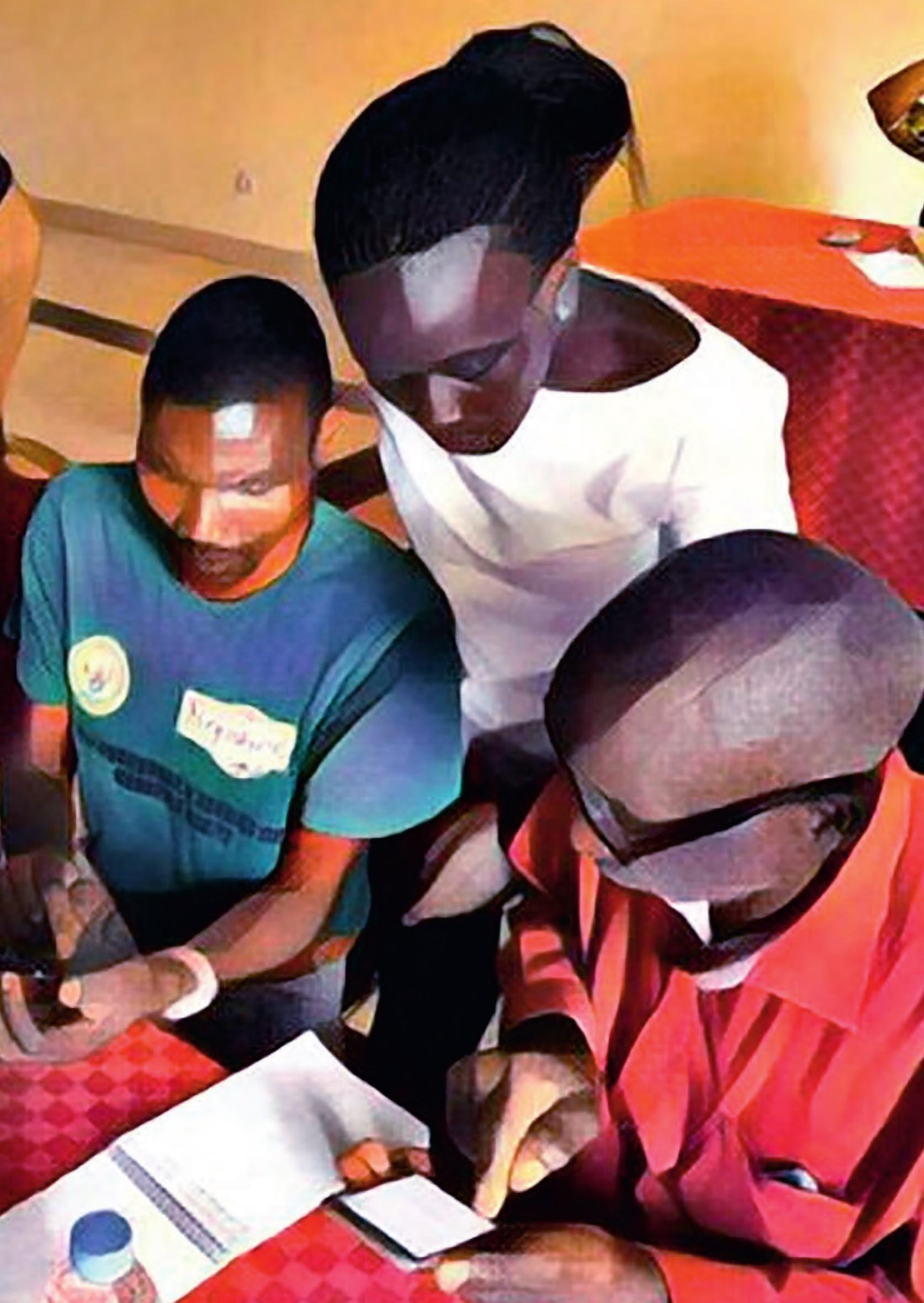




\section{Supplemental material}

\section{Appendix 1: Details about survey data used as input for analysis}

(Belonging to chapter 3)

\begin{tabular}{|c|c|c|c|c|}
\hline Component & Survey question & Definition & $\begin{array}{l}\text { Selectable } \\
\text { options } \\
\end{array}$ & Variables \\
\hline $\begin{array}{l}\text { Physical } \\
\text { capability }\end{array}$ & $\begin{array}{l}\text { Which of these } \\
\text { technologies } \\
\text { have you ever } \\
\text { used? }\end{array}$ & $\begin{array}{l}\text { Device(s) used by } \\
\text { respondent }\end{array}$ & $\begin{array}{l}\text { Radio; TV; } \\
\text { smartphone; } \\
\text { featurephone; } \\
\text { basic phone; PC; } \\
\text { tablet; laptop; } \\
\text { none }\end{array}$ & $\begin{array}{l}\text { UsedDevice_Radio } \\
\text { UsedDevice_TV } \\
\text { UsedDevice_SmartPhone } \\
\text { UsedDevice_featurephone } \\
\text { UsedDevice_BasicPhone } \\
\text { UsedDevice_PC } \\
\text { UsedDevice_Tablet } \\
\text { UsedDevice_Laptop } \\
\text { UsedDevice_None }\end{array}$ \\
\hline \multirow[t]{3}{*}{$\begin{array}{l}\text { Psychological } \\
\text { capability }\end{array}$} & $\begin{array}{l}\text { Which of these } \\
\text { technologies } \\
\text { have you ever } \\
\text { used in the past } \\
30 \text { days? }\end{array}$ & $\begin{array}{l}\text { Device(s) used by } \\
\text { respondent in the past } \\
30 \text { days }\end{array}$ & $\begin{array}{l}\text { Radio; TV; } \\
\text { smartphone; } \\
\text { featurephone; } \\
\text { basic phone; PC; } \\
\text { tablet; laptop; } \\
\text { none }\end{array}$ & $\begin{array}{l}\text { UsedDevice30_Radio } \\
\text { UsedDevice30_TV } \\
\text { UsedDevice30_SmartPhone } \\
\text { UsedDevice30_featurephone } \\
\text { UsedDevice30_BasicPhone } \\
\text { UsedDevice30_PC } \\
\text { UsedDevice30_Tablet } \\
\text { UsedDevice30_Laptop } \\
\text { UsedDevice30_None }\end{array}$ \\
\hline & $\begin{array}{l}\text { How often does } \\
\text { the respondent } \\
\text { use a mobile } \\
\text { phone to do the } \\
\text { following } \\
\text { activities? }\end{array}$ & $\begin{array}{l}\text { Frequency of using } \\
\text { mobile phone for } \\
\text { specific activities: Initiate } \\
\text { phone call; receive } \\
\text { phone call; missed } \\
\text { call/beeping; send sms; } \\
\text { receive sms; internet; } \\
\text { email; facebook; twitter; } \\
\text { receive money; send } \\
\text { money; whatsapp msg; } \\
\text { listen to music; take a } \\
\text { photo }\end{array}$ & $\begin{array}{l}\text { At least once per } \\
\text { day; A few days } \\
\text { per week; Once } \\
\text { per week; At least } \\
\text { once per month; } \\
\text { Once every few } \\
\text { months; Never }\end{array}$ & $\begin{array}{l}\text { phoneuse_initiatecall } \\
\text { phoneuse_receivecall } \\
\text { phoneuse_missed_call } \\
\text { phoneuse_sendsms } \\
\text { phoneuse_receivesms } \\
\text { phoneuse_internet } \\
\text { phoneuse_email } \\
\text { phoneuse_facebook } \\
\text { phoneuse_twitter } \\
\text { phoneuse_receivemoney } \\
\text { phoneuse_sendmoney } \\
\text { phoneuse_msg } \\
\text { phoneuse_music } \\
\text { phoneuse_photo }\end{array}$ \\
\hline & $\begin{array}{l}\text { Did you use a } \\
\text { mobile phone or } \\
\text { tablet to access } \\
\text { any of the } \\
\text { following } \\
\text { agricultural } \\
\text { services in the } \\
\text { last } 30 \\
\text { days/month? }\end{array}$ & $\begin{array}{l}\text { Farmer used in past } 30 \\
\text { days mobile phone or } \\
\text { other device to access } \\
\text { information on: weather } \\
\text { forecast; markets; } \\
\text { farming practices; buying } \\
\text { agro-inputs; specific } \\
\text { farming alerts; alerts on } \\
\text { pests and diseases; other } \\
\text { information; not used for } \\
\text { agriculture related } \\
\text { information }\end{array}$ & True; False & $\begin{array}{l}\text { mobileinfo_weather } \\
\text { mobileinfo_mrkt } \\
\text { mobileinfo_farming } \\
\text { mobileinfo_buysell } \\
\text { mobileinfo_comm } \\
\text { mobileinfo_disease } \\
\text { mobileinfo_other } \\
\text { mobileinfo_nonagri }\end{array}$ \\
\hline
\end{tabular}




\section{Appendix 2: International Sector Policies and Guidelines available for regulating the design of digital agriculture tools and systems}

(Belonging to Chapter 4)

\section{Organization \\ Type}

\begin{tabular}{|c|c|}
\hline \multicolumn{2}{|l|}{ Global } \\
\hline Digital & Principles \\
\hline Impact & Design \\
\hline Alliance & Guidelines \\
\hline \multirow[t]{3}{*}{ Google } & Technical \\
\hline & Design \\
\hline & Guidelines \\
\hline GOFair & Principles \\
\hline \multirow[t]{2}{*}{ Initiative } & Design \\
\hline & Guidelines \\
\hline IRPC & Principles \\
\hline GODAN & Best Practice \\
\hline \multirow[t]{2}{*}{ WSIS } & Principles/ \\
\hline & Charta \\
\hline \multicolumn{2}{|l|}{ Regional } \\
\hline \multirow[t]{2}{*}{ EU } & Legal \\
\hline & Framework \\
\hline EU & Principles \\
\hline
\end{tabular}

Organizational

$\begin{array}{ll}\text { USAID } & \begin{array}{l}\text { Organisational } \\ \text { Policy }\end{array} \\ \text { ICRC } & \begin{array}{l}\text { Organisational } \\ \text { Policy }\end{array} \\ \text { OXFAM } & \begin{array}{l}\text { Organisational } \\ \text { Policy }\end{array} \\ \text { CGIAR } & \text { Organisational } \\ \text { Platform for } & \text { Policy } \\ \text { Big Data in } & \\ \text { Agriculture } & \\ \text { UN System } & \text { Organisational } \\ & \text { PolicyPrinciples } \\ \text { UNDG } & \text { Organisational } \\ & \text { Policy }\end{array}$

WFP
Policy/ Guideline

Principles for Digital

Development

Building for Billions

FAIR principles

Internet Rights and

Principles

Responsible Data in

Agriculture

Declaration of

Principles

General Data

Protection Regulation

Code of Conduct on agricultural data sharing

Considerations for Using Data

Responsibly

Handbook on Data

Protection in

Humanitarian Action

Responsible Data

Policy

Responsible Data

Guidelines

Personal Data

Protection and

Privacy Principles

Guidance note on Big

Data for achievement

of the 2030 Agenda

Organisational Guide to Personal Policy Data Protection and Privacy

\section{Summary/Aim}

\author{
Nine principles to help organisations design impactful \\ and sustainable digital programmes and initiatives. \\ Technical documentation to improve connectivity, device \\ capability, data cost, battery consumption, and content. \\ Guidelines to improve the Findability, Accessibility, \\ Interoperability, and Reuse of digital assets \\ Definition of ten rights and principles within the Internet \\ Government Forum (IGF) \\ Best practices for managing agricultural data responsibly. \\ Vision for key principles of the information society
}

European legal framework to regulate the storage and processing of personal identifiable information General principles for sharing agricultural data within the agro-food chain providing a non-binding code

Organizational framework for identifying and understanding risks associated with development data

Organizational handbook on the management of personal data in humanitarian situations

Policy to define rights of data subjects and responsibilities of Oxfam as data controller Guideline for member organisations of the CG system to manage privacy and personally identifiable information in the research project data lifecycle

Principles for the processing of personal data across the UN System Organisations.

Guidelines on data privacy, ethics and protection concerning the use of Big Data collected and shared by private entities with United Nations Development Group members

Guidelines for WFP personnel regarding the processing of data concerning program beneficiaries. 


\section{Appendix 3: TAM USE survey}

\section{(Belonging to Chapter 4)}

The purpose of this survey is to learn from you about your experience with the ICT4BXW application this far: Have you been using the application? Has it been usable and useful for you? Do you find it easy or difficult to use the application? Are you satisfied with the application? Aim is to understand what is good about the application that you have on the project phone today, and what could still be improved.

1. What has been the frequency of your use of the ICTABXW app since you were trained and equipped with the smartphone?

\section{Very Frequently - Frequently - Occasionally - Rarely - Very Rarely-Never}

2. If never, very rarely, or rarely: What is the reason for your absent or limited use of the application?

The ICT4BXW app.
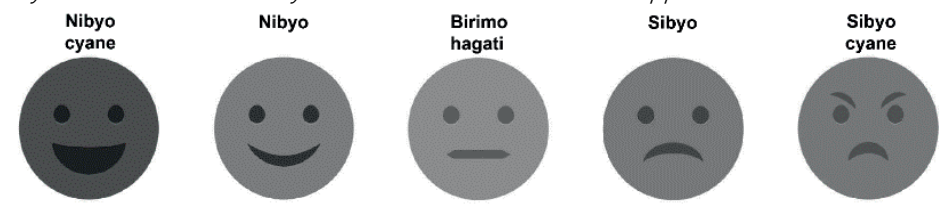

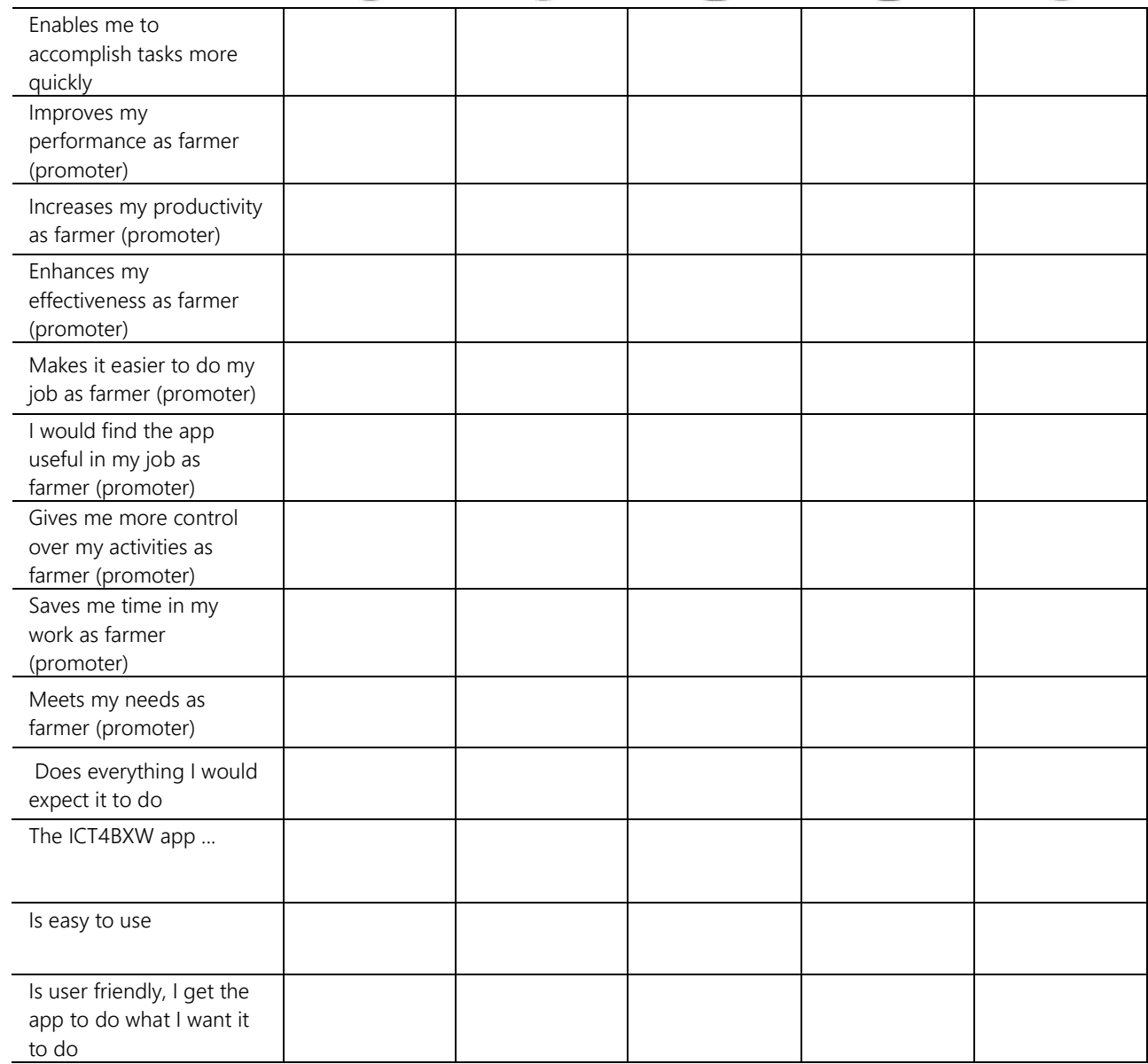




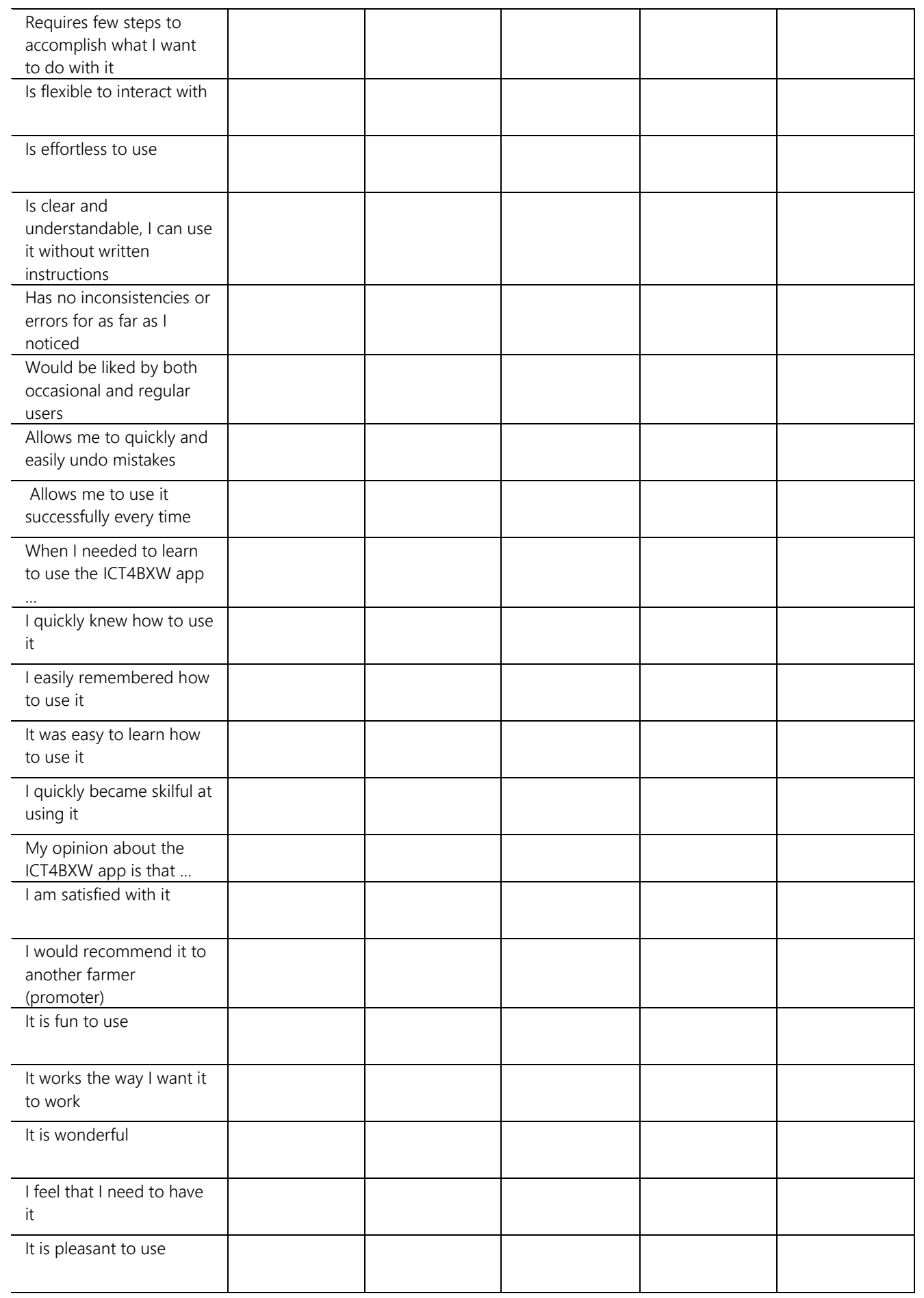




\title{
Appendix 4: FGD questions for farmers
}

\author{
(Belonging to Chapter 4)
}

What I know and think about the ICT4BXW app... (Focus group with farmers)

1. Control question: Did a farmer promoter visit you and your farm to diagnose if your farm is affected by BXW disease and give information about the disease using an application on a mobile phone?

2. If yes, what have you been told about the application and the project when you registered the first time as a farmer (promoter)?

3. When the farmer promoter visited you, did he/she give you a chance to look on the mobile phone and see the text, pictures, and/or audio that is in the application?

4. When the farmer promoter visited you, did he/she show you which information about you and your farm they entered in the application?

5. When the farmer promoter visited you, was the exercise of diagnosing whether or not your farm has BXW useful for you? Why yes/no?

6. If the farmer promoter gave you additional information about banana agronomy and BXW management, was this information useful for you? Why yes/no?

7. To your knowledge, what information about a farmer and his/her farm is collected with the app?

8. Is there information about you or your banana farm that you prefer not to share with the farmer promoter who visits you with the ICT4BXW project application?

9. To your knowledge, who can access the information about a farmer and his/her farm that is collected with the app?

10. To your knowledge, who will be using the information about a farmer and his/her farm that is collected with the app?

11. Are you ever concerned about who is accessing and using information about you and your farm? If yes, can you describe what you are concerned about?

12. To your knowledge, can a farmer ask to have the profile about him/her and his/her farm removed from the application? If yes, what would he/she need to do to achieve this?

13. Which type of organisations do you want to access and use the information about you and your banana farm?

NGO

Researchers

RAB

Farmer promoter

Other farmers

District agronomist

Trader

The government

Village leader

Other

Sector agronomist

14. Would you feel comfortable if the information about you and your banana farm would be available to anyone?

15. If not, who or which organizations do you rather not want to have access to and use the information about you and your banana farm

16. How do you think that sharing information about you and your banana farm through the application could negatively impact you or your family?

17. How do you think that sharing information about you and your banana farm through the application could positively impact you or your family? 


\section{Appendix 5: Consent form FGD and surveys}

\section{(Belonging to Chapter 4)}

Consent form for focus group and survey about use of ICT4BXW app

Researcher: Mariette McCampbell, Knowledge, Technology and Innovation group, Wageningen University

\section{Taking part in the study}

\begin{tabular}{|l|c|}
\hline $\begin{array}{l}\text { Information about the project and this study has been read to me and been understood by me. I } \\
\text { have been able to ask questions about the study and my questions have been answered to my } \\
\text { satisfaction }\end{array}$ & Yes $^{*}$ No $\square$ \\
\hline $\begin{array}{l}\text { I consent voluntarily to be a participant in this study and understand that I can refuse to answer } \\
\text { questions and I can withdraw from the study at any time, up until the collected data has been } \\
\text { analysed, without having to give a reason }\end{array}$ & Yes $\square$ \\
\hline $\begin{array}{l}\text { I understand that taking part in the study means participating in a focus group and a survey } \\
\text { questionnaire completed during the focus group }\end{array}$ & Yes $\square$ \\
\hline I agree to photos being taken during the study & No $\square$ \\
\hline I agree to the focus group being audio or video recorded & Yes $\square$ \\
\hline
\end{tabular}

*Please tick the appropriate boxes

\section{Use of the information in the study}

\begin{tabular}{|l|c|}
\hline $\begin{array}{l}\text { I understand that the information I provide may be used for reports, publications, and (online) } \\
\text { communication }\end{array}$ & Yes $\square$ \\
\hline $\begin{array}{l}\text { I understand that personal information collected about me that can identify me, such as my name } \\
\text { or where I live, will not be shared beyond the study team }\end{array}$ & Yes $\square$ \\
\hline I understand that my data will be stored in a project repository & No $\square$ \\
\hline I agree that my information can be quoted in research outputs & Yes $\square$ \\
\hline I agree that my real name can be used for quotes \\
\hline $\begin{array}{l}\text { I give permission for the data of the focus group and survey to be deposited in a database after } \\
\text { being anonymized and made available to other researchers for future research and learning }\end{array}$ & Yes $\square$ \\
\hline
\end{tabular}

\section{Signatures}

Participant

Name

Signature

Date

Researcher

Name

Signature

Date 


\section{Appendix 6: Overview of variables per category and sub- category \\ (Belonging to Chapter 5)}

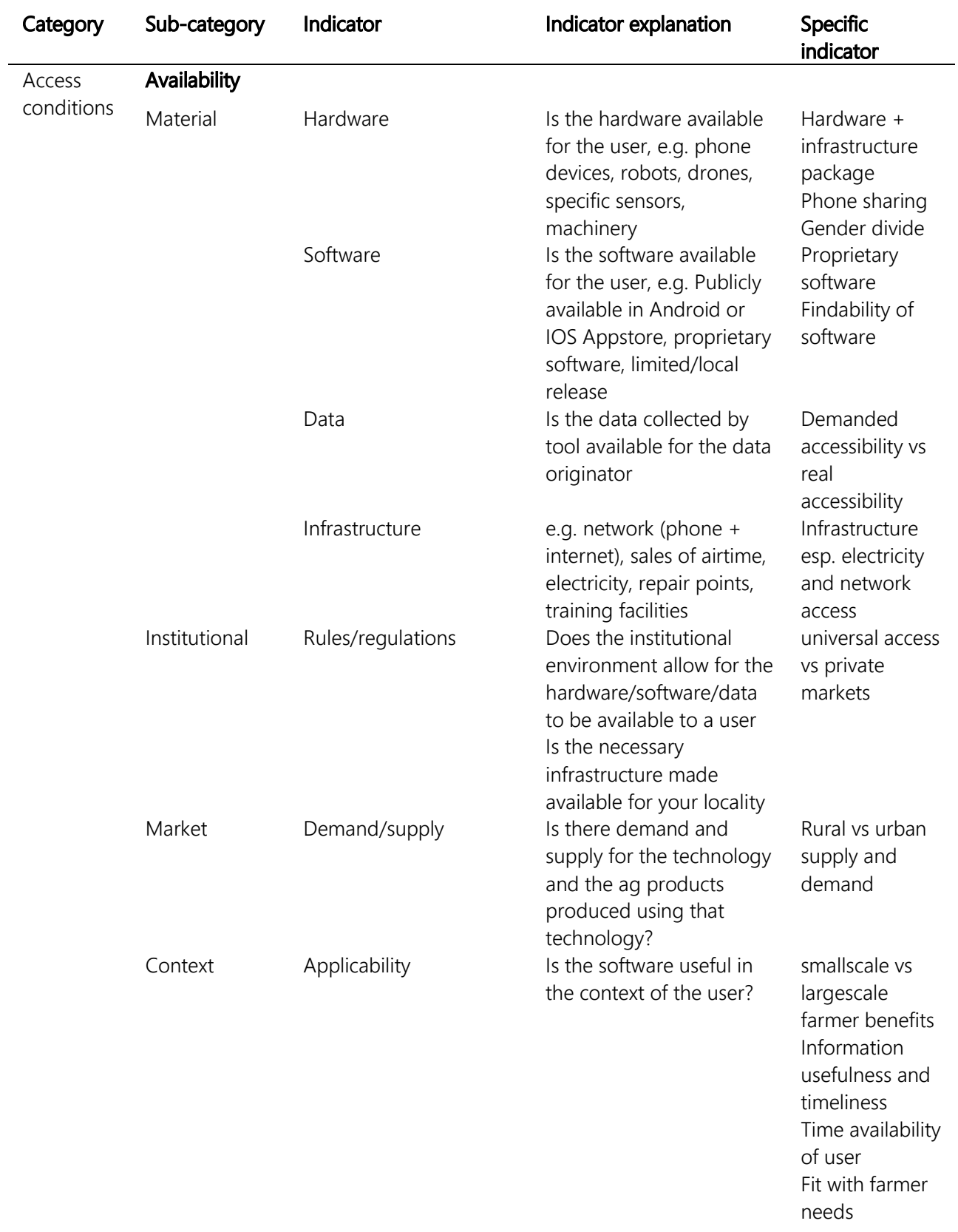




\section{Affordability}

Economic

Income/wealth

Cost of material

Value proposition

Use

Ease of use

and learning

\section{Agency/Awareness}

Socio-cultural (perceived) Autonomy

Identity as farmer

\section{Ability}

Literacy Digital literacy

Gen. literacy

Physical ability Human
Poor, rich, etc.

One off or continuous investment required

Can the investment be justified/lead to profit Is the technology easy to use/is het easy enough to learn how to use it

Is a user 'allowed' to use the technology, either formally (e.g. rules, laws) or culturally (e.g. husband not allowing a wife to own or use a phone)

Influence of social constructs on ownership and use. E.g. internet banned due to religion; girls fearing repercussions of sharing things on social media Does the use of technology fit with the social identity of 'being a farmer' in a certain location and context?

Ability to use digital hardware, software, and make sense of data

Ability to read, write, count, calculate

Physical ability to e.g. read from a screen, use a touch screen, carry machinery, etc.
Wealth gap

Gender gap

One off

investment

Long term

cost/lock-in
Gender based literacy divides Expert skills Digital jargon / understanding (data) regulations Literacy induced risks Complex language and trust Literacy (and gender) Tech made for men 


\section{Land/geography/ crop}

$\begin{array}{ll}\text { Design } & \text { Design related } \\ \text { choices } & \text { risks incl. } \\ & \text { (unequal) } \\ & \text { power } \\ & \text { distribution } \\ & \text { related risks }\end{array}$

Obsolescence of skills (job loss)
Individual and group privacy (incl. surveillance, visibility)

(Data) security

Concentrated/private data ownership
E.g. size of land, terrain (mountains, forests, or intercropped land), or a crop like banana may make some tech not usable or not profitable etc.

Does introduction to the tech lead to disappearance of some jobs (e.g. labourers)

Anonymization of PII. Right to privacy. Group privacy: My individual data may be anonymized, yet I can still be affected, made visible, or excluded due to a policy because based on characteristics I was identified as part of a group.

Is data securely collected, processed, stored, shared?

Is there potential personal risk if data is shared with e.g. governments? Who owns data? What does this do to data reliability and data access? Is data in the hands of few parties? If data is privately owned, who can still access it?
Crop focus Geographical barriers Data have and have nots = data don't wants Replacing the farmer Changing job characteristics Female participation in the

(formal)labour

market

Creating new jobs

Government access to PII data PIl vs non personal data Farmer concerns about data access Data protection policies Insufficient legislative power of data protection law (Women's) privacy within the household

Fear of unrightful sharing Data and cyber security as upcoming issue

Lack of transparency about commercially 'owned' data Farmers maintaining ownership 


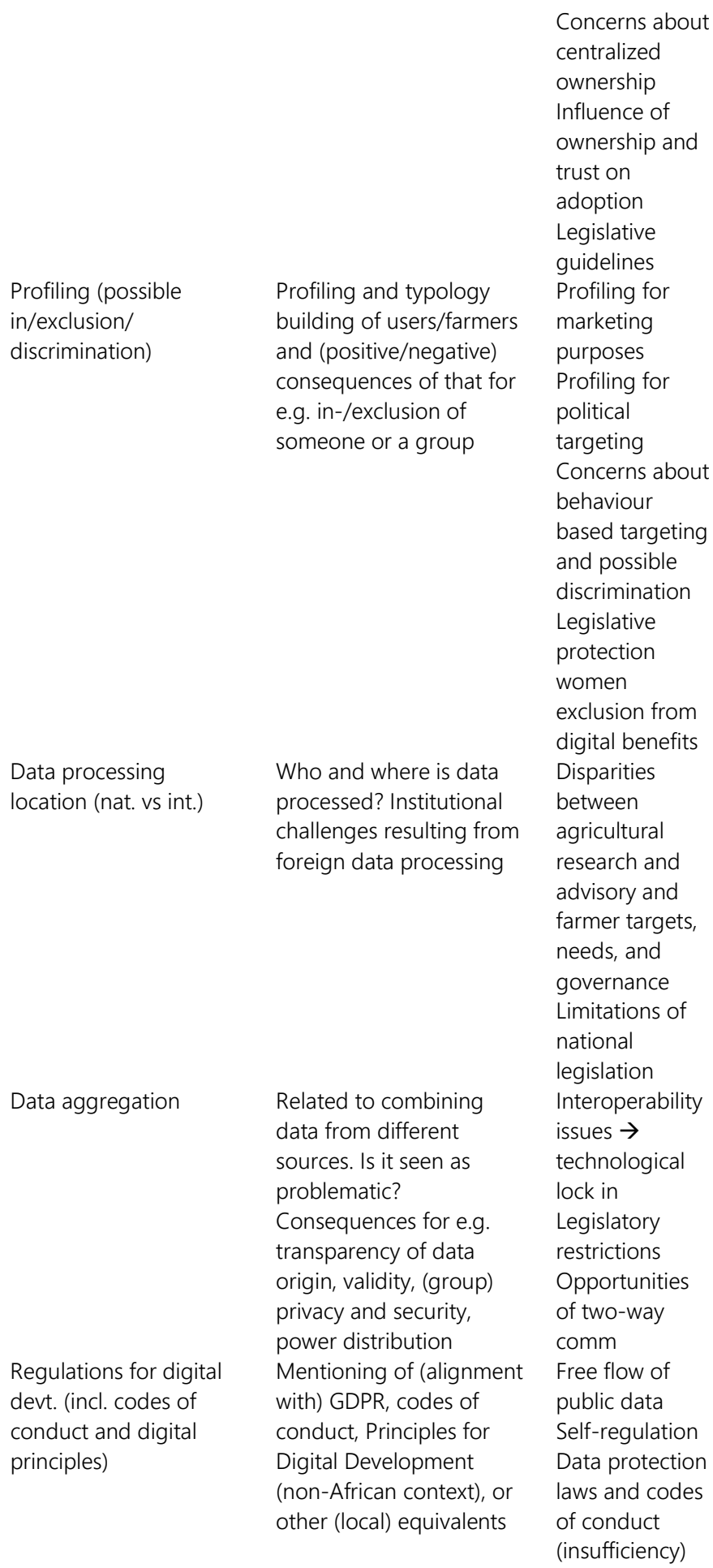


Choice vs obligation to participate/be included (incl consent and optin/out)

Distribution of benefits from digital technology

Associated economic/social arrangements/contracts

Right to repair yes/no

Sustainability

Gender/racial/ biased technology
Is the user given a choice

$=$ is participation fully

voluntary? Is it possible to opt in or out at a later time? Are there (negative) consequences of choosing to exclude oneself or opt out? Who benefits from the technology? How are benefits distributed among different users/developers/data owners etc.? Efforts to achieve inclusion and fairness, or marginalization
Transparency evaluator Universal ethical guidelines Adoption to remain competitive Opt-out option Lock in/dependency

Wealthier farmers benefit more Vulnerable people becoming more vulnerable Rural vs urban divide Large farms benefit more Women benefit less/gender divide Multinational benefit Commercial benefit Additional prescriptions Further that come as a side-effect empowerment of owning/using the digital technology, which a user cannot control

Ability to have the hardware or software repaired or updated (locally)

Is the tech going to be around long term? Possibilities to update and repair and receive support after the tech was introduced (and a project ended) Exclusion that is (unintentionally) build of big agribusinesses Technological lock-in Adaptations and repair impossible

Untransparant and siloed software devt Limited lifetime of non-cloud data storage equipment Large farm bias Male bias 


\begin{tabular}{|c|c|c|c|c|}
\hline & & & $\begin{array}{l}\text { into the design of } \\
\text { hardware or software. } \\
\text { E.g. Al and ML ranking a } \\
\text { specific group always low } \\
\text { for credit worthiness. }\end{array}$ & $\begin{array}{l}\text { Algorithmic } \\
\text { bias } \\
\text { Exclusion of } \\
\text { digitally absent } \\
\text { voices } \\
\text { Exclusion of } \\
\text { less digitally } \\
\text { literate voices }\end{array}$ \\
\hline \multirow[t]{6}{*}{$\begin{array}{l}\text { System } \\
\text { complexity }\end{array}$} & $\begin{array}{l}\text { Technology- } \\
\text { social } \\
\text { organization } \\
\text { integration -- } \\
\text { > digital traps }\end{array}$ & Information overload & $\begin{array}{l}\text { Exponential growth of } \\
\text { available information } \\
\text { making it } \\
\text { difficult/impossible for } \\
\text { users to process it all }\end{array}$ & $\begin{array}{l}\text { Information } \\
\text { overload from } \\
\text { DSS }\end{array}$ \\
\hline & $\begin{array}{l}\text { or socio- } \\
\text { economic } \\
\text { consequences }\end{array}$ & $\begin{array}{l}\text { Information quality } \\
\text { issues }\end{array}$ & $\begin{array}{l}\text { Challenges with reliability } \\
\text { and validity of data, and } \\
\text { the ability of users to } \\
\text { judge this }\end{array}$ & $\begin{array}{l}\text { Inconsistency / } \\
\text { data noise } \\
\text { Evaluating a } \\
\text { multitude of } \\
\text { services } \rightarrow \\
\text { decision } \\
\text { paralysis } \\
\text { Interoperability } \\
\text { issues } \\
\text { Trust in data }\end{array}$ \\
\hline & & $\begin{array}{l}\text { Loss of human control } \\
\text { and oversight over } \\
\text { technology }\end{array}$ & $\begin{array}{l}\text { Can humans control the } \\
\text { introduced digital } \\
\text { technologies that? Who } \\
\text { has that control? } \\
\text { Consequences of } \\
\text { reduced control and } \\
\text { oversight due to } \\
\text { exponential increase in } \\
\text { digital tech options and } \\
\text { their interlinkedness }\end{array}$ & \\
\hline & & $\begin{array}{l}\text { Human/animal-machine } \\
\text { interaction }\end{array}$ & $\begin{array}{l}\text { Interaction between } \\
\text { people or animals and } \\
\text { digital technologies. And } \\
\text { what does the } \\
\text { introduction of digital } \\
\text { tech do to existing } \\
\text { human-human, human- } \\
\text { animal, and human-crop } \\
\text { interaction? }\end{array}$ & $\begin{array}{l}\text { Face-to-face } \\
\text { interaction } \\
\text { Digital curtain } \\
\text { moderating } \\
\text { social } \\
\text { relationships } \\
\text { Human-animal } \\
\text { interaction }\end{array}$ \\
\hline & & Addictions & $\begin{array}{l}\text { Addictions to and } \\
\text { dependencies resulting } \\
\text { from introduction of the } \\
\text { tech. e.g. addiction to } \\
\text { social media, } \\
\text { dependency on } \\
\text { WhatsApp }\end{array}$ & \\
\hline & & Cyber bullying/crime & $\begin{array}{l}\text { Uprise of digital bullying } \\
\text { and digital crime }\end{array}$ & $\begin{array}{l}\text { Cyberstalking } \\
\text { and harassment }\end{array}$ \\
\hline
\end{tabular}




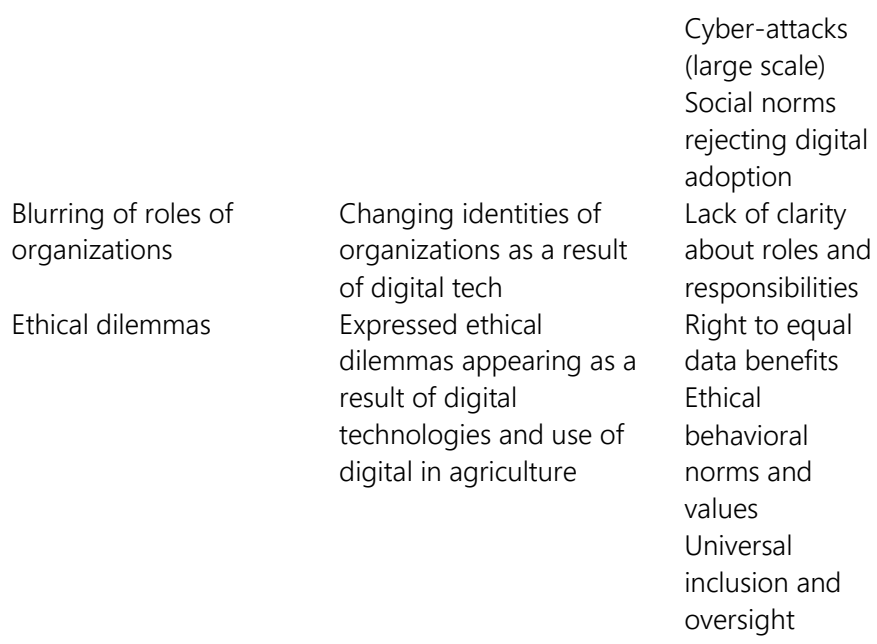




\section{Appendix 7: Input for SES framework adapted to BXW disease in Rwanda}

(Belonging to Chapters 6 and 7)

\section{Components Description and example}

\begin{tabular}{|c|c|}
\hline $\begin{array}{l}\text { Agricultural } \\
\text { livelihood } \\
\text { system (ALS) }\end{array}$ & $\begin{array}{l}\text { This is represented by a specific territory } \\
\text { where diverse agricultural livelihood } \\
\text { activities take place, involving crops, } \\
\text { animal husbandry, and related activities } \\
\text { and assets that provide ecosystem } \\
\text { services to farmers and consumers. }\end{array}$ \\
\hline $\begin{array}{l}\text { Livelihood } \\
\text { unit (LU) }\end{array}$ & $\begin{array}{l}\text { This is a specific agricultural activity } \\
\text { providing ecosystems services needed } \\
\text { to make a living, e.g. cattle for milk and } \\
\text { meat, rice production for human } \\
\text { consumption, maize production for } \\
\text { human or animal feed. }\end{array}$ \\
\hline $\begin{array}{l}\text { Livelihood } \\
\text { assets }\end{array}$ & $\begin{array}{l}\text { Human: peoples' health and ability to } \\
\text { work, knowledge, skills, experience; } \\
\text { Natural: land, water, the forest, livestock; } \\
\text { Social: trust, mutual support, reciprocity, } \\
\text { ties of social obligations; Physical: tools } \\
\text { and equipment, infrastructure, market } \\
\text { facilities, water supply, health facilities; } \\
\text { Financial: conversion of production into } \\
\text { cash, formal or informal credit. }\end{array}$ \\
\hline $\begin{array}{l}\text { Public bad } \\
\text { risk context } \\
\text { (PBRC) }\end{array}$ & $\begin{array}{l}\text { Conditions of vulnerability and } \\
\text { characteristics of the hazard that hinder } \\
\text { or limit the probability of a public bad }\end{array}$ \\
\hline
\end{tabular}

Vulnerability The vulnerability (of any system) is a function of three elements: exposure to hazard, sensitivity to that hazard, and the capacity of the system to cope, adapt, or recover from the effect of those conditions (Turner et al., 2003).

\section{BXW context}

Banana small scale farming for consumption and market.

Banana as food and source of income.

Banana production contributes approximately $50 \%$ of the diet of $32 \%$ of the households in

Rwanda (Nkuba et al., 2015). Therefore, declines in production impact household income as well as food and nutrition security, and social and cultural wellbeing.

(McCampbell, 2018).

BXW can result in yield losses up to $100 \%$. No cure exists for BXW. Once the pathogen establishes, the stem will inevitably die. Eradication of BXW is considered impossible, but outbreaks can be managed with preventative and early response agricultural practices. Collective-coordinated actions are needed, as farmers' production activities and outcomes are interconnected.

Farmers lose their income and food security (loss of livelihood), especially for cooking banana because this one is the crop that provides a stable income.

Exposure is related to agroecological conditions. In higher lands, there is less exposure because there are fewer vector insects, also the variety.

The capacity to cope/adapt/recover is limited and mostly dependant on the wealth of the farmers and their ability to access off-farm income opportunities. More wealthy farmers have more access to information, and female farmers are more isolated from 


\begin{tabular}{|c|c|c|}
\hline Hazard & $\begin{array}{l}\text { A physical event, phenomenon, or } \\
\text { human activity that has the potential to } \\
\text { cause the loss of life or injuries, property } \\
\text { damage, social and economic } \\
\text { disruption, or environmental } \\
\text { degradation. Its potential can be } \\
\text { characterized by its probability } \\
\text { (frequency) and intensity (magnitude or } \\
\text { severity) (Blaikie, et al, 1996). }\end{array}$ & $\begin{array}{l}\text { BXW, caused by the bacterium Xanthomonas } \\
\text { campestris pv. Musacearum, endangers the } \\
\text { livelihoods of millions of farmers in East and } \\
\text { Central Africa (Jackson et al., 2015; Tripathi et } \\
\text { al., 2009) and can result in yield losses up to } \\
\text { 100\%. BXW is highly transmissible and can } \\
\text { spread rapidly through infected plant } \\
\text { material, cutting tools, long-distance trade, } \\
\text { and vectors such as birds, bats, and insects } \\
\text { (Tinzaara et al., 2016). }\end{array}$ \\
\hline $\begin{array}{l}\text { Risk } \\
\text { perception }\end{array}$ & $\begin{array}{l}\text { Risk perceptions are formed by } \\
\text { common-sense reasoning, personal } \\
\text { experiences, social communication, and } \\
\text { cultural traditions. These are the } \\
\text { contextual aspects that individuals } \\
\text { consider when deciding whether or not } \\
\text { to take a risk and selecting reduction or } \\
\text { preventive measures (Van Asselt \& } \\
\text { Renn, 2011; Wachinger, et al, 2013). }\end{array}$ & $\begin{array}{l}\text { Believes about BXW: some farmers compare it } \\
\text { to HIV or apocalypse, and therefore they think } \\
\text { it cannot be controlled. } \\
\text { Uncertainty: farmers feel they are not in } \\
\text { control, and therefore if the plant gets } \\
\text { infected, uproot it and then re-plant it; it is } \\
\text { just to lose it again. } \\
\text { Believes about the system: farmers know they } \\
\text { might be forced to uproot if the plantation is } \\
\text { infected, and therefore, they try to hide it. } \\
\text { Believes about neighbours: Farmers see a risk } \\
\text { in their neighbours' disease management } \\
\text { practices. If the farmer tries to control the } \\
\text { disease, but the neighbours do not, they will } \\
\text { get the disease anyway. }\end{array}$ \\
\hline
\end{tabular}

advice/information/resources (they are more vulnerable).

BXW, caused by the bacterium Xanthomonas campestris pv. Musacearum, endangers the livelihoods of millions of farmers in East and al., 2009) and can result in yield losses up to $100 \%$. BXW is highly transmissible and can spread rapidly through infected plant and vectors such as birds, bats, and insects (Tinzaara et al., 2016).

Believes about BXW: some farmers compare it to HIV or apocalypse, and therefore they think t cannot be controlled.

Uncertainty: farmers feel they are not in control, and therefore if the plant gets infected, uproot it and then re-plant it; it is ust to lose it again. might be forced to uproot if the plantation is infected, and therefore, they try to hide it. Believes about neighbours: Farmers see a risk in their neighbours' disease management get the disease anyway.

Blaikie, P., Cannon, T., Davis, I., and Wisner, B. (1994). At Risk: Natural Hazards, People's Vulnerability and Disasters. Routledge, London.

Hakizamungu, L., Rukundo, P., Muhigirwa, J. C., Mukamuhirwa, F., Umfuyisoni, J., Uzayisenga, B., \& Kalisa, J. P. (2020, December). Pest Management Decision Guide: Banana Xanthomonas Wilt (BXW). CABI Plantwise.

Jackson, N., William, T., Gertrude, N., Nicholas, N., Wellington, J., Innocent, N., ... Eldad, K. (2015). Adverse impact of Banana Xanthomonas Wilt on farmers livelihoods in Eastern and Central Africa. African Journal of Plant Science, 9(7), 279-286.

McGinnis, M. D., \& Ostrom, E. (2014). Social-ecological system framework: Initial changes and continuing challenges. Ecology and Society, 19(2).

Tinzaara, W. \& Karamura, Eldad \& Blomme, Guy \& Jogo, Wellington \& Ocimati, Walter \& Rietveld, Anne \& Kubiriba, Jerome \& Opio, Fina. (2013). Why sustainable management of xanthomonas wilt of banana in east and central africa has been elusive. Acta Horticulturae. 986. 157-164. 10.17660/ActaHortic.2013.986.16.

Tripathi L, Mwangi M, Aritua V, Tushemereirwe WK, Abele S, Bandyopadhyay R. Xanthomonas Wilt: A threat to Banana Production in East and Central Africa. Plant Dis. 2009;93(5). Turner, B. L., Kasperson, R. E., Matson, P. A., McCarthy, J. J., Corell, R. W., Christensen, L., ... Schiller, A. (2003). A framework for vulnerability analysis in sustainability science. Proceedings of the National Academy of Sciences of the Unites States of America, 100(14): 8074-8079.

Van Asselt, M. B. A., \& Renn, O. (2011). Risk governance. Journal of Risk Research, 14(4), 431-449.

Wachinger, G., Renn, O., Begg, C., \& Kuhlicke, C. (2013). The risk perception paradox-implications for governance and communication of natural hazards. Risk Analysis, 33(6), 1049-1065. 


\section{Appendix 8: Manual Musa analysis tool}

(Belonging to Chapters 6 and 7)

Software design by John A. Galarza Villamar

The Musa analysis tool is a software program written in the C\# programming language. It is a tool that was developed for the analysis and interpretation of data obtained during field experiments with the Musa game. The program has four parts: an interface for loading information from a file with an [.xlsx] extension, a panel that uses a color code to display the data, a form-type interface for selecting the type of spatial analysis in combination with the type of actions of the participants to be analyzed, and a section of bar graphs to display the numerical interpretations of the results obtained from the selected analysis. The main objective behind the development of this program was the need for a customizable, compact, and easy-to-use tool for processing and analyzing the experimental data.

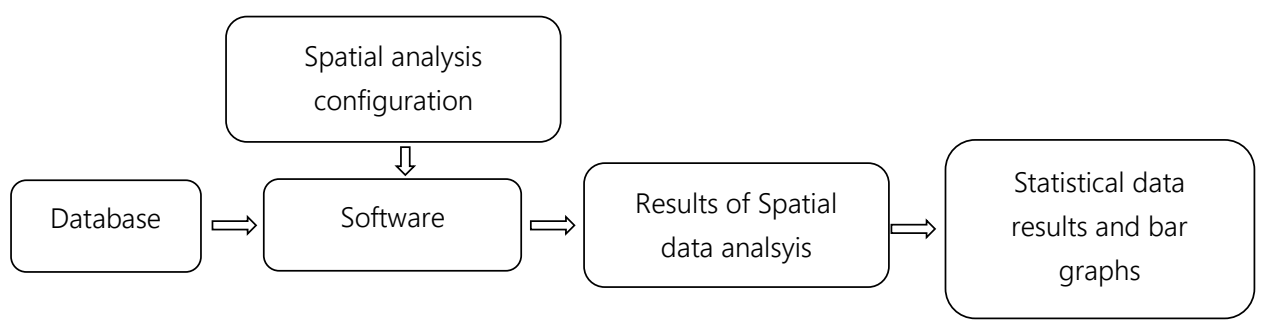

The variables analyzed in the experiment are the decisions made by participants, which consist of three possible actions: Cut Flower, Uproot Yellow Mat, Uproot Red Mat. These decisions are causal and are directly related to the rules of infection of the mat within the experiment. Appearance of an infection is the resultant of the conditions created by a combination of specific variables and game movement rules. At the same time, the objective is to observe only specific variables of interest, namely the decisions made by game participant.

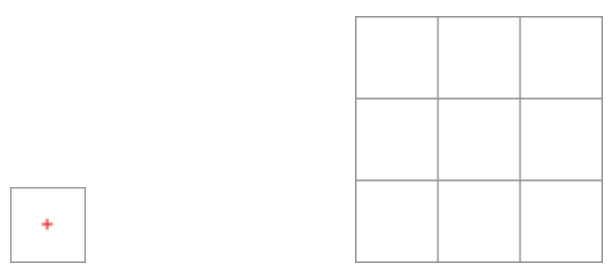

a) Segment b) Section

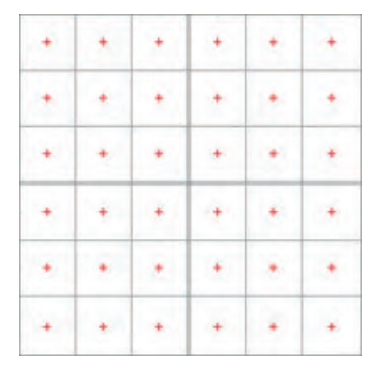

c) Board

Figure 38: Board components used for software development, where a board has 4 sections, and a section has 9 segments.

The data is collected on a flat and uniform $6 \times 6$ segment board, that is divided into four sections that are assigned to the 4 participants. In order to simplify calculations, we assume that each segment corresponds in size to a $1 \times 1$ unit of distance. Likewise, its point of interest will be in the central position of each segment, 0.5 units in $\mathrm{X}$ and 0.5 units in $\mathrm{Y}$ with respect to the upper left corner of each segment. In calculations, the 
notation used for the position of each segment corresponds to its location by row (R) and column (C) within according to the displayed matrix (Figure 39). The expression of the general position of each segment is: $\mathrm{GP}=(\mathrm{R}-1, \mathrm{C}-1)$, where $\mathrm{R}$ and $\mathrm{C}$ are values between 1 and 6 . However, to take the center of each segment as the position of interest for a calculation the expression is: $\mathrm{Pl}=\left(\mathrm{GP}_{\mathrm{x}}+0.5, \mathrm{GP}_{\mathrm{y}}+0.5\right)$.

\begin{tabular}{|l|l|l||l|l|l|}
\hline 0,0 & 0,1 & 0,2 & 0,3 & 0,4 & 0,5 \\
\hline 1,0 & 1,1 & 1,2 & 1,3 & 1,4 & 1,5 \\
\hline 2,0 & 2,1 & 2,2 & 2,3 & 2,4 & 2,5 \\
\hline \hline 3,0 & 3,1 & 3,2 & 3,3 & 3,4 & 3,5 \\
\hline 4,0 & 4,1 & 4,2 & 4,3 & 4,4 & 4,5 \\
\hline 5,0 & 5,1 & 5,2 & 5,3 & 5,4 & 5,5 \\
\hline
\end{tabular}

\section{Figure 39: Notation used for the position of each segment}

Example 1 (Figure 40). The distance between two random points A and B, located at the position GPA $(0,1)$ and $\operatorname{GPB}(5,4)$, will be given by: $D=$

\begin{tabular}{|l|l|l||l|l|l|}
\hline 0,0 & 0,1 & 0,2 & 0,3 & 0,4 & 0,5 \\
\hline 1,0 & 1,1 & 1,2 & 1,3 & 1,4 & 1,5 \\
\hline 2,0 & 2,1 & 2,1 & 2,3 & 2,4 & 2,5 \\
\hline 3,0 & 3,1 & 3,2 & & 3,4 & 3,5 \\
\hline 4,0 & 4,1 & 4,2 & 4,3 & 4,4 & 4,5 \\
\hline 5,0 & 5,1 & 5,2 & 5,3 & 5,4 & 5,5 \\
\hline
\end{tabular}

Figure 40: Example 1, distance calculation between two random points $P G A(0,1)$ and $P G B(5,4)$.

For measurements between a random point and the center of the board, the central point $(\mathrm{Pc})$ is taken as a reference and expressed as PC: (R / 2, C / 2). The central point is a position of interest for measurements because it represents the only position on the game board where the board sections of all four players meet, and hence decisions of each player near the central point can directly affect the other players in the game.

Example 2 (Figure 41). The distance between a random point $A$ located at PGA $(0,1)$ and the central position (Pc) for a $6 \times 6$ board, where $\mathrm{Pc}=(6 / 2,6 / 2)$ is given by: $D=$ 


\begin{tabular}{|l|l|l||l|l|l|}
\hline 0,0 & 0,1 & 0,2 & 0,3 & 0,4 & 0,5 \\
\hline 1,0 & 1,1 & 1,2 & 1,3 & 1,4 & 1,5 \\
\hline 2,0 & 2,1 & 2,2 & 2,3 & 2,4 & 2,5 \\
\hline 3,0 & 3,1 & 3,2 & 3,3 & 3,4 & 3,5 \\
\hline 4,0 & 4,1 & 4,2 & 4,3 & 4,4 & 4,5 \\
\hline 5,0 & 5,1 & 5,2 & 5,3 & 5,4 & 5,5 \\
\hline
\end{tabular}

Figure 41: Example 2, distance calculation between a random point $P G A(0,1)$ and $P C$.

Each distance measured in the experiment corresponds with a distance between a PI (Point of Interest) of a segment(corresponding with the player's actions), and a PI of a second segment (corresponding with a direct value of the board) in one moment in time (Game Round), or the Pc position (Center position).

Said measurements are normalized to a scale of values between 0 and 1 , meaning a value of 0 for positions outside border of the board, and 1 for the position that is exactly in the center of the point of interest/segment, which is taken as a reference for the measurement.

We call the distance given in values between 1 and 0 the normalized distance or $\mathrm{Dn}$, which is given by: $\mathrm{Dn}=$ , where $\mathrm{Dm}$ is the value of the maximum possible distance between two ends of the board, which is the direct result of the maximum diagonal distance of the board $D m=$, except for calculations where the only reference is the Central Position ( $\mathrm{Pc}$ ), in which case Dm has the value of the maximum distance between two points of interest of one of the sections of the board, which is maximum half the diagonal of the board $\mathrm{Dm}=$.

For practical reasons, the round values of 1 and 0 will are be represented for normalized distance (Dn) in the real measurements. Given the rules of the game these values are impossible. The minimum possible value $(V m n p)$ will be given by $V m n p=$, and the maximum possible value $(V m \times p)$ will be given by Vmxp $=$. Likewise, the Vmnp and the Vmxp when the only reference is the Central Position will be Vmnp = and Vmxp =. Since the value of 0 is not possible in the calculation, it has been reserved for distance measurements that do not meet the action criteria between both points. That is, one of the points of interest within the measurement does not exist.

\section{Measurement methodology}

For the experiment, there are eight states of the banana mat that are represented by codes: Dead (5), Intervened (6), Green Flower (1), Green (2), Yellow (3), Yellow Uprooted (31), Red (4 ), Red Uprooted (41), which for purposes of interpretation were catalogued using the following colour codes (Figure 42 and Figure 43). 


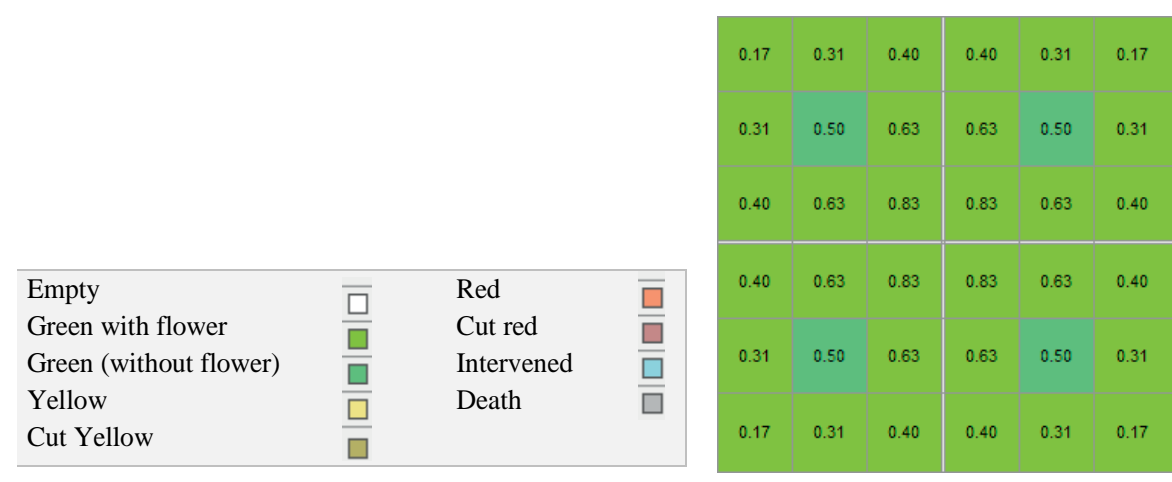

Figure 42: Card colours codes as used in software. Note that the Green with flower refers to the White card in the game.

Figure 43: Example of the Initial state of the boardgame in the Musa analysis tool. It shows the values of the Normalized Distance (Dn) of each segment concerning the Central Point (PC) of all types of card stages for a board in the initia round.

As mentioned, the events of interest for the analysis are the actions of the players, thereby considering the circumstances on the board when said decision is made. The actions of the players to consider were: Cut Flower, Uproot Yellow Mat, Uproot Red Mat. Likewise, the events occurring randomly or controlled by game rules were considered, namely: New Yellow Mat, New Red Mat. These events were identified through an algorithm. It compared the board conditions from one round with another round and then quantified and grouped these by their Normalized Distance (Dn) in different analyzes (Figure 44).

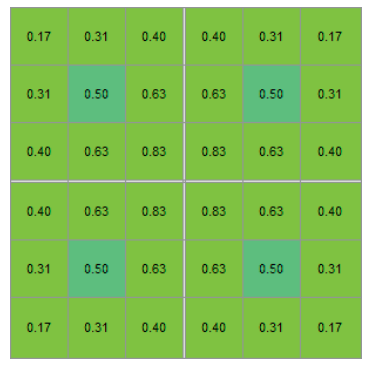

Round $n$

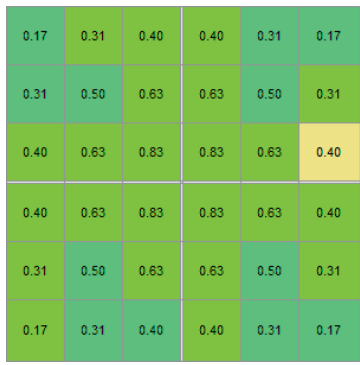

Round $n+1$

Figure 44: Example: 6 Green Flower mats changed to Green (6 Cut Flower actions). 1 Green Flower Mat changed to Yellow (1 New Yellow Mat event), measurements relative to the centre.

To analyse the distance under specific circumstances, the dashboard has values for as long as there is at least one location that serves as a reference or measurement center for the other dashboard segments. For example, distances from a yellow mat. All the segments have numerical values that represent their respective normalized distance (Dn) compared to the variable of interest (Yellow Mat). The location of the Yellow Mat has a value of 0 because there is no second Yellow Mat from which it could obtain its distance value (Figure 45). For investigation and analysis of data, employing the software, all the possible analysis variables were 
parameterized to allow for selection of different combinations and observe possible trends in the results these combinations give (Figure 46).

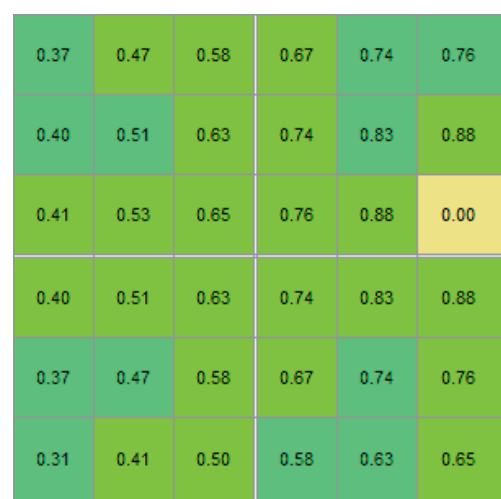

Figure 45: example of numerical values and their respective normalized distance (Dn) compared with the variable of interest (Yellow Mat).

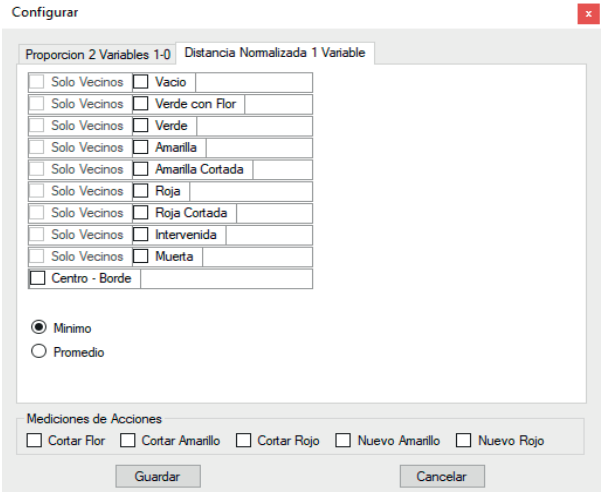

Figure 46: Panel of options for analysis configuration

As a practical example, for the spatial analysis of distance the software is be configured to consider the action to cut flowers. This action is the central reference to measure distances to the Yellow Mat or Red Mat segments only in neighbouring sections. The minimum distance was selected to control for cases in which there is more than one Yellow or Red Mat (Figure 47).

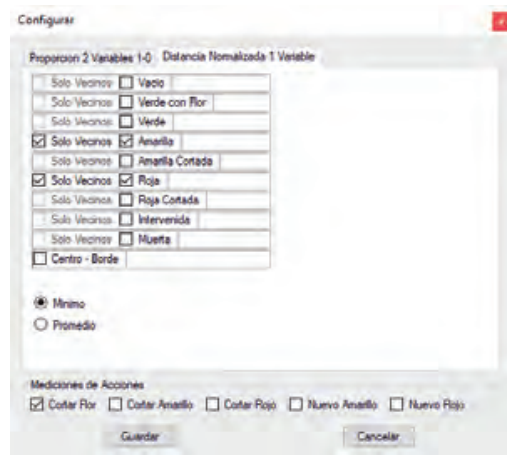

Figure 47 Data analysis configuration window for the example

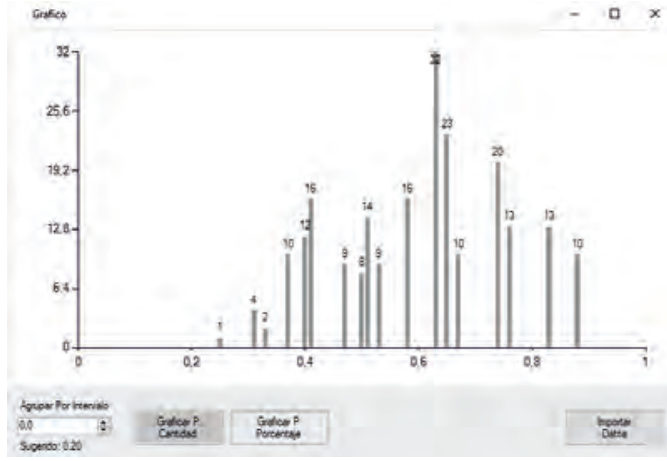

Figure 48 Results based on configuration of Figure 47

In the graph (Figure 48), the axis $Y$ shows the number of Cut Flower actions that players made and the axis $Y$ shows the Normalized Distance $(\mathrm{Dn})$ between 0 and 1 in relation to a diseased mat when making the decision to cut flowers. 


\begin{tabular}{ll} 
Normalized Distance (Dn) & Decisions \\
\hline 0,25 & 1 \\
0,31 & 4 \\
0,33 & 2 \\
0,37 & 10 \\
0,4 & 12 \\
0,41 & 16 \\
0,47 & 9 \\
0,5 & 8 \\
0,51 & 14 \\
0,53 & 9 \\
0,58 & 16 \\
0,63 & 32 \\
0,65 & 23 \\
0,67 & 10 \\
0,74 & 20 \\
0,76 & 13 \\
0,83 & 13 \\
0,88 & 10
\end{tabular}

We can see that there is a uniform distribution in the example results (Table 22). However, due to the nature of the calculation, there are distances among them that are very similar. For example, distances such as 4.0 and 4.1 or 0.50 and 0.51 ). For practical reasons and to simplify data analysis these values can be grouped.

To group data, a uniform distance interval is defined for the data of the variable that is to be analyzed. In this particular case, it will be the distance to which all the sampled distance values will approximate. These are defined as Values close to the interval $(\mathrm{Vi})$ and given by: $V i=\operatorname{Round} * I$, where $\mathrm{V}$ is the real value, and I is the selected interval (Table 23 and Table 24). 
Table 23 (left): Example: Values Close to Interval (Vi) of Normalized Distances (Dn) obtained, for an interval of 0.1 .

Table 24 (right): Decisions Grouped by Vi

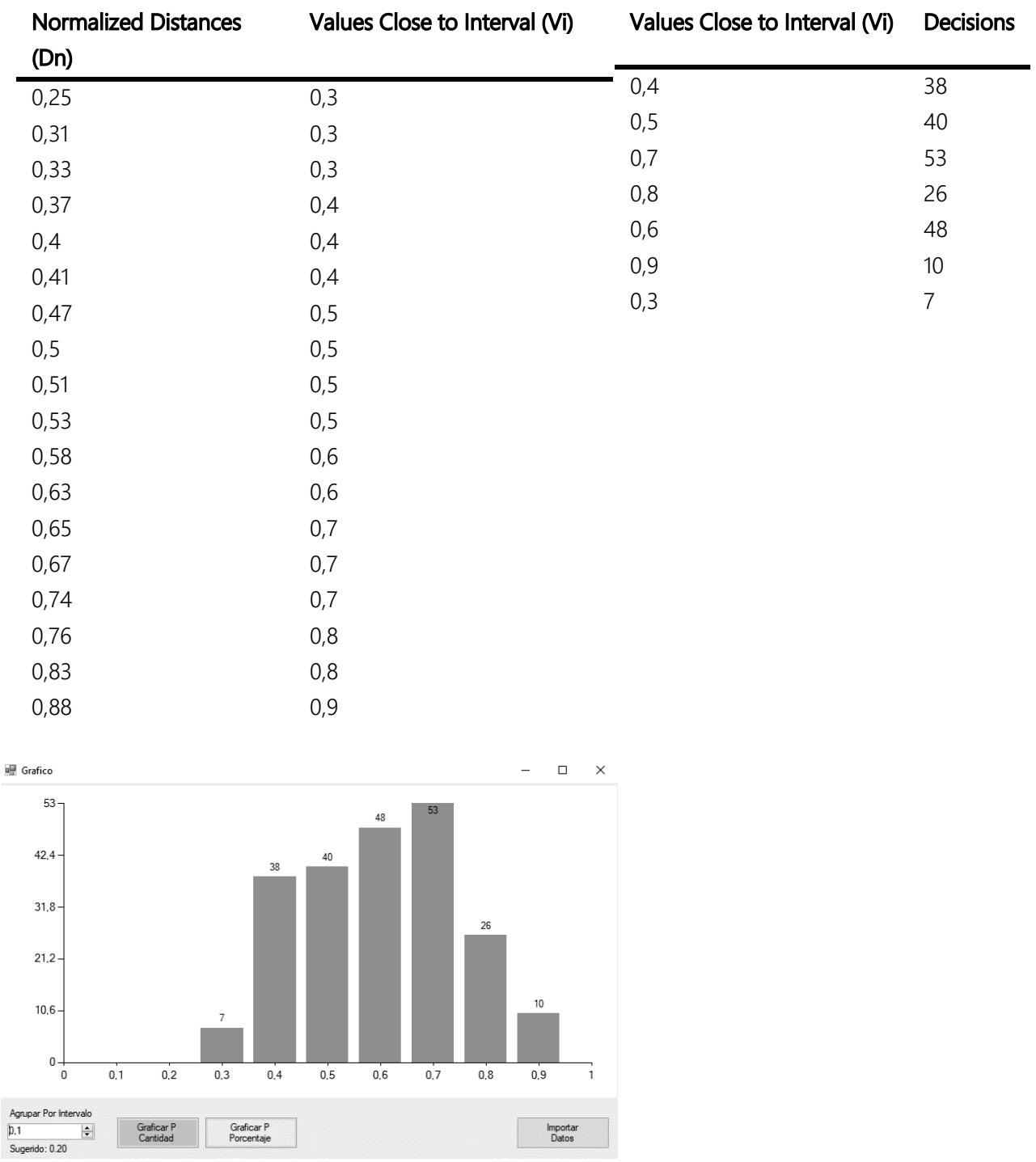

Figure 49: Graph of grouped results with an interval equal to 0.1

Since the interval value can be very relevant for the analysis, an optimal interval value for the data pool can be calculated. For this purpose, an empirical value is calculated defined as: Maximum Interval Value (Vim). The Vim is the quotient of the arithmetic mean of the distances between the Values Near the Interval ( $\mathrm{Vi})$ and the Real Value $(\mathrm{V})$, and the selected interval $(\mathrm{I}), \operatorname{Vim}_{I}=\frac{\left(\frac{2}{I}\right) \sum_{k=0}^{n}\left|V i_{k}-V_{k}\right|}{n}$, where $\mathrm{Vi}$ is the value close to the interval $\mathrm{I}, \mathrm{V}$ is the actual value, I is the selected interval value, and $\mathrm{n}$ is the amount of data. 
With the initial results obtained through the calculations done as exemplified by Figure 49 as input, the Vim values for the intervals $(0.1,0.2,0.3,0.4,0.5,0.6,0.7,0.8,0.9)$ are calculated (Figure 13). For these interval values, we discard all those in which the number of intervals contained in the range from 0 to 1 is less than or equal to 1 since for these the grouped values would give the lowest possible resolution and would not have a significant value for the analysis. The Contained Intervals (Ic) will be given by, Ic $=$ Floor $\left(\frac{1}{I}\right)$, where I is the selected interval (Table 25).

Table 25: Contained Intervals (Ic) values for the intervals $(0.1,0.2,0.3,0.4,0.5,0.6,0.7,0.8,0.9)$

Intervals

$\begin{array}{ll}0,1 & 10 \\ 0,2 & 5 \\ 0,3 & 3 \\ 0,4 & 2 \\ 0,5 & 2 \\ 0,6 & 1 \\ 0,7 & 1 \\ 0,8 & 1 \\ 0,9 & 1\end{array}$

Ic values less than or equal to 1 are discarded, because the only suitable Interval values for this analysis are the intervals: $0.1,0.2,0.3,0.4$ and 0.5 . When calculating the Vim values for these intervals we get Table 26Table 26.

Table 26: Calculated Vim values

\begin{tabular}{cc} 
I & Vim \\
\hline 0,1 & 0,511 \\
0,2 & 0,533 \\
0,3 & 0,481 \\
0,4 & 0,444 \\
0,5 & 0,511
\end{tabular}

Therefore, when looking for the highest possible uniformity in the distribution for the grouped data, the VI value closest to 0.5 will belong to an interval of best-distributed data. Other statistical criteria could be considered for the selection of a grouped interval for the data, such as the standard deviation of the values with respect to the interval, the selection of the minimum possible interval, the minimum amount of data grouped in the said interval, among others.

Selecting 0.2 as Interval, we can observe in the following graph (Figure 50) a distribution that is similar to the 0.1 intervals. The difference with figure 12 is greater visibility of possible trends, which is useful for analysis. 


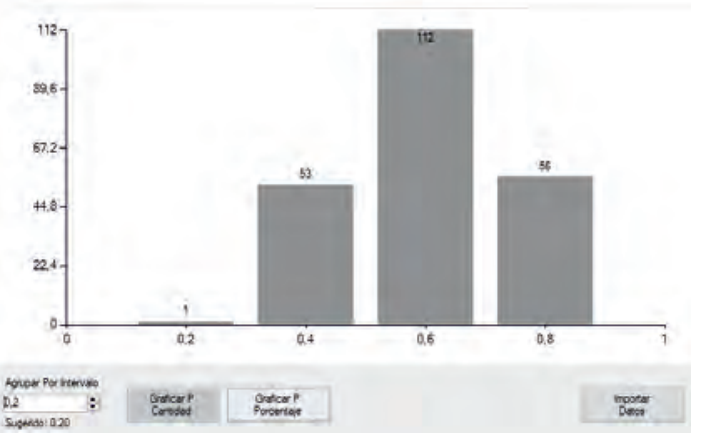

Figure 50: Distribution example with an interval of 0.2

Despite observing a trend in the results, the data of these random events must be contrasted with the actions taken. That is, comparing the event (action) with the participant's decision (reaction). This contrast is necessary because the trends observed from a single analysis might be caused by a rule intrinsic to the game and not the players. Therefore, in the second example, two analysis configurations are performed. The first to get the appearance of Red and Yellow Mats on the board in relation to a Neighbouring Mat with Flower. The second analysis is to obtain the number of Red and Yellow Mats that were uprooted in relation to a Neighboring Mat with a Flower (Figure 51 and Figure 52).

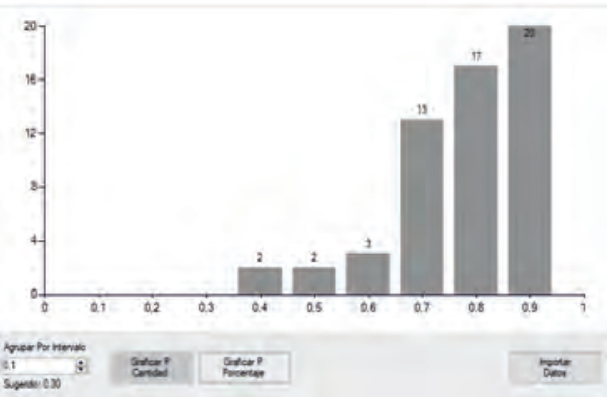

Figure 51: Appearance of Diseased Mats in relation to Healthy Mats

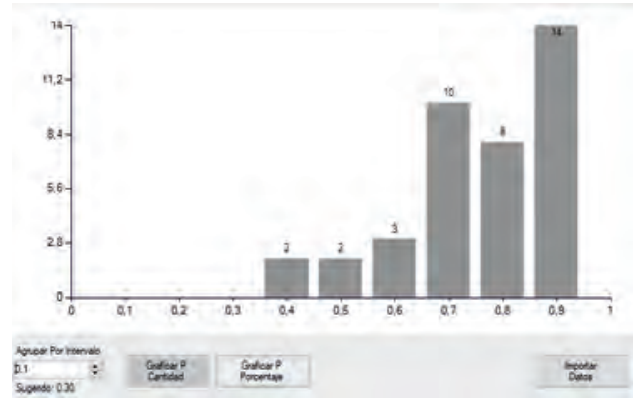

Figure 52: Cutting of Diseased Mats in relation to Healthy Mats

When comparing the results, an increasing trend of uprooting actions in relation to distance is visible which is similar in both graphs and is caused by the appearance of diseased mats (Red or Yellow) (Random Variable). However, by contrasting the information obtained, we can observe a higher frequency in the decision-making of uprooting diseased plants in the farthest distances from the healthy plants. 


\section{Appendix 9: Consent forms for game experiment (the Musa-game)}

(Belonging to Chapters 6 and 7)

(English version)

Researchers: Mariette McCampbell, Julissa Galarza Villamar, Knowledge, Technology and Innovation group, Wageningen University

\section{Purpose of the research}

The research that we ask you to participate in is an experimental field boardgame about the decision making of Rwandan banana farmers about management of Banana Xanthomonas Wilt (BXW/Kirabiranja) disease. This research activity is part of the ICT4BXW project, that is implemented by the International Institute of Tropical Agriculture (IITA) in collaboration with RAB in Rwanda.

\section{What we expect from you}

You will be playing this game together with three fellow banana farmers from your village. Each of you has been randomly selected to participate in this game. Your participation in this research is voluntary. Before playing the game, we would like to ask you a number of questions about you, your banana farm, and your experience with BXW management. After the game we would like you to participate in a group interview, together with the other players. The questions will be about the game itself, if you learned things from playing the game, and if the decisions and events in the game were similar or different to your real-life experiences as banana farmer.

\section{Storing and use of data}

We collect digital surveys, audio, and video files from this research. The audio and video will only be used for research purposes, and not be shared outside the project. We use the data collected during the game activity for research purposes, it can be used for publications, but also to inform further studies, activities of the ICT4BXW. Your data will be stored in a secure database and anonymized before making it open data.

\section{Taking part in the study}

When you sign the consent form it means that you agree that: You have received and understood information about the research project and the experimental game. You were able to aske question about the research and they were answered to you. Your participation in the research is voluntary, and you can refuse to continue or withdraw at any time without having to give a reason, until data collection and analysis has been finalized. You understand that participating means playing the experimental game, being observed during the game, and being asked to answer questions about your experiences. Photos may be taken. The game will be recorded on video, only capturing the game board and the actions on there. The group interview will be audio recorded.

\section{Use of the information in the study}


When you sign the consent form it means that you agree that: The information that you provide may be used for reports, publications, and online communication. Identifiable personal information, such as your name or where you live, will not be shared beyond the study team without your permission. You received information about data storage. You give permission for the data of the experimental game to be deposited in a database after being anonymized and made available to other researchers for future research and learning.

In case of any questions you can contact the ICT4BXW project research assistant: Mr.

Do you agree to the above and participation in this research activity?

Yes/no

Signatures

Participant

Name Signature Date

Researcher

Name Signature Date 


\section{Acknowledgements}

Although this $\mathrm{PhD}$ has my name on the cover page, conducting the research and writing each of the individual chapters was by no means a 'one-woman-show'. I certainly could not have brought this project to a good end without the support of and collaborations with many people.

To start, I am very grateful to all the farmers, farmer promoters, and ICT4BXW project staff and partners who volunteered their time and energy to participate in interviews, workshops, surveys, games, and other activities. My research would have been impossible without their participation.

Next, I want to thank all my co-authors: Without you I could not have written the chapters that are in this dissertation. Each of the articles was a smaller journey within my large PhD expedition and I'm grateful that I could explore, learn, and share together with you. I am proud that most of the chapters we authored have been published in peer-reviewed journals or as a book chapter and that the scientific knowledge that we developed together is accessible for many people.

The staff of the IITA office in Rwanda have been my colleagues and 'family'during the years that I was based in Kigali, and continued to help me after I moved to Wageningen University and the Netherlands. I want to thank all of them. I specifically want to mention Charles Mwizerwa who was always ready to respond to my questions, and requests for assistance and project information. Speciose Kantengwa, taught me many useful lessons about Rwandan culture. Petronille Dusingizimana was a bright research assistant who helped me to collect data. Lydia Tuyizere assisted the MSc students who conducted research for me. I also want to thank those students, Lara Morillo Gonzales and Frenske Blom, for their help with collecting and analysing data and their trust in me as their supervisor. In Rwanda, Sandra Gatete and Betty Kigenza both supported me with all kinds of practical and administrative issues. Dr. Julius Adewopo has supported my research not only as an institutional supervisor but also by giving me access to all the ins and outs of the project. Finally, dr. Marc Schut has been a friend, manager, colleague, and mentor. Although our professional and personal paths have separated, I want to thank him for believing in me during the first years of my East African adventures, and making me realize that my identity and values are worth fighting for. 
Beyond IITA there was dr. Svetlana Gaidashova of Rwanda Agriculture and Animal Resources Development Board (RAB)'s Banana Program, who played an indispensable role as an expert of Rwanda's banana production system and, together with her team, facilitated the necessary institutional and human support for my fieldwork. I am also grateful that I got to work with an incredible team of young, energetic, and talented research assistants while implementing Musa-game: Adeline Umutoni, Benjamin Iradukunda, Emma Uwera, Josephat Kunesha and Yves Shema thank you for your enthousiasm and help with collecting and translating the data.

Although I developed the idea for the PhD myself, I also became part of a community of wonderful people who embraced me from the first minute when I joined them for the second EVOCA annual meeting in Ghana. Emmanuel Nyadzi, Chris Agyekumhene, Marilyn Murindahabi, Domina Asingizwe, Shiferaw Tafesse, Andy Bonaventure Nyamekye, Richard Chepkwony, Faith Mutavi, Nyamwaya Munthali, thank you for welcoming me into the EVOCA community as the only non-African PhD candidate. Special thanks to Elias Damtew Assefa; you became a trusted friend and I have tremendously enjoyed our discussions about science, philosophy, and life in general. Its been a pleasure to engage with you all as fellow PhDs working on topics related to wicked problems, public good/bad dilemmas, communication and knowledge exchange, and digital innovation. I have learned with and from you, partied with you, and experienced the journey of 'becoming a scientist' with you. Also special thanks to dr. Katarzyna Cieslik who has been a great support to all EVOCA PhD candidates. By now, most of us proudly carry the title of $d r$. and I am certain that we will meet each other many more times in the future.

When I moved from Rwanda to Wageningen I had to start a new social and professional life. The transition was made easier thanks to all the staff and PhDs at KTI. I want to thank all the KTI PhDs who have been my friends and colleagues at KTI. Special thanks to dr. Julissa Galarza-Villamar, for your energy and motivation to develop and implement the Musa-game. Kelly Rijswijk, for the many discussions we had and the collaboration on the digital inclusion chapter. Mirjam Schoonhoven, for the discussions while we were both writing our introduction and synthesis chapters. Diana Lopez, for being a sparring partner and the person with whom I shared the position of KTI PhD representative. I also want to thank all the women at KTI's administration and financial secretariat; Inge Ruisch, Bea Prijn, Meta Bakker, Cathelijne Goossens, Germaine Dunselman, and Vera Mentzel, Mirjam Cevat, and Jennifer Koelman, I could not have 
done this job without all your back-stopping and support. Lastly, many of the permanent staff at KTI have been an inspiration at some point during my PhD trajectory. Special thanks to my promotor Prof. dr. ir. Cees Leeuwis. You trusted in my capacity to bring the PhD to a good end and invited me to continue my research at the Knowledge, Technology, and Innovation group at Wageningen University when my time at IITA Rwanda finished and I was forced to find myself a new 'home'. Prof. dr. ir. Laurens Klerkx, for the second time you were willing to become my supervisor after I had gone through some turbulent times. You have been an inspiring promotor, with endless knowledge about the literature. I have benefited a lot from your critical eye and sharp pen while. Many times you encouraged me to believe in myself and go one more mile, which has always helped me to improve my work.

I am tremendously thanksful to all my wonderful friends who have been there with and for me in the past years, being it in East Africa, the Netherlands, or anywhere else. Laurie van Reemst, Suzanne Faber, Marijke den Baas, Bart Hofland, Tamara Hofland-Sayers, Wytze Marinus, Charlotte Schumann, Simon Riley, Mariola Acosta Frances, Abhijit Ranaware, Onno Giller, Murat Sartas, and Elke Vandamme, I shared the highs and lows of my PhD journey with you. Many of you were there whenever I needed you, regardless of where you were on the planet. You have all inspired me and I hope we will continue inspiring each other in the future.

Finally, I want to thank my parents, brothers, and their families for understanding and accepting that I am, and may always be, a woman with wanderlust who is often far away and for whom 'no message' means a good message. 


\section{About the author}

Mariette McCampbell (1986) was born in Den Helder, the Netherlands. She has several years of experience with rural and agricultural development in the Global South, especially East and Central Africa (Uganda, Kenya, Rwanda, DRC, Burundi), and India.

In 2010, Mariette obtained her Bachelor of Engineering (B. Eng.) degree in Human Technology from the Hanze University of Applied Sciences in Groningen, the Netherlands. During her bachelor studies she worked as an intern for LEDlighting South Africa in Cape Town where she did market research on novel applications of LEDlighting for the South African market. For her thesis she conducted research at the Nimbkar Agricultural Research Institute in Phaltan, India, and contributed to improving the technical design of a bio-ethanol cooking and lighting appliance and tested the device with families in non-electrified villages in rural Maharashtra. It was during that time that Mariette developed her interest for socio-technical interactions, participatory technology development, innovation processes, and action research, specifically in a Global South context.

After working for some years, Mariette returned to university for an MSc study in 2013. She received her MSc degree in 2015 from the Development and Rural Innovation programme at Wageningen University, the Netherlands. Both her MSc internship and thesis research were conducted in East Africa (2014). Based in Uganda, she did her internship with the International Institute of Tropical Agriculture's (IITA) to support their Humidtropics programme with implementation of multi-stakeholder processes in East and Central Africa. Simultaneously, she studied adoption of small-scale biogas plants among smallholder farmers in Uganda and Kenya for a start-up company in biogas systems. Mariette's MSc thesis investigated fertilizer adoption challenges among potato farmers for IITA'S PASIC project in Uganda.

After her graduation, Mariette moved permanently to East Africa to work as a research assistant for IITA's Humidtropics programme and CIALCA project. She was involved in the facilitation and M\&E of and scientific research on multi-stakeholder processes and innovation platforms in Uganda, Rwanda, DR congo, and Burundi. During that same period, she also did several consultancy projects, for example for GIZ and FAO's Feed the Future Programme, ZOA International (facilitation of multi-stakeholder workshops in Uganda and Zambia), and Q-Energy Consultants and HIVOS Netherlands (feasibility 
study on biogas production from waste-streams in Rwanda, Uganda, and Kenya). In 2017, she was employed by both IITA and Bioversity International as visiting scientist innovation and scaling for CIALCA and the CGIAR programme on Roots, Tubers and Bananas in Rwanda. During that time, she became particularly interested in the enactment of Human Centered Design processes and participatory research in the context of developing and implementing ICT technologies in agriculture. This resulted in her pursuing the PhD research project that is presented in this book. Based on her initial research ideas she co-developed a project proposal for what would later become the ICT4BXW project, and which received funding by the German Federal Ministry of Economic Cooperation and Development (BMZ). She contributed to the start-up of the project in 2018, while simultaneously conducting her own research.

In 2019 Mariette returned to the Netherlands and continued her PhD research as a PhD candidate (AIO) at Wageningen University's Knowledge, Technology, and Innovation group. She has been the (co)-author of several (peer-reviewed) articles, book chapters, and blogposts, and presented her work at various national and international conferences and events.

\section{Publications}

\section{Peer-reviewed articles}

Galarza-Villamar, J., McCampbell, J.A., Leeuwis, C., Cecchi, F. (2021). Adding Emergence and Spatiality to a Public bad Game to study dynamics in socio-ecological systems (Part I): The design of Musa-game for integrative analysis of collective action in banana disease management. Sustainability, 2021, 13 (16).9370. doi.org/10.3390/su13169370.

Galarza-Villamar, J., McCampbell, M., Galarza-Villamar, J.A., Leeuwis, C., Checchi, F., Galarza-Rodrigo, J. (2021) A public bad game method to study dynamics in socio-ecological systems (Part II): Results of testing Musa-game in Rwanda and adding emergence and spatiality to the analysis.

Sustainability, 2021, 13(16), 9353. doi.org/10.3390/su13169353.

Adewopo, J., McCampbell, M., Mwizerwa, C., \& Schut, M. (2021). A reality check for digital agricultural extension tool development and use. Rural 21, 55(1), 23-25.

Sartas, M., van Asten, P., Schut, M., McCampbell, M., Awori, M., Muchunguzi, P., ... Leeuwis, C. (2019). Factors influencing participation dynamics in research for development interventions with multi-stakeholder platforms: A metric approach to studying stakeholder participation. PLOS ONE, 14(11), e0223044. doi: 10.1371/journal.pone.0223044.

McCampbell, M., Schut, M., Van den Bergh, I., van Schagen, B., Vanlauwe, B., Blomme, G., ... \& Leeuwis, C. (2018). Xanthomonas Wilt of Banana (BXW) in Central Africa: Opportunities, challenges, and pathways for citizen science and ICT-based control and prevention strategies. NJAS-Wageningen Journal of Life Sciences. doi: 10.1016/j.njas.2018.03.002. 
Schut, M., Klerkx, L., Sartas, M., Lamers, D., McCampbell, M., Ogbonna, I., Kaushik, P., Atta-Krah, K. and Leeuwis, C. (2015) Innovation platforms: Experiences with their institutional embedding in agricultural research for development. Experimental Agriculture. doi: 10.1017/S001447971500023X.

\section{Peer-reviewed articles submitted or under review}

Coggins, S., McCampbell, M., Sharma, A., Sharma, R., Haefele, M., Karki, E., Hetherington, J., Smith, J., Brown, B. (Forthcoming). How have smallholder farmers used digital extension tools? Practitioner and user voices from Sub-Saharan Africa, South Asia and Southeast Asia. Global Food Security.

Simelton, S., McCampbell, M. Do digital climate services for farmers discourage resilient farming practices? Pinpointing gaps through the responsible research and innovation framework. (Submitted to journal).

McCampbell, M., Schumann, C., and Klerkx, L. Good intentions in complex realities: Challenges for designing responsibly in digital agriculture in low income countries (Under review).

McCampbell, M., Adewopo, J., Klerkx, L., and Leeuwis, L. Are farmers ready to use phone based digital tools for agronomic advice? Ex-ante User Readiness assessment using the case of Rwandan banana farmers. (Under review).

\section{Peer-reviewed book chapters}

McCampbell, M., Rijswijk, K., Wilson, H., and Klerkx, L. (forthcoming). A problematization of in- and exclusion: Tradeoffs and nuances in how digitalization affects African agricultural development, In Ludwig, D., Boogaard, B., Macnaghten, P., and Leeuwis, C. (Ed.) Making knowledge work: Practices and politics of inclusive development and innovation. UK: Routledge.

Namazzi, S., Muchunguzi, P., Lamers, D., Sole-Amat, A., van Asten, P., Dubois, T., Afari-Sefa, V., Tenywa, M., Mugisa, M., McCampbell, M., and Sartas, M., (2016) Crop-livestock-tree Integration in Uganda: The Case of Mukono-Wakiso Innovation Platform, In Dror, I., Cadilhon, J.J., Schut, M., Misiko, M. and Maheshwari, S. (Ed.). Innovation platforms for agricultural development: Evaluating the mature innovation platforms landscape. UK: Routledge.

\section{Other publications}

Wolfert, S., van Wassenaer, L., van der Burg, S., Ryan, M., Klerkx, L., Rijwijk, K., McCampbell, M., Athanasiadis, I., Beers, G. (2021). Navigating the Twilight Zone: Pathways towards digital transformation of food systems. Wageningen University and Research. Wageningen, the Netherlands. doi.org/10.18174/552346.

Coggins, S., Sharma, R., McCampbell, M., Sharma, A., Haefele, S.M., Karki, E., Hetherington, J., Brown, B. (2020). Assessment framework for digital extension tools. dx.doi.org/10.13140/RG.2.2.35692.59520.

Schut, M., McCampbell, M., Sartas, M., Zawadi, S., Grovermann, Z. C., and K. Nichterlein. (2017). Unlocking the innovation potential for sustainable agricultural intensification in Rwanda. A study on policy, practice, and potential. Food and Agriculture Organization of the United Nations (FAO) and the International Institute of Tropical Agriculture (IITA), Kigali, Rwanda.

McCampbell, M. \& Bos, S. (2016). Scaling successful innovation platform activities: Introducing business model methodologies that contribute to the out-scaling of Innovation Platform activities in East- and Central Africa. CGIAR Research Program for Integrated Systems in the Humid Tropics (Humidtropics). Wageningen University, the Netherlands. pp 116. 


\title{
Completed training and supervision plan
}

\author{
Mariette Danielle McCampbell \\ Wageningen School of Social Sciences (WASS) \\ Completed Training and Supervision Plan
}

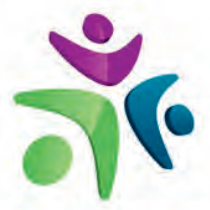

Wageningen School of Social Sciences

\section{Name of the learning activity \\ Project related competences \\ A1. Managing a research project}

Department/Institute

Year ECTS*

WASS introduction course

Organizer + facilitator panel discussion

'Evidence-based approaches to digital

agriculture'

Writing PhD proposal

'Are they ready? Village-level capacity to use phone-based extension services in Rwanda'

Panellist Digital agriculture panel 'Digitally enabled climate-information services'

'ICT4BXW: From proposal plans to design process in practice and app pilot

performance'

Reviewer of article for Agronomy for

Sustainable Development

'Transformations in Agricultural Extension:

Experiences from developing and piloting a

crop disease app'

'Using public bad games as interdisciplinary research method to learn about decision

making about infectious crop diseases:

experiences with a game for Rwandan

banana farmers'
WASS

ICT4D conference, Kampala, Uganda

WUR

Global CSA conference, Bali, Indonesia

2019

2019

Global CSA conference, Bali, Indonesia

2019

ICT4BXW annual planning meeting,

2019

Kigali, Rwanda

Agronomy for Sustainable devt.

2019

IAMO annual forum, Germany (virtual)

2020

Africa Knows! Conference, Netherlands (virtual)

\section{A2. Integrating research in the corresponding discipline}

Research methodology: From topic to

WASS

proposal

Systematic approaches to reviewing literature

WASS

Summerschool Expertise at stake:

ITS-Italia; dep. Political sciences,

Technoscience and public participation in the

University of Pisa, Pisa, Italy

post-truth age

NVIVO-based qualitative data coding and

WASS

2019 


\title{
B) General research related competences
}

\section{B1. Placing research in a broader scientific (social sciences and WUR) context}

\author{
Speaker MDR career event \\ Philosophy of Responsible Innovation
}

WUR

2019

TU Delft/ WUR Phi

2020

1

\section{B2. Placing research in a societal context}

Interview + article for CGIAR RTB annual

IITA/RTB

report 2018

Attending, presenting, and co-organization of KTI, WUR

2017/

3

EVOCA international workshop 2017, 2018,

2018/

2019

2019

\section{C) Career related competences/personal}

development

\section{C1. Employing transferable skills in different domains/careers}

Teaching and supervision (Supervising

KTI/ITA

2018/

2019/

thesis/internship MSc students, teaching

2020

Responsible Innovation'

Speaker webinar 'The origin of asymmetry' with talk titled 'What can we learn from

existing digital tools and platforms in

agriculture?'

$\mathrm{PhD}$ representative Knowledge, Technology

KTI, WUR

${ }^{*}$ One credit according to ECTS is on average equivalent to 28 hours of study load 
The research described in this thesis was financially supported by the CGIAR Research Program on Roots, Tubers and Bananas (RTB). Additional support for this work was provided by the German Federal Ministry of Economic Cooperation and Development (BMZ) commissioned and administered through the Deutsche Gesellschaft für Internationale Zusammenarbeit (GIZ) Fund for International Agricultural Research (FIA), grant number: 81219434, the Consortium for Improving Agricultural Livelihoods in Central Africa (CIALCA) which is funded by the Belgian Directorate General for Development Cooperation and Humanitarian Aid (DGD), and the Wageningen University Interdisciplinary Research and Education Fund (INREF) as part of the programme titled "Responsible life-science innovations for development in the digital age: EVOCA".

Financial support from Wageningen University for printing this thesis is gratefully acknowledged.

Cover and chapter page design: Luc Dinnissen (studio ds)

Lay-out and artwork: Mariette McCampbell

Printed by: Digiforce | ProefschriftMaken

Copyright 2021 | Mariette McCampbell 

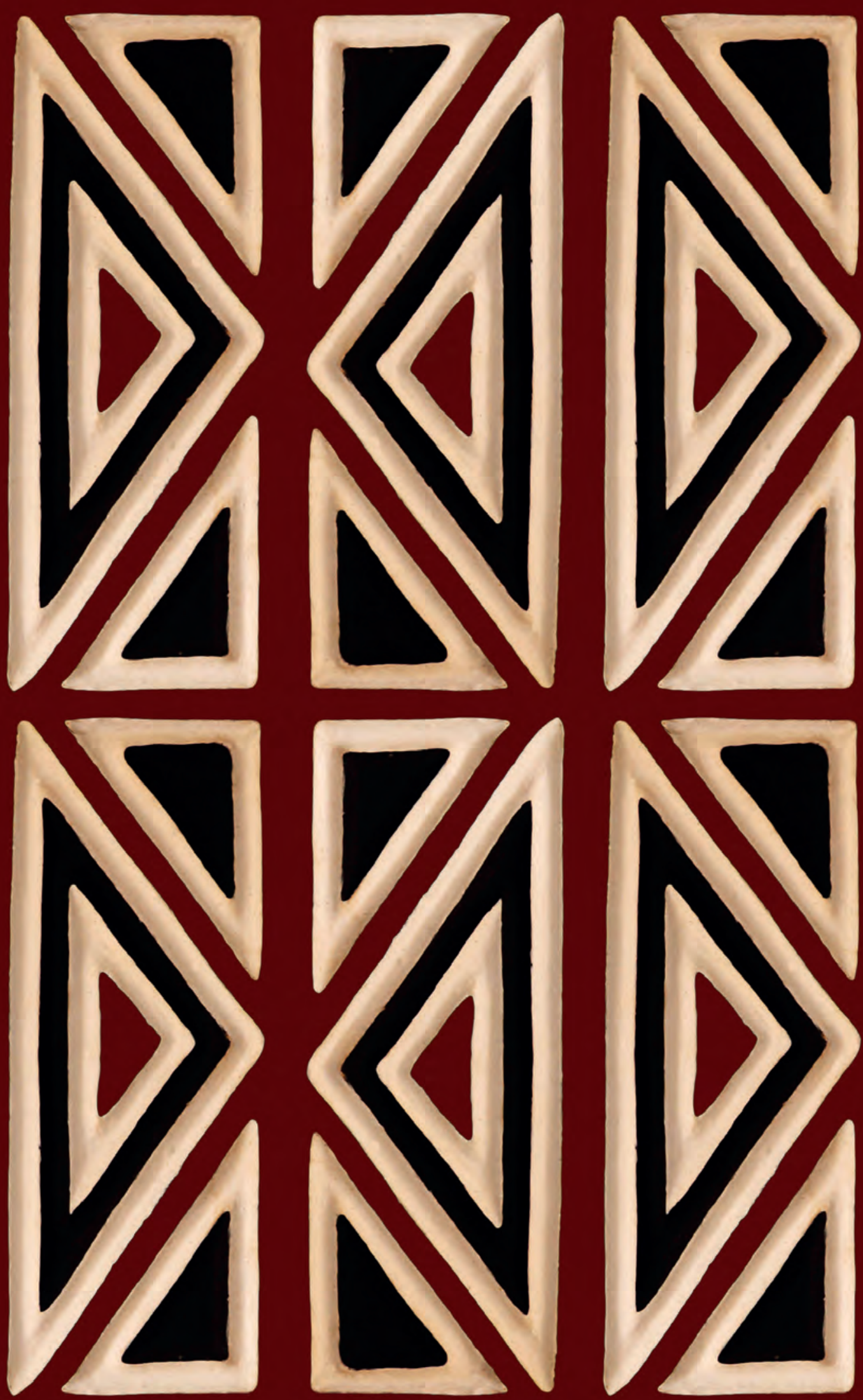